\title{
A STATISTICAL STUDY OF THE MACROEPIDEMIOLOGY OF AIR POLLUTION AND TOTAL MORTALITY
}

\author{
by \\ Frederick W. Lipfert \\ Robert G. Malone \\ Mary L. Daum \\ Brookhaven National Laboratory \\ and \\ Nancy R. Mendell \\ Chin-Chun Yang \\ State University of New York at Stony Brook \\ Prepared for the \\ OFFICE OF ENVIRONMENTAL ANALYSIS \\ UNITED STATES DEPARTMENT OF ENERGY
}

April 1988

BIOMEDICAL AND ENVIRONMENTAL ASSESSMENT DIVISION DEPARTMENT OF APPLIED SCIENCE BROOKHAVEN NATIONAL LABORATORY ASSOCIATED UNIVERSITIES, INC.

UNDER CONTRACT NO. DE-ACO2-76CH0OO16 WITH THE UNITED STATES DEPARTMENT OF ENERGY 

A statistical analysis of spatial patterns of 1980 U.S. urban total mortality (all causes) was performed, evaluating demographic, socioeconomic and air pollution factors as predictors. Specific mortality predictors included cigarette smoking, drinking water hardness, heating fuel use, and 1978-1982 annual concentrations of the following air pollutants: ozone, carbon monoxide, sulfate aerosol, particulate concentrations of lead, iron, cadmium, manganese, vanadium, as well as total and fine particle mass concentrations from the inhalable particulate network (dichotomous samplers). In addition, estimates of sulfur dioxide, oxides of nitrogen, and sulfate aerosol were made for each city using the ASTRAP long-range transport diffusion model, and entered into the analysis as independent variables. Because the number of cities with valid air quality and water hardness data varied considerably by pollutant, it was necessary to consider several different data sets, ranging from 48 to 952 cities.

The regression models and data were tested for outliers, influential observations, and behavior of residuals. The models which passed these tests showed sulfate aerosol, iron particles, and (to a lesser extent) total particle mass to be associated with mortality, although depending on the data set considered and the choice of variables versus factors to account for demographic effects on mortality, there were variations in the spectfic pollutants which showed statistical signfficance.

These results were compared to prevfous results and data for 1970. 1970 air pollution was not shown to be a better predictor for 1980 mortality than 1980 air pollution. Sulfate was not significant in 1970 , but the large standard error for that period does not preclude the 1980 sulfate coefficient for that period as well.

Since the computed sulfate variable was so highly significant in the developmental regression models, the analysis was repeated using computed $\mathrm{NO}_{\mathrm{x}}$ and $\mathrm{SO}_{2}$ data as alternative independent variables. These variables were also highly statistically significant predictors for all-cause mortality. Because of the high degree of similarity of alternative regression models employing different pollutants as predictors, three different bases were employed to compare regression models. Using these criteria, $\mathrm{SO}_{2}$, sulfate aerosol, and manganese particles all showed indications of providing better regression fits than the other pollutant variables. Using a two-stage procedure employing mortality "adjusted" for demographics, smoking, poverty, etc., the differences in fit among the various sulfate measures, $\mathrm{SO}_{2}, \mathrm{NO}_{\mathrm{x}}, \mathrm{Fe}, \mathrm{Mn}$, fine particles and total particles were minimal. Thus it was concluded that statistical criteria alone will not suffice in defining air pollution relationships will total mortality.

The relatively strong associations (ca. 5 - 10\%) shown for 1980 pollution with 1980 total mortality are generally not confirmed by independent studies, for example, in Europe. In addition, the us studies did not find those pollutants with known adverse health effects at the concentrations in question (such as ozone or $\mathrm{CO}$ ) to be associated with mortality. The question of causality vs. circumstantial association must therefore be regarded as still unresolved. 
A statistical analysis of spatial patterns of 1980 U.S. urban total mortality (al1 causes) was performed, evaluating demographic, socioeconomic and air pollution factors as predictors. Specific mortality predictors that were considered included demographic factors, cigarette smoking, hardness of drinking water, heating fuel use, and annual concentrations of the following air pollutants for 1978-1982: ozone, carbon monoxide, sulfate aerosol, particulate concentrations of lead, iron, cadmium, manganese, vanadium, as well as total and fine particle mass concentrations from the inhalable particulate network (size selective samplers). In addition, estimates of sulfur dioxlde, oxides of nitrogen, and sulfate aerosol were made for each of over 900 cities using the ASTRAP long-range transport diffusion model, and entered into the analysis as independent variables $\left(\mathrm{SO}_{2}\right.$ and $\mathrm{NO}_{\mathrm{x}}$ were evaluated in a subsequent phase of the research). Because the number of cities with valid data on air quality and water hardness varied considerably by pollutant, it was necessary to consider several different data sets ranging from 48 to 952 cities.

The regression models and data were tested for outliers, influential observations, and behavior of residuals. The models which passed these tests showed sulfate aerosol, iron particles, and (to a lesser extent) total particle mass to be associated with mortality, although, depending on the data set considered and the choice of variables or factors to account for demographic effects on mortality, there were variations in the specific pollutants which showed statistical significance.

Table 1 lists the main vartables used in this study and some of the statistical findings. The column, "\% of mortality variance explained," 1ndicates the degree of relationship between each variable and the mortality variable, without considering how these relationships change as the effects of age, race, poverty, etc., are taken into account through the use of multiple regressions. The regression coefficients express the change in mortality rate (deaths per thousand population) per unit of the variable in question $\left(\mu \mathrm{g} / \mathrm{m}^{3}\right.$ for the pollutants). The elasticities are nondimensional regression coefficients, whtch relate the percentage change in mortality to a percentage change in the independent variable. Note that some of the elasticities express a degree of mortality dependence that is quite different from that given by the bivariate correlations. The range of elasticities is quite similar for most of the pollutants, for example, while the percentages of mortality variance explained vaxy considerably.

These results were compared to previous results and data for 1970. 1970 pollution was not a better predictor for 1980 mortality than 1980 pollution. The only coefficients which have undergone a statistically significant change since 1970 are those for poverty and the percentage of population 65 years of age or older (borderline significance). Since sulfate was not significant in 1970, the large standard error found does not preclude the 1980 coefficient for that period as well. 
TABLE 1

MORTALITY CONTRIBUTIONS AND SENSTTIVITIES OF VARIABLES USED

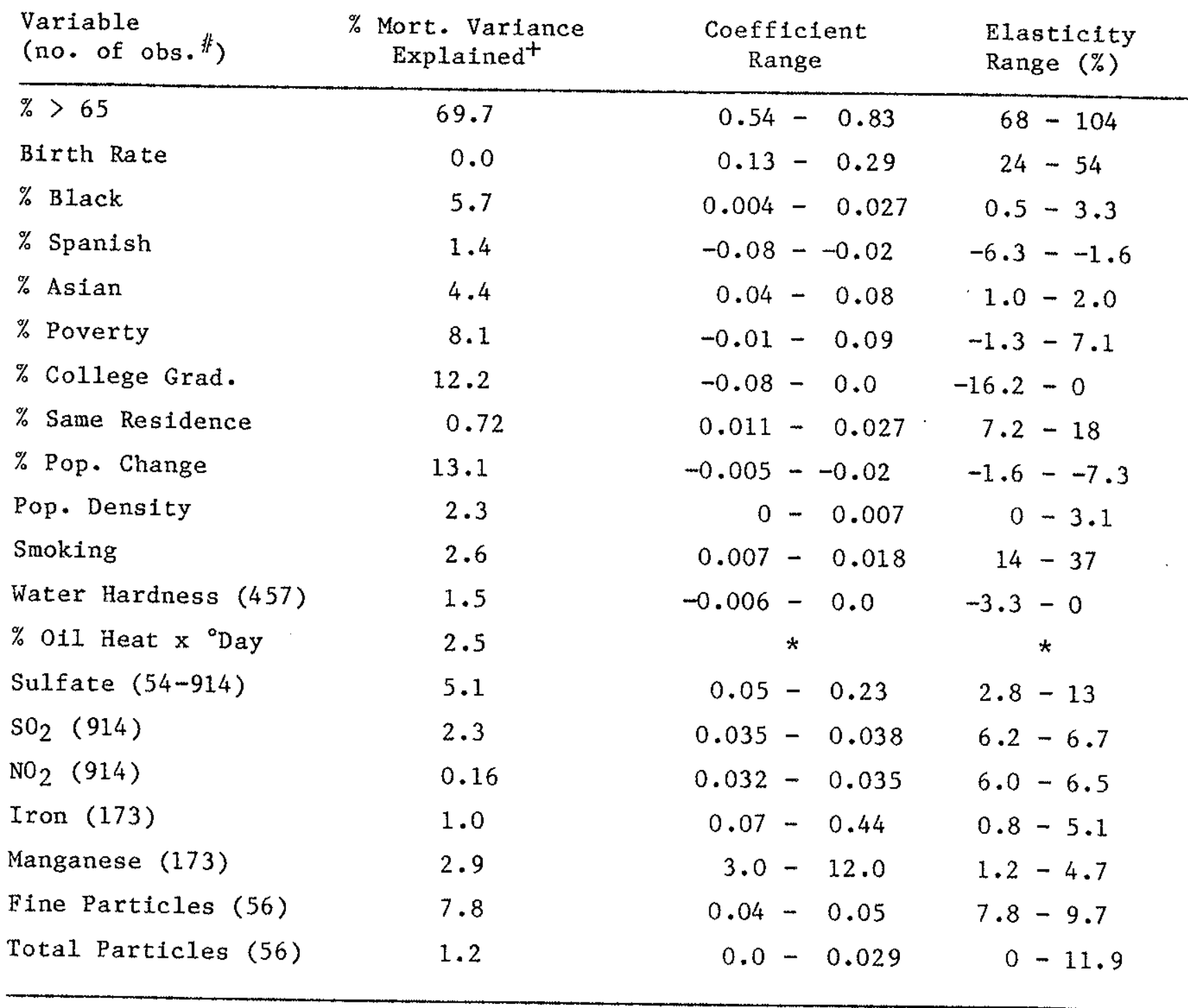

\# Data available for 952 cities unless otherwise indicated

+ Per cent of mortality variance explained by the variable, without considering other variables (bivariate correlation).

* Variable was never significant in multiple regressions 
Since the computed sulfate variable was so highly significant in the developmental regression models, the analysis was continued using computed $\mathrm{NO}_{\mathrm{x}}$ and $50_{x}$ data as alternative independent variables. All of the computed pollutant variables were highly significant predictors for all-cause mortality. Because of the high degree of similarity of alternative regression models employing different pollutants as predictors, three different bases were employed to compare regression models. Using these varying criteria, $\mathrm{SO}_{2}$, sulfate aerosol, and manganese particles all showed indications of providing better regression fits than the other pollutants. Statistical tests for the degree of fit showed that including a pollutant variable made a significant improvement, but that one could not distinguish among pollutants on this basis. Using a two-stage procedure employing mortality "adjusted" for demographics, smoking, poverty, etc., the differences in fit among the various sulfate measures, $\mathrm{SO}_{2}, \mathrm{NO}_{\mathrm{x}}, \mathrm{Fe}, \mathrm{Mn}$, fine particles and total particles were minimal. Further, visual comparison of residual patterns indicated only minimal differences, including comparison with the residuals obtained from a model with no aix pollutants as predictors. Thus it was concluded that statistical criteria alone will not sufflce in defining air pollution relationships with total mortality.

The relatively strong associations (ca. $5-10 \%$ ) shown for 1980 pollution with 1980 total mortality are generally not confirmed by independent studies, for example, in Europe. In addition, the U.S. studies did not find those pollutants with known adverse health effects at current concentration levels (such as ozone or $\mathrm{CO}$ ) to be associated with mortality. The question of causality versus circumstantial association must therefore be regarded as still unresolved. 
TABLE OF CONTENTS

$1.0 \quad$ Introduction $\ldots \ldots \ldots \ldots \ldots \ldots \ldots \ldots \ldots \ldots \ldots \ldots \ldots \ldots \ldots \ldots \ldots$

$2.0 \quad$ Background of Cross-Sectional studies.................. 3

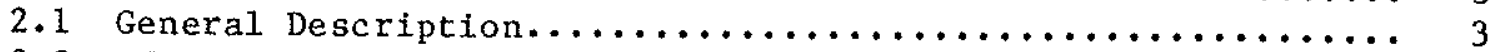

2.2 Effects of Errors in Estimates of Air Quality Exposure..... 3

2.3 Effects of Other Errors and Confounding Factors.......... 5

2.4 Spatlal Patterns in U.S. Mortality Rates.............. 6

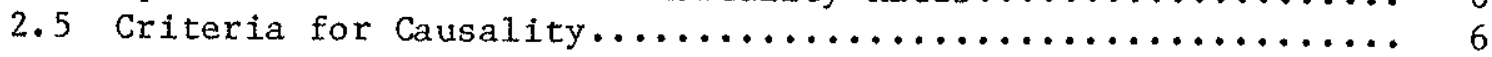

$3.0 \quad$ Data Sources, Descriptions and Methods................. 11

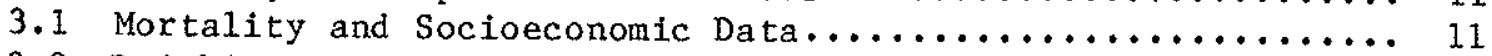

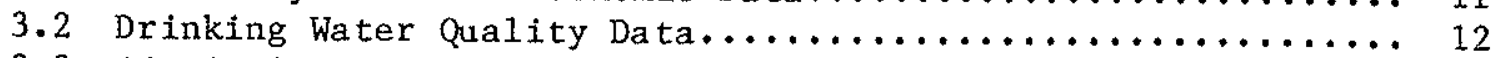

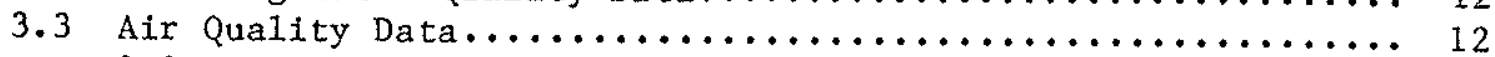

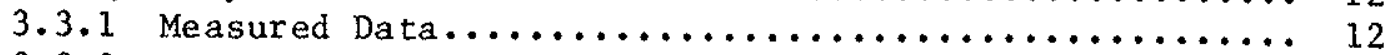

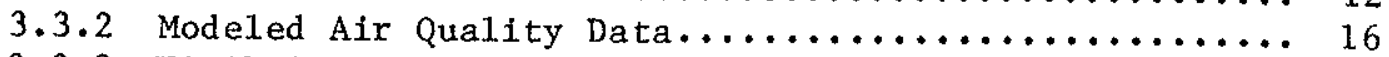

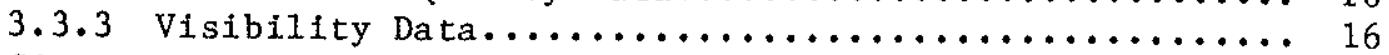

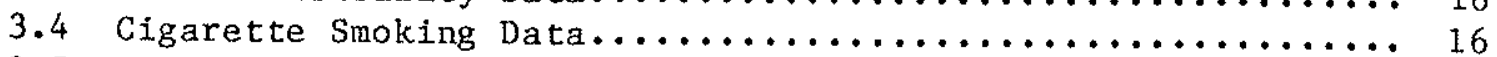

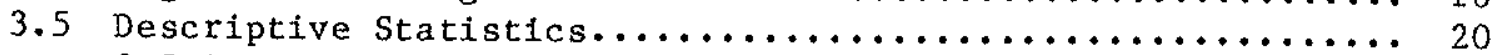

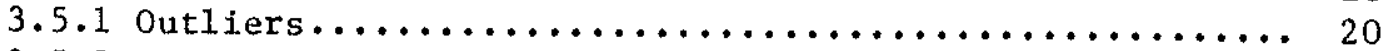

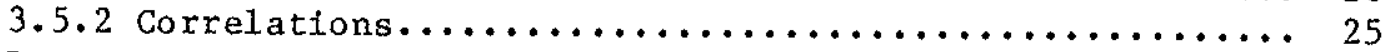

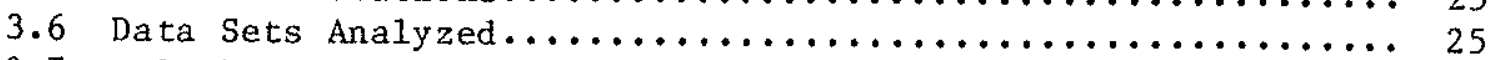

3.7 Reliability of Aix Quality Exposure Estimates........... 28

3.7 .1 Measured versus Computed Sulfate.............. 28

3.7.2 Other Correlations Among Pollutants.............. 29

3.7 .3 Cities with High Levels of Spectfic Pollutants...... 29

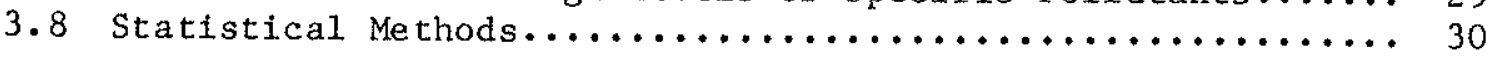

4.0 Regression Analyses on the 1980 Data Set: Phase 1.......... 32

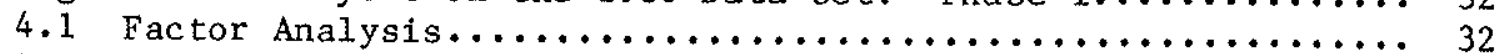

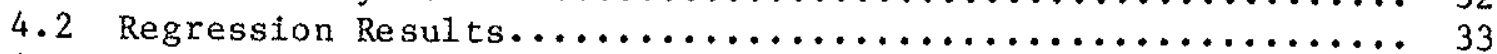

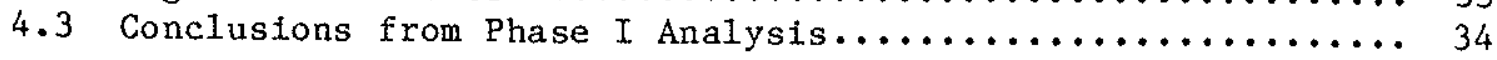

$5.0 \quad$ Phase II Regression Analyses...................... 36

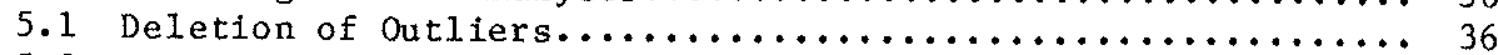

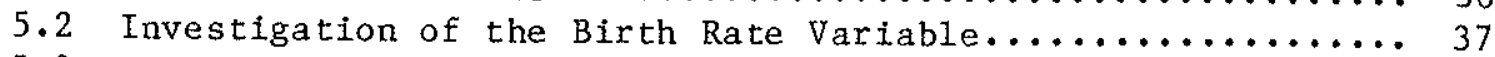

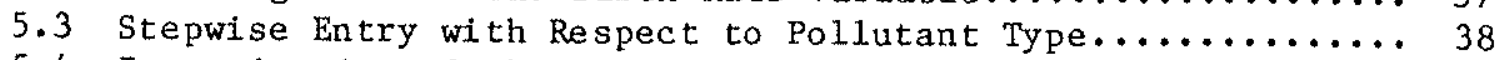

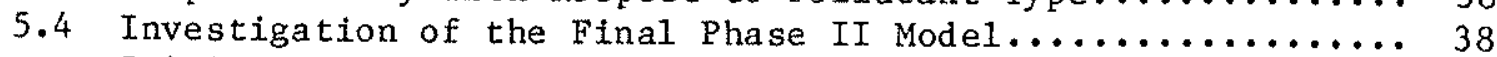

5.4.1 All Possible Subset Regression Analysis............ 38

5.4.2 Robustness to Demographic Variable Set and Data Set.. 46

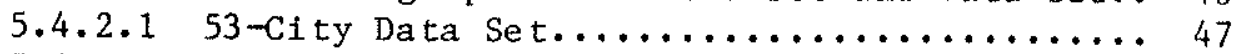

5.4 .2 .2 Additional Demographic Variables......... 51

5.5 Investigation of Residuals for Influential Observations and

Violation of Regression Assumptions.............. 52

5.6 Consideration of Spatial Autocorrelation.............. 57

6.0 Comparison of 1970 versus 1980: Cross Validation and Evaluation of Lag Effects of the Sulfate Variable................... 58

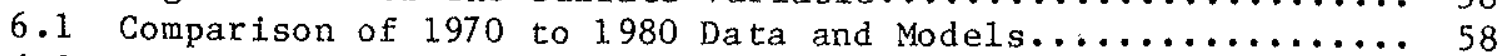

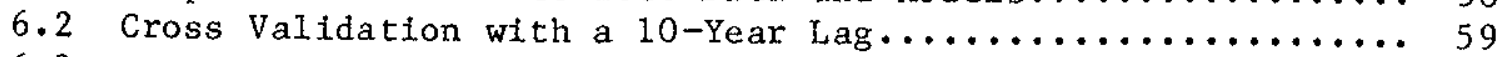

6.3 Regression Including 1980 Total Suspended Particulate Data 61 


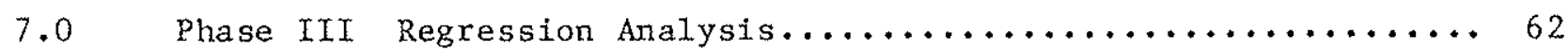

7.1 New Atr Pollution Variables..................... 62

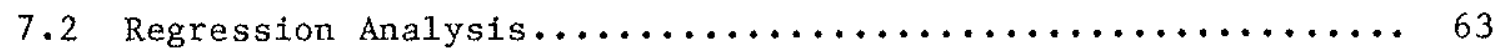

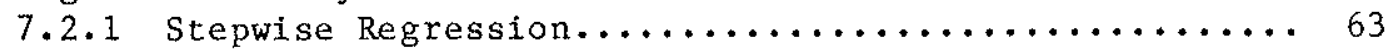

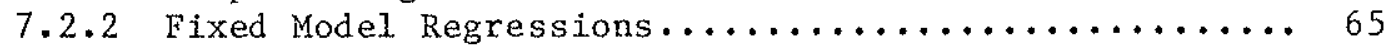

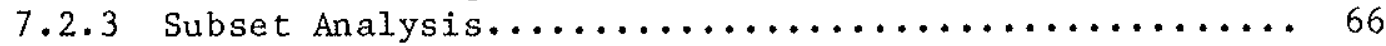

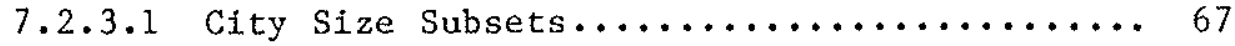

7.2 .3 .2 Pollutant Level Subsets.............. 67

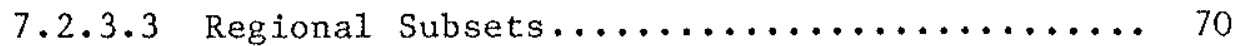

7.2 .4 Multiple Pollutant Regressions............... 72

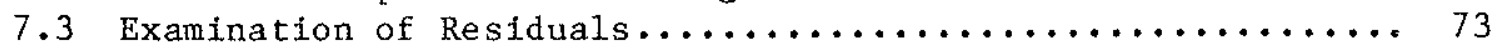

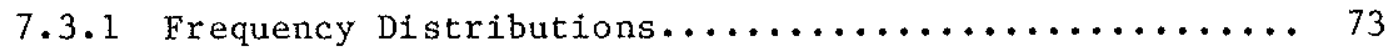

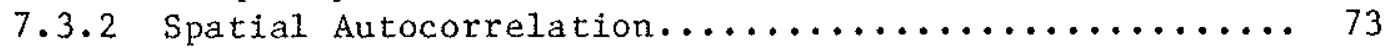

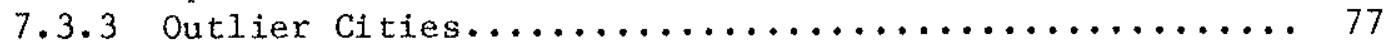

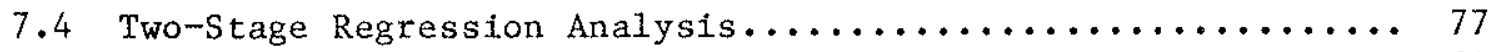

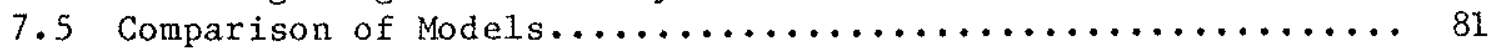

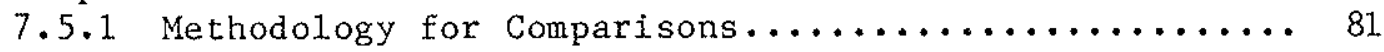

7.6 Summary of Phase III Findings................... 85

8.0 Discussion of Regression Results................... 87

8.1 Interpretation of Air Pollution Results............. 87

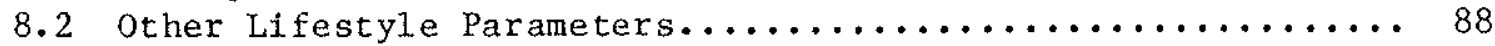

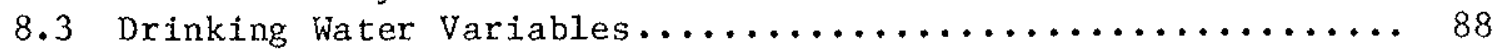

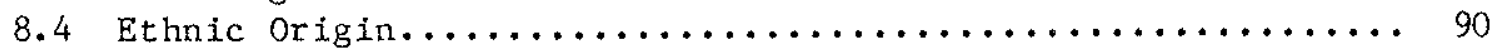

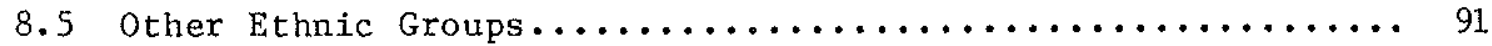

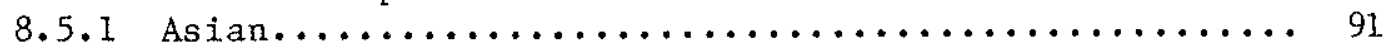

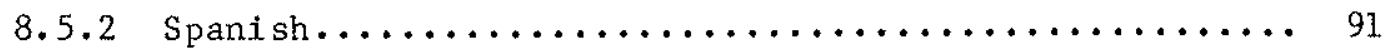

8.6 Discussion - Other Relevant Studies................ 92

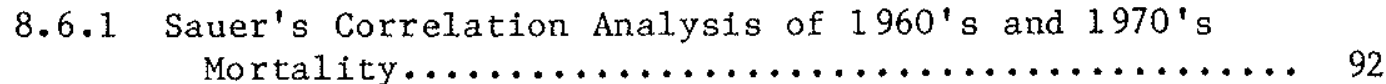

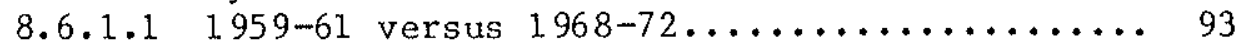

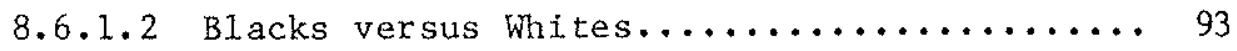

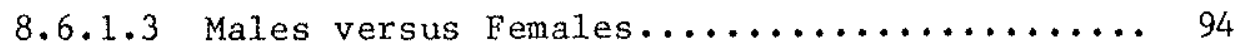

8.6.1.4 Correlation Between Disease Categories...... 944

8.6.1.5 Comparison of Average Rates............ 95

8.6.1.6 Sauer's Explanatory Hypothesis.......... 96

8.6.1.7 Conclusions from Reanalyzing Sauer's Data... 96

8.6.2 Cross-Sectional Studies in other Countries......... 97

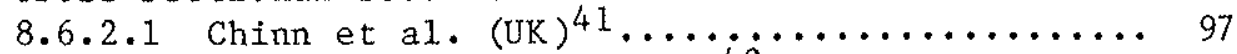

8.6 .2 .2 Göttinger (West Germany) $42 \ldots \ldots \ldots \ldots \ldots . \ldots 9$

8.6.2.3 Krzyzanowski and Wojtyniak (Poland) $43 \ldots . . .99$

8.6.2.4 Comparisons of Individual Mortality

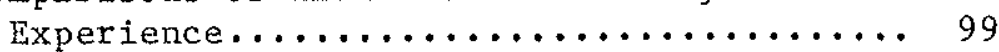

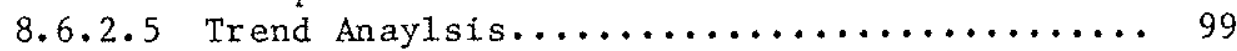

8.7 Evidence for Causality - Physiological Basis........... 99

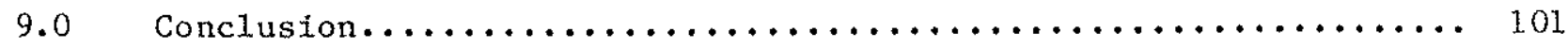

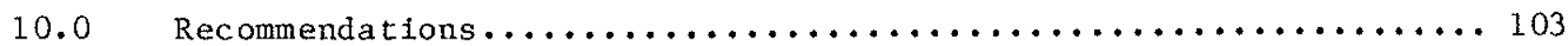

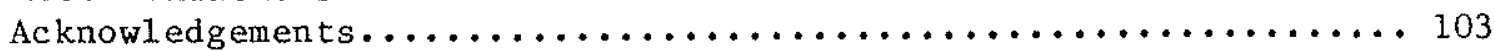

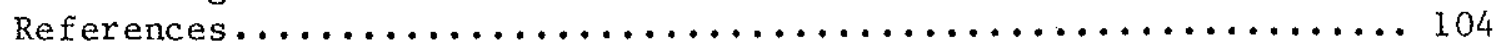

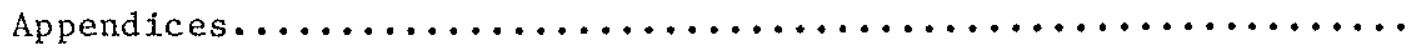




\subsection{INTRODUCTION}

The study of long term or chronic health effects of air pollution has long been fraught with difficulty. Early attention focused on air pollution episodes, such as Donora (PA) or the notorious London fogs of the 1950's and $60^{\prime} \mathrm{s}$, which dealt with short-term or acute effects, primarily $\mathrm{SO}_{2}$ and particulates. In order to discern long-term effects, it was necessary to compare population health statistics in places with different environments, and such comparisons are often compromised by other population differences that may be related to the sources of air pollution (industrialization, for example). In addition, there may be many other attributes of place that relate to health, if the older literature is to be belleved. 1

Lave and Seskin's 1970 cross-sectional (i.e., place-to-place variability) regression analysis ${ }^{2}$ added a new dimension, that of appreciable long-term mortality effects at current U.S. ambient levels (about 9\% of annual mortality associated with air pollution). These mortality effects were inferred from multiple Inear regression analysis of annual mortality rates in a number of US standard metropolitan statistical areas (SMSAs) in relation to available center city annual air quality levels and a few other explanatory variables. The article talked mostly about "aix pollution" as the causal agent; Lave and Seskin's later work ${ }^{3}$ focused more on the sulfate portion of total suspended particulates (henceforth referred to as "sulfate" or "sulfates" with the chemical symbol $\mathrm{SO}_{4}=$ ) as the most important pollutant. This hypothesis gained widespread attention when long-range transport air quality models became available and were used to predict nationwide $\mathrm{SO}_{4}=$ exposure levels and thus "excess deaths." 50,000 annual excess deaths was the figure often mentioned.

Subsequent cross-sectional regression studies both supported 4,5 the importance of sulfur oxides and failed to do so, 6,7 and the scientific community looked to other types of studies for possible confirmation. Even after years of animal and human clinical exposure studies, these long-term health effects are sti11 a matter of debate. 8,9

This type of cross-sectional statistical analysis, the so-called ecologic regression analysis, was accepted by some critics and rejected by others. It makes inferences about the outcomes to Individuals in terms of the behavior of groups, in this case entire SMSAs or cities, based on very limited information about individual exposures to potential causal agents. In addition, the types of group information that are available often do not include important lifestyle variables such as smoking, exercise, diet, etc. Insurance data have shown that mortality rates can vary by as much as a factor of two to three among groups differing in these lifestyle parameters.10 Cross-sectional regressions thus must address all the characteristics that vary regionally and which may affect longevity.

Spatial gradients in mortality have been noted by many authors, especia1ly with respect to heart disease, which is the largest cause of death in most U.S. locations. Kleinman et al.11 attempted to explain both regional and urban/suburban gradients in terms of three major risk factors: smoking, serum cholesterol, and blood pressure, based on individual survey data from about 4,500 individuals. They found that after accounting for these three risk 
factors, heart disease mortality was 18-20\% higher east of about the 96 th meridian, and $5-12 \%$ higher in urban versus suburban locations. They concluded that "other environmental, life-style, medical care or genetic characteristics must be considered in trying to explain the geographic variations which have been observed for many years."

This report describes an attempt to incorporate the most recent (ca. 1980) mortality and air pollution data in the US, and applies more complete statistical analysis methods to this problem. We draw on a larger group of U.S. cities for our study population, and include additional air pollutants, smoking, and data on drinking water quality as well. However, the mortality data analyzed have been limited to the total deaths reported for each city (all ages, causes, etc.). A special effort was devoted to updating the estimates of the geographic distribution of cigarette smoking because of the established importance of smoking as a factor in both cancer and heart disease mortality. This effort is described in detail in a separate report. 12

This report begins with a background discussion of cross-sectional regression techniques and the effects of various types of errors. Sources of data are described next, including data on mortality, demographics, smoking, and air pollution, and their descriptive statistics. The regression analysis is presented in three separate phases. Phase I, Section 4, is exploratory in nature and includes a factor analysis as a means of dealing with the many potential explanatory variables (especially the demographic and socioeconomic variables). Section 5, the Phase II regression analysis, presents the development of two specific mortality "models" which were optimized for subsets of cities having data on several pollutants. Section 6 compares 1970 and 1980 regression results, including a cross-validation. Section 7 presents the Phase III regression analysis, which includes two additional computed pollutant variables $\left(\mathrm{SO}_{2}\right.$ and $\mathrm{NO}_{\mathrm{x}}$ ) and develops some formal means of comparing alternative regression models. Section 8 discusses these results in the context of independent findings and similar studies for other time periods and locations. The report ends with the conclusions (Section 9), recommendations for further research (Section 10) and two Appendices. Appendix A presents the air pollution data base, and Appendix $B$ is a discussion of air pollution health effects from a physiological perspective. 


\subsection{BACKGROOND OF CROSS-SECTIONAL STUDIES}

\subsection{GENERAL DESCRIPTION}

The cross-sectional study attempts to define associations between variables through the analysis of spatial patterns. Typlcally, annual mortality rates are computed for a number of political subdivisions, appropriate demoand air pollution exposures are defined and data obtained from Census sources, for the same time period. Multiple regressom extant monitoring data, usually late a "model" for mortality rates; such causal relation models have often been used to infer usualy daily variations as investigating chronic effects, since no account is taken of annual averages or totals.

Such cross-sectional studies are one of the few ways that chronic health effects in large populations may be studied at reasonable cost. However, there can be problems with this technique with respect to both the data used and the interpretation of results. The study design requires that the average properties of the population groups be interpreted as appropriate to each of the individuals comprising the group. All of the multiple regression variables refer to properties of the group, yet the group mortality rate stems from individuals who died for various individual reasons. This is often referred to as the "ecologic fallacy."13 For example, if a group has both a high rate of mortality and high consumption of tobacco (presumably because of an excess of heavy smokers), the ecologic assumption is that the heavy smokers in the group are the ones who died prematurely. An analysis of groups does not permit verification of such assumptions, except as inferred from statistical robustness. When responses are nonlinear, such that an average value of an independent variable does not correspond to the average response, this type of analysis may yield incorrect answers.

In addition, when only one year's data are analyzed it is generally not possible to distinguish between truly long term or chronic effects and the annual sum of short-term or acute effects. For truly long-term effects, previous or historic values of the independent variables (especially air pollution exposures) should be used. Time-series analyses are better suited for the study of short-term effects.

\subsection{EFFECTS OF ERRORS IN ESTIMATES OF AIR POLLUTANT EXPOSURE}

The accuracy of estimation of alr pollution exposure will vary with the size of the political subdivision used and the pollutant. Some primary poltrations such as TSP, $\mathrm{CO}$, and $\mathrm{SO}_{2}$, tend to be very local in nature, and concentrations may vary substantially within a few city blocks; in addition, concenoxidants and vary between indoors and outdoors. Secondary pollutants, such as ozone can be strongly sulfates, may exhibit less spatial variability, although

The effect of exrors in the measurement of a variable is to decrease both its statistical significance and its regression coefficient relative to the 
true value, assuming that the effect was real in the first place (in the statistical sense). Since concentration patterns of many air pollutants often are collfnear, this may mean that the pollutant with the least error in estimation of exposure may appear most statistically significant, even when the real situation is that a mix of pollutants is responsible for the observed effect. In such situations, measurement errors can mask the true effects. However, none of these considerations affects the overriding issue of causality versus association.

This type of error also is associated with the choice of political subdivision, since the larger the unit is in area, the larger are the likely errors in estimating true population exposures (assuming reasonably local pollution sources are present). For example, assume that there is a true relationship (association) between particle concentration and mortality (this need not be a causal relationship, since there may be other aspects of the pollution source to consider, such as occupational factors). Before implementation of the dichotomous sampler network, there were only two measures of particle concentration generally avaliable: TSP (or total particle mass), which often reflects local pollution because it may include particles up to $50 \mu \mathrm{m}$ in diameter which tend to remain close to the source; and sulfate, which is regional in extent since the particles are much smaller and thus trave1 further. When small areas (such as clties or census tracts) are used in the analysis, TSP exposures may be reasonably well represented and TSP may be statistically significant. On the other hand, if larger units are used, such as whole counties or Metropolitan Statistical Areas (MSAs), the true TSP effect will likely be masked by the exposure error, since a large number of people have now been "assigned" to the TSP monitor but live so far away that they are not actually exposed to the pollution measured there. Now, if at the same time there is a regional trend towards higher mortality (for whatever reason) in the region of high sulfates, sulfate may become the significant variable when MSAs are the observational unit. This result might appear to have a causal basis in physiology, since small particles such as sulfates can penetrate deeper into the lung, but in this case the result could have also appeared only because a regionally distributed pollutant was matched with a regionally distributed mortality trend. It should be obvious that an MSA-based analysis cannot capture local pollution effects, only regional ones, but that a city-based analysis should be able to detect either type. We chose cities as the observational unit for the study which is reported here. The challenge is to identify city-specific effects and to separate causal regional trends from circumstantial ones.

Mortality rates may be statistically unstable if the population base is too small. One solution to this problem is to use small geographic areas (i.e., central cities) and average the data over several years, which will improve the stability of estimates of both mortality and air pollution exposure. However, for cities over 25,000 population, as studied here, the variability of the annual numbers of deaths (ca. 250) should not be a problem; based on the median city size of about $57, \overline{000}$ people and the mean mortallty rate, the sampling variance is only about $1.4 \%$ of the total observed variance. 


\subsection{EFFECTS OF OTHER ERRORS AND CONFOUNDING FACTORS}

In order for error in measurement to increase the significance and regression coefficient for a variable, the error must have a selective bias and not just be random noise. An example might be better measuring instruments or characterization of exposure in areas of high mortallty rates, compared to areas of lower mortality rates.

Patterns of population migration can also cause errors in estimated pollution exposures and can have confounding regression results. The confounding results from elther selective migration of sick people or of the more economically advantaged. In either case, current (loca1) air quality may not represent the true long-term exposures of current residents.

Other problems can arise in these analyses when unadjusted total mortality data are used (all causes, all ages). Often, only total mortality data will be available for the smaller geographic subdivisions. Age adjustment is probably the most important correction to make, since the probability of dying increases exponentially with age above age 35. If mortality rates are available for detalled age groups, they can be combined into one age-adjusted total rate by reference to a standard population. On the other hand, if only total deaths are available but details are available on the population age distribution, then the expected total number of deaths may be computed on the same basis. In many cases, including the work described here, neither procedure has been followed but surrogate age adjustments were attempted by using a population age descriptor as an independent variable in the multiple regression. "Percentage of population aged 65 and over" is a common choice. If all populations have similarly shaped age distributions, such a choice may be acceptable, but a simple calculation will show, for example, that the regression coefficient for "\% $\geq 65 "$ should be numerically equal to the mortality rate for this age group less the rate for the under-65 group. Many of the published studies do not meet this simple test. Similar considerations apply to explanatory variables such as "\% nonwhite" or "\% poverty."

Other problems have arisen due to collinearity between air pollution and demographic variables, which is always present to a certain extent. This is more of a problem in central cities than in MSAs, but the reduction in collinearity for MSAs is only apparent, not real, since it usually results from the use of central city air quality data to (inadequately) represent an entire SMSA. It is not possible a priori to establish acceptable limits on multico1linearity. In this case it arises from the fact that pollution sources have other types of impacts upon communities. Heavily industrialized cities tend to have demographically different populations than, say, bedroom suburbs for large metropolitan areas. These differences typically include education, smoking habits, race, and income, all of which can have independent effects upon average mortality rates. If such effects are not explicitly represented in the regressions, they may be erroneously (1mplicitly) represented in part by the air pollution variables. Such problems can only be handled by incorporating the appropriate independent variables in the analysis and then sorting them out by stepwise or other repetitive regression methods. Factor or principal component analysis may be another approach. However, when repetitive specification searches are made, statistical significance levels may be overstated (due to loss of independence). 
Such regression methods often appear to be rather ad hoc and have been labelled as "data mining" or "fishing expeditions." The basic problem is lack of a theoretical a priori "model" (in the econometric sense) for human mortality and morbidity as well as lack of appropriate data bases for the known risk factors. For example, risk factors for heart disease, which accounts for a large fraction of all deaths, lnclude smoking, diet, exercise, lung function, and perhaps drinking water hardness and ethnic background. A few of the wel1known cross-sectional studies have attempted to represent some of these factors; most have not.

\subsection{SPATIAL PATTERNS IN U.S. MORTALITY RATES}

Spatial patterns of U.S. mortality rates show some well defined trends.14 Total mortality from "natural" causes (excluding accidents, suicides, homicide, etc.) is highest for white males in the southeast and in the northeast for females (Figure 1). Heart disease is higher east of the Mississippi and especially in the Southeast coastal plain (Figure 2). Lung cancer (Figure 3) shows very similar patterns, suggesting a common factor which might well be cigarette smoking. However, chronic respiratory disease deaths are higher in the West (Figure 4). These patterns suggest certain associations; the challenge to the analyst is to establish whether such associations are causal and not just circumstantial. Sauer's data are discussed in more detail in Section 8.6.1.

\subsection{CRITERIA FOR CAUSALITY}

There are no standard tests for causality, and Lave15 suggested that causalfty is only a theoretical construct, based on a consensus of scientific opinion. For long-term health studies, establishing causality requires that the clinical effects of the pollutant (see Appendix B, for example) be consistent with the health endpoint in question, that relationships based on spatial patterns be consistent with those based on temporal trends, and that all reasonably plausible confounding variables be accounted for. These caveats should be kept in mind in reviewing the following results. 
(a) males

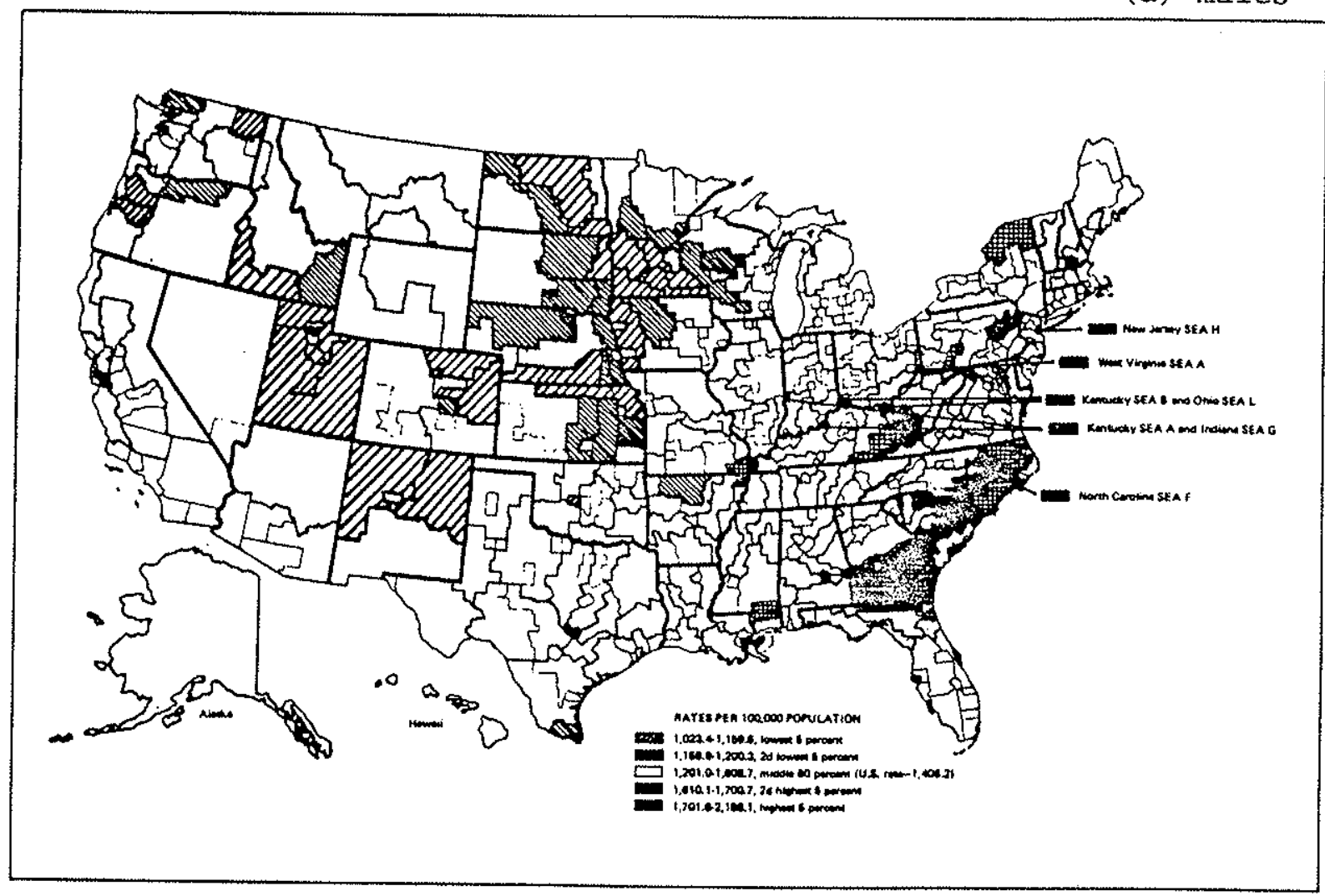

(b) females

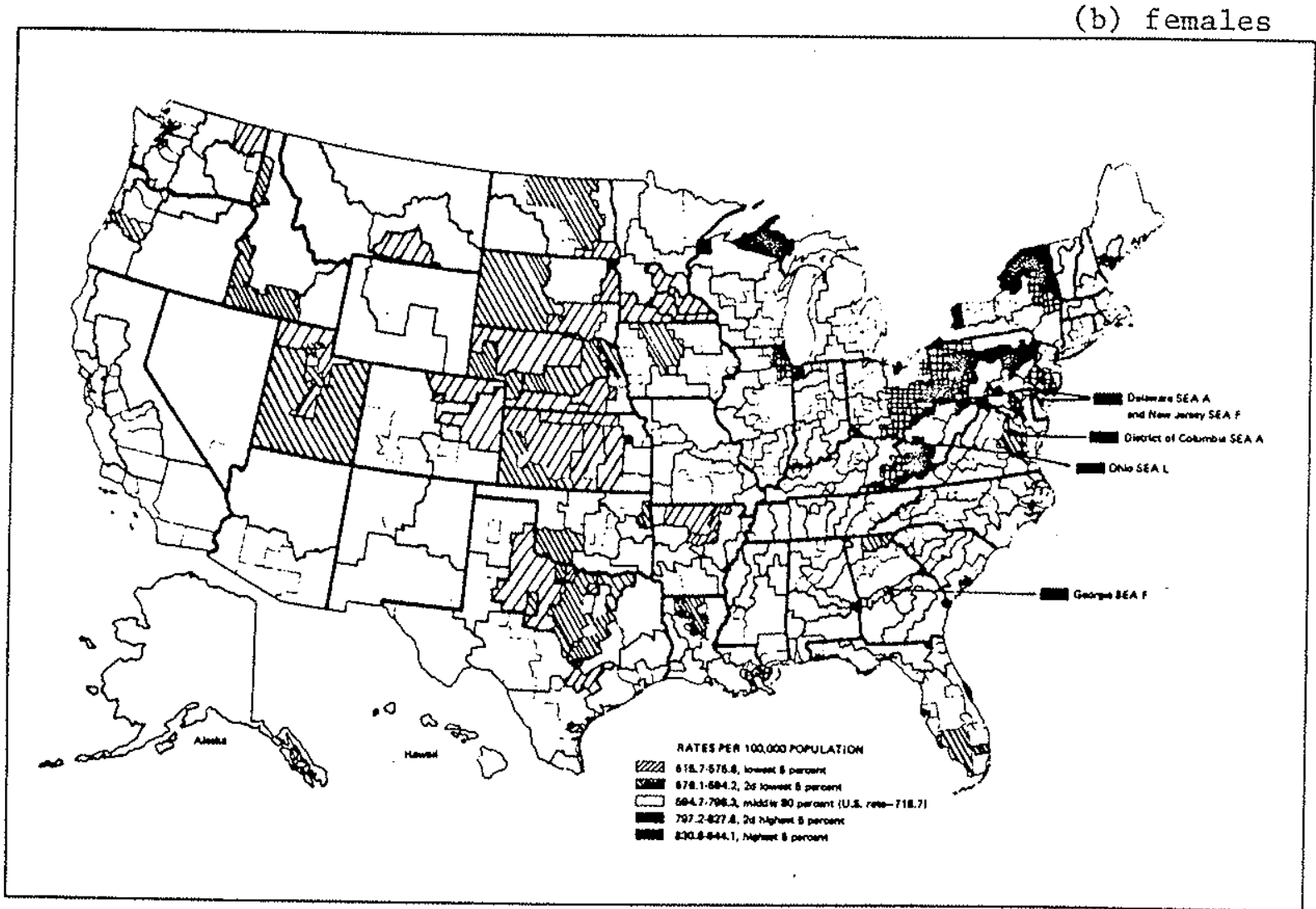

Fig 1. Death rates for natural causes (ICDA 000-796) among whites aged 35-74 years (age-adjusted) in 50 lowest and 50 highest rate state economic. areas United States, 1968-72 (from Sauer, 1980) 
(a) males

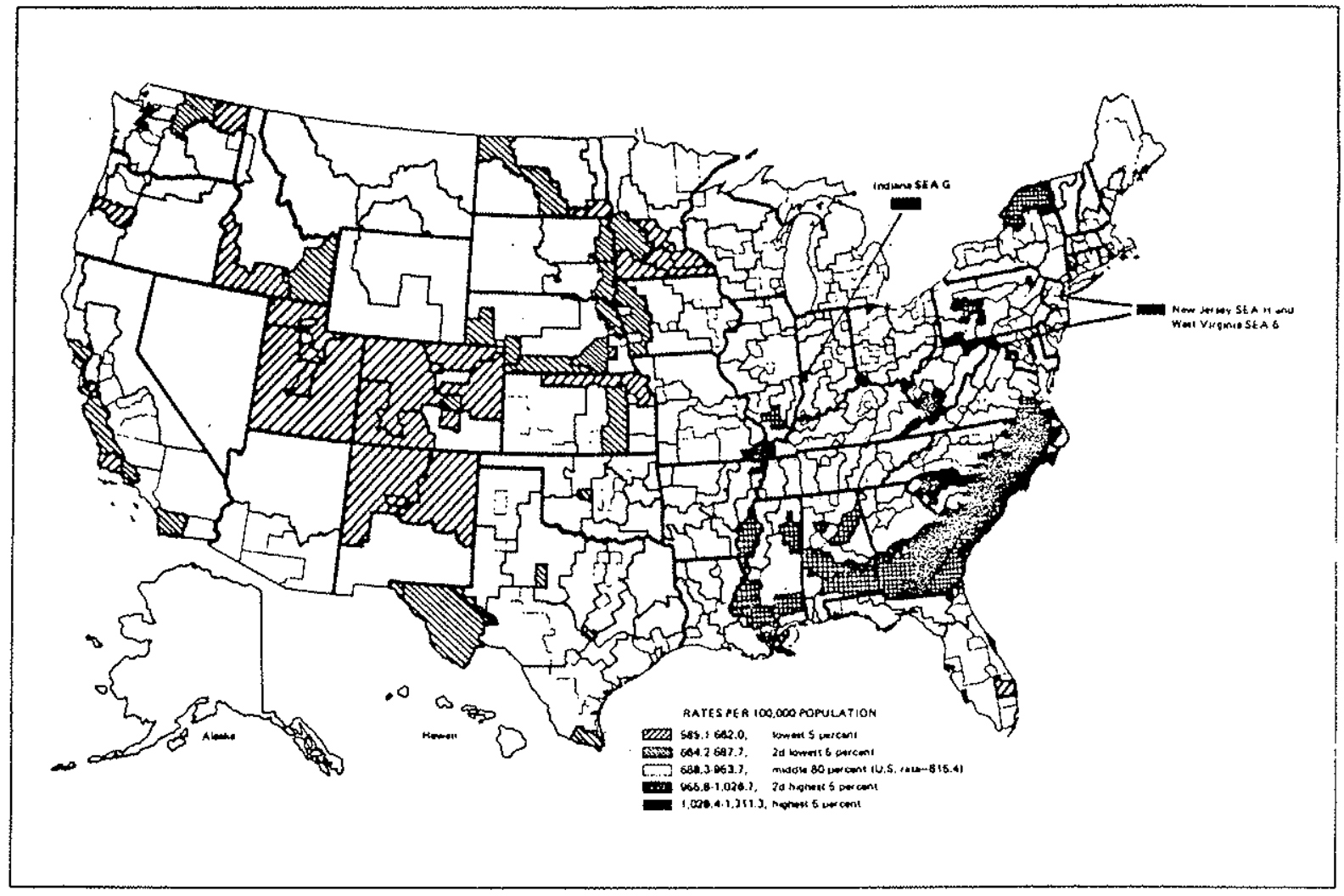

(b) females

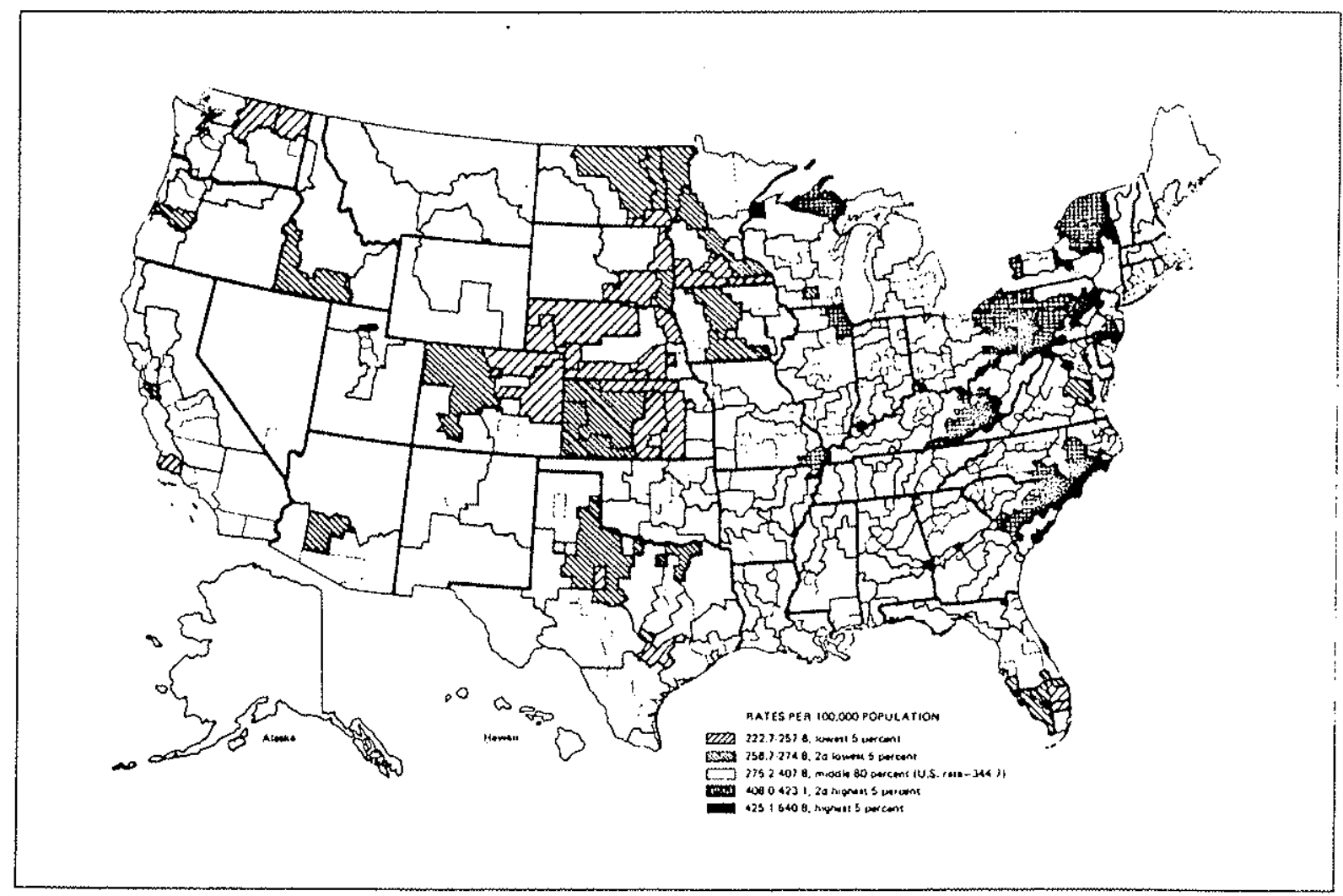

Fig 2. Death rates for cardiovascular diseases (ICDA 390-448, 780-796) among whites aged $35-74$ years (age-adjusted) in 50 lowest and 50 highest rate State economic areas: United States, 1968-72 (from Sauer, 1980) 
(a) males

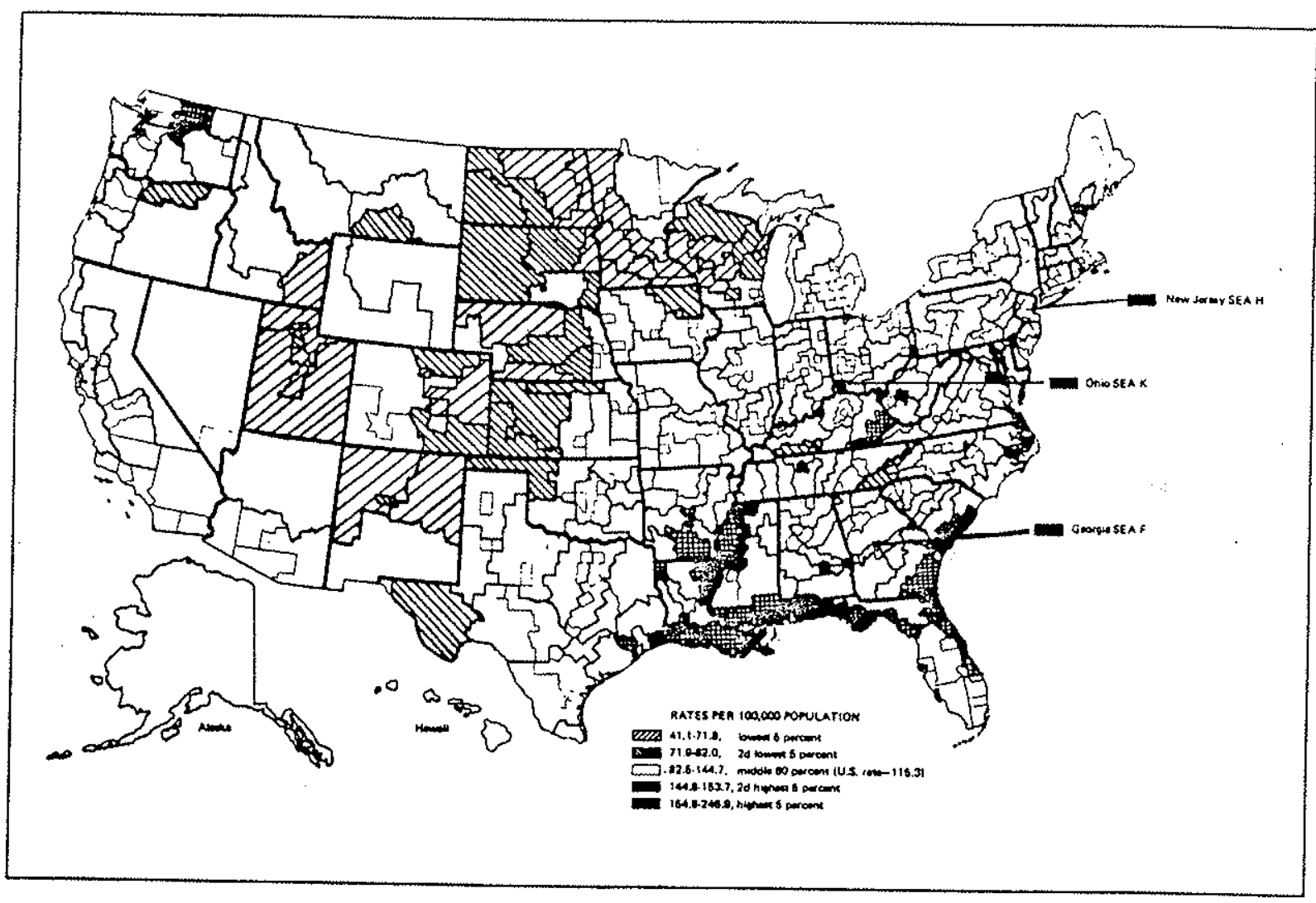

(b) fernales

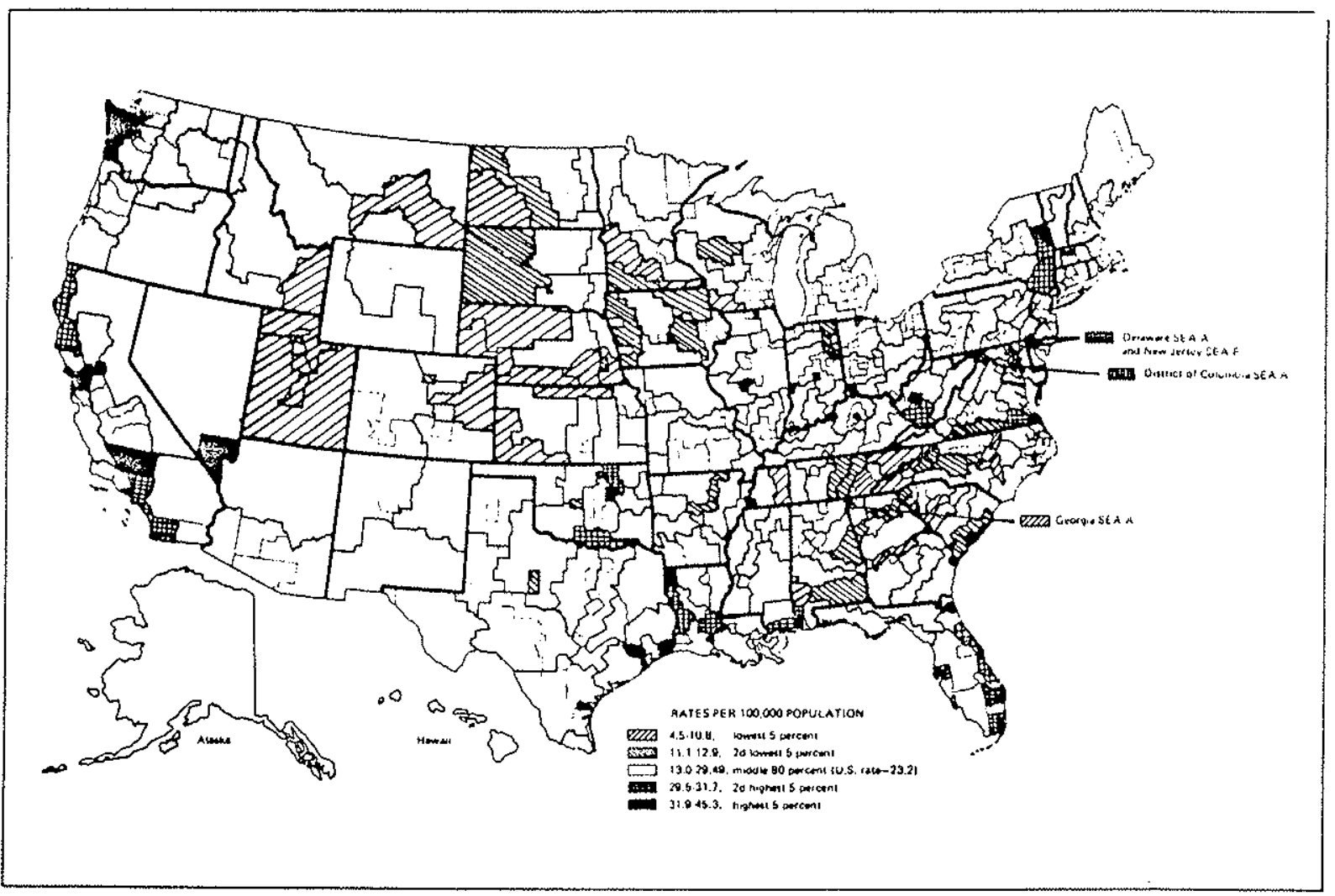

Fig 3. Death rates for respiratory cancer (ICDA 160-I63) among whites aged 35-74 years (age adjusted) in 50 lowest and 50 highest rate State economic areas: United States, 1968-72 (from Sauer, 1980) 


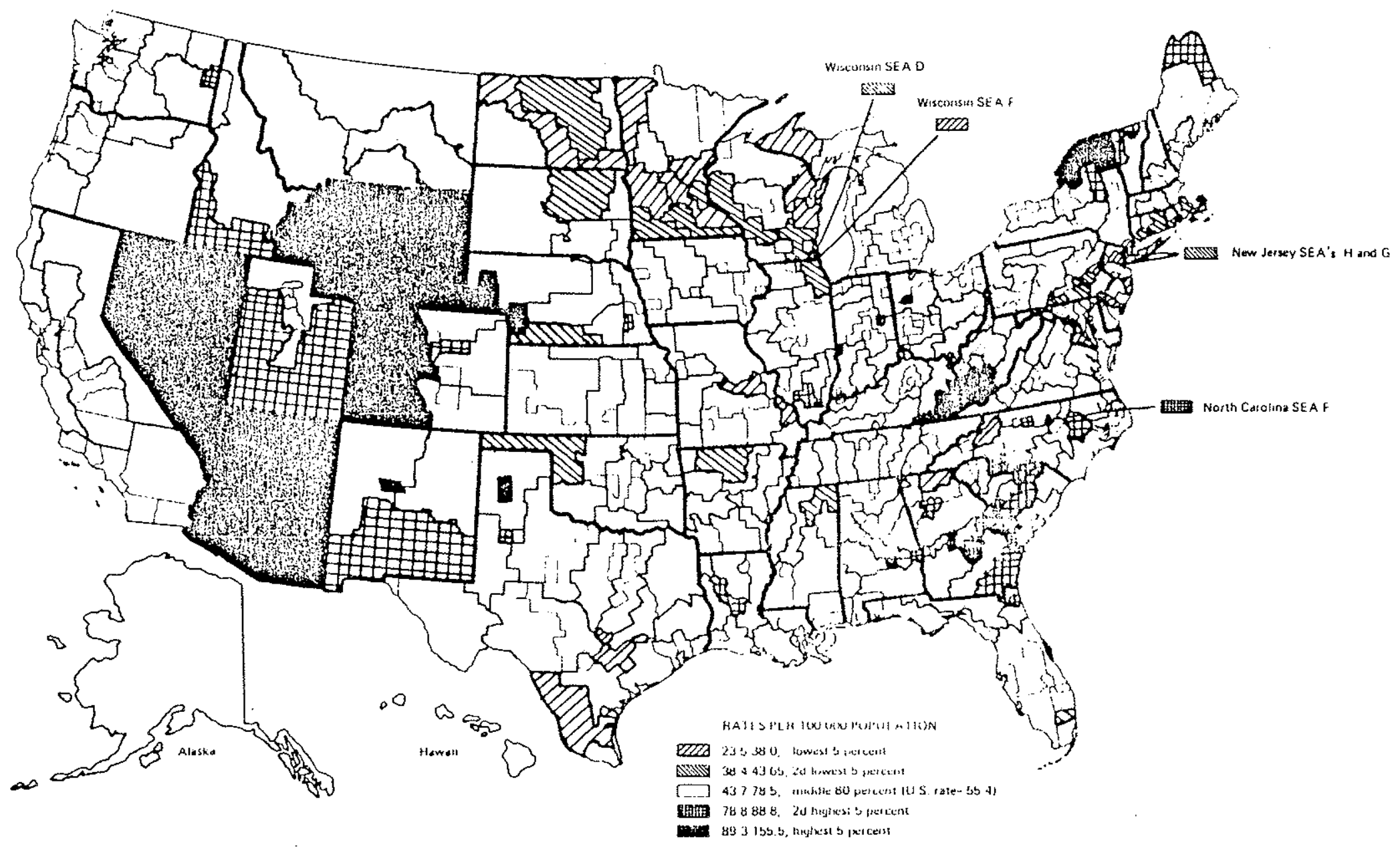

Figure 4. Death rates for chronic respiratory diseases (ICDA 490-493, 517-519) among white males aged 35-74 years (age-adjusted) in 50 lowest and 50 highest rate state economic areas: United States, $1968-72$ 


\subsection{DATA SOURCES, DESCRIPTIONS, AND METHODS}

\subsection{MORTALITY AND SOCIOECONOMIC DATA}

Mortality and descriptive population data were obtained for 916 U.S. cities (having valid data entries) from the 1980 Census of Population, as listed in the magnetic tape file for the 1982 City and County Data Book (CCDB).16 The mortality counts are for 1979 , but death rates (per 1000 population) are computed by dividing by the population as estimated on Apri1 1, 1980 , which could entail a slight error for clties with rapidly changing population.* The mortality variable used as the dependent variable throughout this analysis is based on all causes of death for all ages, races, and sexes, $i . e$. , total mortality.

The following socioeconomic and demographlc (independent) variables were extracted from the CCDB; the rationales for thelr inclusion are given below:

1. $\% \geq 65$ (years of age). Above age 35, mortality rates increase exponentially with age, but the percentage 65 and older is the only useful age statistic available from CCDB. The other age cuts (ages 5 and 25) are too low to influence mortality, and "median age" tends to be collinear with "\% $>65, "$ which thus would add little new information where it is needed (the age distribution within the 65 and older group).

2. Racial and ethnic distribution ( $\%$ black, $\%$ Asian, $\%$ Hispanic). Each of these groups tends to have mortality rates different from whites. Thus cities with higher than average percentages of these groups would be expected to have correspondingly different mortality races for the total population.

3. \% below poverty level. We feel this is a bettex income variable than median income, since any effect of income on mortality would be expected to be most obvious at the low end of the scale.

4. \% college graduates. Education may be a better socioeconomic variable than income since some persons may have low income because they have poor health, not vice versa. Educational attalnment, as a socioeconomic indicator, will not be changed by subsequent iliness.

5. \% population change since $1970^{1}$ ( $\triangle$ pop.); \% born in state of current residence ( $\%$ resident). These two variables are intended to capture population stability and migration, which can be important since ill health can be a factor in the deciston to migrate and since long-term exposure to air pollution would be affected by migration.

6. Ratio of ales to females (\%). This variable could be important since males have higher mortality rates than females.

* The mortality rate 11 sted in CCDB for Wilmington, DE (20.4 per thousand) was found to be in error and was adjusted to 14.4 , based on local information. A similar error was found in the 1970 data for Wilmington. 6 
7. Birth rate (per 1000 population). Birth rates can influence mortality rates in two ways: first, through infant mortality. Second, if the census has undercounted the population base, the errors in population counts would inflate both birth and death rates by the same percentage. Both birth and death counts are believed to be accurate.

8. \% with homes heated by gas or by oil, times annual degree days. These two variables are intended to capture space heating effects on air quality, including possible indoor air quality. These variables are really pseudo-politution variables. Also, homes heated by gas are more likely to have gas cooking stoves, a possible source of indoor air pollution.

9. City size variables: population density, $\log$ of population. City size may have direct effects on mortality through changes in the pace of life, or indirect effects regarding the representativeness of monitoring data on air quality.

\subsection{DRINRING WATER QUALITY DATA}

Data on drinking water hardness and source (surface versus ground) were obtained from a data base compiled by the National Institutes of Health.17 These data were for ca. 1970 and earlier, but it was felt that the values would be reasonably stable over time. Data were available for 450 cities out of the above set of 916. Previous studies 18,19 implicated soft water as a contributing factor in heart disease, primarily for males. Figure 5 is a map of the water hardness data, based on a subset of cities also having data on air quality.

\subsection{AIR QUALITY DATA}

\subsubsection{Measured Data}

Data on air quallty were obtained from the U.S. Environmental Protection Agency as quarterly averages for the years 1978-82 from the Storage and Retrieval of Aerometric Data (SAROAD) system. Those quarters with enough data to provide valid quarterly averages then were combined to produce grand "annual" averages and medians for the entire period. This procedure maximizes the number of cities in the data set for each pollutant and is based on the premise that the long-term temporal trends are small. The only pollutant with obvious appreciable trends is lead. The following data sets resulted (number of cities in brackets):

1. Ozone [167] (annual means or medians of daily maximum hourly concentrations) (ppm). See Figure 6 for an isopleth map of these data.

2. Carbon monoxide [161] (ppm)

3. Lead [189] (ug/m $\left.\mathrm{m}^{3}\right)$

4. Vanadium [167] $\left(\mathrm{ug} / \mathrm{m}^{3}\right)$

5. Iron [173] $\left(\mathrm{ug} / \mathrm{m}^{3}\right)$ (Figure 7) 


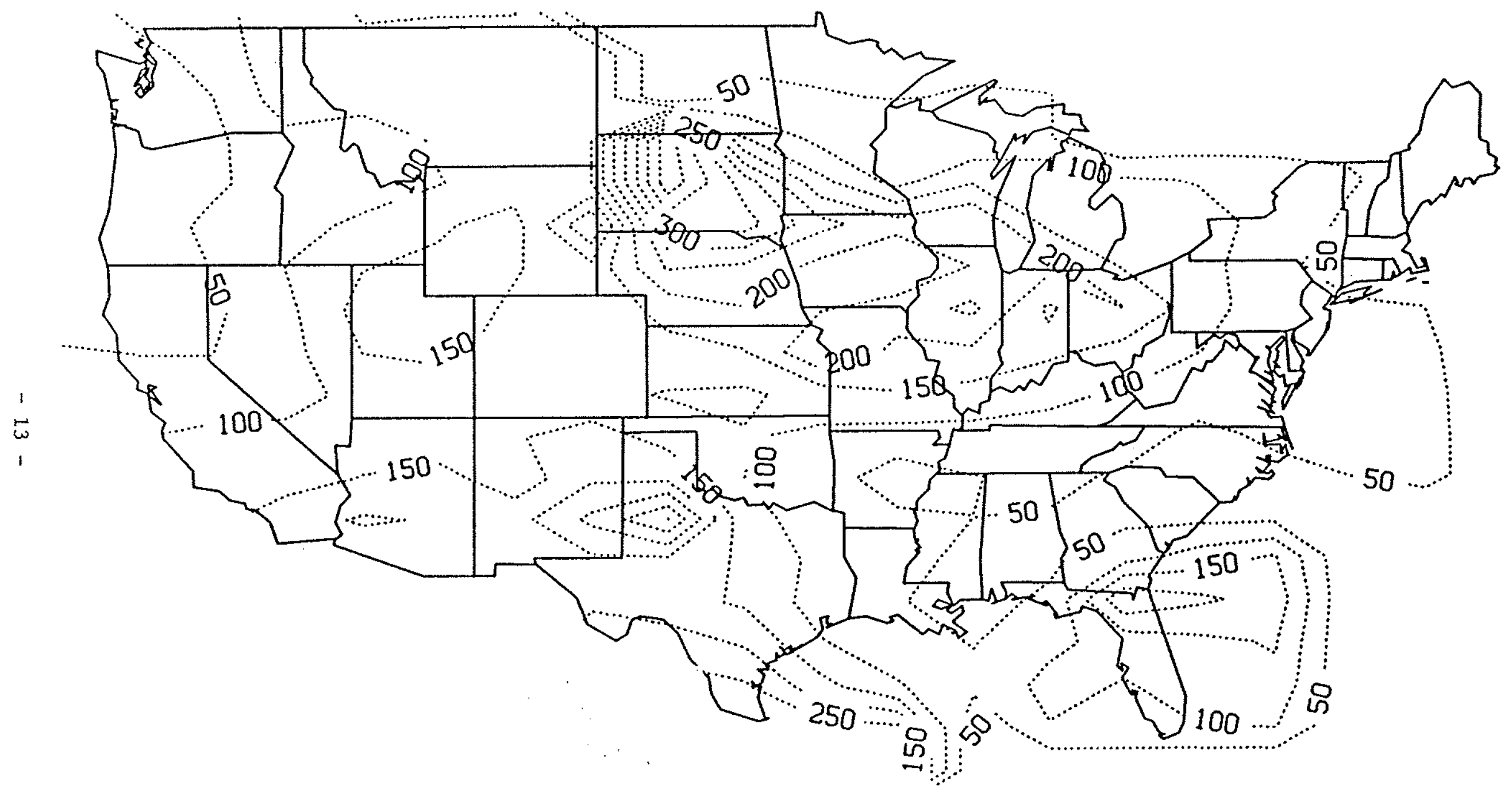

Figure 5. Total hardness of drinking water (ppm as $\mathrm{CaCO}_{3}$ ). 


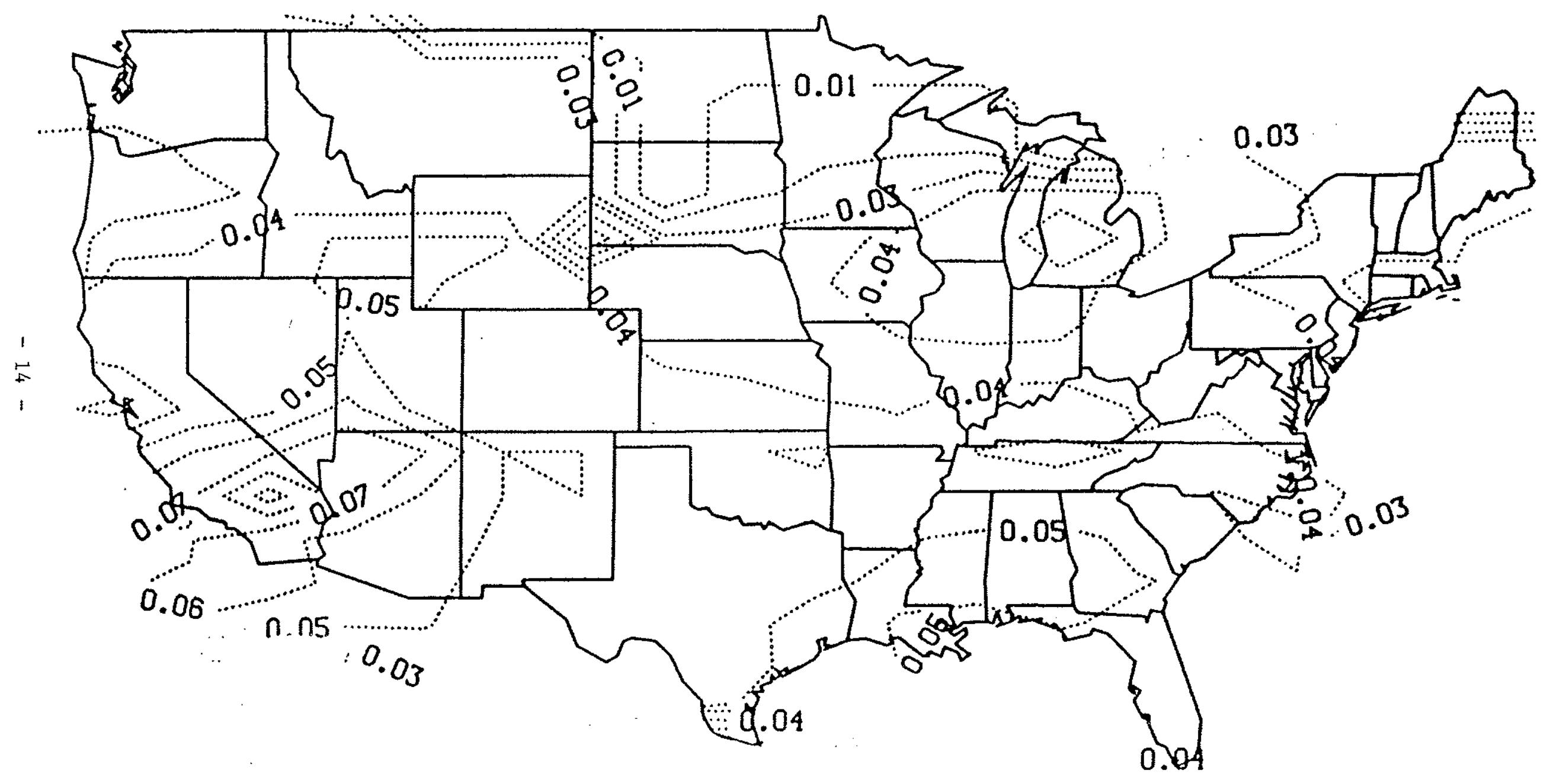

Figure 6. Median dafly maximum ozone (ppm). 


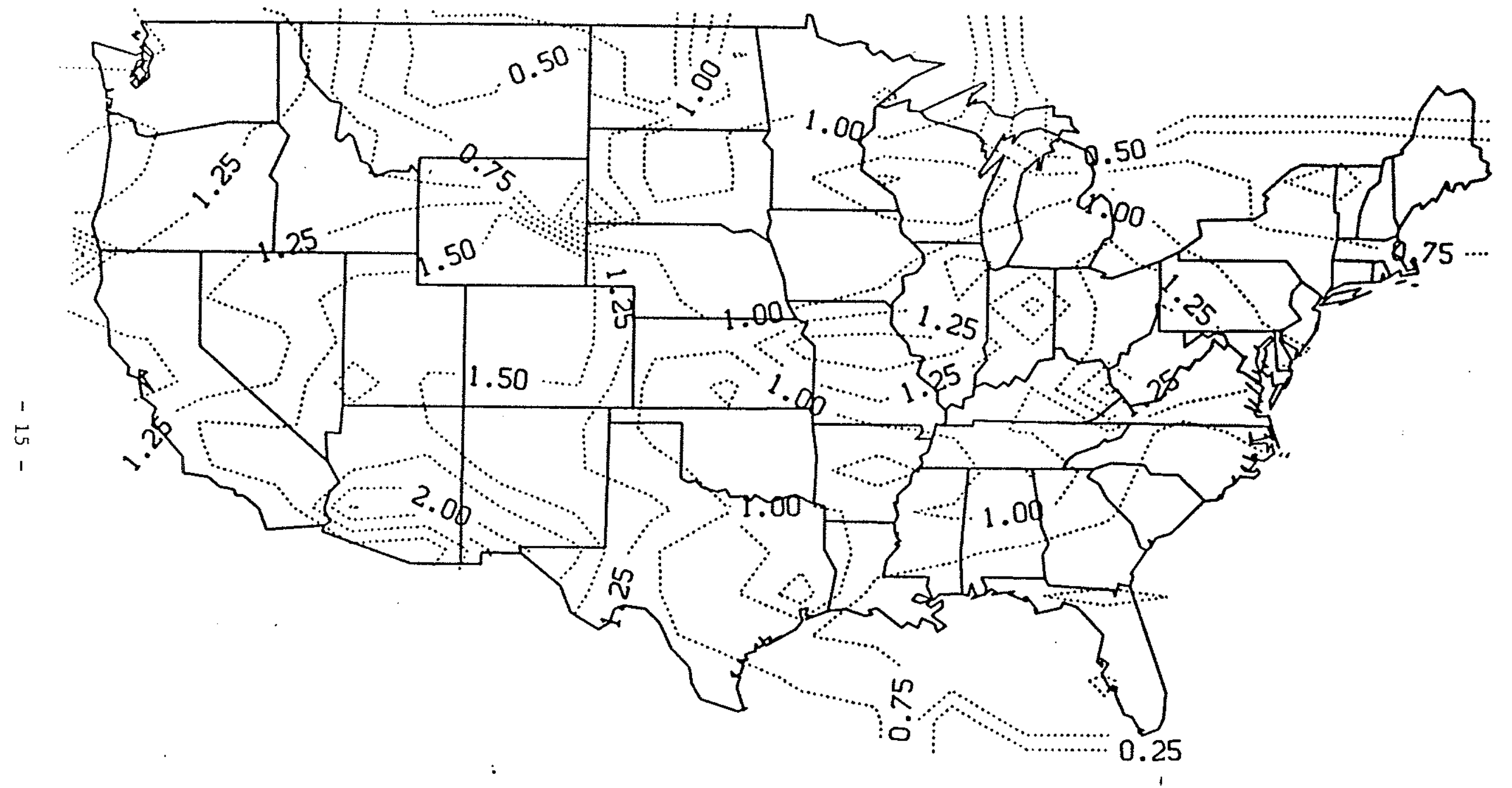

Figure 7. Iron in suspended particulates $\left(\mathrm{ug} / \mathrm{m}^{3}\right)$.

Note: distributions are not necessarily continuous. 
6. Manganese [173] (ug/ $\left./ \mathrm{m}^{3}\right)$

7. Cadmium $[1.73]\left(\mathrm{ug} / \mathrm{m}^{3}\right)$

8. Measured Sulfate [138] (ug/ $\left.\mathrm{m}^{3}\right)$ (Figure 8)

9. Particle data from the dichotomous sampler network (1979-83): Total mass and fine particle mass, $[n=56]$; total sulfate, fine particle sulfate $[n=54]\left(u g / m^{3}\right)$; samples taken every 3 or every 6 days. 20

Measurements of sulfate were restricted to 1978 and 1982 , since the use of alkaline filters in 1979-81 created an artifact due to $\mathrm{SO}_{2}$ conversion on the filter. 21 Either median or mean concentrations of these measured pollutants were used in the regressions, depending upon which was more statistically significant. The final regression models used median values exclusively.

\subsubsection{Modeled Air Quality Data}

The intersecting set containing all these pollutants has too few cities for a robust statistical analysis ( 42 cities, 1 isted in Table 1 ) so the data set was augmented with a sulfate variable that was estimated by model calculations using the ASTRAP model.22 Values were obtained by interpolation for all cities, except that measurements (California Air Resources Board) were used for Southern California since the ASTRAP model is not parameterized to reproduce the highly reactive atmosphere of the South Coast Air Basin. Figure 9 is a map of the ASTRAP data as originally computed.

In the Phase III Analysis (Section 7), computed values for $\mathrm{SO}_{2}$ and $\mathrm{NO}_{x}$ were added to the analysis, also based on the ASTRAP model. ASTRAP computations deal only with anthropogenically generated pollutants, mainly from fuel combustion or smelter emissions sources. Measurements of course reflect all sources, including for example such natural sulfates as $\mathrm{CaSO}_{4}$, etc., which are less likely to affect health.

\subsubsection{Visibility Data}

Airport visibilfty data from 1976-81 for 129 cities were made avallable through the courtesy of Dr. Bart ostro (EPA). Thirty-two of these locations corresponded to dichotomous sampler cities but the correlation between visibility and fine particulate concentrations was low $(0.385)$. Dropping one outlier (Fresno) only improved the correlation to 0.626 . We therefore decided not to use these data as surrogate measures of air quality.

\subsection{CIGARETTE SMOKING DATA}

Cigarette consumption was estimated from state sales taxes for three periods: 1955, 1969 and 1980.6,12 These estimates are based on regression analysis on state-level sales data (per capita for the population aged 18 and over), using various economic and demographic variables as predictors. Lower sales taxes in adjoining states were found to be an important factor in explaining cigarette sales differences. These regresston results were then used to predict cigarette consumption in each state. We could not derive 


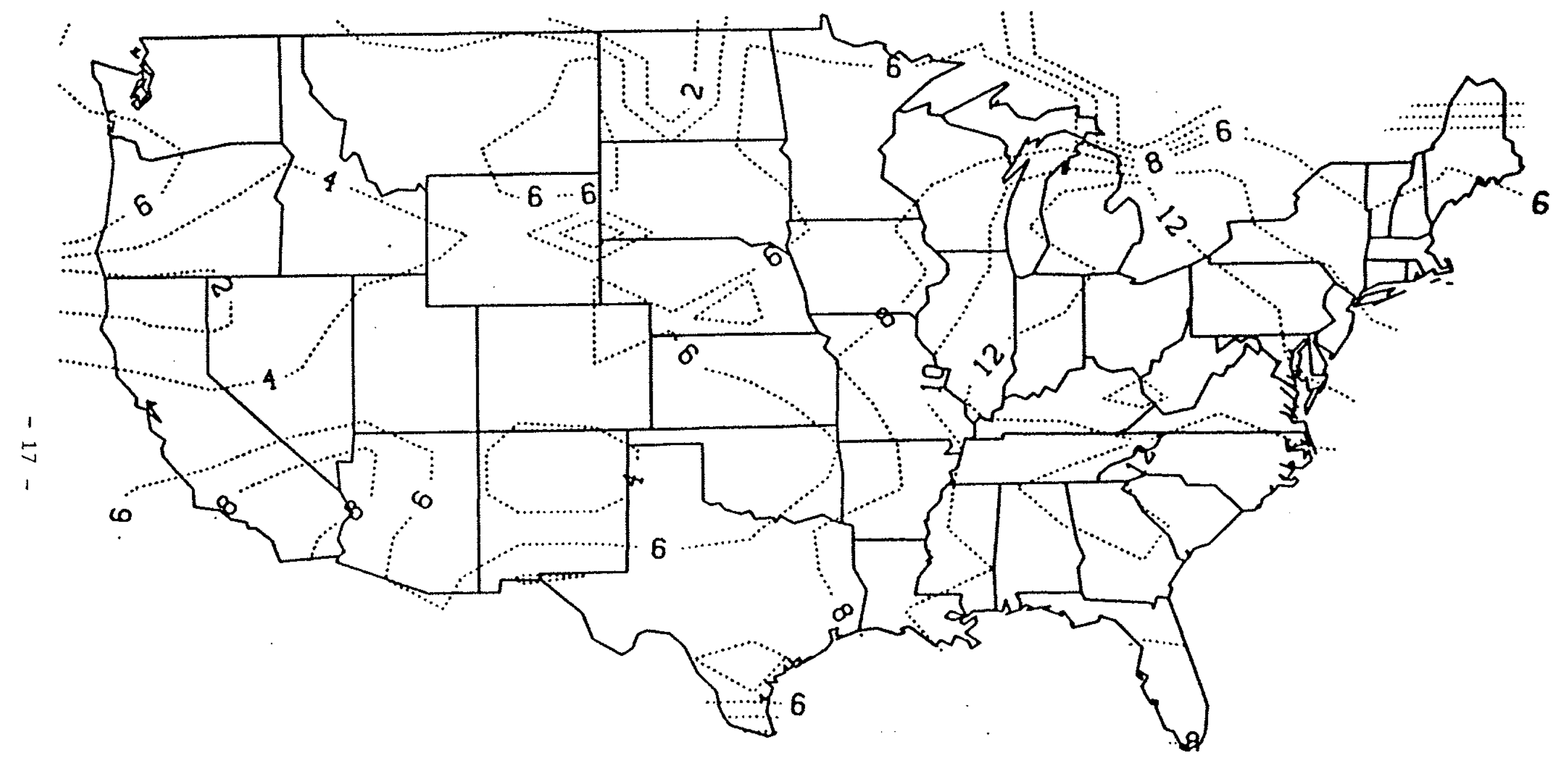

Figure 8. 1978, 1982 composite mean measured sulfate (SAROAD stations) (ug/m $\mathrm{m}^{3}$ ). 
Table 1. Forty-Two Cities Having Available Data on Al1 14 Pollutants

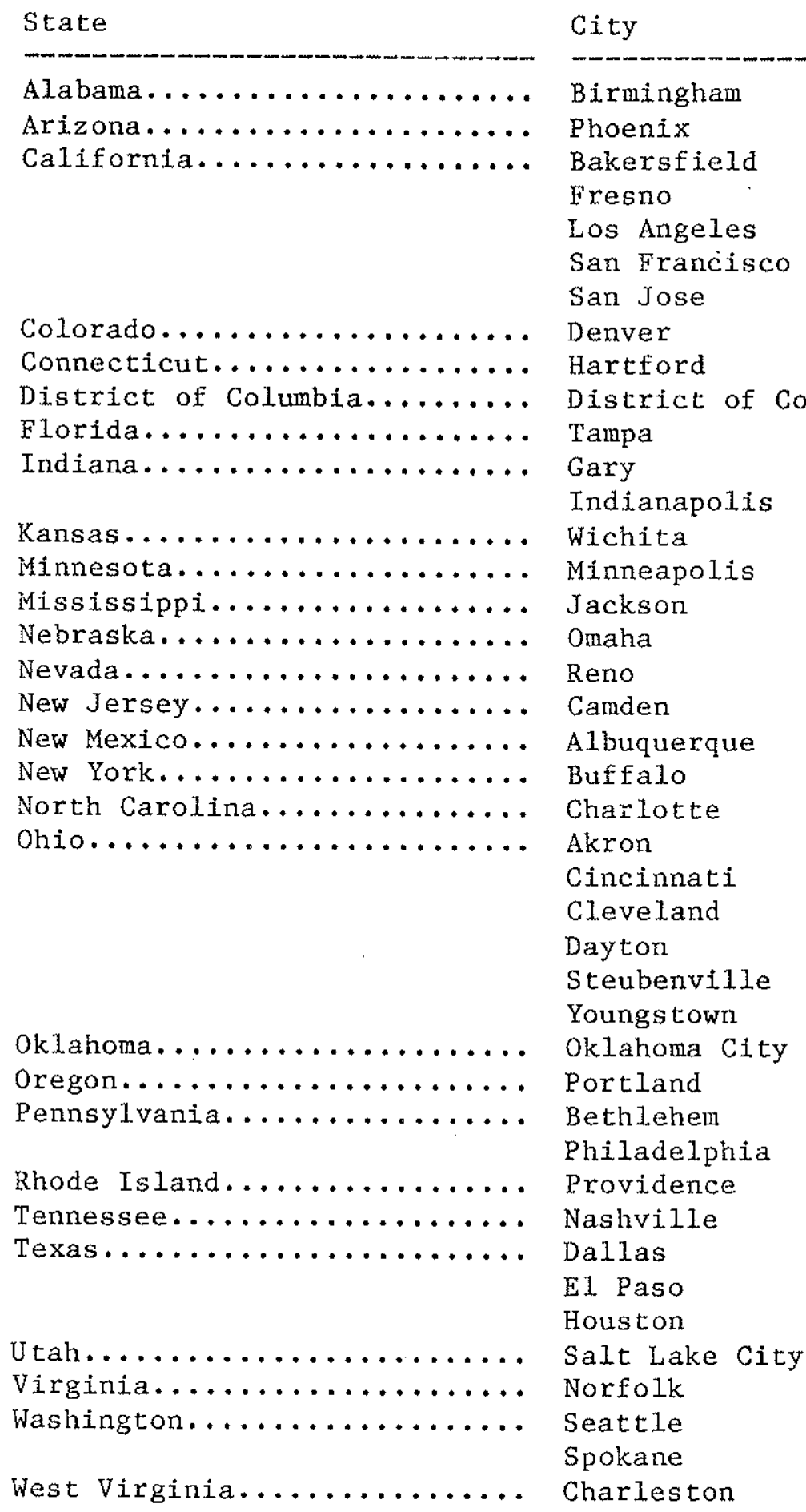




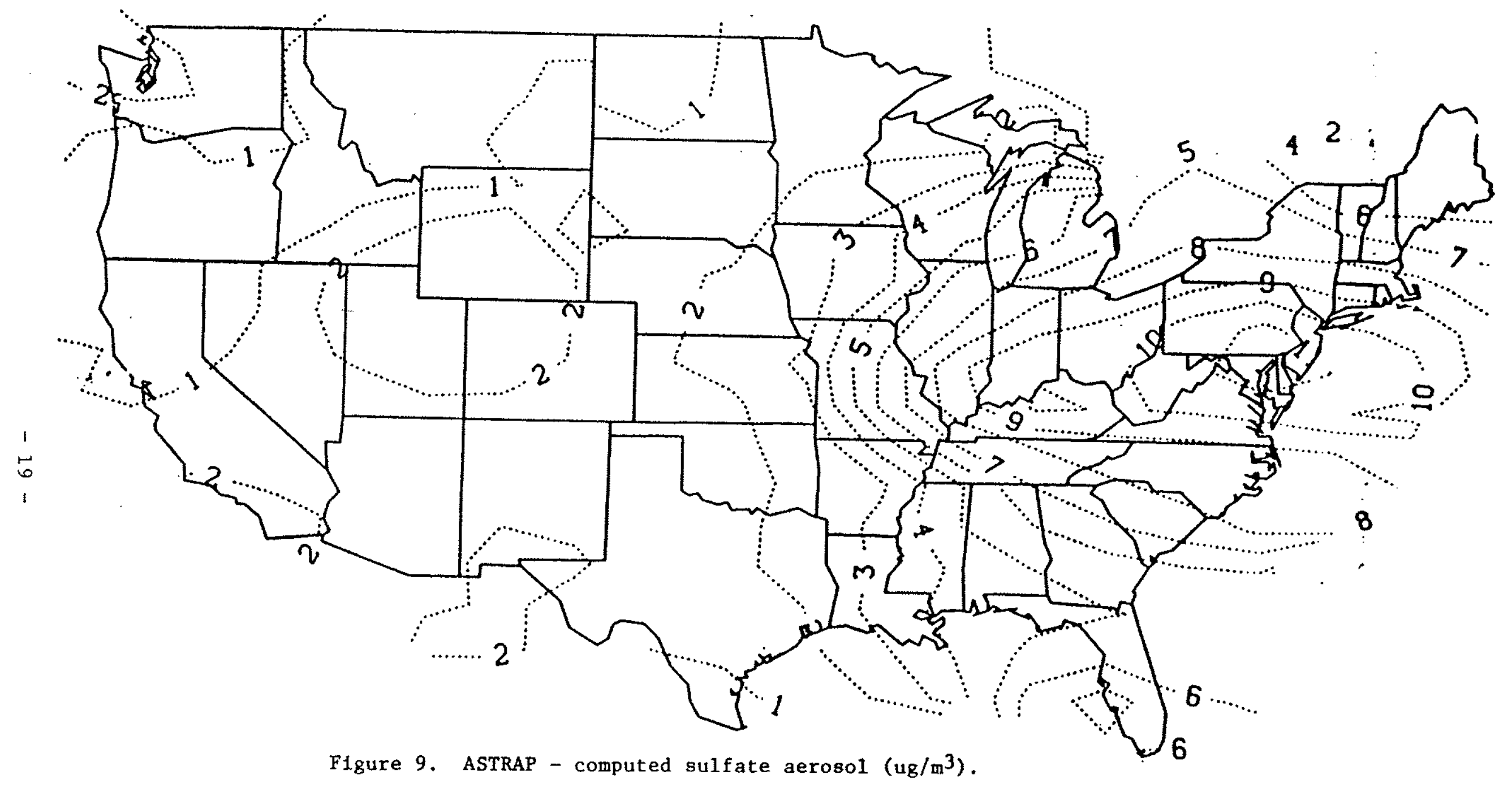


cigarette consumption data at finer geographic resolution and thus were forced to assume uniform consumption throughout each state with discontinuities at the borders. These errors are likely to lead to an underprediction of the effect of smoking on mortality.

Earlier analyses of smoking patterns 23 typically found large urban-rural differences, and it has long been assumed that city people are more likely to smoke. In the study of 1980 smoking data, SMSA tobacco sales from the 1977 Census of Retall Trade were compared to state-wide sales from the same source, and a consistent relationship was found, amounting to an annual urban-statewide difference of about 5 packs per year per person (out of 185). This sma11 but statistically significant difference suggests that regional smoking patterns are now probably more important than urban-rural differences within regions, which supports the use of state-level data in the analysis of mortality effects.

Finally, a comparison was made of our estimates of cigarette consumption with independent state level surveys from 29 states on the percentage of people who smoke (smoking prevalence). The correlation coefficient relating these two measures was only about 0.5 (explaining $25 \%$ of the variance). Possible explanations for this poor correspondence include variations in amount consumed per smoker and underreporting by those responding to the survey. We prefer to use consumption data rather than prevalence, since heavy smokers have a much higher relative mortality risk than light smokers, and since consumption may reflect the possible effects of passive (involuntary) smoking. Cigarette consumption rates are analogous to air pollution emission rates.

For an analysis of chronic health effects, it is not clear whether current cigarette smoking rates or some time integral is the appropriate metric (the same question exists for air quality). For this reason, we considered two possible smoking variables: the 1980 data, as described above, and 1969 data.6 Because of strong collinearity between the two $(x=0.48)$, regression models are limited to one or the other (or alternatively, the average," "SMOK7 8").

\subsection{DESCRIPTIVE STATISTICS}

\subsubsection{Outliers}

Descriptive statistics were obtained for each variable and the distributlons were examined for bimodality and outliers. In Table 2 we present the descriptive statistics for the demographic variables and Table 3 contains these statistics for the pollutants. Outliers were identified by Tukey's exploratory criterion. 24 This procedure involves defining outliers in terms of the upper and lower quartiles, rather than by the standard deviation (see Figure 10) (which only applies to normally distributed variables). A value is considered to be a "possible outlier" if it is outside the range defined by (LQP - $1.5 \mathrm{IQR}, \mathrm{UQP}+1.5 \mathrm{IQR}$ ) where $\mathrm{LQP}$ and UQP denote the lower and upper quartile point respectively. A value is considered to be a "definite outlier" if it is outside the interval from $L Q P-3$ IQR to $U Q P+3$ IQR. A variable is considered to have a bimodal distribution if more than 15 values were designated as "definite" outliers. 
Table 2. Descriptive Statistics for the Demographic and Socioeconomic Variables

\begin{tabular}{|c|c|c|c|c|c|c|c|c|c|c|}
\hline Variables Considered & Mean & S.D. & Minfmup & Maximum & Median & $L Q P$ & UQP & IQR & $\begin{array}{l}\text { Outlier } \\
\text { Possible }\end{array}$ & $\begin{array}{l}\text { Lits }{ }^{*} \\
\text { Definite }\end{array}$ \\
\hline 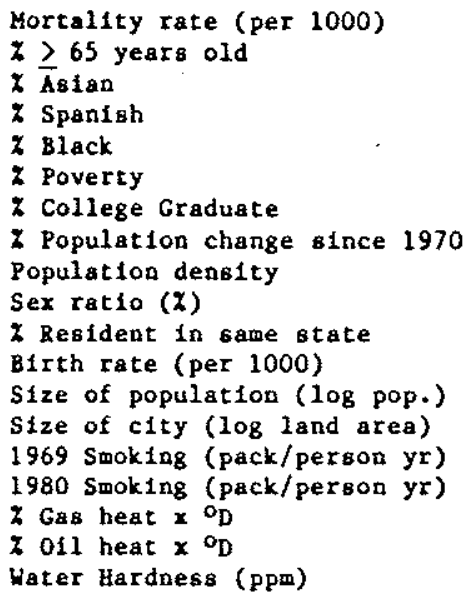 & $\begin{array}{r}9.14 \\
11.50 \\
2.27 \\
7.20 \\
11.18 \\
11.90 \\
18.57 \\
28.94 \\
40.05 \\
92.45 \\
59.62 \\
16.99 \\
4.76 \\
1.30 \\
194.96 \\
186.43 \\
31.3 \times 10^{4} \\
66.4 \times 10^{4} \\
113.29\end{array}$ & $\begin{array}{r}3.32 \\
5.30 \\
6.28 \\
12.23 \\
15.57 \\
6.75 \\
10.06 \\
227.57 \\
34.08 \\
7.79 \\
16.78 \\
5.34 \\
0.34 \\
0.40 \\
24.81 \\
23.15 \\
20.7 \times 10^{4} \\
11.6 \times 10^{4} \\
102.50\end{array}$ & $\begin{array}{r}1.70 \\
1.70 \\
0.00 \\
0.10 \\
0.00 \\
1.40 \\
2.40 \\
-27.20 \\
0.50 \\
74.70 \\
5.50 \\
2.90 \\
4.40 \\
0.00 \\
115.00 \\
125.21 \\
0.00 \\
0.00 \\
4.00\end{array}$ & $\begin{array}{r}28.70 \\
51.80 \\
79.80 \\
93.00 \\
95.60 \\
43.30 \\
68.70 \\
6346 . \\
397.10 \\
220.50 \\
90.80 \\
52.90 \\
6.85 \\
3.20 \\
303.00 \\
324.55 \\
90.1 \times 10^{4} \\
70.7 \times 10^{4} \\
626.00\end{array}$ & $\begin{array}{c}9.2 \\
11.4 \\
0.9 \\
2.3 \\
3.6 \\
11.1 \\
15.8 \\
4.8 \\
30.6 \\
91.8 \\
62.9 \\
16.5 \\
4.7 \\
1.2 \\
202.0 \\
181.9 \\
24.4 \times 10^{4} \\
0.49 \times 10^{4} \\
86.0\end{array}$ & $\begin{array}{c}6.8 \\
8.2 \\
0.5 \\
1.0 \\
0.9 \\
6.8 \\
11.8 \\
-5.8 \\
20.5 \\
87.9 \\
47.7 \\
13.6 \\
4.5 \\
1.0 \\
174.0 \\
174.5 \\
14.9 \times 10^{4} \\
201 \\
38.5\end{array}$ & \begin{tabular}{|c|}
11.5 \\
14.2 \\
1.9 \\
8.0 \\
15.9 \\
15.9 \\
22.4 \\
22.4 \\
48.6 \\
96.3 \\
72.6 \\
19.6 \\
4.9 \\
1.5 \\
209.0 \\
198.6 \\
$52.6 \times 10^{4}$ \\
$7.2 \times 10^{4}$ \\
144.0
\end{tabular} & $\begin{array}{c}4.7 \\
6.0 \\
1.4 \\
7.0 \\
15.0 \\
9.1 \\
10.6 \\
28.2 \\
28.1 \\
8.4 \\
24.9 \\
6.0 \\
0.4 \\
0.5 \\
35.0 \\
24.1 \\
37.7 \times 10^{4} \\
7.2 \times 10^{4} \\
105.5\end{array}$ & $\begin{array}{c}17.6 \\
23.2 \\
4.0 \\
18.4 \\
38.4 \\
29.6 \\
38.3 \\
(-48.01,64.60) \\
90.8 \\
108.8 \\
5.5 \\
28.6 \\
5.4 \\
(0.25,1.8) \\
(121.5,261.5) \\
(138.2,234.9) \\
109.3 \times 10^{4} \\
18 \times 10^{4} \\
302.3\end{array}$ & $\begin{array}{c}24 . \\
32.2 \\
6.1 \\
28.0 \\
60.0 \\
43.2 \\
54.2 \\
106.9 \\
132.9 \\
121.4 \\
90.8 \\
37.6 \\
6.1 \\
3.0 \\
31.4 \\
271.1 \\
105.8 \times 10 \\
28.8 \times 10 \\
460.5\end{array}$ \\
\hline
\end{tabular}

* Lower outlier limits are zero unless indicated. 
Table 3. Descriptive Statistics for the Pollution Variables

\begin{tabular}{|c|c|c|c|c|}
\hline Variable Considered & Mean & S.D. & Minimum & Maximum \\
\hline Computed $\mathrm{SO}_{4}=$ & 5.1 & 3.5 & 0.1 & 14.8 \\
\hline Computed $\mathrm{SO}_{2}$ & 16.1 & 10.9 & 0.28 & 46.4 \\
\hline Computed $\mathrm{NO}_{\mathrm{X}}$ & 17.0 & 10.6 & 0.73 & 50.9 \\
\hline $\begin{array}{lll}\mathrm{SAROAD} \mathrm{SO}_{4} & (1) \\
\mathrm{SAROAD} & \mathrm{SO}_{4} & (2)\end{array}$ & $\begin{array}{l}9.5 \\
9.2\end{array}$ & $\begin{array}{l}3.5 \\
3.3\end{array}$ & $\begin{array}{l}2.392 \\
2.000\end{array}$ & $\begin{array}{l}34.2 \\
34.2\end{array}$ \\
\hline $\begin{array}{lll}\mathrm{SO}_{4} \text { Fine (Dichot.) } & (1) \\
\mathrm{SO}_{4} \text { Fine (Dichot.) } & (2) \\
\mathrm{SO}_{4} \text { Total (Dichot.) } & (1) \\
\mathrm{SO}_{4} \text { Total (Dichot.) } & (2)\end{array}$ & $\begin{array}{l}4.9 \\
3.9 \\
5.3 \\
4.3\end{array}$ & $\begin{array}{l}2.9 \\
2.3 \\
3.0 \\
2.4\end{array}$ & $\begin{array}{l}0.820 \\
0.840 \\
0.860 \\
1.030\end{array}$ & $\begin{array}{l}12.1 \\
11.6 \\
12.9 \\
12.3\end{array}$ \\
\hline $\begin{array}{l}\text { Cadmium (1) } \\
\text { Cadmium (2) }\end{array}$ & $\begin{array}{l}0.005 \\
0.004\end{array}$ & $\begin{array}{l}0.010 \\
0.008\end{array}$ & $\begin{array}{l}0 \\
0\end{array}$ & $\begin{array}{l}0.079 \\
0.040\end{array}$ \\
\hline $\begin{array}{l}\text { Carbon monoxide (1) (ppm) } \\
\text { Carbon monoxide (2) (ppm) }\end{array}$ & $\begin{array}{l}1.966 \\
1.916\end{array}$ & $\begin{array}{l}0.942 \\
0.989\end{array}$ & $\begin{array}{l}0.300 \\
0.300\end{array}$ & $\begin{array}{l}5.91 \\
7.00\end{array}$ \\
\hline $\begin{array}{l}\text { Iron }(1) \\
\text { Iron }(2)\end{array}$ & $\begin{array}{l}1.118 \\
1.052\end{array}$ & $\begin{array}{l}1.685 \\
0.611\end{array}$ & $\begin{array}{l}0.2 \\
0.23\end{array}$ & $\begin{array}{l}4 \cdot 3 \\
4 \cdot 3\end{array}$ \\
\hline $\begin{array}{l}\text { Lead (1) } \\
\text { Lead (2) }\end{array}$ & $\begin{array}{l}0.460 \\
0.418\end{array}$ & $\begin{array}{l}0.272 \\
0.265\end{array}$ & $\begin{array}{l}0.098 \\
0.088\end{array}$ & $\begin{array}{l}2.760 \\
2.760\end{array}$ \\
\hline $\begin{array}{l}\text { Manganese (1) } \\
\text { Manganese (2) }\end{array}$ & $\begin{array}{l}0.040 \\
0.036\end{array}$ & $\begin{array}{l}0.032 \\
0.027\end{array}$ & $\begin{array}{l}0.020 \\
0.020\end{array}$ & $\begin{array}{l}0.219 \\
0.188\end{array}$ \\
\hline 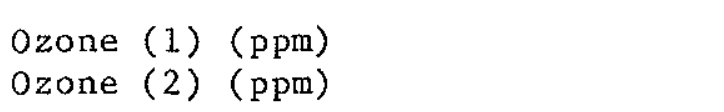 & $\begin{array}{l}0.048 \\
0.047\end{array}$ & $\begin{array}{l}0.017 \\
0.017\end{array}$ & $\begin{array}{l}0.019 \\
0.018\end{array}$ & $\begin{array}{l}0.195 \\
0.195\end{array}$ \\
\hline $\begin{array}{l}\text { Vanadium }(1) \\
\text { Vanadium }(2)\end{array}$ & $\begin{array}{l}0.025 \\
0.019\end{array}$ & $\begin{array}{l}0.04 \\
0.034\end{array}$ & $\begin{array}{l}0.002 \\
0.002\end{array}$ & $\begin{array}{l}0.027 \\
0.345\end{array}$ \\
\hline $\begin{array}{ll}\text { Fine Particle Mass (Dichot.) } & \text { (1) } \\
\text { Fine Particle Mass (Dichot.) } & \text { (2) } \\
\text { Total Particle Mass (Dichot.) } & \text { (1) } \\
\text { Total Particle Mass (Dichot.) } & \text { (2) }\end{array}$ & $\begin{array}{l}20.5 \\
17.7 \\
41.2 \\
37.5\end{array}$ & $\begin{array}{r}6.4 \\
6.0 \\
12.4 \\
11.9\end{array}$ & $\begin{array}{r}10.3 \\
7.2 \\
20.4 \\
21.9\end{array}$ & $\begin{array}{l}42.0 \\
37.1 \\
94.6 \\
98.6\end{array}$ \\
\hline $\begin{array}{l}\text { Fine Particle Lead (Dichot.) (1) } \\
\text { Fine Particle Lead (Dichot.) (2) }\end{array}$ & $\begin{array}{l}0.3 \\
0.2\end{array}$ & $\begin{array}{l}0.30 \\
0.11\end{array}$ & $\begin{array}{l}0.010 \\
0.010\end{array}$ & $\begin{array}{l}2.6 \\
2.6\end{array}$ \\
\hline
\end{tabular}

Note: (1) Mean of site data

(2) Median of site data (all value in $\mathrm{ug} / \mathrm{m}^{3}$ except as noted). 
Table 3. Descriptive Statistics for the Pollution Variables (Cont'd)

\begin{tabular}{|c|c|c|c|c|c|c|}
\hline Variables Considered & Median & LQP & UQP & IQR & $\begin{array}{l}\text { Outlier I } \\
\text { Possible }\end{array}$ & $\begin{array}{l}\text { Limits } \\
\text { Definite }\end{array}$ \\
\hline Computed $\mathrm{SO}_{4}=(1)$ & 4.2 & 2.0 & 7.7 & 5.7 & 16.25 & 24. \\
\hline $\begin{array}{ll}\text { SAROAD } & \mathrm{SO}_{4}=(1) \\
\text { SAROAD } & \mathrm{SO}_{4}=(2)\end{array}$ & $\begin{array}{l}9.98 \\
9.80\end{array}$ & $\begin{array}{l}7.80 \\
7.50\end{array}$ & $\begin{array}{l}12.7 \\
12.0\end{array}$ & $\begin{array}{l}4.9 \\
4.5\end{array}$ & $\begin{array}{l}20 . \\
18.8\end{array}$ & $\begin{array}{l}27 \cdot 5 \\
26 \cdot 8\end{array}$ \\
\hline $\begin{array}{lll}\mathrm{SO}_{4} & \text { Fine Dichot } & (1) \\
\mathrm{SO}_{4} & \text { Fine Dichot } & (2) \\
\mathrm{SO}_{4} & \text { Total Dichot } & (1) \\
\mathrm{SO}_{4} & \text { Total Dichot } & (2)\end{array}$ & $\begin{array}{l}4.395 \\
3.750 \\
4.970 \\
3.965\end{array}$ & $\begin{array}{l}2.192 \\
2.005 \\
2.567 \\
2.232\end{array}$ & $\begin{array}{l}7.110 \\
5.260 \\
7.487 \\
5.697\end{array}$ & $\begin{array}{l}4.918 \\
3.255 \\
4.930 \\
3.465\end{array}$ & $\begin{array}{l}14.487 \\
10.143 \\
1.4 .892 \\
10.894\end{array}$ & $\begin{array}{l}21.9 \\
15.0 \\
22.3 \\
16.1\end{array}$ \\
\hline $\begin{array}{l}\text { Cadmi um (1) } \\
\text { Cadmium (2) }\end{array}$ & $\begin{array}{l}0.002 \\
0.001\end{array}$ & $\begin{array}{l}0.001 \\
0.001\end{array}$ & $\begin{array}{l}0.003 \\
0.003\end{array}$ & $\begin{array}{l}0.002 \\
0.002\end{array}$ & $\begin{array}{l}0.006 \\
0.006\end{array}$ & $\begin{array}{l}0.009 \\
0.009\end{array}$ \\
\hline $\begin{array}{l}\text { Carbon Monoxide (1) } \\
\text { Carbon Monoxide ( } 2)\end{array}$ & $\begin{array}{l}1.868 \\
1.800\end{array}$ & $\begin{array}{l}1.233 \\
1.100\end{array}$ & $\begin{array}{l}2.580 \\
2.600\end{array}$ & $\begin{array}{l}1.347 \\
1.500\end{array}$ & $\begin{array}{l}4.600 \\
4.900\end{array}$ & $\begin{array}{l}6.6 \\
7.1\end{array}$ \\
\hline $\begin{array}{l}\text { Iron (1) } \\
\text { Iron (2) }\end{array}$ & $\begin{array}{l}0.922 \\
0.907\end{array}$ & $\begin{array}{l}0.675 \\
0.656\end{array}$ & $\begin{array}{l}1.298 \\
1.270\end{array}$ & $\begin{array}{l}0.623 \\
0.614\end{array}$ & $\begin{array}{l}2.233 \\
2.191\end{array}$ & $\begin{array}{l}3.2 \\
3.1\end{array}$ \\
\hline $\begin{array}{l}\text { Lead (1) } \\
\text { Lead (2) }\end{array}$ & $\begin{array}{l}0.401 \\
0.359\end{array}$ & $\begin{array}{l}0.289 \\
0.259\end{array}$ & $\begin{array}{l}0.562 \\
0.495\end{array}$ & $\begin{array}{l}0.273 \\
0.236\end{array}$ & $\begin{array}{l}0.9715 \\
0.809\end{array}$ & $\begin{array}{l}1.38 \\
1.20\end{array}$ \\
\hline $\begin{array}{l}\text { Manganese (1) } \\
\text { Manganese ( } 2)\end{array}$ & $\begin{array}{l}0.029 \\
0.027\end{array}$ & $\begin{array}{l}0.023 \\
0.020\end{array}$ & $\begin{array}{l}0.040 \\
0.037\end{array}$ & $\begin{array}{l}0.017 \\
0.017\end{array}$ & $\begin{array}{l}0.066 \\
0.0625\end{array}$ & $\begin{array}{l}0.09 \\
0.088\end{array}$ \\
\hline $\begin{array}{l}\text { Ozone (1) } \\
\text { Ozone (2) }\end{array}$ & $\begin{array}{l}0.045 \\
0.046\end{array}$ & $\begin{array}{l}0.040 \\
0.036\end{array}$ & $\begin{array}{l}0.051 \\
0.053\end{array}$ & $\begin{array}{l}0.011 \\
0.017\end{array}$ & $\begin{array}{c}0.0625 \\
(0.011,0.079)\end{array}$ & $\begin{array}{l}0.084 \\
0.10\end{array}$ \\
\hline $\begin{array}{l}\text { Vanadium (1) } \\
\text { Vanadium (2) }\end{array}$ & $\begin{array}{l}0.010 \\
0.006\end{array}$ & $\begin{array}{l}0.005 \\
0.005\end{array}$ & $\begin{array}{l}0.036 \\
0.021\end{array}$ & $\begin{array}{l}0.031 \\
0.029\end{array}$ & $\begin{array}{l}0.083 \\
0.045\end{array}$ & $\begin{array}{l}0.12 \\
0.069\end{array}$ \\
\hline $\begin{array}{l}\text { Mass Fine Dichot (1) } \\
\text { Mass Fine Dichot (2) } \\
\text { Mass Total Dichot(1) } \\
\text { Mass Total Dichot(2) }\end{array}$ & $\begin{array}{l}19.6 \\
16.9 \\
38.6 \\
34.6\end{array}$ & $\begin{array}{l}15.3 \\
12.9 \\
33.5 \\
30.6\end{array}$ & $\begin{array}{l}24 \cdot 5 \\
21.6 \\
46.1 \\
43.2\end{array}$ & $\begin{array}{r}9.2 \\
8.7 \\
12.6 \\
12.5\end{array}$ & $\begin{array}{l}38.3 \\
34.7 \\
65.1 \\
61.9\end{array}$ & $\begin{array}{l}51.9 \\
47.8 \\
84.0 \\
80.7\end{array}$ \\
\hline $\begin{array}{l}\text { Lead Time Dichot (1) } \\
\text { Lead Time Dichot (2) }\end{array}$ & $\begin{array}{l}0.220 \\
0.170\end{array}$ & $\begin{array}{l}0.150 \\
0.125\end{array}$ & $\begin{array}{l}0.300 \\
0.245\end{array}$ & $\begin{array}{l}0.150 \\
0.120\end{array}$ & $\begin{array}{l}0.525 \\
0.425\end{array}$ & $\begin{array}{l}0.75 \\
0.60\end{array}$ \\
\hline
\end{tabular}

Note: (1) Mean

(2) Median

(3) (all value in $u g / \mathrm{m}^{3}$ except as noted). 


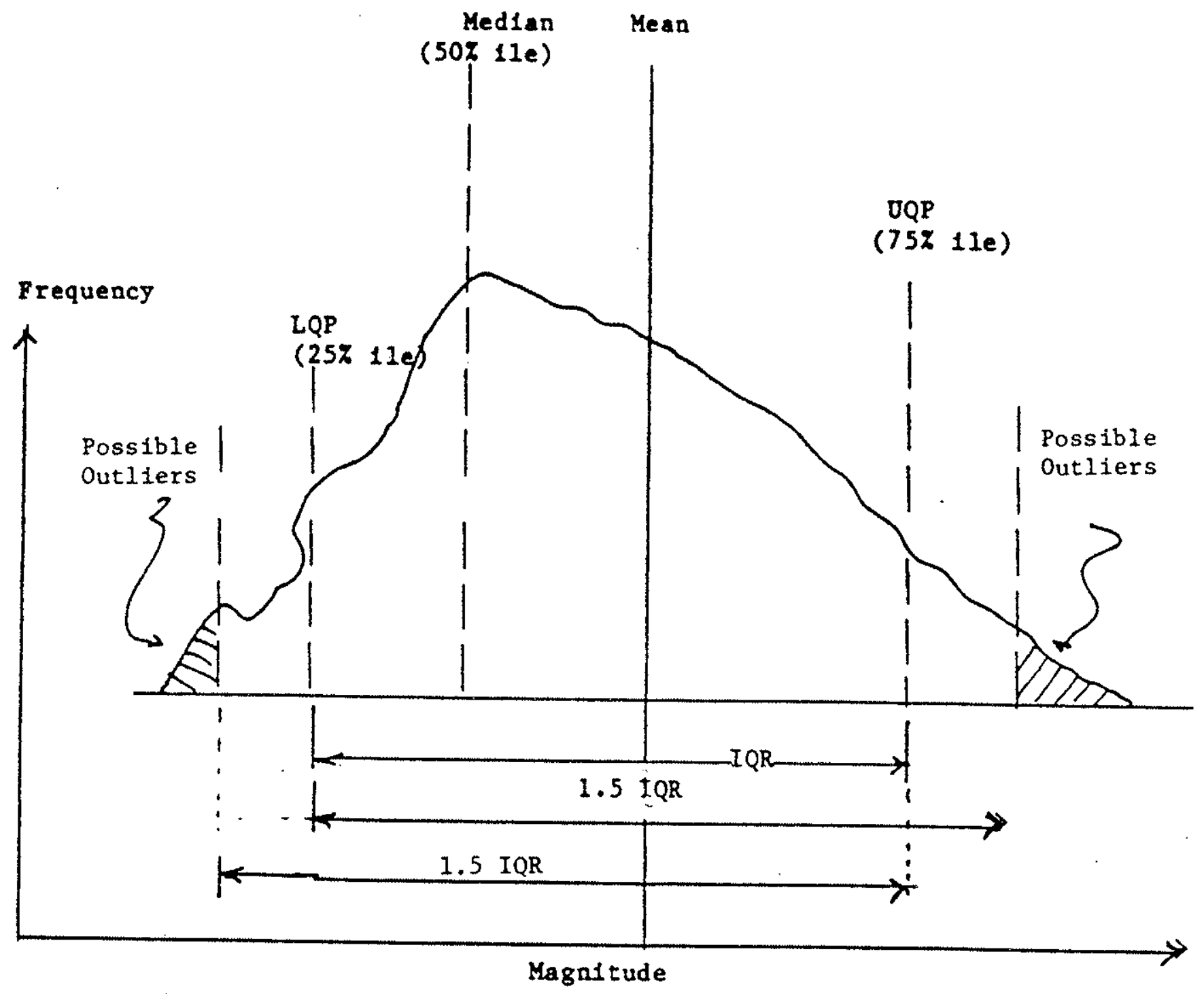

Figure 10. Nomenclature for quartile analysis. 
Several demographic variables had a large number of definite outliers, examples being the ofl heat variable with 90 and \% Asian with 63 . In the case of the poliutants, cadmiun and manganese had a large number of cities which were definite outliers. In future analyses we might consider these variables as categorical, i.e., high and low cadmium, as well as analysing the values themselves. For those variables having fewer than 15 outliers one could consider regression analysis with jacknifing (omitting one outlying city at a time).

\subsubsection{Correlations.}

The next task was to obtain the patrwise correlations for the demographic set and for the pollution set. These are reported in Tables 4 through 6 respectively. Before obtaining these correlations a factor analysis was done (with a Varimax rotation), ordering the correlation matrix so that sets of collinear variables appear together. It is interesting that on combining pollutants with demographic variables we observed \% resident and \% Asian to be correlated with $\mathrm{SO}_{4}=$ variables, and that cadmium is correlated with $\%$ sanish (both high in Texas) and birthrate with \% college graduate. Several politutants are not highly correlated with demographic variables, including No $x$, iron, manganese and total particle mass. Correlations among the pollutant variables are discussed below.

\subsection{DATA SETS ANAL YZED}

As is often the case with this type of analysis, the analysis had to be performed on various subsets because data were missing for one or more variables. For the Phase I analysis, these subsets were arranged to permit hypothesis testing on each of the limiting variables, generally one at a time. The usual hypothesis was that a given variable has a statistically significant effect on mortality in the direction expected (positive for air pollutants; negative for drinking water hardness). A few corollary hypotheses were examined, dealing with possible sources of confounding such as regional trends or interactions among variables.

The bulk of the Phase II statistical analysis was performed for a set of 159 cities that had relatively complete air monitoring data in addition to water hardness data. These data are listed in Appendix A. Large cities that are missing from this list (primarily because of missing air quality data) include: Boston, Washington, Miami, New York, Pittsburgh, St. Louis, Austin, Richmond and Milwaukee. However, the median population of the group is about 130,000 ; the total population studied is about 41 million or about $25 \%$ of the total U.S. urban population.

The data set of 159 cities was selected primarily for the availability of metals, which were complete for $\mathrm{Mn}, \mathrm{Fe}, \mathrm{Pb}$, and $\mathrm{Cd}$; only six cities were missing vanadium data. However, 41 cities lacked CO data; 48, ozone data; 106, total and fine particulate mass; 108, total and fine sulfur portions of particulate mass. These latter two items were obtained from the dichotomous sampler network.

Twenty-two smaller cities (but greater than 100,000 population) were excluded because of missing air quality data. The 53 cities having dichotomous 
Table 4. Correlation Matrix (All Variables)

\begin{tabular}{|c|c|c|c|c|c|c|c|c|c|c|c|c|c|c|c|c|c|c|}
\hline$k^{k}$ & & 1.0000 & .0037 & $8547 \%$ & $.2381 * *$ & $-0.2112 * \star$ & $-0.3178 * *$ & $.2850^{* *}$ & $0.3489 * *$ & $-0.3618^{* *}$ & $.0 .5798^{* * x}$ & $.0850^{*}$ & $.1530^{* * *}$ & .0308 & .0 .0554 & . $1317^{* * *}$ \\
\hline & \multicolumn{3}{|c|}{$\begin{array}{l}\text { BIRITH RAAE } \\
x>65 \text { YEARS }\end{array}$} & .0031 & 1.0000 & $0.2530^{\circ * *}$ & $.1765=*$ & .0353 & $.4925 * *$ & $.3053^{\circ *}$ & $-0.3266 * *$ & $.1492^{* *}$ & $.0938 *$ & $-0.0839^{*}$ & $.0 .0783^{*}$ & .0268 & .0607 & $.0 .1460^{n+4}$ \\
\hline$i x$ & \multirow{2}{*}{\multicolumn{3}{|c|}{$\begin{array}{l}x>65 \text { YEARS } \\
x \text { BLACK }\end{array}$}} & 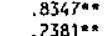 & $-0.2530 \% * *$ & 1.0000 & .0664 & $0.1584 * *$ & $-0.1329 * *$ & $.1152 * *$ & $0.2360 * \pi$ & $.0 .0805^{*}$ & $-0.54599^{*} *$ & $.0 .0898^{\circ}$ & $.1242^{* *}$ & .0034 & $0.0794 *$ & $.1594^{* *}$ \\
\hline $15 x$ & \multirow{2}{*}{\multicolumn{3}{|c|}{$\begin{array}{l}X B L A C K \\
X A S 1 A N\end{array}$}} & $.2381=x$ & $.1765 * *$ & .0664 & 1.0000 & $0.1005 \times *$ & $0.1043=$ & $.6144 * k$ & $0.1790^{* * *}$ & -0.0656 & $-0.2293^{*}=$ & $.0970^{*}$ & $.1204 * *$ & $.1585 * *$ & $.1065 * *$ & .0489 \\
\hline $\begin{array}{l}\text { SPK } \\
\text { SPK }\end{array}$ & \multirow{2}{*}{\multicolumn{3}{|c|}{ 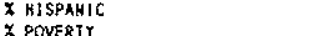 }} & $\begin{array}{l}-0.2112^{2 * *} \\
-0.17 g^{* * *}\end{array}$ & $\begin{array}{l}.0353 \\
6125 \times x\end{array}$ & 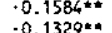 & $=0.1005 * *$ & & $.1262^{* *}$ & $-0.1024 * *$ & $.0964^{*}$ & .0072 & $.1848 * *$ & $0.1242 * *$ & $.1143=*$ & .0225 & -0.0171 & $0.1185 * *$ \\
\hline DOR & & & & $-0.1780^{* * *}$ & $\begin{array}{l}.4155^{\circ * *} \\
.3053^{* * *}\end{array}$ & $\begin{array}{l}0.1329^{* * *} \\
.1152^{* *}\end{array}$ & $\begin{array}{l}0.1043^{* * *} \\
.6144^{* *}\end{array}$ & $\begin{array}{l}.12624 * \\
-0.1024 *\end{array}$ & $\begin{array}{l}1.0000 \\
.1985 * *\end{array}$ & $\begin{array}{l}19855^{* *} \\
10000\end{array}$ & $\begin{array}{l}-0.91843 * * \\
-0.1237 * *\end{array}$ & $\begin{array}{l}0.0092 \\
.0 .0030 *\end{array}$ & $\begin{array}{l}.1191 * * \\
.0 .170 * *\end{array}$ & $\cdot 0.2982^{* * *}$ & $.3142 * *$ & $.0819^{\circ}=$ & .0012 & $.0963 *$ \\
\hline No & $x$ COLEGE & iRAOUATES & & $.0 .3489 * *$ & 0.3265 .4 & .236 & $-0.3796=*$ & $.0964 *$ & $.0 .1843^{\star * *}$ & $.0 .1237^{* * *}$ & 1.0000 & 0.0370 & $0.7850^{* *}$ & $.0 .0893^{\circ}$ & $\begin{array}{r}.1285 * * * \\
0.9293 * *\end{array}$ & $\begin{array}{l}.1284 * * \\
0185\end{array}$ & .0086 & $0.1559 *$ \\
\hline LPOF & $x$ POPUL'K & EHAMGE SIMC. & E 1970 & & & & -0.06 & .007 & .0 .0092 & $.0 .0939 *$ & .0379 & 1.0000 & $.0765^{\circ}$ & $.0 .1041^{\text {*k }}$ & -0.0700 & 37 & & 0.0538 \\
\hline & $E \angle E F$ & & & & & 0.56 & 0.2 & & $.119\}^{*}$ & $0.1776^{* *}$ & $.8850 * *$ & $.0765 *$ & 1.0000 & $-0.2597 *$ & $-0.102 \sigma^{\circ}$ & 86 & & $\begin{array}{l}0.0227 \\
0.0228\end{array}$ \\
\hline & $\cos 10$ & & & & $0 . a$ & & & & & $n$ & $\cdot 0.2268^{* *}$ & & $97 * *$ & 1.00 & .0 .11 & & & 2828. \\
\hline & PUIATIOA & o & & $.1530^{* * *}$ & $0.0783 *$ & $.1242^{* *}$ & $.1204 * t$ & $.1143 * *$ & .3 & $.1285 \mathrm{NA}$ & $.0 .1293=\ldots$ & & & & & ** & $0.1606^{0}$ & 2402 \\
\hline & 1980 POPULA & אונומו & & .0308 & .0268 & .0034 & $.1585 n$ & .0225 & .08 & $.1284 \mathrm{ne}$ & & & & & & & $* *$ & \\
\hline ND & LAMO AREA & & & -0.0654 & .0607 & $-0.0794^{*}$ & $.1065 * *$ & 0.0171 & .00 & .0586 & & & & 0. & .0 .1 & & 1.00 & .0 .8749 \\
\hline & 1969 SHOK: & & & $.1317 *$ & $-0.1466 * *$ & $.1594 * *$ & .0 .0489 & $-0.1185 * *$ & $.0963^{*}$ & $-0.1559 \%$ & -8. & .0 .0 & 0. & & $.2402^{* *}$ & .0 .0093 & 0.0749 & 1.0000 \\
\hline 1080 & 1980 SHOK: : & & & $.1442 * *$ & $-0.1494 * *$ & $.2275 * *$ & .0419 & $-0.2707 * *$ & $-0.1165=*$ & .0 .0222 & .0 .0453 & .0260 & $0.1015 \times \cdots$ & $0.1107^{*}$ & $0.1058^{* * *}$ & 0.0074 & $0<6$ & 530 \\
\hline $0 \times 78$ & & & & . $1599 \mathrm{gm*}$ & $-0.17190^{*}$ & $.2205 * *$ & $\cdot 0.0058$ & $-0.2202 * *$ & .0 .0 & $.0 .1048^{n \times}$ & .0. & 0 & .0 .0698 & $0.2303^{* * 4}$ & $.0840^{*}$ & & .0 .0 & 887 \\
\hline t50kY & Gas & $D$ & & $-0.1328^{* *}$ & $-0.0970^{*}$ & $0.1550^{* * t}$ & & & & $-0.2393 * *$ & & $0.0874 *$ & & & 0.0 & & & 3.0746 \\
\hline LDAY & $\begin{array}{cc}x \\
x\end{array}$ & IEE D & & $.1580^{* * *}$ & $-0.2646 * *$ & $.1581 * *$ & .0 & & & .03 & 0.1 & & .0 .1 & $.2167 * *$ & ;*** & 13 & 0.0504 & $279 *$ \\
\hline $4 c 2$ & $\begin{array}{l}\text { COOPPUTYO SO } \\
\text { COAPUED SO }\end{array}$ & $\begin{array}{l}x=(1) \\
4=(2)\end{array}$ & & $\begin{array}{l}.22188 * * \\
.2255^{* *}\end{array}$ & $\begin{array}{l}-0.2821 * * \\
-0.3365 * *\end{array}$ & $\begin{array}{l}-10577^{10 * *} \\
.1224 *\end{array}$ & $.22955^{* * *}$ & $\begin{array}{l}-0.20280 * * \\
-0.2264 * *\end{array}$ & $\begin{array}{l}-0.25 \\
.0 .22\end{array}$ & $.0875^{*}$ & 0.1 & -0.0375 & $0.2002 * *$ & $.3300^{* * *}$ & $.2365 * \pi$ & .0514 & $0.0898 *$ & \\
\hline & COMPUIED SO & & & $150 \alpha^{* *}$ & $.0 .2633^{*}=*$ & & . & $-0.2264 * \pi$ & & .08 & & & & & & & & \\
\hline$x$ & COMPUTED WO & & & -0.0400 & $.0 .1230^{* *}$ & 0.10 & 0.00 & .0222 & & $0.1809 * x$ & & & & & & & & .28 \\
\hline & SOL $=$ & & & $.4331^{* * *}$ & .0 .09 & .2 & $.3003 * *$ & $.0 .2802 * *$ & .0 .2 & $.3335 * *$ & & & $94 * *$ & $.4398 * *$ & .4088 & .0 .0298 & $-0.1894 *$ & .1505 \\
\hline $4: 19$ & If so & & & & -0.16 & & & & & $.3686 * *$ & & & $67 * *$ & $.3037^{*}$ & .2621 & .1437 & .0 .0888 & .1225 \\
\hline & $\$ 1$ & EES & & $.2788^{*}$ & -0.0 & & $.2747^{\circ}$ & & & .1285 & & & & .2344 & & .1367 & -0.1086 & .1657 \\
\hline FPG & TOTAL PARI: & CLES (IP) & & .1085 & .244 & -0.03 & -0.0010 & & & & & & & .0049 & 0.0778 & .0210 & $\cdot 0.0114$ & .1012 \\
\hline FPS & F1NE LEED & $\begin{array}{l}\text { (PS) } \\
\text { (SARON) }\end{array}$ & & -0.2068 & .2203 & -0.248 & .0291 & -18 & .52 & .13 & -0. & .0 & & 86 & & .2 & & 2 \\
\hline & IROW (SAROA & (SAROND) & & .0613 & $\begin{array}{l}.1528 \\
.1507\end{array}$ & $\begin{array}{r}.0208 \\
-0.0209\end{array}$ & .0006 & $\begin{array}{r}-3003 \\
-0.0181\end{array}$ & $.20190^{*}$ & .9071 & & .02 & $\cdot 0.0781$ & $-0.2130 * *$ & $.2221 * *$ & $.1761^{*}$ & & .0513 \\
\hline & YHNGANESE & (SAROAD) & & $\begin{array}{l}.0990 \\
.1696\end{array}$ & $\begin{array}{l}.100213 \\
0.0213\end{array}$ & $\begin{array}{r}.0 .0299 \\
.0630\end{array}$ & $\begin{array}{l}.0144 \\
.0490\end{array}$ & $\begin{array}{l}-0.0181 \\
.0 .9611\end{array}$ & $.01958^{\circ}$ & .0051 & $0.0624 * *$ & .0286 & .0932 & .0 .3400 & -0.0397 & .1479 & .0424 & -0.0335 \\
\hline & CNOAISA & & & $.0 .2567^{*}$ & $.2172^{*}$ & 0.23 & .00 & .0 .0749 & $\begin{array}{l}-0.01087 \\
-.457\end{array}$ & $\begin{array}{l}-0.0418 \\
.1467\end{array}$ & & -0.71 & & & & .0880 & $\cdot 0.0581$ & .0306 \\
\hline & & & & .0 .1636 & .11 & .0 .0918 & .0 .148 & .0621 & $.3197 \star *$ & -0.1197 & .0517 & $.188 i^{*}$ & . .0675 & .0 .1 & .0 .0430 & .0 .0324 & $\begin{array}{l}.0 .0359 \\
.0 .0354\end{array}$ & $\begin{array}{l}.0 .24222^{\circ} \\
.0953\end{array}$ \\
\hline & CARBOW! & $=(\operatorname{siR} 0)$ & & $\cdot 0.1534$ & .0 .1229 & -0.0573 & -0.0964 & .1149 & .8403 & -0.1152 & .1567 & .0504 & .0702 & $-0.3083 * *$ & .0599 & .0560 & .0 .0118 & .8134 \\
\hline & GASOA & 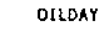 & H & so4c: & souc2 & 502 & kox & $50<x$ & $\$ 041 P$ & $\mathbb{E P}$ & ip & FPQ & $\mathrm{PQ}$ & $\mathrm{fE}$ & MN & CAD & 03 & co \\
\hline & & $.1580^{* * *}$ & $*^{*}$ & $.2118^{* * *}$ & **** & $.1506 * *$ & -0.04 & & 5* & & & -0.2068 & & & & & & \\
\hline & & 0.2 & & $.0 .2821^{* \star}$ & 0.33 & & & & & & & & & & & & & \\
\hline 5 & & .15 & -0.11 & $.1057^{* * *}$ & $.1124 * *$ & .03 & -0.10 & $.2733^{k *}$ & .18 & .1957 & & 0 & & .0 .0 & & $0.2370^{\mathrm{kN}}$ & & \\
\hline & & & & & $.2031 \%$ & .11 & .0 .0052 & $.3003=0$ & & $.2747^{\circ}$ & & & & & & & 0.1 & \\
\hline & & -0.1 & -0.0 & $-0.2089+4$ & $.0 .2264=4$ & -0.1 & .02 & 0.2 & .0. & -0.1 & .0. & .1 & .16 & .0 .0 & 0 & .0 .07 & .06 & .1149 \\
\hline 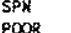 & $-0.2836^{* k}$ & -0.1 & .1 & -0.23 & .0 .24 & -0. & & $\cdot 0.2$ & & -0.1 & & & & & & 7.* & & .1403 \\
\hline OA & $\begin{array}{l}-0.23930 * x \\
.0259\end{array}$ & .0378 & -0.1 & .0 & .0 & -0.0 & -0.1 & & & & & 0 & & & & & .0 .1197 & -0.1152 \\
\hline $\begin{array}{l}A D \\
\text { IPOP }\end{array}$ & $\begin{array}{r}.02 \\
-0.08\end{array}$ & & -0.0 & & 0.1 & -0.1 & -0.0 & & & & & .0 .8 & & & & & & 67 \\
\hline r & $\begin{array}{r}-3.08 \\
.03\end{array}$ & $.0 .1989 * *$ & .0 & $\begin{array}{l}-0.0 \\
.0 .2\end{array}$ & $\begin{array}{l}0.0636 \\
0.2622=1\end{array}$ & $=0.0614$ & -0.0 & & & -0.3 & & & & & & & & 04 \\
\hline & & 2 & .0 .08 & $.3300^{* * *}$ & & & & & & $\begin{array}{r}-0.3 \\
.2\end{array}$ & & .0 & & .0 .1 & & .10 & $\begin{array}{l}.0 .0673 \\
.0 .1722^{*}\end{array}$ & .0 .3 \\
\hline & & & & & & & & & & & & & & & & .0 .1 & & \\
\hline & & .0 & & & .0 & & & -0.5 & & & & & & & & .0 & & 60 \\
\hline & & -0.0 & -0 & & & & & & & & & & & & & .0 & $\cdot 0$ & -0.0118 \\
\hline $\begin{array}{l}40 \times 69 \\
40 \times 80\end{array}$ & $\begin{array}{l}0.0 \\
0.0\end{array}$ & .0 .12 & & & & & & & & & & & & & & & & 34 \\
\hline 8 & .0 .0 & 0.00 & -0. & & & & -0.0 & & & & & & & & & & & \\
\hline & & .0 & & .2 & & .21 & & & & & & & & & & & & \\
\hline & & & & & & & & & & & & & & & & & & \\
\hline & 0.7 & & & & & & & & & & & & & & & & & \\
\hline & .34 & & & .0 .0 & $\cdot 0.2$ & -0.0 & 0.0 & & & & & & & & & & & \\
\hline 24 & .229 & .25 & & 1.0 & & & & & & & & & & & & & & \\
\hline & & & & & & & & & & & & & & & & & & \\
\hline & 0.0 & $\begin{array}{l}2880^{* *} \\
1997^{*}\end{array}$ & -0.0 & & .88 & 1.000 & .7 & & & & & & & & & & -0.0 & .0208 \\
\hline 6 & 0.0 & .0 .08 & -0.0 & & .45 & & 1.08 & .38 & & & & & & & & & & 02 \\
\hline & .0 & $\cdot 0.0$ & .0 .0 & & .70 & .722 & & 1.00 & .73 & & .2 & & & & & & & \\
\hline & & .0 .0 & & & & & & & 1.0 & $*$ & & & & & & & -0.05 & \\
\hline & & & & & .0 & & & & & & & & & & & & & \\
\hline & & & .0 & & & & & & & & & & & & & & & \\
\hline & & .0 .0 & 0.0 & 0 & 0.0 & & & & & & & & & & 0.2 & Bi* & & \\
\hline & & & & & & & & & & & & & & & & & & \\
\hline & & 0.1 & .1 & & .14 & .28 & .0 & & . & 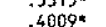 & & .0 .2 & & & & & & \\
\hline & & & .1 & & $-0.3140^{* *}$ & 1. & 0.0 & & & .7 & & & & & & & & \\
\hline & & & & $=0.2296^{\circ}$ & .0003 & 1264 & 2 & & & $4 *$ & & & & & & & & \\
\hline & & $.2444 * 1$ & .0 .1429 & & & & & 0.1546 & -0.1011 & .049 & 02 & & & & & & & \\
\hline
\end{tabular}

* SIGHIF. LE .01 *.. SIGMIf. LE .001 
Table 5. Pollutant Correlation Matrix

(Number of city pairs given in parenthesis)

Sh. SO4 SAR.804 Dich.FSO4 Dich.TSO4 Dich.FMass D1ch.TMass

$\begin{array}{ll}0.760 & 0.702 \\ (128) & (54) \\ 1.0 & 0.725 \\ 1 & (48)\end{array}$

0.696
$(54)$
0.724
$(48)$

0.590

0.059

Iron

Manganese Cadmlum Variadium

Lead

Osone

Sar.SO4

1.0

$0.994 \quad 0.750$

(56)

0.046

0.202

$\begin{array}{ll}-0.319 & 0.268 \\ (163) & (157)\end{array}$

0.008

$-0.239$

$0.687 \quad 0.220$

(163) (163)

163)

(163)

(114)

(126)

Dich. $\mathrm{SSO}_{4}$

(50)

$0.166 \quad 0.235$

$-0.133$

(i) 133

$-0.088$

$-0.105$

$-0.155$

0.245

$0.207 \quad 0.413$

$-0.167$

0.243

(138)

(103)

(110)

Dlch. TSO4

1.0

0.762

0.271

$(64)$

(54)

(54)

-0.130
$(54)$

-0.11
$(47)$

$-0.170$

Dich. FHass

1.0

0.605

(54) (54)

$(54)$

(54)

$-0.122$

$-0.129$

$-.0 .160$

$0.331 \quad 0.401 \quad-0.1120 .028$

$(54)$

(47) (51)

Dich.TMass

1. 0

(56)

(56)

0.11

$(56)$

0.19
$(56)$

0.133

$-0.028$

Iron

(56)

0.528
$(56)$

0.079

$-0.144$

0.275

(49)

(53)

1.0

0.780

(56)

(56)

(56)

0.188

$-0.073$ (173)

0.074

0.132

0.307

(49)

(53)

Manganese

1.0

-0.041
$(173)$

0.241

(119)

0.111

(126)

Cadmium

1. 0

$0.08 \%$

(16?)

(173)

(1i9)

-0.065
$(126)$

Varadium

1.0

$-\dot{0}$ טง

0.054

(119)

$-0.263$

(126)

Lead

(167)

$-0.076$

0.027

(167)

0.281

0.274

(119)

(126)

Ozone

1. 0

0.167

(106)

1.0 
Table 6. Correlation Between Selected Pollutants and Demographic Variables

\begin{tabular}{|c|c|c|c|c|c|c|c|}
\hline & $\begin{array}{l}\text { Computed } \\
\mathrm{SO}_{4}=\end{array}$ & $\begin{array}{l}\text { Me asured } \\
\mathrm{SO}_{4}=\end{array}$ & $\begin{array}{l}\text { Computed } \\
\mathrm{NO}_{\mathrm{x}}\end{array}$ & $\begin{array}{l}\text { Total } \\
\text { Particle } \\
\text { Mass }\end{array}$ & Iron & Ozone & $\mathrm{CO}$ \\
\hline $\begin{array}{l}\% \text { Resident in } \\
\text { same State }\end{array}$ & 0.38 & 0.40 & 0.00 & 0.005 & -0.14 & -0.18 & -0.32 \\
\hline$\%$ Asian & -0.25 & -0.29 & 0.02 & -0.14 & -0.02 & 0.06 & 0.12 \\
\hline$\%$ B1ack & 0.23 & 0 & -0.01 & 0.0 & 0.01 & -0.15 & -0.10 \\
\hline$\% \geq 65$ & 0.12 & 0.26 & -0.10 & -0.04 & -0.03 & -0.09 & -0.05 \\
\hline Birthrate & -0.31 & -0.07 & -0.12 & 0.24 & 0.16 & 0.11 & -0.13 \\
\hline Log Population & 0.01 & -0.12 & 0.09 & 0.07 & 0.01 & -0.06 & 0.07 \\
\hline Smoking & 0.19 & 0.16 & 0.16 & 0.10 & -0.13 & 0.09 & 0.12 \\
\hline Water Hardness & -0.13 & -0.07 & -0.08 & 0.24 & 0.13 & 0.06 & -0.14 \\
\hline$\%$ Poor & 0.23 & 0.33 & -0.18 & 0.01 & 0.14 & -0.12 & -0.13 \\
\hline$\%$ College & -0.13 & -0.37 & -0.05 & -0.28 & -0.26 & 0.06 & 0.15 \\
\hline Pop. Density & 0.26 & 0.12 & 0.47 & -0.08 & -0.04 & -0.04 & 0.06 \\
\hline
\end{tabular}

samplers in addition to SAROAD and water hardness data are also Iisted in Appendix A. These include both major and smaller cities and cover most regions of the country fairly well, with the possible exception of New York State and New England. The total population of the 53 cities is 23 million people, or about $13 \%$ of the total U.S. urban population.

\subsection{RELIABILITY OF AIR QUALITY EXPOSURE ESTIMATES}

Appendix A gives the numbers of observations and the numbers of monitoring sites for the SAROAD air quality data. These vary from thousands of observations for the gaseous pollutants with hourly data ( $\mathrm{CO}$ and $\mathrm{O}_{3}$ ), to fewer than ten observations for some of the metals and for measured sulfate. The numbers of monitoring stations assigned to a city range from one to seventeen; the average number of monitoring sites was less than three for all measured pollutants. The dichotomous sampler data are generally from only one or two samplers per city, ${ }^{*}$ with some exceptions. 20

\subsubsection{Measured versus Computed Sulfate}

One way to assess the adequacy of monltoring coverage from a statistical point of view is to use the number of observations or monitors as a weighting factor in the regression analysis. Another method is to examine the correlation between the mean value and the number of observations, i.e., do high concentration values occur in locations with fewer or more observations than average? This was found to be the case for cadmium (positive correlation) and

*Cities with more than one dichotomous sampler include Birmingham (5), Phoenix (3), Los Angeles (4), San Jose (2), San Francisco (2), Denver (2), Hartford (2), Chicago (3), Boston (2), Baltimore (2), Detroit (2), Minniapolis (2), St. Louis (2), Durham (2), Buffalo (3), Cleveland (3), Portland (2), Philadelphia (14), Pittsburgh (3), Houston (3), Salt Lake City (2), Seattle (2). 
vanadium (negative correlation). Only for cadmium was the number of monitor locations correlated (positively) with the mean value. Use of weighting factors in regression is limited to a single choice of welghting factor per regression, which could lead to difflculties in choosing the "best" weight factor and regression. As an exploratory step, we calculated the correlation between ASTRAP computed $\mathrm{SO}_{4}=$ and measured (SAROAD) values, using four alternative weighting factors:

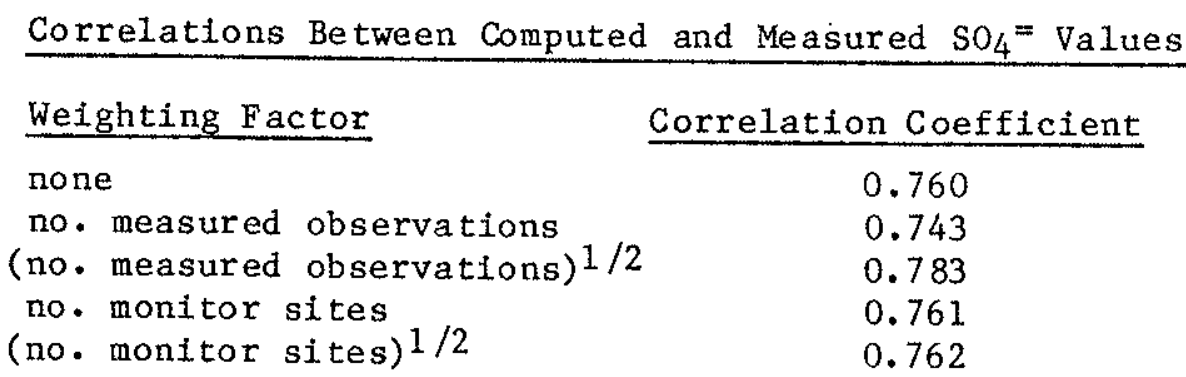

Since none of these correlation coefficient values are statistically different from one another, we conclude that random noise in the sulfate measurements is not a major consideration in comparison to the spatial variation from city to city. The welghted mean values were not significantly dfferent from the unweighted values.

\subsubsection{Other Correlations Among Pollutants}

Other correlations among pollutants measures are given in Table 5, for the "159" city data set. They are grouped according to particle characteristics or source type, for example, all the various sulfate measures and industrial sources: total mass (dichotomous) ixon, and manganese. Manganese is also significantly correlated with sulfates and small particles. Cadmium and manganese are largely uncorrelated with the other pollutants, with the exception of manganese versus vanadium. Vanadiun is associated with sulfate, perhaps reflecting heavy fuel oil as a common source (or, more speculatively, catalytic action of manganese in oxidizing $\mathrm{SO}_{2}$ to $\mathrm{SO}_{4}=$ ).

Lead, ozone, and carbon monoxide are all associated with mobile sources, although not exclusively so. The correlations among this group are much more modest than in the other groups. Lead was also associated with total particle mass and with iron, perhaps reflecting a coarse particle mode.

\subsubsection{Cities with High Levels of Specific Pollutants}

Based on the 159 city data set, the following cities rank high in terms of median pollutant concentration levels.

Co: Los Angeles, Pasadena, San Jose, Denver, Des Moines, Boise, Indianapolis, Chattanooga, Spokane. This may well be as a result of the monitor locations, in relation to traffic density.

Ozone: San Bernadino, Burbank, Los Angeles, Pasadena. Those rankings result from the well-known tendency for Southern California to have high photochemical reactivity. 
Lead:

Ashland (KY), Grand Rapids, Ogden, Salt Lake City. These high values appear to be mostly due to industrial (rather than moblle) sources.

Vanadium: This appears to be a bimodal data set; cities with heavy fuel oil use, mostly along the Eastern Seaboard have higher values than those in the interior or on the West coast. Exceptions are Bakersfield (CA), several cities in Illinois, and Greensboro (NC).

Iron: High values are found in Phoenfx, Bakersfield, Granite City (IL), Ashland (KY), Detroit, Steubenville, and Youngstown, $\mathrm{OH}$. Most of these cities have heavy industrial manufacturing.

Manganese: High values are found in Granite City (IL), East Chicago (IN), Gary (IN), Hammond (IN), Ashland (KY), Detroit, Steubenvilie (OH), Youngstown $(\mathrm{OH})$ and Sioux Falls (SD). These are largely manufacturing cities, as was the case with iron.

Cadmium: The highest values are all found in Texas; it is not known whether this may be an artifact of either sampling or analytical procedures.

Measured The highest values are found in Gadsden (AL), Atlanta, Evansville,  and New Albany (IN), Terre Haute (IN), Ashland (KY), New Orleans; Flint, Grand Rapids and Lansing (MI); Akron, Canton, Cleveland, Steubanville, Toledo, Youngstown (OH); Chattanooga, Norfolk, Kenosha (WI), and Charleston (WV). As can be seen by comparing Figures 8 and 9, the patterns of measured sulfate are much less uniform than the computed values. It is not known whether these local differences are real or artificial.

Total (Dichotomous Samples): The highest values are found in Phoenix, Particle Bakersfield, Pasadena, Denver, Gary (IN), and Ashland (KY). These Mass locations appear to have a mixture of natural and anthropogenic sources of particles.

Fine (Dichotomous Samples): The highest values are found in Particle Birmingham, Pasadena, Gary (IN), Ashland (KY), Akron and Mass Cleveland, which are mostly manufacturing locations.

Total \& Fine (Dichotomous Samples): The highest values are found in Gary (IN), Particle Buffalo, Akron, Cleveland, and Chattanooga, all manufacturing Sulfur Mass locations.

\subsection{STATISTICAL METHODS}

Most of the statistical computations upon which this analysis is based were performed at the State University of New York at Stony Brook using standard statistical package programs: BMDP25 and SPSS.26 These calculations include bivariate correlations, multiple linear regressions, factor analysis, and analysis of the frequency distributions of the residuals from these regressions. The spatial autocorrelation analysis was performed at Brookhaven. 
For the Phase I analysis, the regressions were run in the stepwise mode, both forward and backward, with a tolerance of 0.15 on the significance of a variable for retention in the prediction equation. This allows a $15 \%$ chance of falsely rejecting a variable in the backward mode (in which all variables are included initially and then the least significant ones are sequentially eliminated), or a $15 \%$ chance of wrongly entering a variable in the forward mode. Because of collinearity in the data set, backward and forward modes do not always end up with the same model specification.

For the regressions, we require a probability less than $5 \%$ that the results might be due to chance for a result to be "statistically significant." Some cases where $0.05<\mathrm{p}<0.10$ are described as "borderline significant."

As seen in Tables 4,5 and 6 , there are some collinear variables in this data set, which requires special care in selecting candidate regression models. Factor analysis was one of the statistical methods used as a result of this situation. More details on the factor analysis procedure are given below. 


\subsection{REGRESSION ANAL YSES ON THE 1980 DATA SET: PHASE I}

In the first phase of the analysis, each pollutant was considered separately. This was done for several reasons, the first being that the ratio of the number of variables (35) to the number of cities having complete data sets (42) or data on at least two pollutants (about 160 cities on average) was far less than the desired rule of thumb value of 5. Moreover, some of these pollutants were known to be collinear. In particular, SAROAD sulfate, computed sulfate, total sulfur (dichotomous) and fine particle mass all measure the level of sulfate and hence were not considered simultaneously. To further allow for the number of variables considered, two regressions were run for each pollutant. The first involved stepwise regression of all demographic variables plus each pollutant, and the second involved stepwise regression of the demographic factor scores plus each pollutant. Each of these pairs of regressions was done on the following two data sets: (1) the cities having data on the pollutant (one at a time) and (2) the cities having data on the pollutant of interest plus values for drinking water hardness. Thus a total of four regression analyses were done for the data sets deffned by each pollutant.

\subsection{FACTOR ANALYSIS}

The factor analysis approach was used to reduce the very large and partially collinear set of demographic variables to a smaller set of uncorrelated variables, called factor scores. The factor analysis results were based on the correlations between the demographic variables obtained from the entire set of cities using "pairwise deletion". This means that wherever a city had information on two variables, that city was included in the computation of the correlation for these two variables. The resulting correlations then were based on the maximum possible number of observations. Two factor analyses were done. The first used data from all the 916 cities and included all demographic variables. The second was done using the 450 cities for which data on water hardness were available; these data were included in the demographic variable set.

The factor analysis (set (1) above) which excluded the hardness variable resulted in seven significant factors. After VARIMAX rotation of the factors, we could consider the loadings for each variable on each factor as reflecting what that factor is measuring. The first factor had highest loadings on log of the land area and log of the city population, hence was named "the city size" factor. The second factor loads highest on percentage over 65 (negative loading) and ratio of males to female (positive loading) and is the "age/sex" factor. The third factor loads highest on percentage black and percentage below poverty level and is the black/poverty factor. The fourth had high negative loadings on the gas heat variable and percentage of long term residents, the fifth factor was the population density/oil heat factor and the slxth the smoking/Astan factor (since it assigns essentially equal weight to the 1969 and 1980 smoking figures and a smaller negative loading on the percentage of Astans). The seventh factor could be seen as the birthrate factor since the loadings are high and positive for percentage spanish and the birthrate and negative for percentage of college graduates.

The factor analysis of the citles with water data available gave somewhat similar results; the city size factor was present with high loadings on the 
same variables observed above on exclusion of water. The same was true for the $\mathrm{black} /$ poverty, age/sex, smoking/Asian, and birthrate factors. However, the addition of water hardness resulted in density and population change forming a factor and in water hardness and oil heat forming an additional factor.

\subsection{REGRESSION RESULTS}

In Table 7 we report the results of stepwise regressions on the variables and on the factors. On comparing the two columns, with the exception of fine particle mass and fine lead, one sees essentially the same results for each pollutant regardless of whether factor scores are used to represent the demographic variables or the demographic variables themselves. That is, significant positive coefficlents are observed for iron, manganese, SAROAD sulfate, computed sulfate, total sulfate and fine sulfate with both approaches. For the regression which included computed sulfate, the analyses with factor scores estimated significant coefficients for all factors except city size. All coefficients were positive except the coefficient for the age/sex factor scores. The adjusted, $\mathrm{R}^{2}$ was 0.68 . On using the individual demographic variables, significant $(\mathrm{p}<0.10)$ positive coefficients are observed for percentage over 65, the birthrate, smoking in 1969, percentage poor, and percentage of long-term residents. Significant negative coefficients are observed for the change in population, the male to female ratio, percentage Spanish, gas heat and oil heat variables. The resulting adjusted $\mathrm{R}^{2}$ was 0.87 .

Table 7. Results of the Regressions on

(a) All Demographic Factors plus One Pollutant at a Time

(b) All Demographic Variables Plus One Pollutant at a Time

All Cities With Given Pollutant Available

\begin{tabular}{l|cc|cc|c}
\hline & $\begin{array}{c}\text { (a) Using Demographic } \\
\text { Factors }\end{array}$ & $\begin{array}{c}\text { (b) Using Demographic } \\
\text { Variables } \\
\text { Coefficient } \pm \text { SE (p) }\end{array}$ & $n$ \\
\hline Cadmium & $-66 \pm 11$ & $(0.000)$ & $-1.9 \pm 9.2$ & $(0.84)$ & 173 \\
Co & $-0.268 \pm 0.12$ & $(0.031)$ & $-0.160 \pm 0.09$ & $(0.082)$ & 194 \\
$\mathrm{Fe}$ & $0.59 \pm 0.16$ & $(0.000)$ & $0.56 \pm 0.10$ & $(0.000)$ & 172 \\
$\mathrm{Mn}$ & $12.8 \pm 3.5$ & $(0.000)$ & $10.6 \pm 2.29$ & $(0.000)$ & 172 \\
$\mathrm{~Pb}$ & $0.49 \pm 0.46$ & $(0.28)$ & $0.35 \pm 0.33$ & $(0.29)$ & 214 \\
$\mathrm{O}_{3}$ & $-30.6 \pm 6.90$ & $(0.000)$ & $-13.7 \pm 5.7$ & $(0.017)$ & 211 \\
Vanadium & $-1.7 \pm 4.8$ & $(0.73)$ & $0.70 \pm 3.1$ & $(0.82)$ & 165 \\
Fine Particle Mass & $0.026 \pm 0.03$ & $(0.39)$ & $0.036 \pm 0.02$ & $(0.086)$ & 81 \\
Total Particle Mass & $0.002 \pm 0.01$ & $(0.89)$ & $0.01 \pm 0.01$ & $(0.34)$ & 68 \\
Fine Pb & $-4.40 \pm 1.68$ & $(0.011)$ & $-0.06 \pm 1.4$ & $(0.97)$ & 77 \\
SO 4 (SAROAD) & $0.129 \pm 0.04$ & $(0.001)$ & $0.100 \pm 0.03$ & $(0.000)$ & 202 \\
SO 4 (Computed) & $0.081 \pm 0.02$ & $(0.000)$ & $0.084 \pm 0.02$ & $(0.000)$ & 872 \\
Total SO (dich.) & $0.272 \pm 0.07$ & $(0.001)$ & $0.188 \pm 0.05$ & $(0.000)$ & 78 \\
Fine SO $_{4}$ (dich.) & $0.276 \pm 0.08$ & $(0.002)$ & $0.200 \pm 0.05$ & $(0.000)$ & 78 \\
\hline
\end{tabular}

* Median readings used

$\mathrm{p}=$ level of statistical significance. 
In Table 8 we report the results of stepwise regressions for the data set for cities with drinking water data. There are significant positive coefficients for tron, manganese, computed sulfate, total sulfate, and fine sulfate with both demographic variables and factor scores as the covariates. Vanadium has significant positive coefflcients only if factor scores are used as the covariates, and fine mass and SAROAD sulfate have signiflcant positive coefficients only if the demographic variables themselves are used as covariates. The regression for computed sulfate included all factors except the hardness/oil heat and the density/population change factors. All other factors had significant positive coefficients except the long term resident/gas heat and the city size factor. The adjusted $\mathrm{R}^{2}$ was 0.79 . In the analysis of these cities with water data which included all demographic vartables plus hardness values plus computed sulfate, four demographic variables had significant positive coefficlents. They were (in order of entry) percentage over age 65, birthrate, percentage poor, and the 1969 smoking variable. Five variables had significant negative coefficients. These were the percentage Spanish, the percentage college graduate, oil heat, haxdness, and population change variables. The adjusted $R^{2}$ was 0.87 .

Table 8. Results of the Regressions on

(a) All Demographic Factors plus One Pollutant at a Time

(b) All Demographic Variables Plus One Pollutant at a Time

Al1 Cities With Water Hardness Data Plus Pollutant Available

\begin{tabular}{|c|c|c|c|c|c|}
\hline$\frac{\text { Pollutant* }}{\text { Cadmium }}$ & \multicolumn{2}{|c|}{$\begin{array}{l}\text { (a) Demographic Factors } \\
\text { Coefficient } \pm \text { SE (p) }\end{array}$} & \multicolumn{2}{|c|}{$\begin{array}{l}\text { (b) Demographic Variables } \\
\text { Coefficient } \pm S E(p)\end{array}$} & $\frac{\mathrm{n}}{169}$ \\
\hline $\begin{array}{l}\text { Cadmium } \\
\mathrm{CO} \\
\mathrm{Fe} \\
\mathrm{Mn} \\
\mathrm{Pb} \\
\mathrm{O}_{3} \\
\text { Vanadium } \\
\text { Mass Fine } \\
\text { Mass Total } \\
\text { Fine Pb } \\
\mathrm{SO}_{4} \text { (SAROAD) } \\
\mathrm{SO}_{4} \text { (Computed) } \\
\text { Total } \mathrm{SO}_{4} \text { (dich.) } \\
\text { Fine } \mathrm{SO}_{4} \text { (dich.) }\end{array}$ & $\begin{aligned}-60.5 & \pm 1.1 .5 \\
-0.14 & \pm 0.1 \\
0.48 & \pm 0.1 \\
8.2 & \pm 3.2 \\
0.71 & \pm 0.4 \\
-13.9 & \pm 4.9 \\
4.6 & \pm 2.7 \\
0.023 & \pm 0.02 \\
0.016 & \pm 0.01 \\
1.35 & \pm 1.37 \\
0.04 & \pm 0.03 \\
0.15 & \pm 0.02 \\
0.18 & \pm 0.07 \\
0.16 & \pm 0.07\end{aligned}$ & $\begin{array}{l}(0.000) \\
(0.18) \\
(0.001) \\
(0.011) \\
(0.110) \\
(0.005) \\
(0.087) \\
(0.30) \\
(0.14) \\
(0.33) \\
(0.22) \\
(0.000) \\
(0.08) \\
(0.023)\end{array}$ & $\begin{aligned}-7.96 & \pm 10.29 \\
-0.15 & \pm 0.09 \\
0.55 & \pm 0.1 \\
10.5 & \pm 2.3 \\
0.35 & \pm 0.35 \\
-9.99 & \pm 4.2 \\
-0.03 & \pm 3.24 \\
0.03 & \pm 0.02 \\
0.01 & \pm 0.01 \\
-0.19 & \pm 1.1 \\
0.04 & \pm 0.02 \\
0.12 & \pm 0.02 \\
0.19 & \pm 0.05 \\
0.18 & \pm 0.05\end{aligned}$ & $\begin{array}{l}(0.4) \\
(0.091) \\
(0.000) \\
(0.000) \\
(0.31) \\
(0.018) \\
(0.992) \\
(0.08) \\
(0.10) \\
(0.86) \\
(0.052) \\
(0.000) \\
(0.001) \\
(0.001)\end{array}$ & $\begin{array}{r}169 \\
185 \\
168 \\
168 \\
214 \\
199 \\
161 \\
68 \\
68 \\
64 \\
197 \\
418 \\
65 \\
65\end{array}$ \\
\hline
\end{tabular}

* Median readings used

$\mathrm{p}=$ level of statistical signiflcance.

\subsection{CONCLUSIONS FROM PHASE I ANAL YSIS}

Taken individually, many of the pollutant variables are significant with positive coefficlents, although some are significant and negative. Clearly, 
both results cannot be valid (at least in a causal sense) and multiple pollutant regressions axe the next step to clarify the findings. The most significant pollutants $(+)$, sulfate, Iron, manganese, are consistant across all four sets of regressions, although some of the negattve ones also display this consistency.

None of the mobile-source pollutants showed significant positive coefficients. In the case of lead and CO, the monitoring data could be from sites not representative of true population exposures. Ozone is highest in Southern California, where age-adjusted mortality rates are average. It is also possible that the ozone monitoring data are not representative, since they are average daily maximum values (as opposed to annual averages) and since urban ozone may be depressed by local $\mathrm{NO}_{\mathrm{x}}$ sources. 


\subsection{PHASE II REGRESS ION AKAL YSES}

The exploratory and regression analyses described above were followed by investigations of the outliers and of the birthrate varlable, and by a set of "planned" stepwise regression analyses. Outliers which could be seen as resulting from clearly unreliable data or as being artifacts were deleted from the data set. All subsequent analyses reported in this section were done on this reduced data set. The birthrate variable which was originally included to account for an undercount of the population in the low income cities was investigated for the validity of this hypothesis. The planned regressions were built around stepwise entry of pollutants based on physical significance as well as statistical significance. These analyses and the results are described below.

\subsection{DELETION OF OUTLIERS}

Table 9 shows the outliers which were deleted and the reason for doing so. Then, pairwise correlations were obtained for the relevant variables and compared to those obtained prior to the deletion of these cities. In general, removal of these values made little change in the pairwise correlations. When differences were observed, they were usually in the form of an increase in the absolute value of the correlation coefficient. This is as one would expect, since errors in data usually result in an increase in the proportion of variance due to deviations from the linear model, which causes a decrease in correlation.

\begin{tabular}{|c|c|c|}
\hline City & $\begin{array}{l}\text { Variable } \\
\text { Deleted }\end{array}$ & Reason for Deletion \\
\hline \multirow[t]{2}{*}{ Burbank, California } & $\mathrm{CO}$ & $\begin{array}{l}\text { Data anomalously high, probably due to } \\
\text { sampler being in a high traffic loca- } \\
\text { tlon, not representative of residential } \\
\text { areas. }\end{array}$ \\
\hline & $\mathrm{Pb}$ & $\begin{array}{l}\text { Only } 1 \text { year of data; } \\
\text { Suspiciously high value. }\end{array}$ \\
\hline Glendale, California & 03 & $\begin{array}{l}\text { Only } 1 \text { year of data; } \\
\text { Suspiciously high value. }\end{array}$ \\
\hline Granite City, IlIinois & Vanadium & $\begin{array}{l}\text { Only } 1 \text { year of data; } \\
\text { Suspiciously high value. }\end{array}$ \\
\hline Lawrence, Indiana & A11 & $\begin{array}{l}\text { Anomalously low birth and death counts. } \\
\text { No measured air quality data available. }\end{array}$ \\
\hline Norwalk, Connecticut & $\mathrm{CO}$ & $\begin{array}{l}\text { Data anomalously high, probably due to } \\
\text { sampler in high traffic locations, not } \\
\text { representative of residential areas. }\end{array}$ \\
\hline Stamford, Connecticut & $\mathrm{CO}$ & $\begin{array}{l}\text { Data anomalously high, probably due to } \\
\text { sampler in high traffic locations, not } \\
\text { representative of residential areas. }\end{array}$ \\
\hline
\end{tabular}




\subsection{INVESTIGATION OF THE BIRTHRATE VARIABLE}

The estimated effect of birthrate on mortality was nearly an order of magnitude higher than expected if it were representing solely the census undercount (20-30\% versus a few percent). If this variable is indeed proportional to census undercount then one would expect it to be a better predictor of mortality in cities with high poverty than in very affluent cities. It was also of interest to determine whether the significance of the pollution variables was dependent on the birthrate variable.

To investigate the effect of the birthrate variable in various strata, we determined the top, middle and bottom 33rd percentiles of the poverty and Spanish variables. We then defined a city to be in the High Poor/High Spanish stratum if its poverty and Spanish variables were both in the top $33 \%$ of the observed values. The values for these percentiles were $14 \%$ and $5 \%$, respectively. Similarly the cut-off values for the Low Poor/Low Spanish groups were $8 \%$ and $1.4 \%$, respectively.

Separate regressions were run on the High Poor/High Spanish cities and the Low Poor/Low Spanlsh clties with all demographic variables (excluding \% Poverty and \% Spanish variables). In the 92 Low Poor/Low Spanish cities, the birthrate variable was non significant, as might be expected if the effect being measured was indeed a surrogate for undercount. In the $106 \mathrm{High}$ Poor/High Spanish cities, the birthrate coefficient was significant $(b+S . E .=0.12 \pm 0.025 ; p<$ $0.00005)$, also in accordance with this hypothesis.

This apparent interaction (between poverty and birthrate) was not observed in regressions in the marginal strata. In the 304 cities in the bottom $33 \%$ of the sample with respect to the percentage Spanish (less than $1.4 \%$ Spanish population), Low Spanish cities, the estimated birthrate coefficient is $0.18 \pm$ $0.02 ; \mathrm{p}<0.0005$ whereas in cities in the top 33rd percentile for \% Spanish (more than $5 \%$ Spanish population), the coefficient is quite similar at $(0.14 \pm$ $0.01, p<0.00005)$. Similarly, in the 288 cities in the bottom $33 \%$ of the sample with respect to poverty, the estimated birthrate coefficient is $0.12 \pm 0.02$ ( $\mathrm{p}<$ $0.0005)$, essentially identical to the estimate for the 317 High Poor cities in the top 33rd percentile for poverty $(0.12+0.01 ; \mathrm{p}<0.00005)$. Moreover, the interaction terms birth $x$ Spanish and birth $x$ Poverty were not significant, in a separate linear regression. In addition, all of the birthrate coefficients for these subsets were significantly lower than those for the entire data set.

Thus, while comparison of the first two regressions (High Poor/High Spanish versus Low Poor/Low Spanish) Indicated that the birthrate variable might in some way account for undercount in the poor cities, the results of the second set of regressions are more equivocal, so that it may be of interest to investigate the results of regressions which do not include the birthrate variable. Stepwise regressions with all demographic variables except birthrate, plus each of the $\mathrm{SO}_{4}=$ measures, gave no consistent pattern. On excluding the water variable ( $\mathrm{n}$ $=872$ ) and the birthrate variable, the computed $\mathrm{SO}_{4}=$ term was nonsignificant ("beta value" $=0.02 ; p=0.21$ ), whereas when birthrate was included, a high1y significant coefficient for the computed $\mathrm{SO}_{4}=$ is estimated $(0.08 \pm 0.02$; beta $=0.08 ; \mathrm{p}<0.0005)$. However, including the water variable (418) and excluding the birthrate variable resulted in only a slight drop in the computed $\mathrm{SO}_{4}{ }^{2}$ 
coefficient from that observed in the corresponding analysis with birthrate (from 0.113 to $0.08 \pm 0.02$ ): the coefficient remains significant in both cases. Interestingly, the water variable never enters as a significant term, leading us to conclude that the relationship between computed $\mathrm{SO}_{4}=$, birthrate, and mortality is different in the cities for which we have water data than in those for which we do not. The coefficients for Total Sulfur Mass (STD) and Fine Particulate Mass (MFD) are unaffected by the inclusion or exclusion of the birthrate variable. In the analyses which included the birthrate variable the coefficients for these pollutants are significant both in the entire set (of 78 cities for STD and 81 cities for MFD) and in the subset with water data (65 for STD and 68 for MFD). On exclusion of the birthrate variable from the four regressions the coefficient shows little change and remains significant. We thus concluded that subsequent models should include the birthrate variable, even if its meaning is not fully understood, since it contributes substantially to the overall goodness of fit.

\subsection{STEPWISE ENTRY WITH RESPECT TO POLLUTANT TYPE}

Rather than build a model based solely on statistical signiflcance, it was decided to build a model based on pollutant variables selected from groups of similar species. This was done in part because of the large amount of missing data for many pollutants, which reduced the data set to a sample of 42 cities, if all pollutants are considered sinultaneously. Pollutants were entered in a stepwise manner as illustrated in the flow chart given in Table 10 .

The pollutants were grouped according to their source (as in Table 5), the four groups being (1) Elne Particles (sulfates) (2) Large Particles (3) Industrial Particles (4) Heating Fuel Variables and (5) Mobile Source (Automotive) Pollutants. The intent was to select the "best" pollutant variable from each group based on avallability of data and on statistical significance. Each group was investigated in a stepwise manner, beginning with the fine particles (sulfates). During this phase of the analysis, the demographic variables were entered in a stepwise fashion, as needed to optimize the overall model fit. These regression analyses were done with and without the water variable. The results are summarized in Tables 11 to 15 . The resulting "final" model included computed $\mathrm{SO}_{4}=$ and iron, in agreement with the Phase I analysis. Both pollutants were available in 159 cities. Table 16 shows the final model obtained from this analysis; most of the variables are significant and the pollutant variables are highly significant.

\subsection{INVESTIGATION OF THE FINAL PHASE II MODEL}

\subsubsection{All Possible Subset Regression Analysis}

The final model was investigated first by doing "all possible subset" regression on the 159 cities having data on iron, computed $\mathrm{SO}_{4}=$ and water hardness (listed in Appendix A). All demographic variables were considered, one change being that the average of the 1969 and the 1980 smoking values were used instead of two separate variables. All subsequent analyses followed suit since regressions using either 1969 smoking, 1980 smoking or the average resulted in models with identical $R^{2}$ values and significant and essentially equal coefficients for whichever smoking variable was included. Moreover, earlier factor analysis had indicated that equal weighting of these two values was appropriate. 
Table 10. Flowchart For Planned Stepwise Regressions I. Stepwise Regressions with all demographic variables plus a selected sulfate
variable.

Possible sulfate variables are:

(1) Computed $\mathrm{SO}_{4}\left(\mathrm{NSO}_{4}\right)$ :

$\mathrm{n}=872$ without inclusion of water variable;

$\mathrm{n}=418$ on inclusion of water variable

(2) SAROAD SO4(LSO4)

$\mathrm{n}=187$ without inclusion of water variable;

$\mathrm{n}=182$ on inclusion of water variable

(3) Fine Particle Mass (Dichotomous Samplers) (MFD):

$\mathrm{n}=81$ without inclusion of water variable;

$\mathrm{n}=68$ on inclusion of water variable

(4) Sulfate Portion of Total Particle Mass (Dichotomous Samplers)(STD):

$\mathrm{n}=78$ without inclusion of water variable;

$\mathrm{n}=65$ on inclusion of water variable

I. Select Best Sulfate Variable

(A) Is NSO4 coefficient significant?

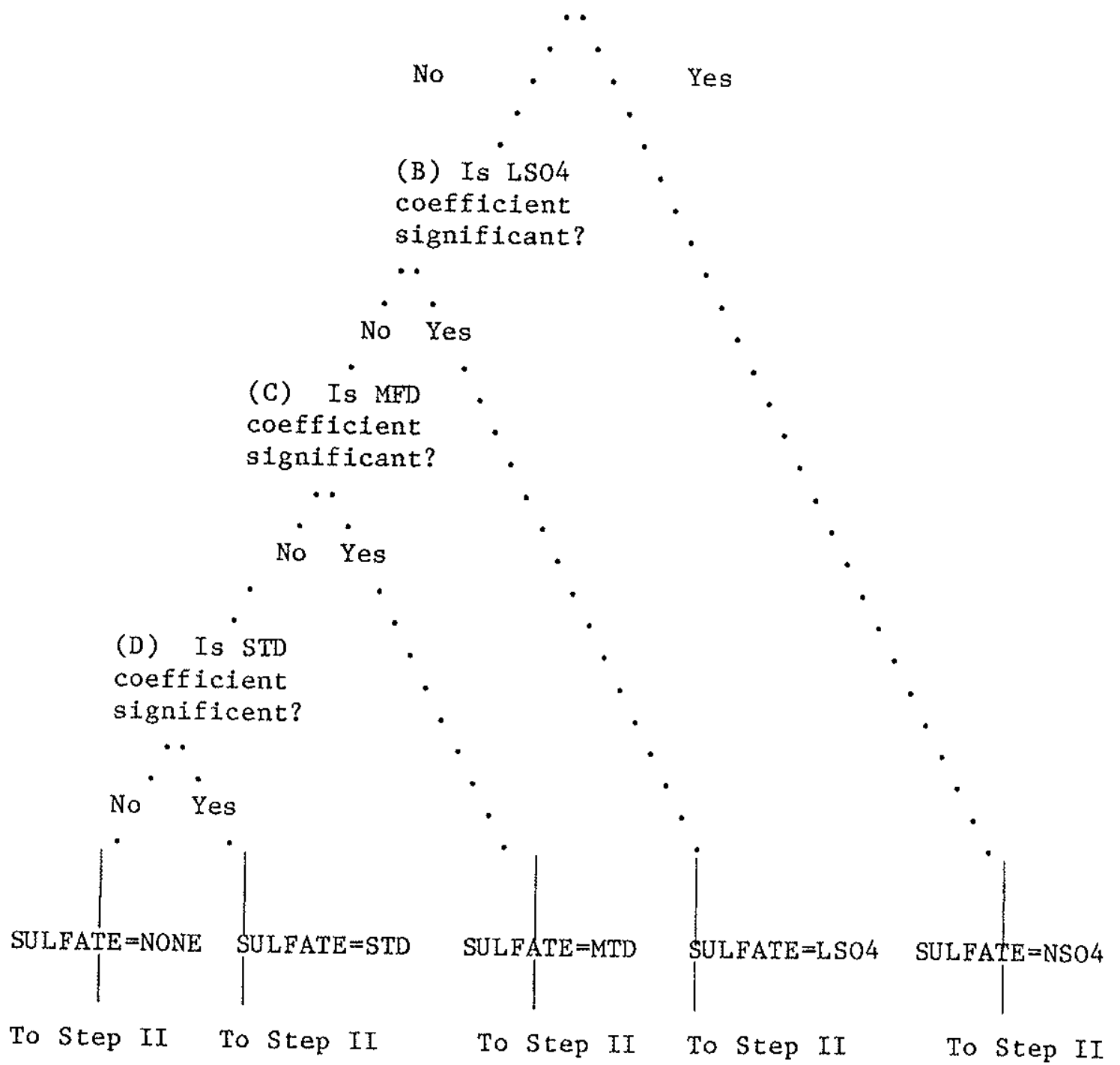


Table 10. Flowchart For Planned Stepwise Regressions (cont.)

II. Stepwise Regressions with all demographic variables plus SULFATE VARIABLE PLUS (Total Mass) PARTICLE VARIABLE. (MTD)

(A) Is MTD Coefficient Significant?

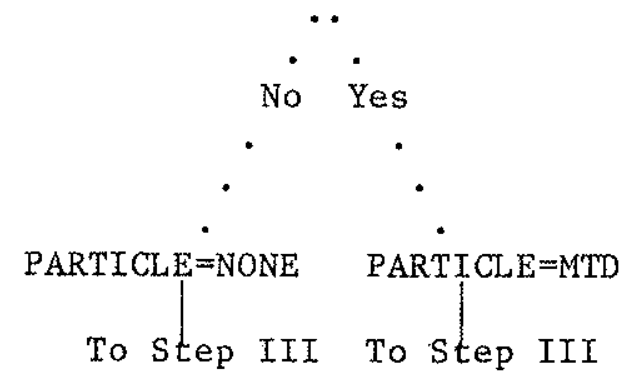

III. Stepwise Regressions with all demographic variables plus SULFATE AND PARTICLE VARIABLES PLUS INDUSTRIAL POLLUTANT VARIABLE. INDUSTRIAL POLLUTANT VARIABLES ARE:

(1) Iron ( $\mathrm{Fe})$

(2) Manganese (Mn)

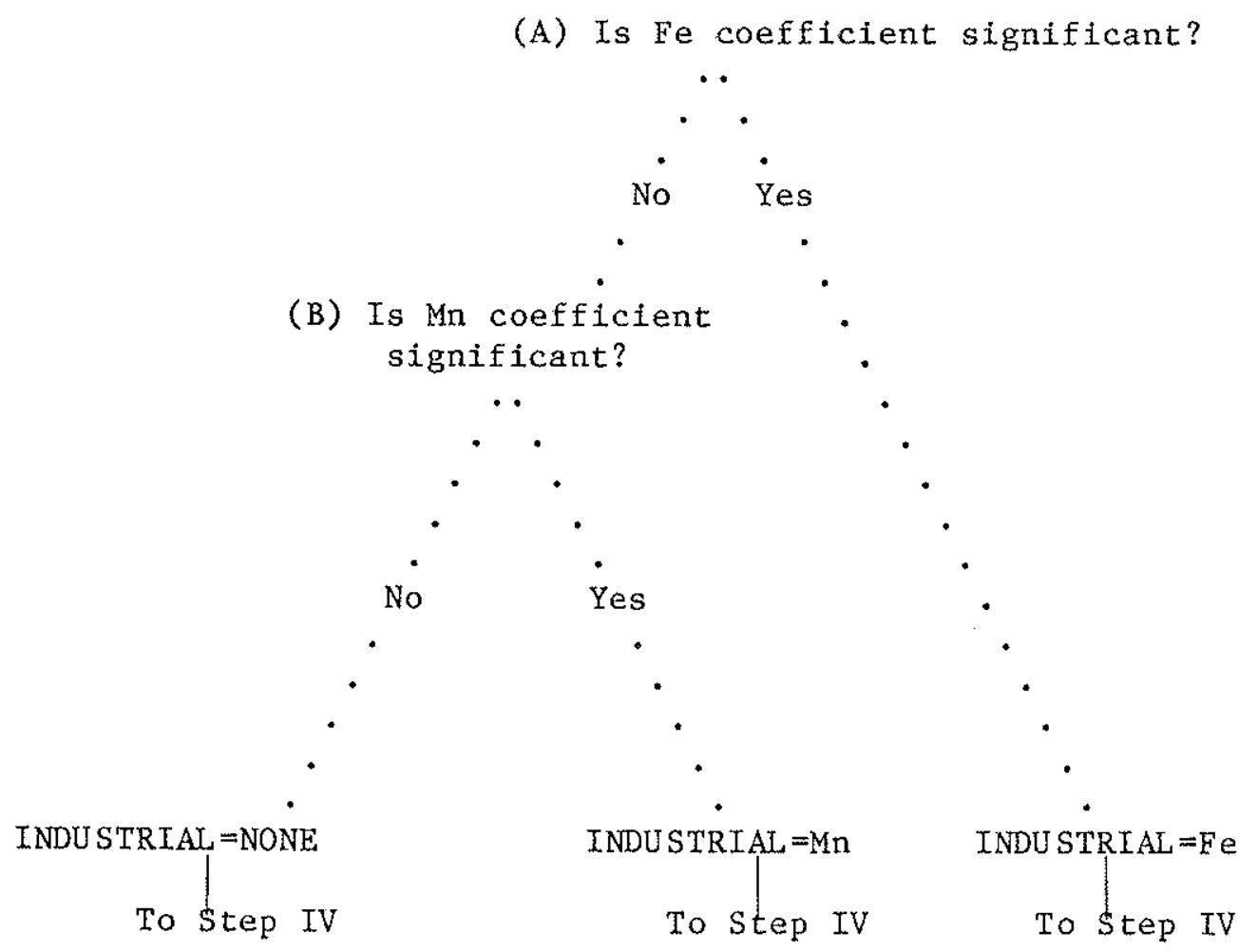


IV. Stepwise Regressions with all demographic variables plus SULFATE, PARTICLE, INDUSTRIAL POLLUTANT VARIABLE, PLUS FUEL VARIABLE. FUEL VARIABLES ARE:

(1) Vanadium(VANADIUM)

(2) Gas Heat (GASDAY)

(3) Oil Heat (FUELDAY)

Are any fuel variable coefficients significant?

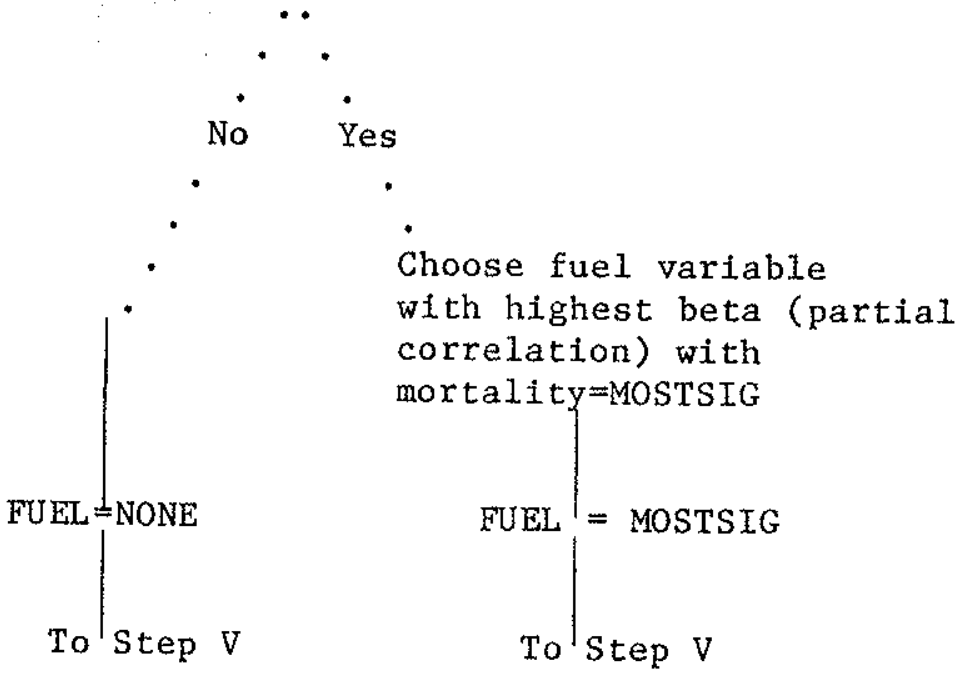

V. Stepwise Regressions with all demographic variables plus

SULFATE, PARTICLE, INDUSTRIAL VARTABLES AND FUEL VARIABLES PLUS AUTOMOTIVE POLLUTANT

AUTOMOTIVE POLLUTANTS ARE:

(1) Lead ( $\mathrm{Pb})$

(2) Carbon Monoxide (CO)

(3) Ozone $\left(\mathrm{O}_{3}\right)$

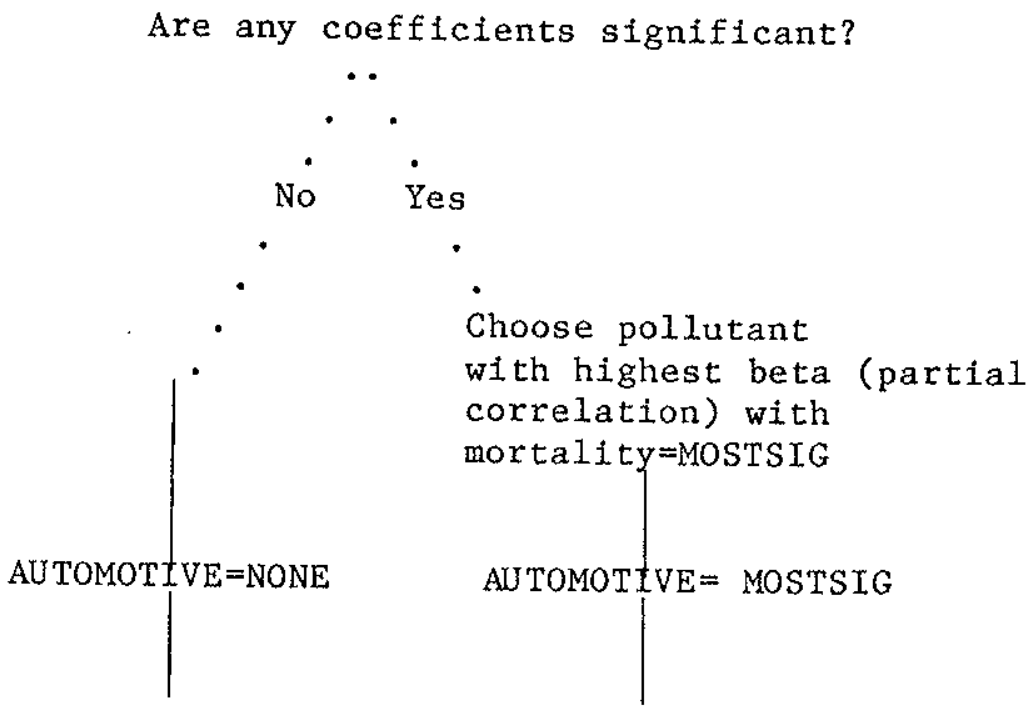


Table 11. Results of Planned Stepwise Regressions:

Results of Stepwise Entry of Demographic Variables

Plus Various Sulfate Measures, One at a Timel

Sulfate Coefficient \pm S.E.

(level of significance, ${ }^{2}$ sample size)

\begin{tabular}{|c|c|c|c|c|c|}
\hline \multicolumn{2}{|c|}{$\begin{array}{l}\text { Data Set---- } \rightarrow \rightarrow \\
\text { Sulfate }\end{array}$} & \multirow{2}{*}{ 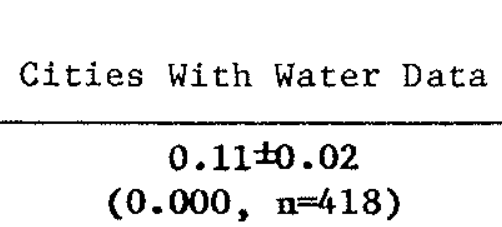 } & \multirow{2}{*}{$\begin{array}{c}\text { All Available Cities } \\
(0.08 \pm 0.02 \\
(0.000, \quad \mathrm{n}=872)\end{array}$} & \multicolumn{2}{|c|}{ Elasticity } \\
\hline (1) & $\begin{array}{l}\text { Computed } \mathrm{SO}_{4} \\
\left(\mathrm{NSO}_{4}\right)\end{array}$ & & & 0.061 & 0.045 \\
\hline (2) & $\begin{array}{l}\mathrm{SAROAD} \\
\left(\mathrm{LSO} \mathrm{SO}_{4}\right)\end{array}$ & $\begin{array}{c}0.07 \pm 0.02 \\
(0.004, n=182)\end{array}$ & $\begin{array}{c}0.10 \pm 0.02 \\
(0.000, \quad n=187)\end{array}$ & 0.07 & 0.10 \\
\hline (3) & $\begin{array}{l}\text { Fine Particle } \\
\text { Mass (MFD) }\end{array}$ & $\begin{array}{c}0.05 \pm 0.02 \\
(0.000, n=68)\end{array}$ & $\begin{array}{c}0.04 \pm 0.02 \\
(0.000, n=81)\end{array}$ & 0.096 & 0.077 \\
\hline (4) & $\begin{array}{l}\text { Tntal Sulfate } \\
\text { Mass (STD) }\end{array}$ & $\begin{array}{c}0.19 \pm 0.05 \\
(0.000, n=65)\end{array}$ & $\begin{array}{c}0.20 \pm 0.05 \\
(0.000, n=78)\end{array}$ & 0.088 & 0.094 \\
\hline
\end{tabular}

$1_{\text {See Table }} 10$ for description of planned stepwise regressions.

2. Level of significance $=0.000$ denotes $p<0.0005$

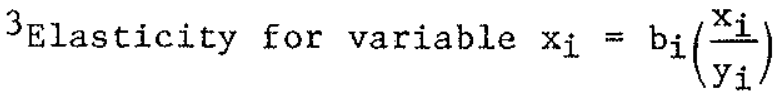

Variable in bold selected for next step

Table 12. Results of Planned Stepwise Regressions:

Results of Stepwise Entry of Demographic Variables

plus Computed Sulfate plus Particle Mass Variable

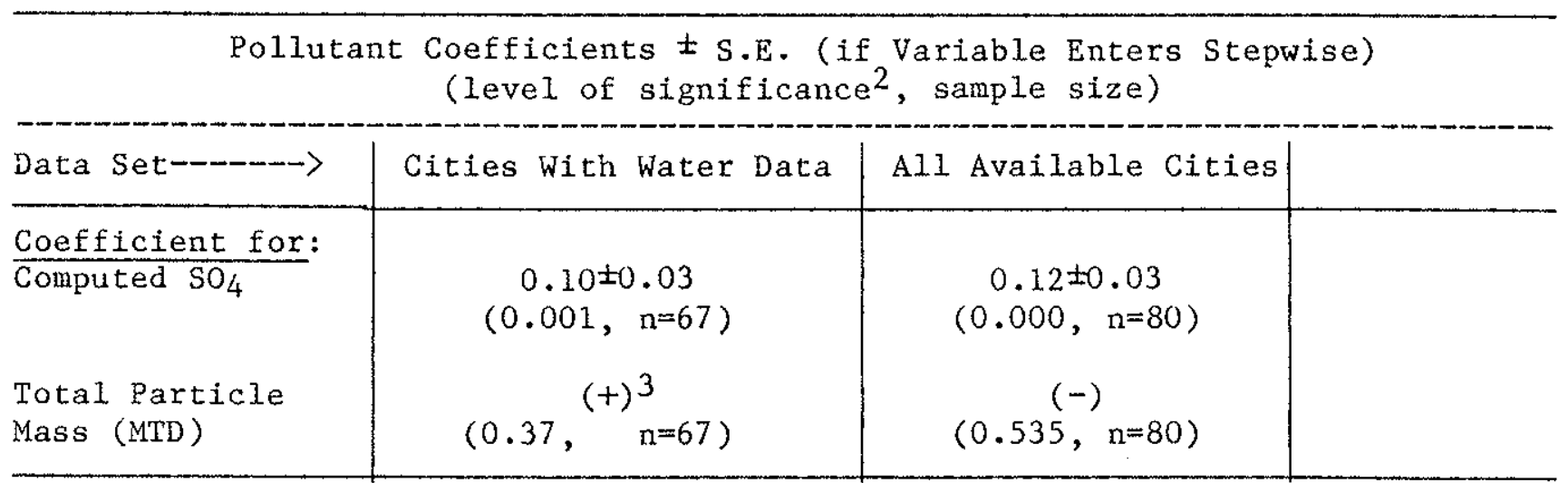

$1_{\text {See Table }} 10$ for description of planned stepwise regressions

${ }^{2}$ Level of significance $=0.000$ denotes $\mathrm{p}<0.0005$

${ }^{3}$ Sign of partial correlation reported if variable did not enter. 
Table 13. Results of Planned Stepwise Regressions:

Results of Stepwise Entry of Demographic Variables

Plus Computed Sulfate Plus Industrial Pollutants One at a Time ${ }^{1}$

\begin{tabular}{|c|c|c|c|c|c|}
\hline & $\begin{array}{r}\text { oefficients } t \mathrm{~s} \text {. } \\
\text { (level of } \mathrm{s}\end{array}$ & $\begin{array}{l}\text { E. (if Variable } \\
\text { significance }{ }^{2} \text {, }\end{array}$ & $\begin{array}{l}\text { Enters Stepwise) } \\
\text { mple size) }\end{array}$ & & \\
\hline Data Set-----> & Citles With & Water Data & A11 Availab & ble Cities & Elasticity \\
\hline Regr, with $\rightarrow \longrightarrow$ & Iron & Manganese & Iron & Manganese & \\
\hline \multicolumn{6}{|l|}{ Coefficient for: } \\
\hline Computed $\mathrm{SO}_{4}$ & $\begin{array}{c}0.09 \pm 0.02 \\
(0.000, \mathrm{n}=159)\end{array}$ & $\begin{array}{c}0.11 \pm 0.02 \\
(0.000, \quad \mathrm{n}=159)\end{array}$ & $\begin{array}{c}0.08 \pm 02 \\
(0.000, n=163)\end{array}$ & $\begin{array}{c}0.11 \pm 0.02 \\
(0.000, \quad n=1.63)\end{array}$ & 0.06 \\
\hline \multicolumn{6}{|l|}{$\begin{array}{l}\text { Industrial } \\
\text { Pollutants: }\end{array}$} \\
\hline (1) Iron & $\begin{array}{c}0.45 \pm 0.10 \\
(0.000, \mathrm{n}=159)\end{array}$ & $x^{3}$ & $\begin{array}{c}0.41 \pm 0.11 \\
(0.000, \quad \mathrm{a}=163)\end{array}$ & $\mathrm{x}$ & 0.05 \\
\hline (2) Manganese & $\mathrm{x}$ & $\begin{array}{c}9.9 \pm 2.25 \\
(0.000, \quad n=159)\end{array}$ & $x$ & $\begin{array}{c}9.3 \pm 2.23 \\
(0.000, \quad n=163)\end{array}$ & 0.04 \\
\hline
\end{tabular}

$\mathrm{I}_{\text {See }}$ Table 10 for description of planned stepwise regressions

2Level of significance $=0.000$ denotes $p<0.0005$

$3 X$ denotes variable not entered

Varlables in bold selected for next step. 
Table 14. Results of Planned Stepwise Regressions:

Results of Stepwise Entry of Demographic Variables

Plus Computed Sulfate and Iron Plus Fuel Variables, One at a Time ${ }^{1}$

\begin{tabular}{|c|c|c|c|c|c|}
\hline \multicolumn{6}{|c|}{$\begin{array}{l}\text { Coefficient } \pm \text { S.E. (if Variable Enters Stepwise) } \\
\text { (level of significance, } 2 \text { sample size) }\end{array}$} \\
\hline Data Set------ $\rightarrow$ & \multicolumn{2}{|c|}{ Cities With Water Data } & \multicolumn{3}{|c|}{ All Available Cities } \\
\hline $\begin{array}{l}\text { Regression with } \rightarrow> \\
\text { Coefficient for: }\end{array}$ & Vanadium & Gás Heat & Vanadium & Gàs Heat & Fuel Heat \\
\hline Computed $\mathrm{SO}_{4}=$ & $\begin{array}{c}0.08 \pm 0.02 \\
(0.000, n=153)\end{array}$ & $\begin{array}{cc}0.09 \pm 0.02 & 0.09 \pm 0.02 \\
(0.000, n=159) & (0.000, n=159)\end{array}$ & $\begin{array}{c}0.08 \pm 0.02 \\
(0.000, n=157)\end{array}$ & $\begin{array}{c}0.08 \pm 0.02 \\
(0.000, n=163)\end{array}$ & $\begin{array}{c}0.08 \pm 0.02 \\
(0.000, n=163)\end{array}$ \\
\hline Iron & $\begin{array}{l}0.43 \pm 0.10 \\
(0.000, n=153)\end{array}$ & $\begin{array}{cc}0.45 \pm 0.10 & 0.45 \pm 0.10 \\
(0.000, \mathrm{n}=159) & (0.000, \mathrm{n}=159)\end{array}$ & $\begin{array}{c}0.41 \pm 0.10 \\
(0.000, n=157)\end{array}$ & $\begin{array}{c}0.41 \neq 0.11 \\
(0.000, n=163)\end{array}$ & $\begin{array}{c}0.41 \neq 0.11 \\
(0.000, n=163)\end{array}$ \\
\hline $\begin{array}{l}\text { Fuels: } \\
\text { (1) Vanadium }\end{array}$ & $\begin{array}{l}(+) 3 \\
(0.541, n=153)\end{array}$ & $x^{4}$ & $(0.68, n=157)$ & $\mathrm{X}$ & $\mathrm{X}$ \\
\hline (2) Gas Heat & $\mathrm{X}$ & $\begin{array}{c}(+) \\
(0.56, n=159)\end{array}$ & $\mathrm{X}$ & $\begin{array}{c}(t) \\
(0.81, n=163)\end{array}$ & X \\
\hline (3) $0 i 1$ Heat & $\mathrm{X}$ & $\begin{array}{c}(+) \\
(0.96, n=159)\end{array}$ & $\mathrm{X}$ & $\mathrm{X}$ & $\begin{array}{c}(-) \\
(0.98, n=163)\end{array}$ \\
\hline $\begin{array}{l}\text { 1See Table } 10 \text { for } \\
2 \text { Level of signific } \\
3 \text { Sign of partial c } \\
4 \mathrm{X} \text { denotes variabl }\end{array}$ & $\begin{array}{l}\text { description of } \\
\text { ance }=0.000 \mathrm{de} \\
\text { orrelation repo } \\
\text { e not entered. }\end{array}$ & $\begin{array}{l}\text { planned stepwise regressions } \\
\text { enotes } p<0.0005 \\
\text { rted if variable did not ent }\end{array}$ & ter & & \\
\hline
\end{tabular}


Table 15. Results of Planned Stepwise Regressions:

Results of Stepwise Entry of Demographic Variables

Plus Computed Sulfate and Iron, Plus Automotive Pollutant Variables, One at a Time 1

\begin{tabular}{|c|c|c|c|c|c|c|}
\hline \multicolumn{7}{|c|}{$\begin{array}{l}\text { Coefficient } \pm \text { S.E. (if Variable Enters Stepwise) } \\
\text { (level of significance, }{ }^{2} \text { sample size) }\end{array}$} \\
\hline Data Set $-\cdots \rightarrow-\rightarrow>$ & \multicolumn{3}{|c|}{ Cities With Water Data } & \multicolumn{3}{|c|}{ Al1 Ava1lable Cities } \\
\hline Regression with $\rightarrow$ & Lead & $\mathrm{CO}$ & Ozone & Lead & $\mathrm{CO}$ & Ozone \\
\hline Coefficient for: & & & & & & \\
\hline Computed $\mathrm{SO}_{4}$ & $\begin{array}{c}0.10 \pm 0.02 \\
(0.000, n=159)\end{array}$ & $\begin{array}{l}0.06 \pm 0.26 \\
(0.03, \mathrm{n}=116)\end{array}$ & $\begin{array}{c}0.06 \pm 0.03 \\
(0.024, \mathrm{n}=111)\end{array}$ & $\left(\begin{array}{c}0.11 \pm 0.02 \\
(0.000, n=163)\end{array}\right.$ & $\begin{array}{l}0.05 \pm 0.03 \\
(0.07, \mathrm{n}=119)\end{array}$ & $\begin{array}{c}0.06 \pm 0.03 \\
(0.000, n=114)\end{array}$ \\
\hline $\begin{array}{l}\text { Iron } \\
\text { Automotive } \\
\text { Pollutants: }\end{array}$ & $\begin{array}{c}0.48 \pm 0.10 \\
(0.000, n=159)\end{array}$ & $\begin{array}{c}0.44 \pm 0.11 \\
(0.0001, n=116)\end{array}$ & $(0.52 \pm 0.11$ & $\begin{array}{c}0.46 \pm 0.10 \\
(0.000, n=163)\end{array}$ & $\begin{array}{l}0.46 \neq 0.11 \\
(0.000, n=119)\end{array}$ & $\begin{array}{c}0.46 \pm 0.11 \\
(0.000, n=11)\end{array}$ \\
\hline (1) Lead & $\begin{array}{l}-0.64 \pm 0.22 \\
(0.005, \mathrm{n}=159)\end{array}$ & & & $\left(\begin{array}{c}-0.68 \pm 0.22 \\
(0.002, n=163)\end{array}\right.$ & & \\
\hline $\begin{array}{l}\text { (2) Carbon } \\
\text { Monoxide }\end{array}$ & & $\begin{array}{c}(-) \\
(0.426, n=116)\end{array}$ & & & $(0.493, n=119)$ & \\
\hline (3) Ozone & & & $(0.68, n=111)$ & & & $(0.97, n=114)$ \\
\hline
\end{tabular}

${ }^{1}$ See Table 10 for description of planned stepwise regressions

2 Level of significance $=0.000$ denotes $\mathrm{p}<0.0005$ 
Table 16. Final Model After Residual Evaluation $(n=159)$

Coefficient \pm S.E. Variable (followed by Order of Entry) (level of significance)

$\%$ age 65 or over 1

Birthrate

$\%$ Spanish

$\%$ Black

$\%$ Asian

Smoking (1969)

$\%$ Poverty

$\%$ Long-term Res.

Iron

Computed $\mathrm{SO}_{4}=$
(1)

$$
\begin{array}{rll}
0.699 & \pm 0.028 & (0.0000)^{I} \\
0.21 & \pm 0.02 & (0.0000) \\
-0.04 & \pm 0.007 & (0.0000) \\
0.01 & \pm 0.006 & (0.077) \\
0.05 & \pm 0.04 & (0.12) \\
0.015 & \pm 0.003 & (0.0000) \\
0.04 & \pm 0.02 & (0.072) \\
0.015 & \pm 0.002 & (0.033) \\
0.45 & \pm 0.10 & (0.0000) \\
0.09 & \pm 0.02 & (0.0002)
\end{array}
$$

Constant

$-7.68 \pm 0.95 \quad(0.0000)$

Ad justed $\mathrm{R}^{2}=0.88$

$1_{\text {Level of }}$ significance; 0.000 indicates $p<0.0005$

In all regression of possible subsets, all subsets of $1,2,3 \ldots 21$ independent variables are considered. The optimal subset is that which results in the highest "CP" value, "CP" being a statistic which takes into account the fact that non-nested models are being compaxed. Compared to Table 16, the optimal model resulted in essentially identical estimates for the computed sulfate coefficient $(0.11 \pm 0.02, \mathrm{p}<0.0005)$, a slightly lower coefficient for the iron variable $(0.34 \pm 0.11, \mathrm{p}=0.008)$ and a few different demographic variables. As expected, water hardness entered with a negative coefficient $(-0.0010 \pm 0.0006, \mathrm{p}=0.002)$, as did the percentage of college graduates $(-0.02 \pm 0.01, p=0.004)$. Those variables which were common to both models had essentially the same estimated coefficients as in the planned stepwise regression mode1. These included birthrate $(0.22 \pm 0.02, \mathrm{p}<0.0005)$, percentage age 65 and over $(0.665 \pm 0.03, p<0.0005)$, percentage Asian $(0.07 \pm$ $0.03, p=0.004)$, percentage Spanish $(-0.04 \pm 0.01, p=0.0 .04)$ and percentage below poverty leve1. $(0.048 \pm 0.02, p=0.002)$. The variables $\%$ Black and $\%$ long term residents did not enter. The adjusted $\mathrm{R}^{2}$ value for this optimal model was 0.87 , essentially identical to that of the model resulting from the planned stepwise regressions. We thus concluded that our normal stepwise regression procedures were resulting in near-optimum models.

\subsubsection{Robustness to Demographic Variable Set and Data Set.}

In addition to supporting the hypothesis that conputed $\mathrm{SO}_{4}=$ and iron are reasonable predictors of mortality, the planned regressions and the subsequent "al1 possible subset regression analysis" indicated several other aspects of this data set. It became clear that the demographic variable set which was 
fncluded in the model was partly dependent on the data set (i.e., selection of cities) and the pollutants being studied and that the pollutants selected might depend in turn on the demographic variables chosen. Further analyses supported this finding. For example, whereas the planned analysis of 67 cities with water data, computed $\mathrm{SO}_{4}=$ data, and total particle mass (MTD) data indicated that MTD was not a significant predictor, a subsequent analysis of 53 cities which also had iron data found MTD to be a significant predictor. Iron was not significant, and computed $\mathrm{SO}_{4}=$ was only borderline significant $(\mathrm{p}=0.10)$. Moreover, in this data set, the $\mathrm{SO}_{4}=$ coefficient was estimated at $0.057 \pm$ 0.03 , half the value obtained in all previous analyses. The important point here is that iron was not entered in the model, merely available in the data set, yet we obtained totally different conclusions with respect to the relative importance of the sulfate and particle variables, apparently because of the unique characteristics of this particular set of 53 cities.

\subsubsection{53-City Data Set}

The final model for the 53 cities included variables for water hardness and \% college graduates, which were excluded from the analysis of 159 cities. However, the 53 city model excluded \% Spanish, \% Black and \% at the Poverty Level, variables included in the analysis of 159 cities (having iron, computed $\mathrm{SO}_{4}=$, and water hardness but no data on particle mass). Moreover, this model fit as well as the model which excluded the particle mass variable and included the iron variable. The adjusted $\mathrm{R}^{2}$ was 0.89 as compared to 0.88 for the iron and $\mathrm{SO}_{4}=$ mode1. Thus the discrepancies in the pollutant coefficient estimates obtained in the analyses could be due in part to the selection of different demographic variable sets for the different data sets.

Although the objective of this project is to estimate the effects of air pollution on mortality, we found that the results may be sensitive to both the selection of cities for analysis (i.e., the data set) and the selection of nonpollution variables to "adjust" the mortality rates for demographic and socioeconomic effects (i.e., the demographic variable set or DVS). Often, the avallability of pollution data defines the (maximum) data set, but we have provided enough demographic vartables for any number of DVS's to be selected in a given situation. For the smaller data sets, this is a matter of concern, since it was shown that allowing too wide a choice in stepwise regression can
lead to $\mathrm{R}^{2}$ inflation.

Accordingly, we attempted to define a "best" demographic model for each of the two major data sets of interest, $\mathrm{n}=159$ (water hardness, computed sulfate, and iron) and $n=53$ (the previous variables plus total particle mass), using stepwise regression. To check the robustness of the results, we then crossvalidated the two models, i.e., evaluated the $159 \mathrm{clty}$ DVs with the 53 city data set (Table 17) and vice versa (Table 18).

Two approaches were used to investigate this problem and to obtain a final model. A first approach was to do factor analysis (with VARIMAX rotation) 26 of the demographic variables in the 159 cities with data on computed sulfate, water hardness and iron. Our objective was to reduce this extensive demographic variable set to a smaller set of demographic factors which would not be collinear. The factor analysts was done solely on the 159 city data set, since 
Table 17. Regression Resulta for Demograph1c Model Defined by 159-City Data Set

\begin{tabular}{|c|c|c|c|c|c|c|c|c|c|c|c|c|}
\hline MODEL & $1-1$ & $1-2$ & $1-3$ & $1-4$ & $1-5$ & $1-6$ & $1-7$ & $1-8$ & $1-9$ & $1-10$ & $1-11$ & $l-12$ \\
\hline$z \geq 65$ & $\begin{array}{l}0.699 * \star \\
(.032)\end{array}$ & $\begin{array}{l}0.698^{\star \star} \\
(.033)\end{array}$ & $\begin{array}{l}0.704 * \star \\
(.031)\end{array}$ & $\begin{array}{l}0.790 * * \\
(.068)\end{array}$ & $\begin{array}{l}0.793 * * \\
(.067)\end{array}$ & $\begin{array}{l}0.794 \star \star \\
(.067)\end{array}$ & $\begin{array}{l}0.821 \star \star \\
(.068)\end{array}$ & $\begin{array}{l}0.809 * k \\
(.064)\end{array}$ & $\begin{array}{l}0.829^{\star *} \\
(.065)\end{array}$ & $\begin{array}{l}0.822 \star \star \\
(.068)\end{array}$ & $\begin{array}{l}0.668 * \star \\
(.016)\end{array}$ & $\begin{array}{l}0.544 * * \\
(.012)\end{array}$ \\
\hline $\begin{array}{l}\text { Birth } \\
\text { Rate }\end{array}$ & $\begin{array}{l}0.222^{\star \star} \\
(0.01)^{*}\end{array}$ & $\begin{array}{l}0.223 * \star \\
(0.01)\end{array}$ & $\begin{array}{l}0.216^{\star \star} \\
(0.01)^{2}\end{array}$ & $\begin{array}{l}0.288^{\star \star} \\
(0.01)\end{array}$ & $\begin{array}{l}0.287^{\star \star} \\
(0.01)\end{array}$ & $\begin{array}{l}0.290 * * \\
(0.01)\end{array}$ & $\begin{array}{l}0.288^{\star \star} \\
(0.01)\end{array}$ & $\begin{array}{l}0.294 * * \\
(0.01)\end{array}$ & $\begin{array}{l}0.293 * \star \\
(0.01)\end{array}$ & $\begin{array}{c}0.288 * \star \\
(0.014)\end{array}$ & $\begin{array}{c}0.176 \star \star \\
(0.004)\end{array}$ & $\begin{array}{l}0.158 * * \\
(0.005)\end{array}$ \\
\hline Black & $\begin{array}{r}0.009 \\
(0.01)\end{array}$ & $\begin{array}{r}0.011 \\
(0.01)\end{array}$ & $\begin{array}{r}0.008 \\
(0.01)\end{array}$ & $\begin{array}{r}0.020 \\
(0.01)\end{array}$ & $\begin{array}{l}0.019 \\
(0.01)\end{array}$ & $\begin{array}{r}0.021 \\
(0.01)\end{array}$ & $\begin{array}{r}0.024 \\
(0.01)\end{array}$ & $\begin{array}{c}0.022 \\
(0.01)\end{array}$ & $\begin{array}{r}0.027 \\
(0.01)\end{array}$ & $\begin{array}{c}0.023 \\
(0.014)\end{array}$ & $\begin{array}{c}0.006 \\
(0.004)\end{array}$ & $\begin{array}{c}0.004 \\
(0.005)\end{array}$ \\
\hline $\begin{array}{l}1969-80 \\
\text { Smoking }\end{array}$ & $\begin{array}{c}0.012 \star \star \\
(0.00)\end{array}$ & $\left\{\begin{array}{l}0.011 * * \\
(0.00)\end{array}\right.$ & $\begin{array}{c}0.016 * * \\
(0.003)\end{array}$ & $\begin{array}{r}0.015 * \\
(0.005)\end{array}$ & $\begin{array}{l}0.015^{\star} \\
(0.01)\end{array}$ & $\begin{array}{l}0.015 * \\
(0.01)^{*}\end{array}$ & $\begin{array}{l}0.017 \star \\
(0.005)\end{array}$ & $(0.015 *$ & $\begin{array}{c}0.017 \star \star \\
(0.005)\end{array}$ & $\begin{array}{c}0.017 * * \\
(0.004)\end{array}$ & $\begin{array}{c}0.008 * \\
(0.002)\end{array}$ & $\begin{array}{c}0.004 \\
(0.003)\end{array}$ \\
\hline ¿ College & $\begin{array}{l}m 0.009 \\
(0.01)\end{array}$ & $\begin{array}{l}m 0.017 \\
(0.01)\end{array}$ & $\begin{array}{l}-0.021 * \\
(0.01)\end{array}$ & $\begin{array}{l}-0.061^{\star} \\
(0.03)\end{array}$ & $\begin{array}{l}-0.065 * \\
(0.03)\end{array}$ & $\begin{array}{l}-0.061 \star \\
(0.03)\end{array}$ & $\begin{array}{l}-0.076^{\star} \\
(0.03)\end{array}$ & $\begin{array}{l}-0.071^{*} \\
(0.024)\end{array}$ & $\begin{array}{l}-0.077^{\star} \\
(0.03)\end{array}$ & $\begin{array}{l}-0.078 * \\
(0.03)\end{array}$ & $\begin{array}{l}-0.020 * \\
(0.007)\end{array}$ & $\begin{array}{l}-0.019 * \\
(0.006)\end{array}$ \\
\hline $\begin{array}{l}\text { Pop. } \\
\text { Dengity }\end{array}$ & $\begin{array}{c}0.004 \\
(0.002)\end{array}$ & $\begin{array}{c}0.003 \\
(0.002)\end{array}$ & $\begin{array}{c}0.007 * \\
(0.003)\end{array}$ & $\begin{array}{c}0.007 \\
(0.004)\end{array}$ & $\begin{array}{c}0.006 \\
(0.004)\end{array}$ & $\begin{array}{c}0.007 \\
(0.004)\end{array}$ & $\begin{array}{c}0.007 \\
(0.004)\end{array}$ & $\begin{array}{c}0.006 \\
(0.004)\end{array}$ & $\begin{array}{c}0.007 \\
(0.004)\end{array}$ & $\begin{array}{c}0.006 \\
(0.004)\end{array}$ & $\begin{array}{l}-0.0001 \\
(0.001)\end{array}$ & $\begin{array}{r}0.004 \star \\
(0.002)\end{array}$ \\
\hline * Spantsh & $\begin{array}{l}-0.042 * \star \\
(0.01)\end{array}$ & $\begin{array}{l}-0.037 * * \\
(0.01)\end{array}$ & $\begin{array}{l}-0.051 * \star \\
(0.01)\end{array}$ & $\begin{array}{l}m 0.022 \\
(0.02)\end{array}$ & $\begin{array}{l}-0.02 \\
(0.02)\end{array}$ & $\begin{array}{l}-0.02 \\
(0.02)\end{array}$ & $\begin{array}{l}-0.02 \\
(0.02)\end{array}$ & $\begin{array}{l}-0.016 \\
(0.02)\end{array}$ & $\begin{array}{l}-0.078 \\
(0.02)\end{array}$ & $\begin{array}{l}-0.019 \\
(0.02)\end{array}$ & $\begin{array}{l}-0.03 * \star \\
(0.006)\end{array}$ & $\begin{array}{l}-0.029 * \\
(0.006)\end{array}$ \\
\hline$\%$ Poor & $\begin{array}{r}0.029 \\
(0.02)\end{array}$ & $\begin{array}{r}0.018 \\
(0.02)\end{array}$ & $\begin{array}{l}0.050^{\star} \\
(0.02)\end{array}$ & $\begin{array}{l}-0.051 \\
(0.05)\end{array}$ & $\begin{array}{l}-0.051 \\
(0.05)\end{array}$ & $\begin{array}{l}-0.055 \\
(0.05)\end{array}$ & $\begin{array}{r}0.009 \\
(0.02)\end{array}$ & $\begin{array}{l}-0.064 \\
(0.05)\end{array}$ & $\begin{array}{l}-0.050 \\
(0.05)\end{array}$ & $\begin{array}{l}-0.043 \\
(0.05)\end{array}$ & $\begin{array}{l}0.055^{\star \star} \\
(0.01)\end{array}$ & $\begin{array}{l}0.046 \star \star \\
(0.01)\end{array}$ \\
\hline $\begin{array}{l}\text { Computed } \\
\mathrm{SO}_{4}=\end{array}$ & $\begin{array}{l}0.093 * * \\
(0.02)\end{array}$ & $\begin{array}{l}0.104 * \star \\
(0.02)\end{array}$ & $x$ & $\begin{array}{l}0.068 \\
(0.04)\end{array}$ & $\begin{array}{r}0.067 \\
(0.04)\end{array}$ & $\begin{array}{r}0.070 \\
(0.04)\end{array}$ & $\mathrm{x}$ & $\begin{array}{r}0.070 \\
(0.04)\end{array}$ & $x$ & $x$ & $\begin{array}{l}0.130 \star \star \\
(0.02)\end{array}$ & $\begin{array}{l}0.126 * * \\
(0.02)\end{array}$ \\
\hline Iron & $\left\{\begin{array}{l}0.376^{\star \star} \\
(0.11)^{*}\end{array}\right.$ & $x$ & $\begin{array}{l}0.429 \star \star \\
(0.11)\end{array}$ & $\begin{array}{r}0.100 \\
(0.22)\end{array}$ & $x$ & $\begin{array}{r}0.147 \\
(0.77)\end{array}$ & $\begin{array}{r}0.073 \\
(0.23)\end{array}$ & $X$ & $\begin{array}{r}0.151 \\
(0.18)\end{array}$ & $\mathrm{X}$ & $\mathrm{X}$ & $X$ \\
\hline $\begin{array}{l}\text { Total } \\
\text { Particle } \\
\text { Mass }\end{array}$ & $\mathrm{x}$ & $x$ & $X$ & $\begin{array}{r}0.005 \\
(0.02)\end{array}$ & $\begin{array}{c}0.010 \\
(0.01)\end{array}$ & $x$ & $\begin{array}{r}0.009 \\
(0.02)\end{array}$ & $\mathrm{X}$ & $x$ & $\begin{array}{r}0.013 \\
(0.01)\end{array}$ & $x$ & $\mathrm{X}$ \\
\hline Ady. $R^{2}$ & $\begin{array}{l}0.88 \\
159\end{array}$ & $\begin{array}{l}0.87 \\
159\end{array}$ & $\begin{array}{l}0.86 \\
159\end{array}$ & $\begin{array}{r}0.87 \\
53\end{array}$ & $\begin{array}{r}0.88 \\
53\end{array}$ & $\begin{array}{r}0.88 \\
53\end{array}$ & $\begin{array}{r}0.87 \\
53\end{array}$ & $\begin{array}{r}0.88 \\
53\end{array}$ & $\begin{array}{r}0.87 \\
53\end{array}$ & $\begin{array}{r}0.87 \\
53\end{array}$ & $\begin{array}{l}0.86 \\
418\end{array}$ & $\begin{array}{l}0.80 \\
872\end{array}$ \\
\hline
\end{tabular}


Table 18. Regression Results for Demographte Model Defined by 53-C1ty Data Set

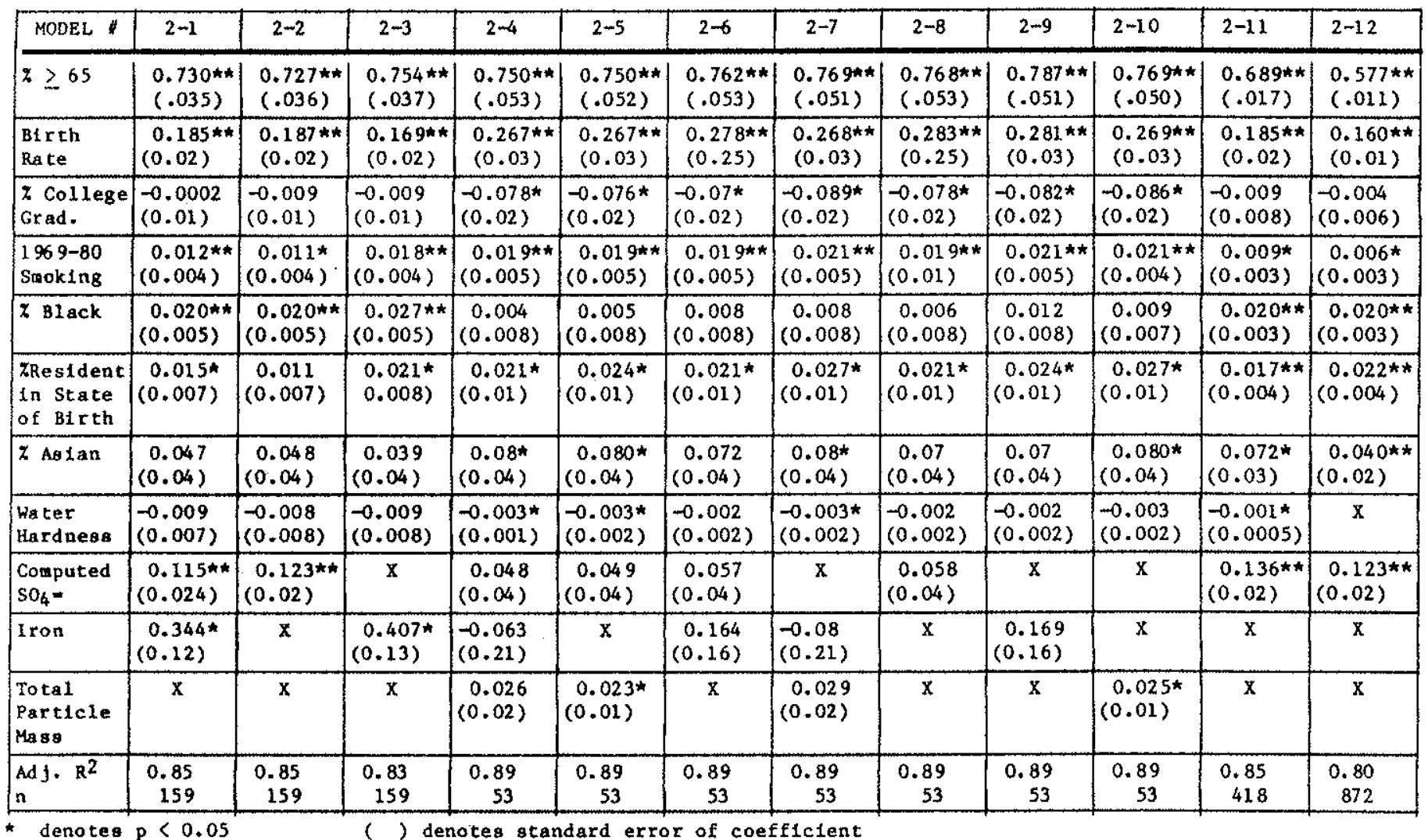

* denotes $p \leq 0.05$

** denotes $p \leq 0.001$

( ) denotes standard error of coefficient

$X$ denotes variable not entered 
the 53 city data set is too small (the number of observations divided by the number of variables was well below the rule of thumb value of 5). This was followed by stepwise regression of the demographic factors plus water hardness, the average smoking variable, iron and computed $\mathrm{SO}_{4}=$. The results are given in Table 19. The first factor, which accounted for the largest proportion of the variance, loaded highest on the ratio of males to females, the percentage of long term residents, the percentage of Asians, the percentage of college graduates, and $\log$ of the population. This factor entered stepwise in the analysis done without the pollutants and had a significant negative coefficient in the forced entry regression which included iron, computed sulfate and hardness as wel1 as the significant demographic factors. The second factor, which loaded highest on density, population change since 1970, and percentage over the age of 65 , also was a significant predictor of mortality, with a positive coefficient. The fourth factor, percentage Spanish and Birthrate, was also a significant positive predictor. The third factor, percentage black and percentage below the poverty level, was not a significant predictor, nor was the fifth (percentage of gas heating degree days and percentage of fuel heating degree days). If we use adjusted $\mathrm{R}^{2}$ as a criterion, the factor model does not fit these data as well as

Table 19. Regression Results for Demographic Factor Model

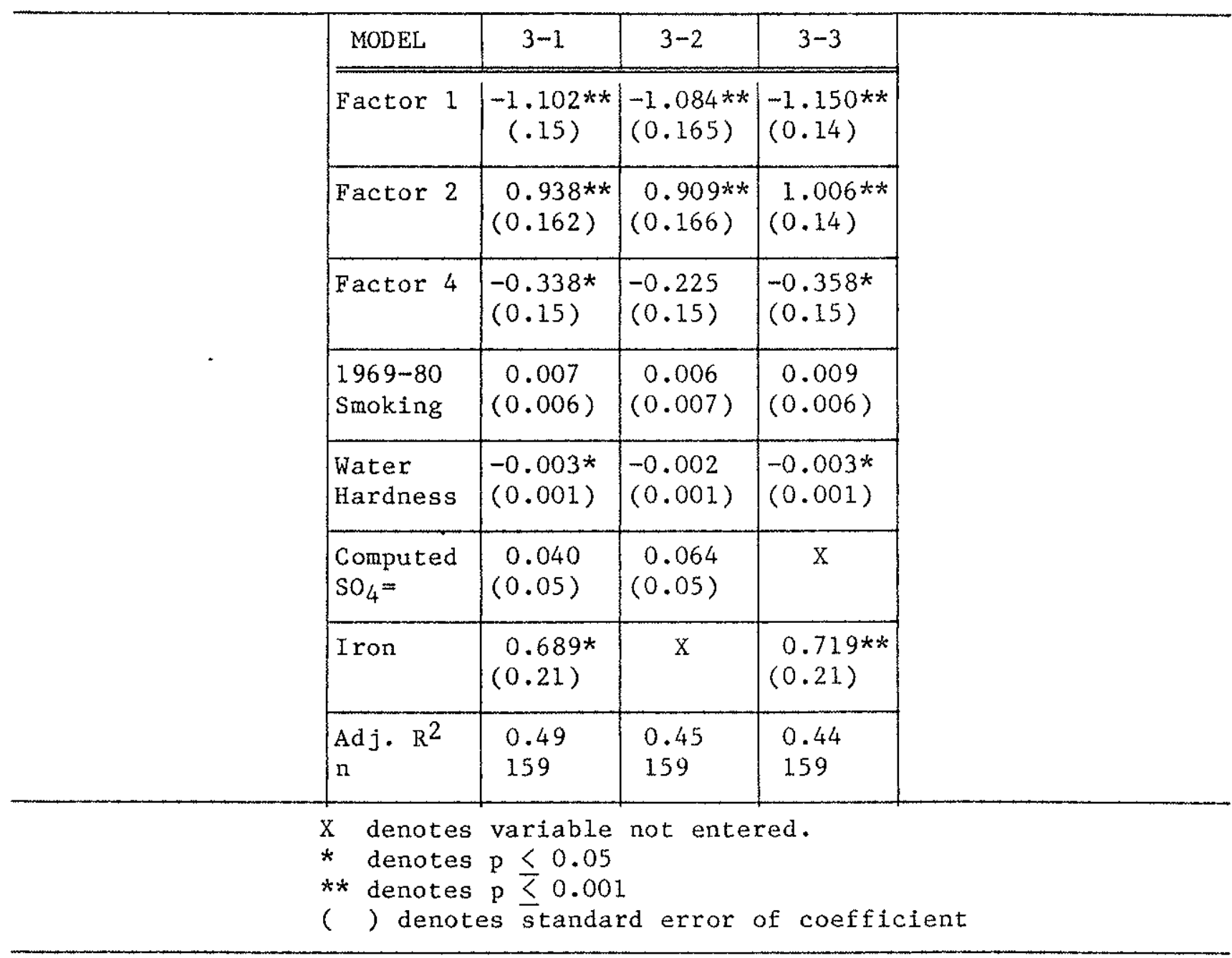


the models which use the individual demographic variables. The adjusted $\mathrm{R}^{2}$ is 0.49 for the model using factors, compared to 0.85 for most models using the demographic variables themselves. This is likely due to the fact that factor model does not fit the individual variables perfectly and thus has a greater error of measurement than the variables per se. On the other hand, the factor analysis model is the more appropriate in the case of many collinear variables and it is likely to be more robust when a large number of predictor variables must be considered relative to the number of cities. For this reason we should note carefully that only iron appears to be a significant pollutant in the factor model, that the sulfate coefficlent is greatly reduced and nonsignificant both with and without the inclusion of the iron variable.

\subsubsection{Additional Demographic Variables}

While factor analysis is considered as a direct method of variable reduction, it yielded a model with much lower predictive power (lower $\mathrm{R}^{2}$ ). Thus a second approach was to obtain two other demographic variable sets (DVS) through stepwise regression and to use these DVS in forced entry regression in severaI data sets defined by pollutant and availability of data on water hardness. The first DVS was obtained by doing stepwise regression of all demographic variables in the 159 cities having computed $\mathrm{SO}_{4}=$, iron, and water hardness data and is referred to as the 159 City Demographic Variable Set (or 159 CDVS) (Table 17). The second DVS was obtained by stepwise regression of all demographic variables in the 53 cities having data on computed $\mathrm{SO}_{4}=$, iron, and total particle mass and hence is referred to as the 53 city DVS (Table 18). After obtaining these CDVS, regressions with forced entry of the two DVS plus computed $\mathrm{SO}_{4}=$, iron, total particle mass, water hardness mass, and average smoking were done on the several data sets depending on their availablillty. The data sets considered were:

(1) the 53 city data set having values for total particle mass, computed $\mathrm{SO}_{4}=$, iron, and water hardness,

(2) the 159 city data set with values for iron plus computed $\mathrm{SO}_{4}=$ plus water hardness, $(n=418)$.

3) the city data set having values for computed $\mathrm{SO}_{4}=$ plus water hardness,

(4) the city data set having data on MTD, computed $\mathrm{SO}_{4}$, and iron,

(5) the city data set having information on iron plus computed $\mathrm{SO}_{4}=$,

(6) the city data set having information on computed $\mathrm{SO}_{4}=$.

Tables 17 and 18 show that the coefficients for the demographic variables depend greatly on the data set. The pollutant coefficients depend to some extent on the DVS but to a greater extent on the data set. In any case all models fit equally well from the vantage point of $\mathrm{R}^{2}$. In the case where the 159 city demographic variable set is considered, the sulfate variable is significant at the 0.05 level in all data sets but the 53 city data set (in which particles are considered) and the estimate ranges from 0.067 to 0.104 . Where the 53 CDVS 
is used the computed sulfate coefficient is again significant in all data sets except the 53 city data set. The particle mass variable is significant only in the 53 city data set and only in the case where the 53 city demographic variable set is used.

\subsection{INVESTIGATION OF RESIDUALS FOR INFLUENTIAL OBSERVATIONS AND VIOLATION OF REGRESSION ASSUMPTIONS}

The residual analyses described in this section were done for two data sets for two models. The models considered were (1) the model obtalned using the 159 cities having data on computed sulfate, hardness and iron plus the 159 city demographic variable set, and (2) the model obtained using the 53 cities having data on computed sulfate, iron, Total Particle Mass (MTD) Dichotomized, and hardness. These models are given then in Table 17 as Model $1-1$ and in Table 18 as Model 2-5. The residuals were evaluated through identification of outliers, tests of homogeneity of mean and variance, and tests for spatial autocorrelation. Tests for linearity with respect to the sulfate variable were also done and we also to determined whether transformation of the mortality variable would produce a better model.

The residual plots were inspected visually for outliers. The following statistics were calculated for each city: (1) the standardized residual, (2) the standardized deleted residual, (3) Mahalanobis Distance. 26 The first two statistics evaluate the residual for a given city, the first being the residual divided by the standard error of the estimate and the second being the residual on deleting the city, and recalculating the coefficients. The third statistic measures the extent to which the vector of measures for the independent variables is an outlier, and hence the extent to which the city might be an influential observation. On plotting these values and, in the case of standardized residuals, taking into account the fact that there were 159 cities, only one city (Bakersfield, CA) appeared to be an outlier with respect to lack of fit. This city also appeared to be an influential observation. Deletion of this city from the 159 city data set slightly lowered the sulfate coefficient (from $0.09 \pm 0.02$ to $0.06 \pm 0.02$ ), but also reduced the birthrate coefficient considerably (from $0.22 \pm 0.02$ to $0.15 \pm 0.02$ ). Deletion of Bakersfield did not seem to affect the results in the 53 data set. Deletion of the city with the second highest deleted residual and the second highest distance value had no effects in either data set.

The normality of the residuals was evaluated by computation of the coefficient of skewness and kurtosis. These were non significant for the 53 city residuals (skewness $=-0.29$, kurtosis $=3.54$ ) and non significant after deletion of the Bakersfield residual from the 159 city data set (skewness $=0.23$, kurtosis $=3.06$ ).

The assumption that the mean residual equalled 0.0 and the variance was constant was tested by grouping the cities with respect to the each of the following variables: (1) region, (2) the value of computed $\mathrm{SO}_{4}=$, (3) the value of the iron variable, and (4) the mortality value predicted by the model $(\hat{y})$. For each list of these variables, analyses of variance of the residuals were done, $95 \%$ confidence interval estimates of the mean residual were obtained, and a Bartlett test for homogeneity of variance was done. In every 
case the analysis of variance indicated equality of the mean residual with respect to the variable being considered. In Figure 11 we plot the $95 \%$ confidence intervals obtained for the 5 groups defined for each of the above mentioned variables in the 158 cities. With the exception of values of $y$ in the interval from 4.4 to 7.0 , the mean residual equals zero. Hence we conclude that at worst we have very slight evidence that the model for the 158 cities underestimates mortality. The Bartlett test for homogenefty of variance was significant $(0.02)$ with respect to region indicating that the model might have slightly better precision as a predictor for cities in the north central and southern ( $s$ tandard deviation $=s=0.62, n=55$ north central cities; $s=0.66$, $\mathrm{n}=47$ southern cities), intermediate precision in the northeast cities ( $\mathrm{s}=$ $0.8, \mathrm{n}=28$ ) and the worst precision for the western cittes $(\mathrm{s}=0.99, \mathrm{n}=28$ cities). However, these estimates are all inversely proportional to the size of the sample from each region and hence we do not read too much into this calculation. A similar explanation cannot be given for the observation of borderline heteroscedasticity with respect to the value of $y$. The standard deviation of the residuals is lowest $(s=0.49$ as compared to $0.63,0.67$, and 0.93) in the 11 cities having the lowest predicted values. The precision of the model appears to be completely independent of the value of the sulfate variable $(p=0.16)$ and of the value of the iron variable $p=0.26)$ indicating that the dependence on $y$ must reflect variability in precision with respect to some demographic variable. Similar investigations were done for the $53 \mathrm{city}$ data set after grouping the citles with respect to each of the following variables: (1) region, (2) the predicted value, $y$, (3) the value of total particle mass MTD, and (4) the value of the computed sulfate (Figure 12). In this case the Bartlett test was always nonsignificant as were the the four tests of equality of mean residual. However, this could result simply from our having lower power to detect departures from the regression assumptions with only 53 values.

A test for linearity with respect to the sulfate variable was done for the 159 city model in the 158 city data set (less Bakersfield, CA). We tested the Iinearity of the relation between $Y_{1}$, mortality for the ith city, adjusted for all independent variables but the sulfate variable and $x_{i}{ }^{\prime}$, the ith cities sulfate value after adjusting for all other predictor variables. The cities were grouped with respect to their value of adjusted sulfate value by dividing the range of $X^{\prime}$ into 5 intervals of equal width (Figure 13). We then did an analysis of variance of the five means and partitioned the sum of squares between groups to estimate the mean squared error due to deviations from Iinearlty. On comparing this term to the mean square error within groups, we conclude that there is no evidence of nonlinearity $(F(3,153)=0.38, p=0.91)$.

The Bartlett test cited above indicated that some power transform of the mortality itself might result in a model with homogeneity of variance. Therefore, the Box-Cox approach was used to determine the optimal power transformation which would stablize the residual variance so that it was uncorrelated with the mean predicted value. The estimated power transform was 0.5 for the 159 city data set and 0.1 for the 53 city data set indicating that the square root of mortality might be a better dependent variable than mortality itself in the first case and the tenth root, or the log of mortality might be more appropriate dependent variables. 

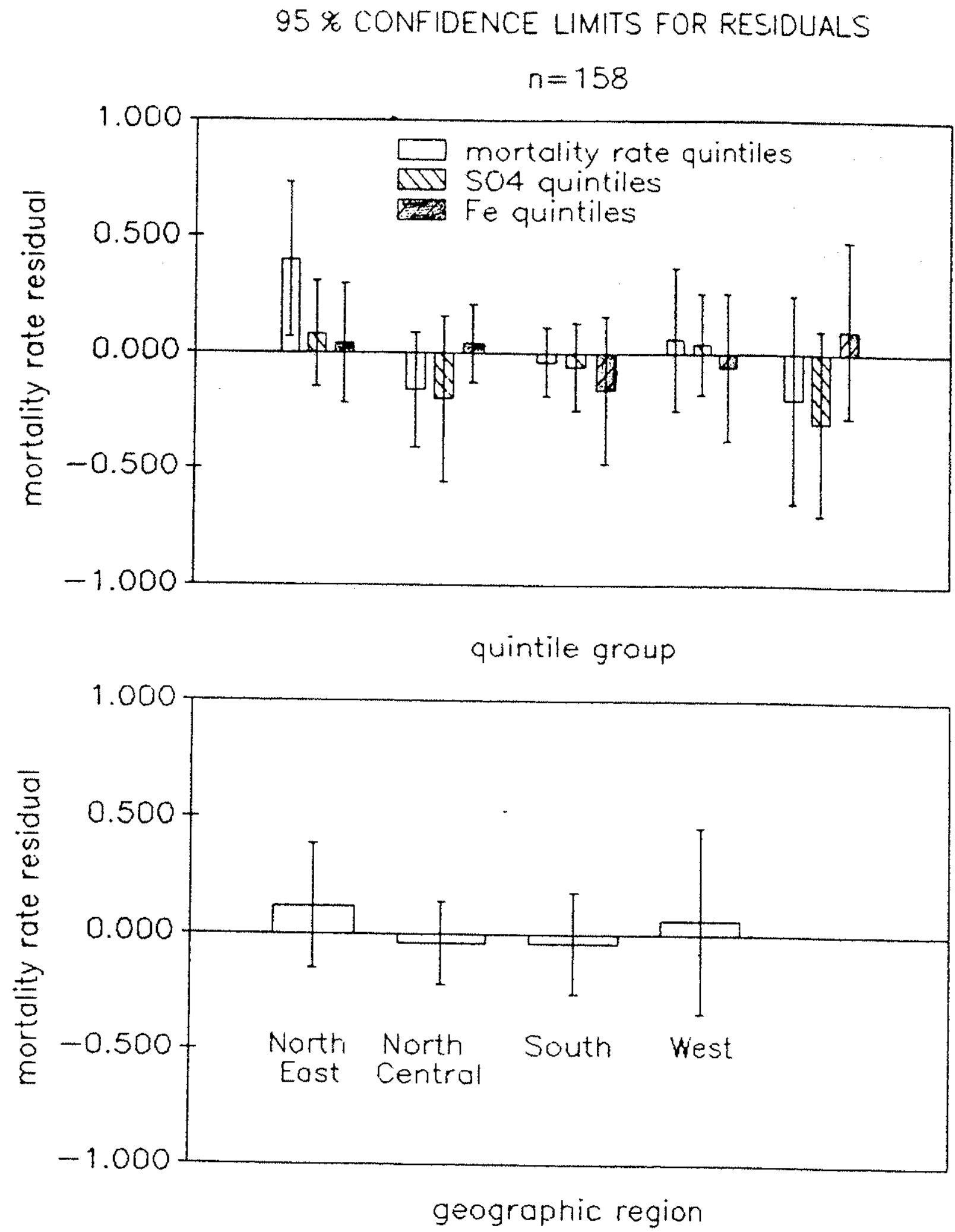

Figure 11. $95 \%$ confidence limits for regression residuals $(n=158)$. 
$95 \%$ CONFIDENCE LIMITS FOR RESIDUALS

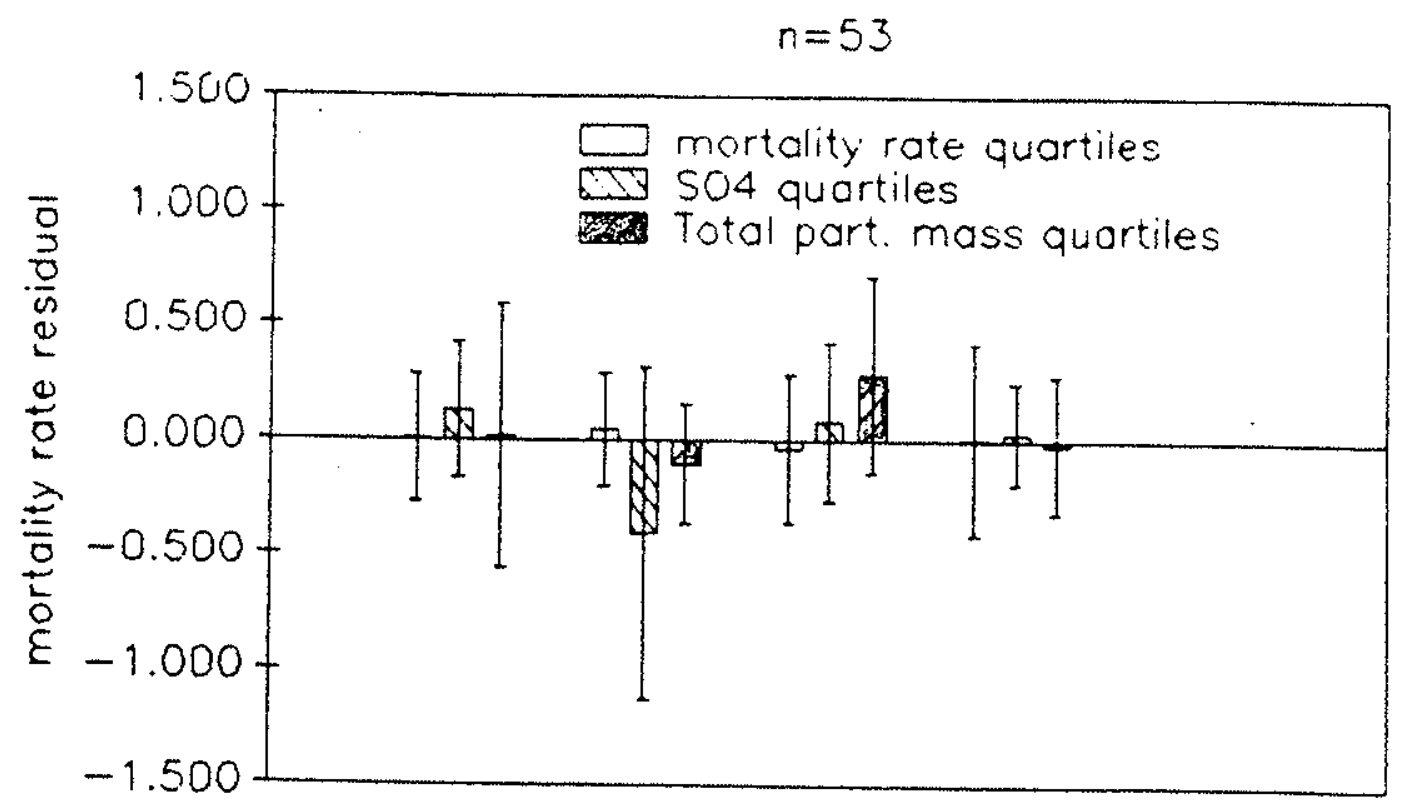

quortile group

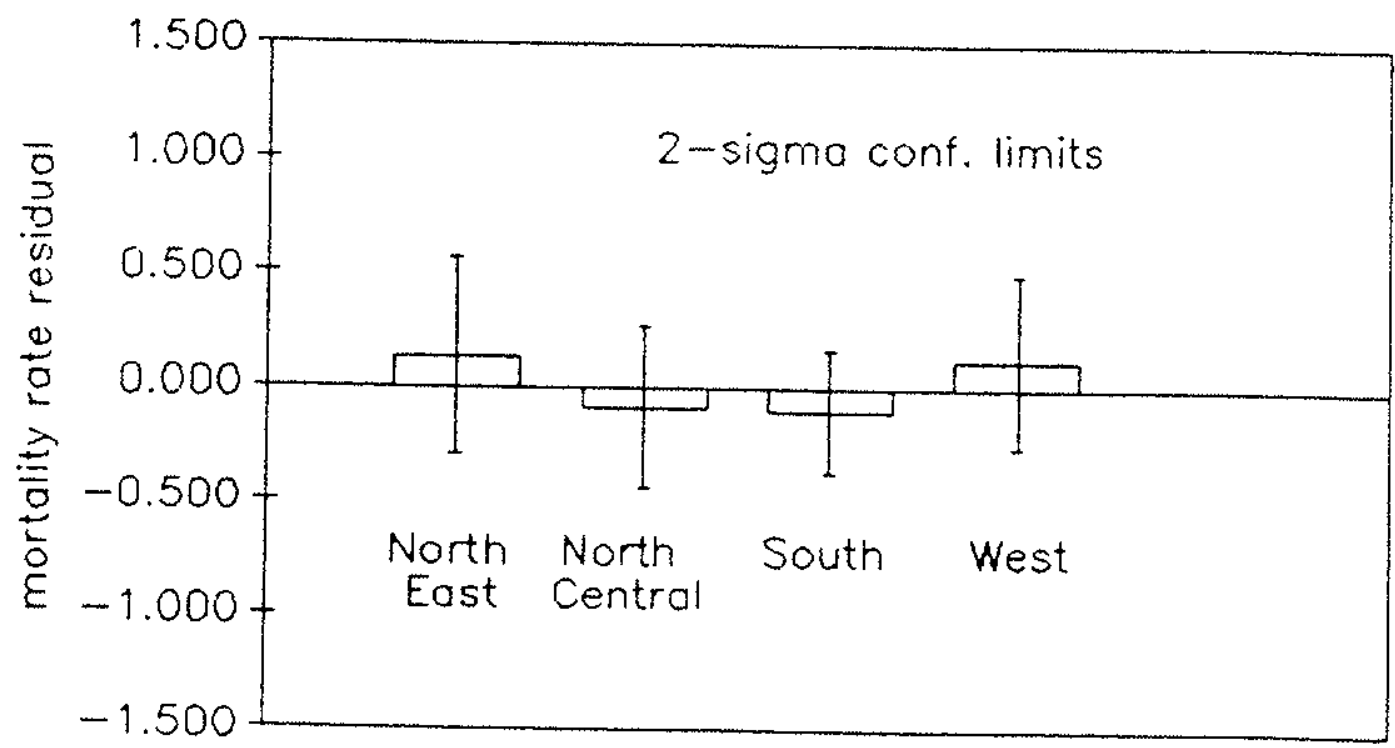

geographic region

Figure 12 . $95 \%$ confidence 1 imits for regression residuals $(n=53)$. 


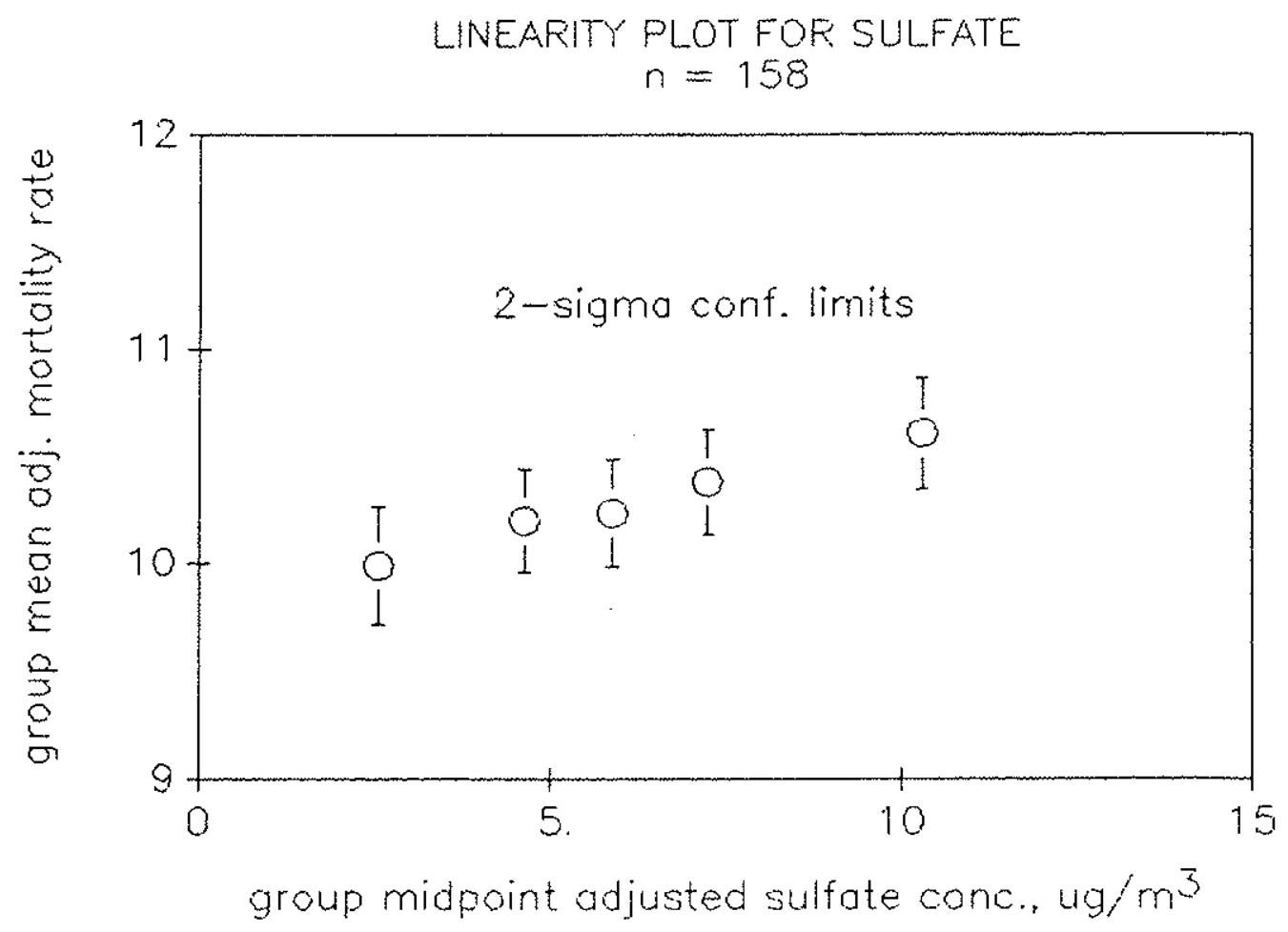

Figure 13. Linearity plot for sulfate $(\mathrm{n}=158)$. 


\subsection{CONSIDERATION OF SPATIAL AUTOCORRELATION}

Least squares models of the type considered here assume that the data are generated by adding a normally distributed error term to a linear combination of predictors. At each point measured, the error term is assumed to be independent of, and distributed indentically to, the error terms at all other points. If this assumption is not met, the least squares estimation method may not be appropriate. Under the model, the residuals are estimates of the error terms. We can therefore get some idea of whether the least squares assumptions are met by inspecting the residuals which should have little or no systematic behavior when plotted against the predictors (Figures 11 and 12). In addition, there should be no spatial pattern to the residuals. This last requirement may be tested by inspecting the spatial autocorrelation of the residuals. Spatial autocorrelation may be thought of as a measure of the similarity between residuals as a function of their geographic distance. Cliff and ord 27 give a method suitable for testing for spatial autocorrelation in a set of least squares residuals which is a generalization of the we11-known Durbin-Watson test for autocorrelation of residuals in time series data.

Models I-1 to 1-3 (Table 17) were evaluated* using the C1iff and ord procedures, in addition to a regression employing the same demographic predictors but no air pollution variables. Spatial autocorrelation was not significant for any of the four models $(\mathrm{p}=0.6-0.8)$; that is, spatial autocorrelation is not present regardless of whether air pollution is used as a predictor variable.

\footnotetext{
* Analysis courtesy of Dr. Neal Oden, Brookhaven National Laboratory.
} 


\subsection{COMPARISON OF 1970 TO 1980: CROSS VALIDATION AND EVALUATYON OF LAG EFFECTS OF THE SULFATE VARIABLE}

\subsection{COMPARISON OF 1970 TO 1980 DATA AND MODELS}

1970 data* were available for 122 of the 159 cities defined above. In Table 20 we list the variables for which the 1970 measures correspond to the 1980 measures. In the second column we give the estimated coefficient using the 1980 value to predict 1980 mortality in this data set and in the third column, the estimated coefficient on using the 1970 value to predict 1970 mortality. The sulfate, manganese, birthrate, nonwhite and $\log$ population density coefficients appear to increase in absolute value while the iron, $\%$ over $65, \%$ college, $\%$ poor, smoking and hardness coefficients appear to have decreased in absolute value. Of these, particular attention should be pald to the sulfate coefficient which was not a significant predictor in 1970 but became significant in 1980, and to the birthrate coefficient, which appears to have increased. Simple $t$ tests to compare these coefficients, which ignore the correlation between the estimates, indicate that only the change in the poverty coefficient is significant. This conclusion results in part from the relatively large standard errors in 1970.

Table 20. Results of Cross Validation Study: Coefficients Obtained for 122 cities having Pollution Data for 1970 and $1980 \quad(n=122)$

\begin{tabular}{l|cc|cc}
\hline \multirow{2}{*}{ Variable } & \multicolumn{3}{|c}{ Coefficent \pm SE $(p)$} \\
\cline { 2 - 5 } & \multicolumn{3}{|c|}{1.980 Data Set } & \multicolumn{1}{c}{1970 Data Set } \\
\hline $\mathrm{SO}_{4}=$ & $0.053 \pm 0.03$ & $(0.06)$ & $0.007 \pm 0.03$ & $(0.80)$ \\
$\mathrm{Fe}$ & $0.053 \pm 0.10$ & $(0.78)$ & $0.168 \pm 0.09$ & $(0.05)$ \\
$\mathrm{Mn}$ & $2.90 \pm 5.07$ & $(0.57)$ & $1.6 \pm 1.17$ & $(0.28)$ \\
$\%>65$ & $0.740 \pm 0.03$ & $(0.000)$ & $0.774 \pm 0.03$ & $(0.000)$ \\
$\mathrm{Bixth}$ rate & $0.147 \pm 0.02$ & $(0.000)$ & $0.101 \pm 0.03$ & $(0.002)$ \\
$\%$ College & $-0.029 \pm 0.01$ & $(0.05)$ & $-0.052 \pm 0.02$ & $(0.015)$ \\
$\%$ Poor & $0.019 \pm 0.02$ & $(0.41)$ & $0.134 \pm 0.04$ & $(0.0001)$ \\
Non-White & $0.022 \pm 0.01$ & $(0.001)$ & $0.014 \pm 0.01$ & $(0.11)$ \\
Log Pop. Density & $0.081 \pm 0.28$ & $(0.77)$ & $0.061 \pm 0.13$ & $(0.64)$ \\
Smoking & $0.008 \pm 0.002$ & $(0.005)$ & $0.009 \pm 0.003$ & $(0.006)$ \\
Water Hardness & $-0.0006 \pm 0.0008$ & $(0.39)$ & $-0.001 \pm 0.0008$ & $(0.18)$ \\
\hline Constant & $-3.86 \pm 1.19$ & $(0.002)$ & $-2.46 \pm 17$ & $(0.038)$ \\
Adj. R & 0.88 & & 0.88 & \\
\hline p = level of statistica1 significance & & & \\
\hline
\end{tabular}

*1969 mortality data with demographic data from the 1970 Census and measured air quality data from 1969-71, taken from Lipfert. 6 
To test a general hypothesis that the set of coefficients has not changed, we regressed the change in mortality rate (1980 minus 1970, see Table 21) on the change in each independent variable (for all variables but water hardness, which did not change) plus the 1980 values. This is done because the coefficients of the 1980 value estimate the difference in the coefficient (1970-1980) as follows:

Let $Y_{j, 1980}$ denote the mortality for city $j$ in $1980, B_{i, 1980}$ the

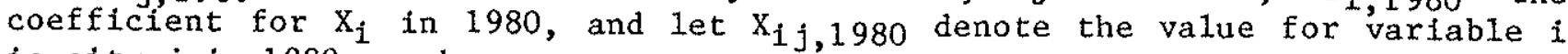
in city $j$ in 1980 , we have

$$
Y_{j, 1980}=a_{1980}+B_{i, 1980} X_{i j, 1980}+e_{i j, 1980}
$$

Similarly, we define $Y_{j, 1970,} B_{1,1970}$ and $X_{i j, 1970}$ and note that

$$
Y_{j, 1970}=a_{1970}+B_{1970} X_{i j, 1970}+e_{i j, 1970}
$$

We can then define for all variables where $C_{i}=B_{11980}-B_{i 1980}$ and $A=a_{1980}-a_{1970:}$

$$
\mathrm{X}_{j, 1980}=A+\mathrm{a}_{1970}+\left(B_{i, 1970}+\mathrm{C}_{i}\right) \mathrm{X}_{1 j, 1980}+\mathrm{e}_{j, 1980}
$$

Subtracting (2) from (3) and setting $D_{j}=Y_{j, 1980}-Y_{j, 1970}$, and $D X_{i j}=X_{1 j, 1980}-X_{i j, 1970}$, we obtain

$$
D j=A+C_{i} X_{i j, 1980}+B_{i, 1970} D X_{i j}+\left(e_{j, 1980}-e_{j, 1970}\right)
$$

Thus to test the hypothesis that there has been no change in the regression coefficlents, we first regress change in mortality versus DX, the change in the values of the independent variable and then regress change in mortality versus the 1980 values plus the changes in the independent variable. In the case of hardness we have $D X_{i j}=0$ and hence no $D X_{i j}$ variable in the first regression. We then test the significance of the $C_{i}$ terms in the usual manner. On doing this we obtain $F(11,100)=1.7$, and $0.10>p>0.05$, borderline significance for the 159 city data set. Inspection of the appropriate terms indicates a significant change in the poverty coefficient $(p=0.04)$ and borderline signiffcance for the percentage over age $65(\mathrm{p}=0.07)$.

In Table 22 we show simflar results from including only cities having total particle mass data as well as data on sulfate, iron, and water hardness. In general, by inspection one can see very little change in the coefficients. This is substantiated through t-tests comparing the individual coefficients and through the above described analysis, in which the set of coefficients which measure change in the coefficients from 1970 to 1980 contribute little to the prediction of change in mortality.

\subsection{CROSS-VALIDATION WITH A 10-YEAR LAG}

Just as 1969 cigarette smoking was shown to be an acceptable, if not better, predictor for 1980 mortality than 1980 smoking, it is possible that 1970 pollution might similarly be a better predictor than 1980 data. As a check, the 1980 cross-validation model was evaluated with 1970 values for 
Table 21. Mean Values for 122 Cities in 1980 and 1970

\begin{tabular}{|c|c|c|c|}
\hline Title & 1980 & 1970 & Difference \\
\hline $\begin{array}{l}\text { Mortality rate (deaths } / 1000) \\
\mathrm{Log} \text { pop. density } \\
\% \geq 65 \\
\% \text { poor } \\
\% \text { college } \\
\mathrm{Birth} \text { rate (births } / 1000) \\
\mathrm{SO}_{4}=\left(\mu \mathrm{g} / \mathrm{m}^{3}\right) \\
\text { Total particle mass }\left(\mu \mathrm{g} / \mathrm{m}^{3}\right) \\
\mathrm{Fe}\left(\mu \mathrm{g} / \mathrm{m}^{3}\right) \\
\mathrm{Mn}\left(\mu \mathrm{g} / \mathrm{m}^{3}\right) \\
\text { Smoking (packs/person } \mathrm{yr})\end{array}$ & $\begin{array}{r}10.37 \\
1.55 \\
12.56 \\
15.61 \\
16.5 \\
17.8 \\
6.1 \\
37.1 \\
1.044 \\
0.035 \\
187\end{array}$ & $\begin{array}{r}11.15 \\
1.39 \\
10.98 \\
10.43 \\
10.9 \\
19.1 \\
8.95 \\
88.4 \\
2.040 \\
0.080 \\
192\end{array}$ & $\begin{array}{r}-0.78 \\
0.15 \\
1.59 \\
5.22 \\
5.6 \\
-1.27 \\
-2.86 \\
-57.6 \\
-0.991 \\
-0.045 \\
-4.7\end{array}$ \\
\hline
\end{tabular}

Table 22. Cross Validation Results for 1980 and 1970

(50 cities having particle mass data)

\begin{tabular}{l|cl|cl}
\hline Variable & \multicolumn{2}{|c|}{1980 Data Set } & \multicolumn{2}{c}{1970 Data Set } \\
\hline $\mathrm{SO}_{4}$ & $0.032 \pm 0.04$ & $(0.40)^{\mathrm{a}}$ & $-0.054 \pm 0.04$ & $(0.23)$ \\
Total particle mass & $0.018 \pm 0.014$ & $(0.21)$ & $0.002 \pm 0.009$ & $(0.85)$ \\
$\mathrm{Fe}$ & $-0.112 \pm 0.32$ & $(0.73)$ & $-0.017 \pm 0.13$ & $(0.90)$ \\
$\mathrm{Mn}$ & $-2.28 \pm 8.50$ & $(0.79)$ & $4.64 \pm 1.8$ & $(0.01)$ \\
$\%>65$ & $0.715 \pm 0.05$ & $(0.00)$ & $0.715 \pm 0.05$ & $(0.000)$ \\
$\mathrm{Bi}$ rth rate & $0.154 \pm 0.04$ & $(0.002)$ & $0.166 \pm 0.05$ & $(0.002)$ \\
$\%$ College & $0.07 \pm 0.03$ & $(0.013)$ & $0.064 \pm 0.04$ & $(0.10)$ \\
$\%$ Poor & $-0.011 \pm 0.05$ & $(0.80)$ & $0.094 \pm 0.05$ & $(0.07)$ \\
Non-White & $0.018 \pm 0.01$ & $(0.14)$ & $0.019 \pm 0.01$ & $(0.12)$ \\
Log Pop. Density & $0.65 \pm 0.38$ & $(0.095)$ & $0.18 \pm 0.21$ & $(0.36)$ \\
Smoking & $0.010 \pm 0.004$ & $(0.03)$ & $0.011 \pm 0.004$ & $(0.008)$ \\
Watex Hardness & $-0.002 \pm 0.001$ & $(0.18)$ & $-0.003 \pm 0.002$ & $(0.08)$ \\
\hline Constant & $-3.845 \pm 1.85$ & $(0.045)$ & $-2.543 \pm 1.75$ & $(0.154)$ \\
Adjusted R & 0.89 & & 0.89 & \\
\hline
\end{tabular}

${ }^{a}$ Statistical significance level

$\mathrm{SO}_{4}=$ and TSP. Run in the stepwise mode for 122 cities, 1970 measured sulfate was just significant, with a coefficient of $0.05 \pm .024(p=0.04)$. This is virtually the same coefficient found using 1980 computed sulfate for this data set. TSP was not significant $(p=0.47)$. However, when regressed against all the denographic variables in addition to both $1970 \mathrm{SO}_{4}$ and TSP, neither was significant, although TSP was close $(p=0.12)$. This finding thus confirms the finding of some measure of sulfate aerosol as a predictor for 1980 mortality, and fails to indicate any importance for lagged rather than same year pollution. 
Since same-year pollution data is implicated if not favored, it is also possible that the effects on mortality are acute (short-term) rather than chronic (long-term). However, the magnitude of the air pollution effect indicated by this study (ca. $10 \%$ ) is much larger than what has been found in most studies of short term or episodic effects (typically 2-4\%). This hypothesis could be checked by examining the seasonal trends in mortality in high pollution areas versus those in low pollution areas.

The final cross-validation check consisted of regressing 1970 mortality against 1970 demographlc variables, but with 1980 computed sulfate to see if the lack of measurement exror inherent in the computed data might be more important than the inconsistent time periods. The result was non-significant.

\subsection{REGRESSIONS INCLUDING" "1980" TSP DATA}

Attempts to evaluate total particle mass as a predictor for 1980 mortality were linited by the small number of cities with the required data (53). Two other data sets were evaluated for this purpose. Dropping the iron variable increases the dichotomous sampler data set to 67 cities. For this data set, the coefficient for computed $\mathrm{SO}_{4}$ was about the same as for 159 cities, $0.096 \pm$ $0.031(p=0.003)$. The total particle mass coefficient was greatly reduced with respect to the $n=53$ case and non-significant, $0.007 \pm 0.009(p=0.45)$. Dropping the outlier city of Bakersfield, CA made only slight changes:

$$
\begin{array}{lll}
\text { Computed } \mathrm{SO}_{4}=: & 0.073 \pm 0.029 & (p=0.014) \\
\text { Total Particle Mass: } & 0.010 \pm 0.008 & (p=0.21)
\end{array}
$$

The final step in this part of the analysis was to use a preliminary set of (1982) TSP measurements, extracted manually from published SAROAD data. The 1979-81 data were avoided because of the filter problems mentioned earlier. This gave a data set of 143 cities. The number of TSP monitors in each city used in compling these data varted from 1 to 26 .

The results of these regressions, run as forced entry using the 159 city DVS (Mode1 1-1 in Table 17) were to reduce the iron coefficient slightly and increase the computed $\mathrm{SO}_{4}=$ coefficlent and its level of significance, with marginal significance for TSP (coefficlents from 0.005 to 0.012 , lowest p value of 0.08 . We thus tentatively conclude that it is the 53 city data set which led to reduced significance for $\mathrm{SO}_{4}=$, not the inclusion of a total particle mass variable. 


\subsection{PHASE III REGRESSION ANAL YSIS}

The computed sulfate variable obtained from Shannon's ASTRAP model 22 was perhaps the most successful air pollution variable in the Phase I-II analyses, for two possible reasons:

- concentration values were estimated for every city in the contfguous United States.

o the values were all self-consistent with no random measurement error, having been generated by a model providing smooth contours.

The question arises as to how much the success of this variable stems from these properties, as opposed to the intrinsic nature of any sulfate aerosol. health effects per se.

\subsection{NEW AIR POLLUTION VARIABLES}

To test the hypothesis that computed pollutants are more successful than measured pollutants, regardless of composition, distributions of two other pollutants were calculated by Shannon using the ASTRAP model: $\mathrm{SO}_{2}$ (gas) and $\mathrm{NO}_{\mathrm{X}}$ (NO $+\mathrm{NO}_{2}$, gas). Values were computed for the centroids of each of the 952 cities in the data set, although the implied concentration differences between locations closer than the ASTRAP grid size (ca. $120 \mathrm{~km}$ ) were not considered meaningful. At the same time, $\mathrm{SO}_{4}=$ concentrations were recomputed for these same locations ("new" $\mathrm{SO}_{4}=$ ), to preclude the interpolation errors that might have been introduced by the previous (Ist and 2nd phases) data treatment. These computations were based on ca. $1980 \mathrm{SO}_{\mathrm{x}}$ and $\mathrm{NO}_{\mathrm{x}}$ emission rates, but 24-year average meteorology was used. Thus they should be considered estimates of long-term spatial average concentrations. The pertinent statistics are given in Table 23, which shows that all three sulfur measures are highly

Table 23. Statistics of Computed Air Quality Variables $\left(\mathrm{g} / \mathrm{m}^{3}\right)$

\begin{tabular}{|c|c|c|c|c|c|c|c|c|}
\hline Variable & Mean & $\begin{array}{l}\text { Std. } \\
\text { Dev. }\end{array}$ & Min. & Max. & New $\mathrm{SO}_{4}=$ & $\begin{array}{c}\text { Correla } \\
\mathrm{SO}_{2}\end{array}$ & $\begin{array}{l}\text { tions } \\
\text { No } x\end{array}$ & $\begin{array}{l}\text { Measured } \\
\text { (SAROAD) } \\
\mathrm{SO}_{4}=\end{array}$ \\
\hline $\begin{array}{l}\text { "old" } \mathrm{SO}_{4}= \\
\text { "new" } \mathrm{SO}_{4}= \\
\mathrm{SO}_{2} \\
\mathrm{NO}_{\mathrm{x}}\end{array}$ & $\begin{array}{r}4.81 \\
5.78 \\
15.94 \\
16.89\end{array}$ & $\begin{array}{r}3.60 \\
3.81 \\
10.97 \\
10.63\end{array}$ & $\begin{array}{l}0 \\
0 \\
0 \\
0\end{array}$ & $\begin{array}{l}14.78 \\
13.08 \\
46.38 \\
50.89\end{array}$ & $\begin{array}{r}0.860 \\
1.0\end{array}$ & $\begin{array}{r}0.801 \\
0.884 \\
1.0\end{array}$ & $\begin{array}{r}0.353 \\
0.455 \\
0.708 \\
1.0\end{array}$ & $\begin{array}{l}0.760 \\
0.706 \\
0.722 \\
0.382\end{array}$ \\
\hline
\end{tabular}

correlated, but that $\mathrm{NO}_{\mathrm{x}}$ has distinctly different spatial patterns from $\mathrm{SO}_{\mathrm{X}}$. This results from the additional emissions sources for $\mathrm{NO}_{\mathrm{x}}$ which emit neg1igible $\mathrm{SO}_{\mathrm{x}}$, including transportation sources and natural gas combustion. Although the "old" $\mathrm{SO}_{4}=$ values correlate somewhat better with the SAROAD measurements (128 observations), these correlation coefficients $(0.706-0.760)$ 
are not statistically different. The differences in $\mathrm{SO}_{\mathrm{x}}-\mathrm{NO}_{\mathrm{x}}$ correlations among the $\mathrm{SO}_{\mathrm{x}}$ variables imply that there are some differences among the $\mathrm{SO}_{\mathrm{x}}$ variables as we11.

\subsection{REGRESSTON ANAL YSIS}

\subsubsection{Stepwise Regressions}

Following the analyses used in Phases I and II, the inttial exploration of these new data sets was by stepwise regressions, taking one pollutant at a time. The measured pollutant data from Phases $I$ and II were included in these trials. These calculations were made for the largest possible data sets and for the data sets limited by the cities having water hardness data. The results are given in Table 24, and show virtually identical results for all four computed pollutants.

Even for identical "fits", the magnitude of a regression coefficient $b_{i}$ will vary according to the mean values of the variable $x_{i}$, which have a considerable range for the pollutants shown in Table 24. Computing the elasticity at the mean $\left(E_{i}=b_{i} \bar{x}_{i} / \bar{y}\right)$ is one way to remove these scale effects. These elasticity values range from 0.033 for manganese to 0.087 for measured $\mathrm{SO}_{4}=$ and may be interpreted as the fraction of the mean mortality rate associated with the pollutant. The last entry in Table $24,\left(\mathrm{SO}_{4}=\star_{0} \mathrm{O}_{3}\right)$, examined the interaction between these two pollutants, if any. As can be seen, this combined variable was not significantly associated with mortality variations and thus was not considered further.* An additional interaction variable $\left(x_{i} * \%\right.$ (prior) resident), was also investigated as a means of implying air pollutant dose rather than concentration.* These "dose" results were not significantly better than concentrations and thus were not considered further.

Although the overall regressions for (new) $\mathrm{SO}_{4}=$ and $\mathrm{NO}_{\mathrm{x}}$ provided virtually identical fits, there were some interesting differences in the models defined by the final steps and in the stepwise regression sequences. Both models had the same $(p<0.05)$ regression coefficients for the following variables:

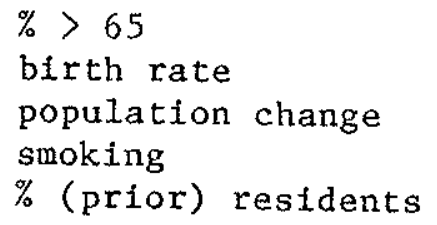

The coefficients for the two stepwise models were statistically different for $\%$ poor and \% Spanish (both larger in absolute magnitude for the No $\mathrm{N}_{\mathrm{x}}$ model), and \% black and \% Astan falled to enter in the $\mathrm{NO}_{\mathrm{x}}$ mode1. Table 25 gives the results for the stepwise sequences of variable entry. $\mathrm{SO}_{4}=$ enters on the third step with a very high $\beta$ (partial regression coefficient), which then decays as additional variables enter the model. On the other hand, $\mathrm{NO}_{\mathrm{x}}$ entered

*Interaction variables $x_{i} * x_{j}$ were entered into regressions along with the separate variables $x_{i}$ and $x_{j}$, to test for the significance of interactions vis-a-vis the separate contributions. 
Table 24. Phase III Stepwise Regression Results

(each pollutant entered separately)

\begin{tabular}{|c|c|c|c|c|c|c|c|c|}
\hline \multicolumn{5}{|l|}{ Full Data Set } & \multicolumn{4}{|c|}{ Water Hardness Data Set } \\
\hline Pollutant $\left(x_{i}\right)$ & $\mathrm{n}$ & Adj. $R^{2}$ & $b_{i}\left(S \cdot E_{\cdot}\right)$ & $\mathrm{E}_{\mathrm{i}}$ & $\mathrm{n}$ & Adj. $R^{2}$ & $b_{i}(S . E)$. & $\mathrm{E}_{\mathrm{i}}$ \\
\hline $\mathrm{Old} \mathrm{SO}_{4}=$ & 908 & 0.814 & $0.085(.016)$ & 0.045 & 454 & 0.853 & $0.098(.016)$ & 0.052 \\
\hline New $\mathrm{SO}_{4}=$ & 908 & 0.817 & $0.103(.016)$ & 0.066 & 454 & 0.854 & $0.123(.017)$ & 0.081 \\
\hline $\mathrm{SO}_{2}$ & 908 & 0.816 & $0.035(.005)$ & 0.061 & 454 & 0.854 & $0.037(.005)$ & 0.063 \\
\hline $\mathrm{NO}_{\mathrm{X}}$ & 908 & 0.817 & $0.035(.005)$ & 0.065 & 454 & 0.848 & $0.032(.006)$ & 0.050 \\
\hline$\widehat{\mathrm{SAROAD}} \mathrm{SO}_{4}=$ & 187 & 0.831 & $0.100(.024)$ & 0.087 & 185 & 0.858 & $0.082(.022)$ & 0.071 \\
\hline IP $\mathrm{SO}_{4}=$ & 78 & 0.813 & $0.195(.052)$ & 0.083 & 68 & 0.883 & $0.177(.053)$ & 0.077 \\
\hline Fine Part. & 80 & 0.806 & NS & {$[0.059] *$} & 68 & 0.867 & NS & {$[0.059]^{*}$} \\
\hline Total Mass & 80 & 0.806 & NS & {$[0.047]^{*}$} & 68 & 0.867 & NS & {$[0.027]^{*}$} \\
\hline $\mathrm{Fe}$ & 172 & 0.851 & $0.401(.115)$ & 0.041 & 172 & 0.851 & $0.401(.115)$ & 0.041 \\
\hline Mn & 172 & 0.849 & $9.60(2.54)$ & 0.033 & 172 & 0.849 & $9.61(2.54)$ & 0.033 \\
\hline $\mathrm{SO}_{4}=\mathrm{O}_{3}$ & 211 & 0.806 & NS & {$[0.018]^{*}$} & 201 & 0.849 & NS & {$[0.007] *$} \\
\hline
\end{tabular}

$(\quad)=$ standard error of regression coefficient

$\mathrm{E}_{i}=$ elasticity $\approx \mathrm{b}_{i} \frac{\mathrm{x}_{i}}{\mathrm{y}}$ (evaluated at the mean)

NS = not significant (pollutant did not enter stepwise regression)

[]$^{*}=$ elasticity if pollutant had entered. 
Its model on the 7 th step and its value improved with each succeeding step, ending with a value identical to sulfate. Thus, if the analysis had been terminated on the 8th step or earlier, the conclusions from the comparison of the two variables might have been quite different ( $\mathrm{SO}_{4}=$ appearing to be "better" than $\mathrm{NO}_{\mathrm{x}}$ ).

The water hardness variable usually had a negative coefficient (as expected), but never achieved statistical signiffcance. Thus the chief difference between the two data sets was in the selection of clties, not the effects of the water hardness variable per se. As discussed above, the "water hardness clties" tended to be larger in population.

Table 25. Sequences of Stepwise Regressions

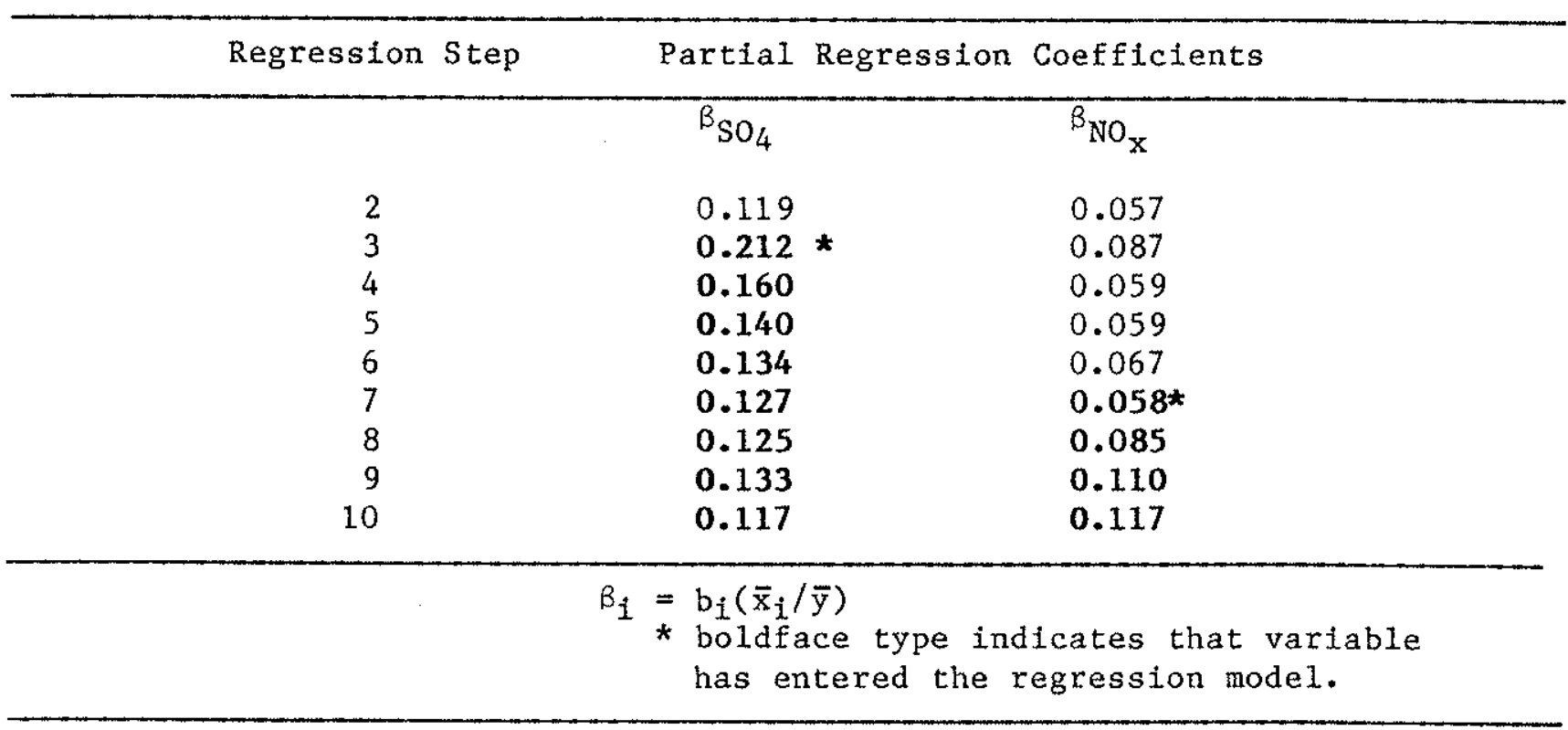

\subsubsection{Fixed Model Regressions}

Based on the preliminary results of the stepwise regression analysis, a fixed demographic model was selected to further examine pollutant effects. Stepwise regression models for the three computed pollutants $\left(\mathrm{SO}_{4}{ }^{\mathrm{N}}, \mathrm{SO}_{2}, \mathrm{NO}_{\mathrm{X}}\right)$ were examined. Fron the list of all demographic variables entering for each of three pollutants, six were chosen for the fixed model: \% of population aged 65 and over, birth rate, \% population change since 1970 , \% of population of Hispanic origin, average of 1969 and 1980 cigarette smoking estimates (packs per person per year), and \% of population classified as below the poverty line. Three other variables were not included in the fixed mode1: \% of population classified as black or Asian, which entered only with one or two of the computed pollutants and were not significant when they entered; \% of population residing in their state of birth was significant only with $\mathrm{NO}_{x}$. Results of the fixed-model regressions are shown in Table 26. The pollutant regression coefficients are not significantly different from those given in Table 24; adjusted $\mathrm{R}^{2}$ values are slightly lower for the fixed model regressions, as expected, since they are not "optimal" models. 


\begin{tabular}{|c|c|c|c|c|c|c|}
\hline MODEL \# & $4-1$ & $4-2$ & $4-3$ & $4-4$ & $4-5$ & $4-6$ \\
\hline$\% \geq 65$ & $\begin{array}{l}0.546 * * \\
(0.010)\end{array}$ & $\begin{array}{l}0.547 * * \\
(0.010)\end{array}$ & $\begin{array}{l}0.551 * * \\
(0.010)\end{array}$ & $\begin{array}{l}0.670 * * \\
(0.015)\end{array}$ & $\begin{array}{l}0.670 * * \\
(0.015)\end{array}$ & $\begin{array}{l}0.672 * * \\
(0.016)\end{array}$ \\
\hline $\begin{array}{l}\text { BIRTH } \\
\text { RATE }\end{array}$ & $\begin{array}{l}0.187 * * \\
(0.011)\end{array}$ & $\begin{array}{l}0.182 * * \\
(0.011)\end{array}$ & $\begin{array}{l}0.180 * * \\
(0.011)\end{array}$ & $\begin{array}{l}0.219 * * \\
(0.014)\end{array}$ & $\begin{array}{l}0.209 * * \\
(0.014)\end{array}$ & $\begin{array}{l}0.203^{* *} \\
(0.014)\end{array}$ \\
\hline$\triangle \mathrm{POP}$. & $\begin{array}{l}-0.013 * * \\
(0.001)\end{array}$ & $\begin{array}{l}-0.013 * * \\
(0.001)\end{array}$ & $\begin{array}{l}-0.014 * * \\
(0.001)\end{array}$ & $\begin{array}{l}-0.010 * \\
(0.004)\end{array}$ & $\begin{array}{l}-0.009 * \\
(0.004)\end{array}$ & $\begin{array}{l}-0.014 * * \\
(0.004)\end{array}$ \\
\hline $\begin{array}{l}\% \\
\text { SPANISH }\end{array}$ & $\begin{array}{l}-0.025 * * \\
(0.004)\end{array}$ & $\begin{array}{l}-0.031 * * \\
(0.004)\end{array}$ & $\begin{array}{l}-0.042 * * \\
(0.005)\end{array}$ & $\begin{array}{l}-0.031 * * \\
(0.005)\end{array}$ & $\begin{array}{l}-0.035 * * \\
(0.005)\end{array}$ & $\begin{array}{l}-0.042 * * \\
(0.005)\end{array}$ \\
\hline $\begin{array}{c}\text { SMOK ING } \\
78\end{array}$ & $\begin{array}{l}0.009 * * \\
(0.002)\end{array}$ & $\begin{array}{l}0.008 * * \\
(0.002)\end{array}$ & $\begin{array}{l}0.009 * * \\
(0.002)\end{array}$ & $\begin{array}{l}0.011 * * \\
(0.003)\end{array}$ & $\begin{array}{l}0.011 * * \\
(0.003)\end{array}$ & $\begin{array}{l}0.013 * * \\
(0.003)\end{array}$ \\
\hline $\begin{array}{c}\% \\
\text { POOR }\end{array}$ & $\begin{array}{l}0.041 * * \\
(0.008)\end{array}$ & $\begin{array}{l}0.053 * * \\
(0.008)\end{array}$ & $\begin{array}{l}0.064 * * \\
(0.008)\end{array}$ & $\begin{array}{l}0.067 * * \\
(0.009)\end{array}$ & $\begin{array}{l}0.076 * * \\
(0.009)\end{array}$ & $\begin{array}{l}0.086 * * \\
(0.009)\end{array}$ \\
\hline $\begin{array}{l}\text { WATER } \\
\text { HARDNESS }\end{array}$ & $x$ & $\mathrm{X}$ & $\mathrm{x}$ & $\begin{array}{l}-0.0006 \\
(0.0005)\end{array}$ & $\begin{array}{l}-0.001 \\
(0.0005)\end{array}$ & $\begin{array}{l}0.0007 \\
(0.0005)\end{array}$ \\
\hline $\begin{array}{l}\text { COMPUTED } \\
\mathrm{SO}_{4}=\end{array}$ & $\begin{array}{l}0.112 * * \\
(0.015)\end{array}$ & $x$ & $x$ & $\begin{array}{l}0.109 * * \\
(0.016)\end{array}$ & $\mathrm{x}$ & $\mathrm{X}$ \\
\hline $\begin{array}{l}\text { COMPUTED } \\
\mathrm{SO}_{2}\end{array}$ & $\mathrm{X}$ & $\begin{array}{l}0.038 * * \\
(0.005)\end{array}$ & $\mathrm{X}$ & $\mathrm{X}$ & $\begin{array}{l}0.038 * * \\
(0.005)\end{array}$ & $\mathrm{X}$ \\
\hline $\begin{array}{l}\text { COMPUTED } \\
\mathrm{NO}_{\mathrm{x}}\end{array}$ & $\mathrm{X}$ & $\mathrm{X}$ & $\begin{array}{l}(0.038) * * \\
(0.005)\end{array}$ & $x$ & $\mathrm{X}$ & $\begin{array}{l}0.032 * * \\
(0.006)\end{array}$ \\
\hline$\underset{n}{\operatorname{Ad} j \cdot R^{2}}$ & $\begin{array}{r}.813 \\
916\end{array}$ & $\begin{array}{r}.814 \\
916\end{array}$ & $\begin{array}{r}.813 \\
916\end{array}$ & $\begin{array}{r}.850 \\
459\end{array}$ & $\begin{array}{r}.851 \\
459\end{array}$ & $\begin{array}{r}.845 \\
459\end{array}$ \\
\hline \multicolumn{7}{|c|}{$\begin{array}{l}\text { * denotes } p<0.05 \\
* * \text { denotes } p<0.001 \\
\text { () denotes standard } \\
x \text { denotes variable }\end{array}$} \\
\hline
\end{tabular}

\subsubsection{Subset Analysis}

Because of the implied differences due to selection of cities, several different subsets were analyzed. The criteria for subset selection were:

- availability of measured air pollution data

- city size

- level of (computed) pollutant concentration

- geographic region 
These subsets were investigated using stepwlse regressions to allow different demographic models for each subset. The largest data sets, employing the computed pollutant variables, were most useful, since quartiles with over 100 observations each could be defined. The abllity to perform such sub-set analyses is another advantage for the computed air pollutant variables.

\subsubsection{City Size Subsets}

Table 27 presents the results of stepwise regressions for mortality rate by city size. The full data set was divided into four quartiles, as shown. As city size increased, the percentages of tuinorities increased as did the birth rate and poverty fraction, whereas there was a slight decrease in the percentages of long term residents. Sulfate was statistically significant in three out of the four quartiles; the coefficients were not significantly different among quartiles. It is also interesting to note that the average death rate shows an increase with city size (whereas the percentage over 65 does not), and the regression coefficient of mortality on $\% \geq 65$ also increases, implying that people over 65 live longer in smaller cities.

City size quartiles could not be used with the measured pollutant data, since these locations overwhelmingly fell into the largest city size quartile. The final portion of the city size analysis used weighted regressions to deal with possible heteroscedasticity. Weights used were the number of deaths in each city and the square root of that number. These regression results were whthin the confidence limits implied by Table 24 for the full data set.

\subsubsection{Pollutant Level Subsets}

As discussed above, many of the pollutants in this study are highly correlated with each other. One way to examine the interrelationships is to study the variation of one pollutant within quartiles of another. Accordingly, stepwise regressions were run for all pollutants, one at a time, for subsets of the full data set defined by quartiles of each of the computed variables: "new" $\mathrm{SO}_{4}=\mathrm{SO}_{2}$, and $\mathrm{NO}_{\mathrm{X}}$. This analysis explored the possible presence of pollution thresholds as well as the collinearity issue.

If a pollutant threshold were present, regression coefficients would lose significance or take on lower values in the lower quartiles. To understand how use of pollutant quartiles may help to deal with collinearity between pollutants, consider a matrix ( $i j$ ) of cities grouped according to their $\mathrm{SO}_{2}$ ( $i$ ) and $\mathrm{NO}_{x}(j)$ values. The collinearity would appear on the diagonal of this matrix. However, a regression along a row or column would consider the effect of varying $\mathrm{SO}_{2}$ at constant $\mathrm{NO}_{\mathrm{X}}$ or vice versa, and thus should be influenced by collinearity less than the full data set.

The demographic characteristics of the cities grouped according to pollutant level also showed some interesting trends. Death rates increased with pollutant level for $\mathrm{SO}_{2}$ and $\mathrm{SO}_{4}=$, but not with $\mathrm{NO}_{\mathrm{x}}$. City size (population) was constant. The age distributions showed mixed trends; birth rate tended to decrease. Population change showed a strong decrease with pollution level. The percentage of black population increased with $\mathrm{SO}_{\mathrm{x}}$ level, but not with $\mathrm{NO}_{\mathrm{x}}$. The percentage of Hispantes and Asians was generally mixed; \% Hispanics 
Table 27. Stepwise Regressions of Mortality on $\mathrm{SO}_{4}=$ By Quartiles of City Size

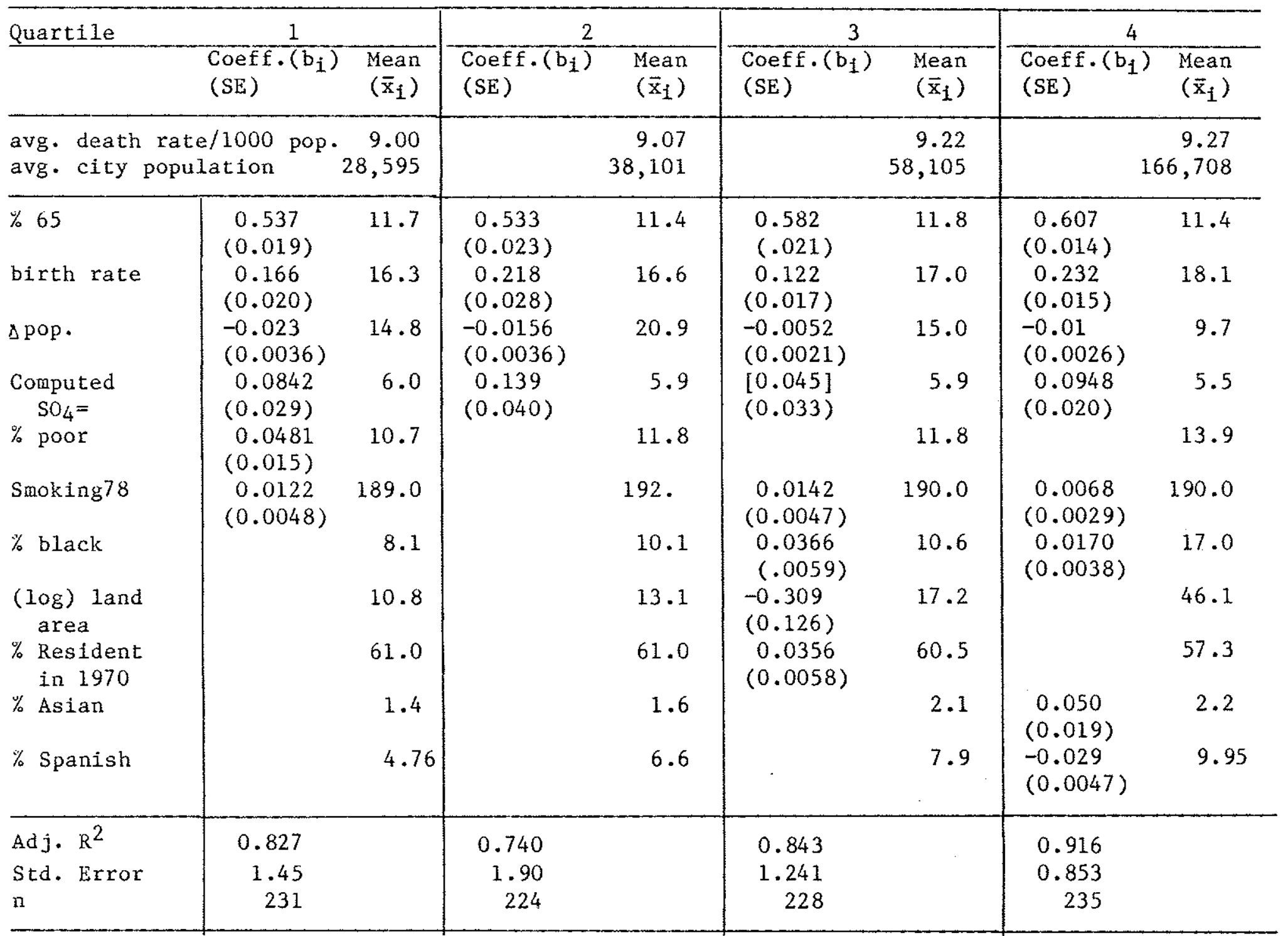

$(\quad)=$ standard error of regression coefficient

$L]=$ coefficient if pollutant had entered the regression

blank indicates variables not entered. 
decreased with $\mathrm{SO}_{4}=$ level. The age coefficient (mortality attributed to those 65 and over) increased sharply with $\mathrm{SO}_{\mathrm{x}}$ level and was mixed for the four $\mathrm{NO}_{\mathrm{x}}$ levels.

Table 28 presents elasticities for the pollution coefficients by pollution quartile, for those pollutants that were significant for the full data set, based on stepwise regressions. The $10 \%$ signiffcance level was selected to compensate for the smaller data sets in each quartile. It is seen that almost a11 pollutants are significant in the third quartile (next to highest concentrations). Within the same pollution quartile, $\mathrm{SO}_{2}$ was significant in 3 out of the $4 \mathrm{SO}_{4}=$ quartiles. $\mathrm{NO}_{\mathrm{X}}$ and $\mathrm{SO}_{4}=$ were no more significant within quartiles than might be expected by chance, even though they had previously been found significant for the full data set. However, $\mathrm{NO}_{x}$ was significant at the 0.15 level in 8 out of 12 instances. Overal1, there are 72 possibilities for statistical significance in Table 28; at the $10 \%$ level, 7 entries would be expected. 19 entries are shown, which is substantially more than would be expected due to chance alone.

$\mathrm{No}_{\mathrm{x}}$ tends to be significant within the lower pollution quartiles, whereas $\mathrm{SO}_{4}=$ and $\mathrm{SO}_{2}$ were significant for the higher pollution quartiles. $\mathrm{SO}_{2}$ was especially significant within quartiles other than $\mathrm{SO}_{2}$ as expected; the regression coefficients were not statistically different between quartiles. $\mathrm{SO}_{4}=$ regression coefficients also were not statistically significantly different between quartiles, but had some resemblance to a conventional dose-response relationship (higher values at higher $\mathrm{SO}_{4}=$ levels).

Table 28. Elasticities of Pollutant Variables Within Pollution Quartiles (Stepwise Regressions, one pollutant at a time)

\begin{tabular}{|c|c|c|c|c|c|c|c|c|}
\hline \multicolumn{9}{|c|}{ Pollutants } \\
\hline Quart & les & $\mathrm{SO}_{4}=$ & $\mathrm{SO}_{2}$ & $\mathrm{NO}_{\mathrm{X}}$ & $\mathrm{Fe}$ & $\mathrm{Mn}$ & $\mathrm{SO}_{4}=$ & $\mathrm{O}_{3}$ \\
\hline $\mathrm{SO}_{2}$ & $\begin{array}{l}1 \\
2 \\
3 \\
4\end{array}$ & $\begin{array}{l}(-.037) \\
(0) \\
(0.021) \\
(0.048)\end{array}$ & $\begin{array}{c}(0.003) \\
(0.03) \\
0.079 \star \\
(0.01)\end{array}$ & $\begin{array}{c}(0.056) \\
0.050^{\star} \\
0.076^{*} \\
(0.017)\end{array}$ & $\begin{array}{l}(0.01) \\
(0) \\
0.13 * \\
(0.01)\end{array}$ & $\begin{array}{c}(0.002) \\
(0.004) \\
0.15^{\star} \\
(0.05)\end{array}$ & $\begin{array}{c}(0.05) \\
(0.16) \\
(0.09) \\
0.08^{\star}\end{array}$ & $\begin{array}{l}(-0.06) \\
(-0.08) \\
(-0.08) \\
(-0.12)\end{array}$ \\
\hline $\mathrm{SO}_{4}=$ & $\begin{array}{l}1 \\
2 \\
3 \\
4\end{array}$ & $\begin{array}{c}(-.06) \\
(0.03) \\
0.05 * \\
0.11 \star\end{array}$ & $\begin{array}{c}(0.01) \\
0.09 * \\
0.10^{\star} \\
0.07 \star\end{array}$ & $\begin{array}{c}(0.06) \\
0.11^{\star} \\
(0.09) \\
(0.05)\end{array}$ & $\begin{array}{c}(-.05) \\
(0.08) \\
0.24^{\star} \\
(0.02)\end{array}$ & $\begin{array}{c}(0.05) \\
(0.02) \\
0.16^{\star} \\
(0.05)\end{array}$ & $\begin{array}{r}(-0.07) \\
(-0.02) \\
(0.04) \\
(0.09)\end{array}$ & $\begin{array}{c}(-0.11) \\
(0) \\
(-.07) \\
(-.18)\end{array}$ \\
\hline $\mathrm{NO}_{\mathrm{X}}$ & $\begin{array}{l}1 \\
2 \\
3 \\
4\end{array}$ & $\begin{array}{c}(0.05) \\
(0.04) \\
0.16 * \\
(0.05)\end{array}$ & $\begin{array}{c}(0.02) \\
(0.04) \\
0.14 * \\
(0.05)\end{array}$ & $\begin{array}{r}(0.04) \\
0.05 * \\
(0.04) \\
(0.02)\end{array}$ & $\begin{array}{r}(0.14) \\
(0.06) \\
0.23 * \\
(-0.12)\end{array}$ & $\begin{array}{r}(0.09) \\
(0.07) \\
0.26 * \\
(-0.05)\end{array}$ & $\begin{array}{c}(0) \\
(0.06) \\
0.15 * \\
(0.12)\end{array}$ & $\begin{array}{l}(-0.01) \\
(-0.02) \\
(-0.11) \\
(-0.10)\end{array}$ \\
\hline
\end{tabular}


In summary, the pollutant quartile analysis achieved a partial separation of the collinear pollutants, in that $\mathrm{NO}_{X}$ showed statistical significance in several instances when the other pollutants did not. The technique did not distinguish among $\mathrm{Fe}, \mathrm{Mn}, \mathrm{SO}_{4}{ }^{m}$ or $\mathrm{SO}_{2}$, nor between $\mathrm{SO}_{4}{ }^{\mathrm{m}}$ and $\mathrm{SO}_{2}$.

\subsubsection{Regional Subsets}

Subsets by geographic regions were defined as follows; West: west of $92^{\circ} \mathrm{W}$. longitude. For the remainder of the US, east of $92^{\circ} \mathrm{W}$. longitude, Northeast: north of $42^{\circ} \mathrm{N}$. latitude; Southeast: south of $37^{\circ} \mathrm{N}$. latitude; Midsection: between $35^{\circ}$ and $42^{\circ} \mathrm{N}$. latitude (Fig. 14). In many cases, these subdivisions are less arbitrary than state boundaries, and were also chosen with a view towards equalizing the numbers of cities in the three eastern subdivisions. The results are given in Table 29. Only the computed pollutants showed statistical significance for these subsets; it was not possible to determine whether the lack of significance of $\mathrm{Fe}, \mathrm{Mn}$, and measured $\mathrm{SO}_{4}=$ was due to the reduced number of observations in each subset or due to collinearity between other regional factors and pollutant levels.

It should also be recognized that the use of state-wide average smoking data may have compromised this regional analysis, because there may not be an adequate range for the smoking variable in all regions, since local city differences are not accounted for.

Table 29 indicates that the pollution regression coefficients are reasonably consistent across regions (with the exception of a high value for $\mathrm{NO}_{X}$ in the Northeast). All four regions showed some sensitivity to pollution, but the Southeast was the least sensitive (the Northeast and Midsections being the most). By pollutant, all three computed pollutants were significant in 5 out of 8 possible entries. $\mathrm{SO}_{4}=$ was never significant in the West; $\mathrm{SO}_{2}$ and $\mathrm{NO}_{\mathrm{X}}$ were never significant in the Southeast. Ozone generally showed negative regression coefficients within regions, including the West. To estimate between-region pollution effects, the mean values for the demographic variables were used together with their corresponding regression coefficients to calculate a predicted regional average mortality rate, without considering air pollution. The resulting residuals (observed-predicted) then were regressed against regional average $\mathrm{SO}_{2}, \mathrm{SO}_{4}=$, and $\mathrm{NO}_{\mathrm{x}}$ values $(\mathrm{n}=4)$. Most of the results were not statistically significant, but the coefficients compared well with the values obtained within regions.An alternative approach towards investigating the influence of unspecified regional factors uses dummy variables, m-1 variables for $m$ regions. The dummy variable takes on the value 1.0 if the city is in the region, 0 if it is not. Regressions were performed on this basis using a fixed model regression and both the full data set and the subset having water hardness data. The results were:

- increases in the coefficients for computed $\mathrm{SO}_{2}$ and $\mathrm{SO}_{4}=$

- decreases, but still significant values, for computed $\mathrm{NO}_{\mathrm{X}}, \mathrm{Fe}$, and $\mathrm{Mn}$.

- loss of statistical significance for $\mathrm{SAROAD} \mathrm{SO}_{4}=$, fine particles, and total particles.

In the full data set the coefficient for IPSO $_{4}=$ decreased and lost significance, while in the water hardness data set, this coefficient became only slightly smallex with the addition of the regional dummy variables. In 


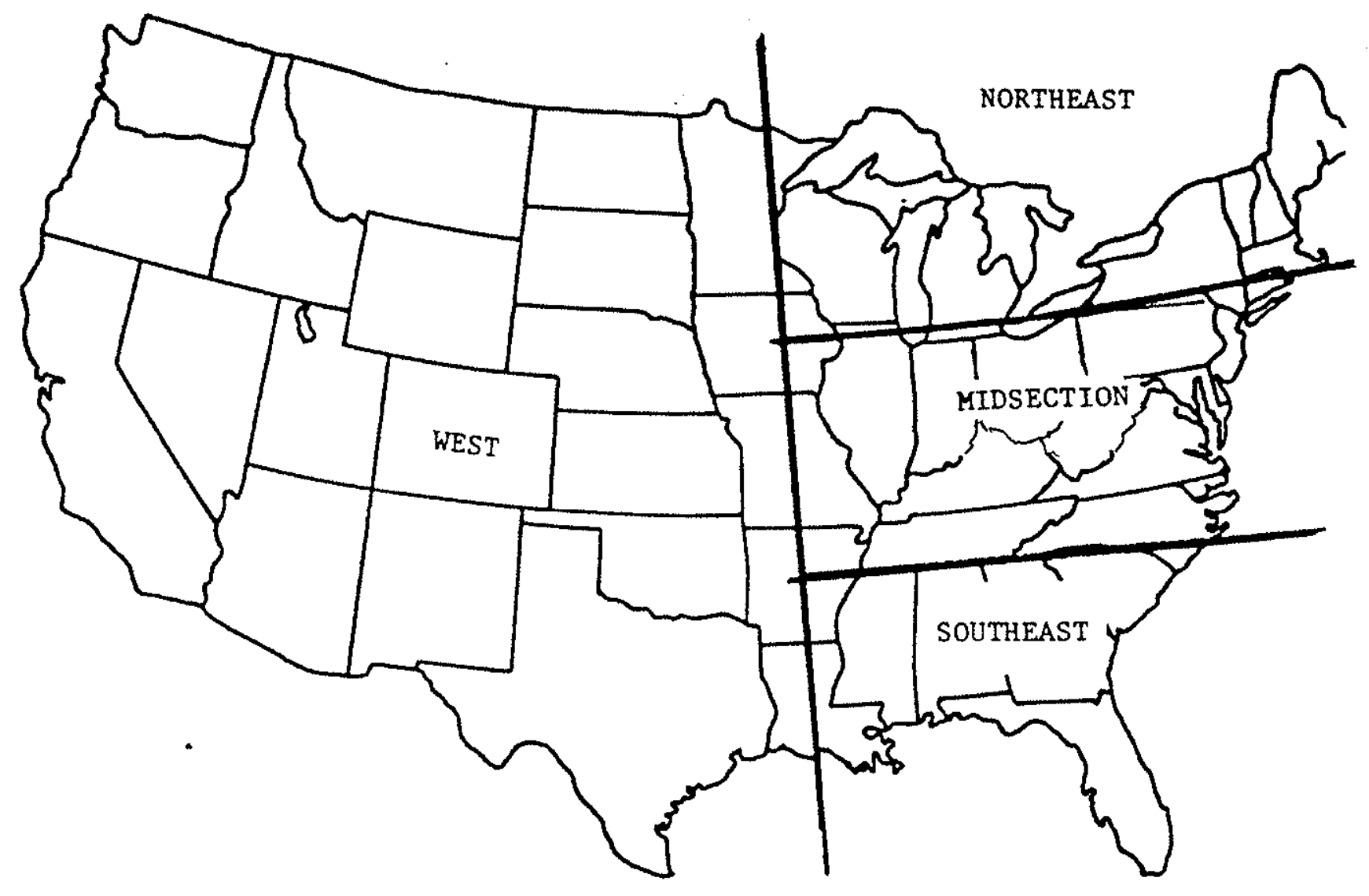

Figure 14: Reglonal definitions used in section 7.2.2.3 
Table 29. Pollution Regression Coefficients By Region

(Stepwise regressions with one pollutant at a time)

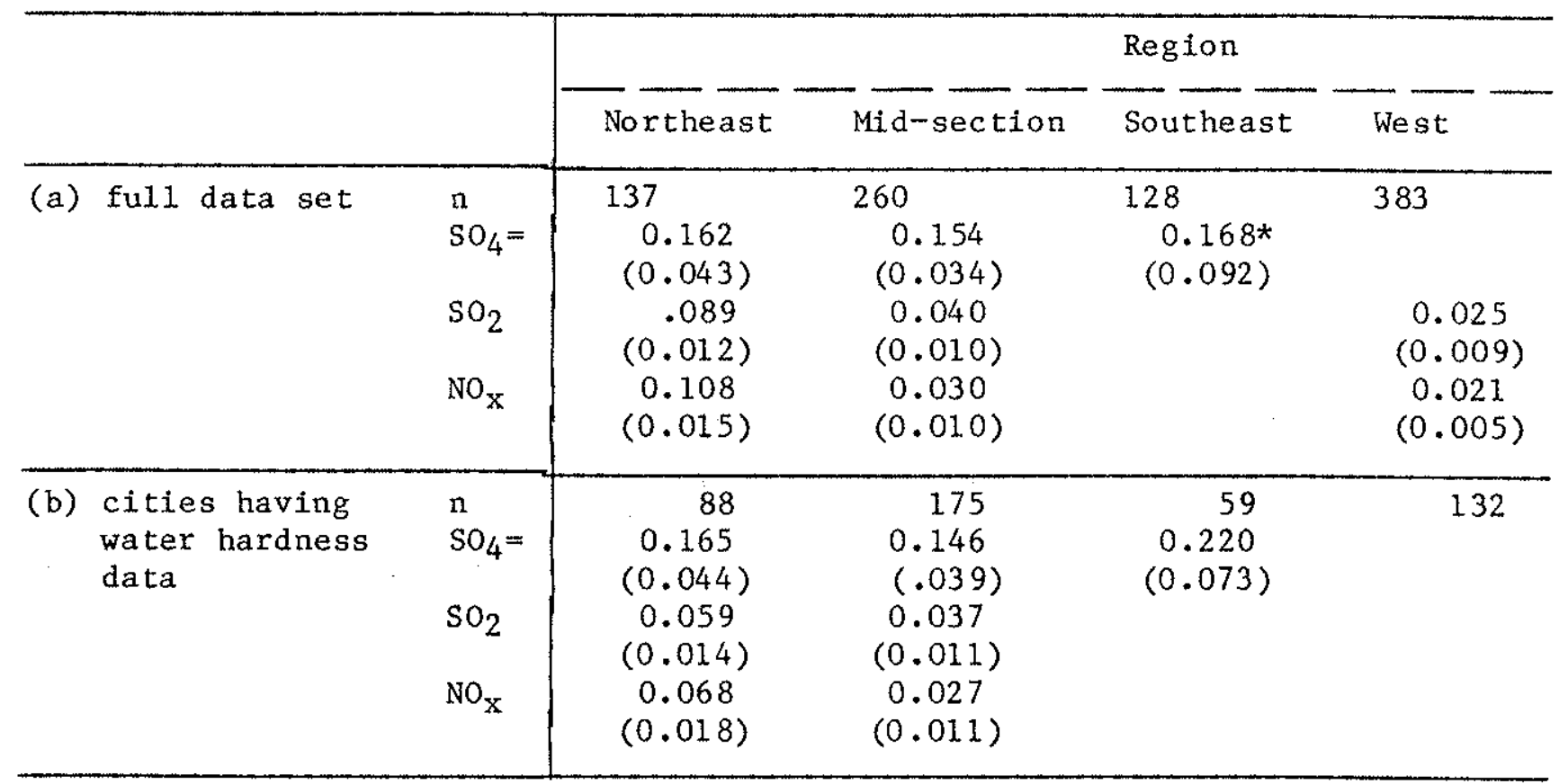

()$=$ standard error of regression coefficient

blank: indicates variable did not enter stepwise regression

* this coefficient is not statistically significant but is provided for reference.

general, the "midsection" dummy variable was most of ten statistically significant, with coefficients ranging from 0.4 to 1.4 (in mortality rate units). Values for dummy variable coefficients correspond to the average mortality rate increment relative to the Western US (the region for which no dumm variable was entered). Since the South is often mentioned as the region having different dietary patterns and lifestyle parameters, it was of interest that the "South" dummy variable was statistically significant in only one out of the 18 regressions. Evidently, the model adequately accounts for any differences between the South and the rest of the U.S. in terms of their effects on total inortality.

In summary, this regional and subset analysis indicated that most pollutants were significant within regions (as well as between regions). There was no firm evidence that the indicated pollution effects in the national data sets were surrogates for regional differences.

\subsubsection{Multiple Pollutant Regressions}

The subset analyses suggested that different pollutants could have their primary effects in different parts of the country. Accordingly, some multiple pollutant regression models were evaluated. For the combination of computed $\mathrm{SO}_{4}=$ and $\mathrm{NO}_{\mathrm{x}}$, ozone, and $\mathrm{Fe}(\mathrm{n}=119)$, ozone did not enter, $\mathrm{SO}_{4}{ }^{\mathrm{m}}$ and $\mathrm{NO}_{\mathrm{x}}$ showed reduced significance $(\mathrm{p}=0.0377$ and 0.0652 , respectively), and Fe showed 
Increased significance. However, the combined elasticity, $13.5 \pm 6 \%$, was not significantly greater than that given by $\mathrm{SO}_{4}=$ alone. This result suggested that $\mathrm{Fe}$ was the most important pollutant for this. set of cities. When manganese was substituted for iron, $\mathrm{SO}_{4=}$ became less significant and $\mathrm{NO}_{\mathrm{x}}$ more so. $\mathrm{SO}_{2}$ and iron showed equal significance, with $\mathrm{NO}_{\mathrm{X}}$ becoming non-significant. A simflar calculation for 172 cities, not using ozone, resulted in similar findings. It was difficult to conclude that one pollutant was more important than another; however, either Fe or Mn consistently showed higher statistical significance when entered in combination with the computed pollutants.

\subsection{EXAMINATION OF RESIDUALS}

The validity of hypothesis tests on regressions requires that the distribution of residuals be normal and that residuals be independent. In this section, we consider the degrees to which these criteria were met.

\subsubsection{Frequency Distributions}

As in the second phase of the analysis, examination of the residuals from the various regressions revealed a few outliers (greater than 3 standard deviations from the mean). As a result, the frequency distribution of residuals has too few values in the mid-range and too many on the tails. This situation persisted when outliers were dropped; the standard deviation was reduced and different observations became "outliers," preserving the same general shape of the frequency distribution of residuals. It is not known what effect this slightly non-normal distribution has on hypothesis testing based on the regressions, but it is believed that the effect is minor except perhaps for marginal significance levels.

\subsubsection{Spatial Autocorrelation}

Spatial autocorrelation was not apparent from visual observations of the maps of residuals (Flgures 15-17).* The next step was to test the distributions of residuals for spatial autocorrelation. This was done through the cooperation of Dr. N. L. Oden of BNL, using the method developed by Cliff and ord. 24 This procedure computes a spatial autocorrelation coefficient $I$ and its significance level. The results are tabulated in Table 30 . The parameters of spatial autocorrelation are the correlation coefficient $I$ and its statistical significance level. Significance depends on properties of the spatial autocorrelation matrix in addition to the number of observations, but the results of Table 30 indicate a tendency for statistical significance to increase with n. Spatial autocorrelation may still be present at lower values of $n$ but the test may not be capable of discerning 1t. None of the regional data sets created by subdividing the water hardness data set showed significant spatial autocorrelation; all of the subsets based on the full data set did. However, all of the magnitudes of the spatial autocorrelation coefficient are quite low, so that the practical effects on the validity of hypothesis tests are not believed to be serious.

* The consequences of the "hidden observations" on Figures 15-17 are discussed below. 


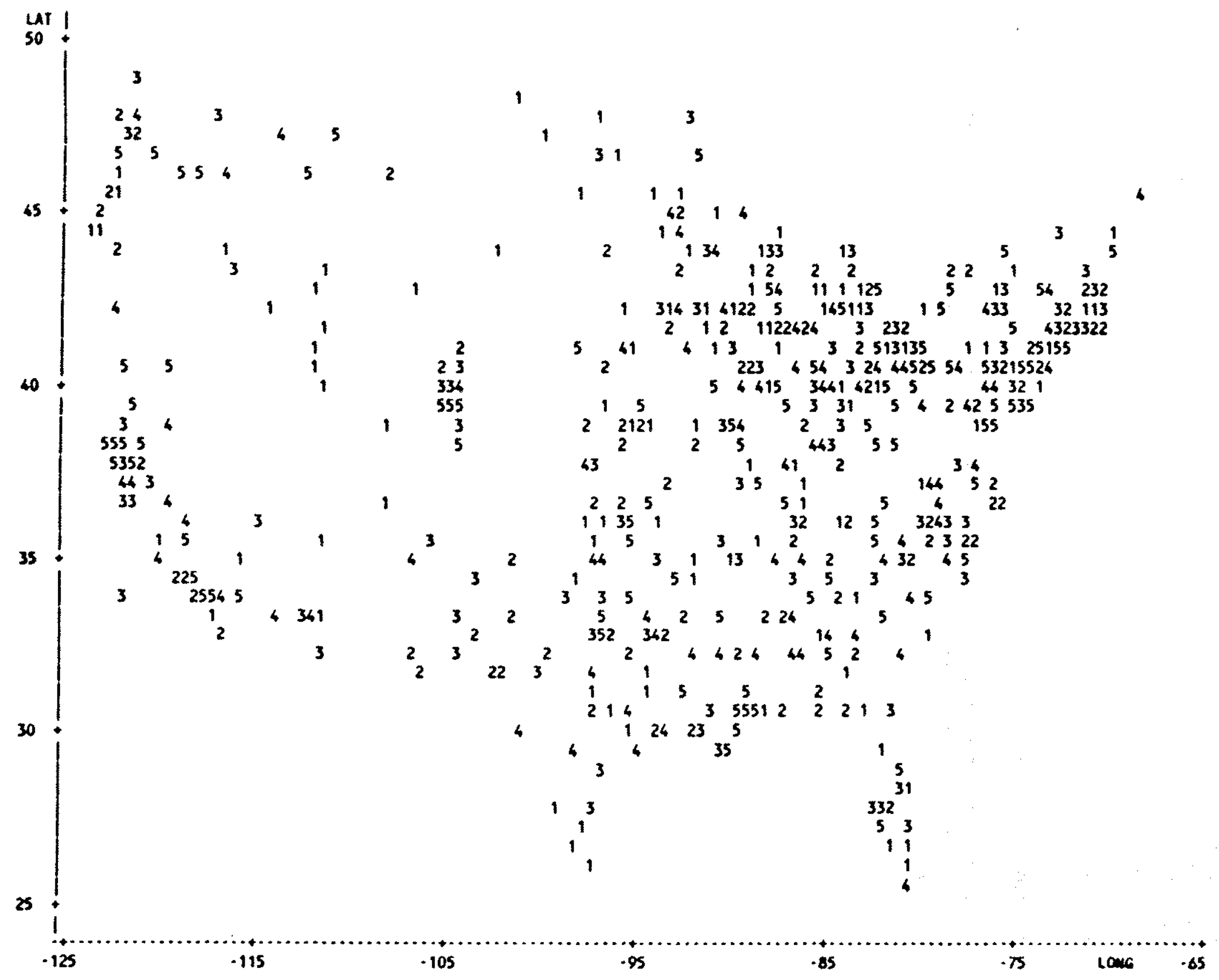

Figure 15. Map of restduals from multiple regression of mortality on computed $\mathrm{SO}_{4}=$ concentrations. $\mathrm{RSO}_{4}=$ observed - predicted mortality rate, where $5=$ highest value and $1=1$ lowest value. 470
observations are hidden. 


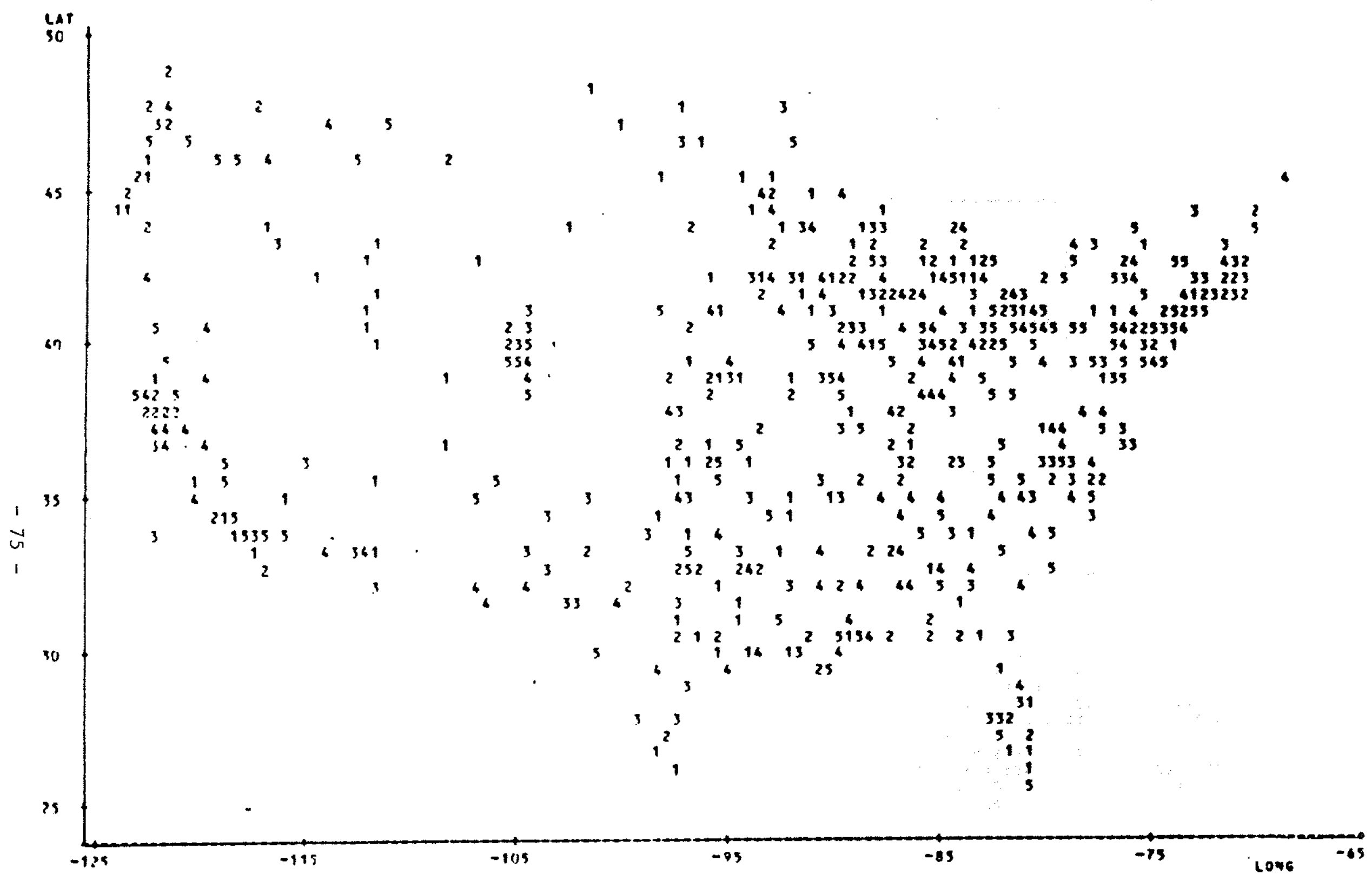

Figure 16. Map of residuals from multiple regression of mortality on computed No $x$ concentration. $\mathrm{RNO}_{\mathrm{x}}=$ observed - predicted mortality rate, where $5=$ highest value and 1 - lowst value. 470 observations are hidden. 


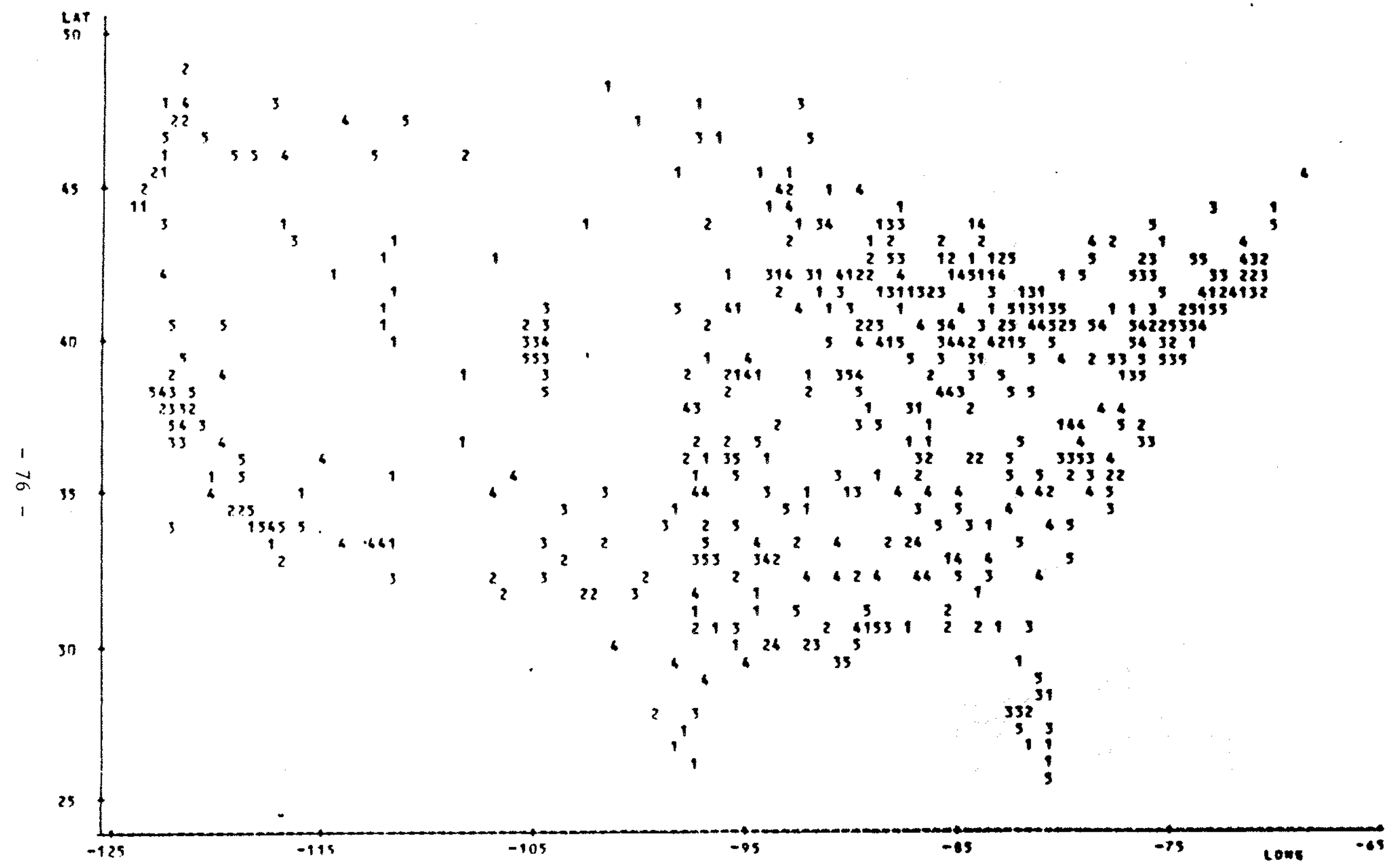

Figure 17. Map of residuals from multiple regression of mortality on computed $\mathrm{SO}_{2}$ concentration. $\mathrm{RSO}_{2}=$ observed - predicted mortality rate, where $5=$ highest value and $1=1$ lowest value. 470 observations are hidden. 
Table 30. Results of Spatial Autocorrelaton Analysis

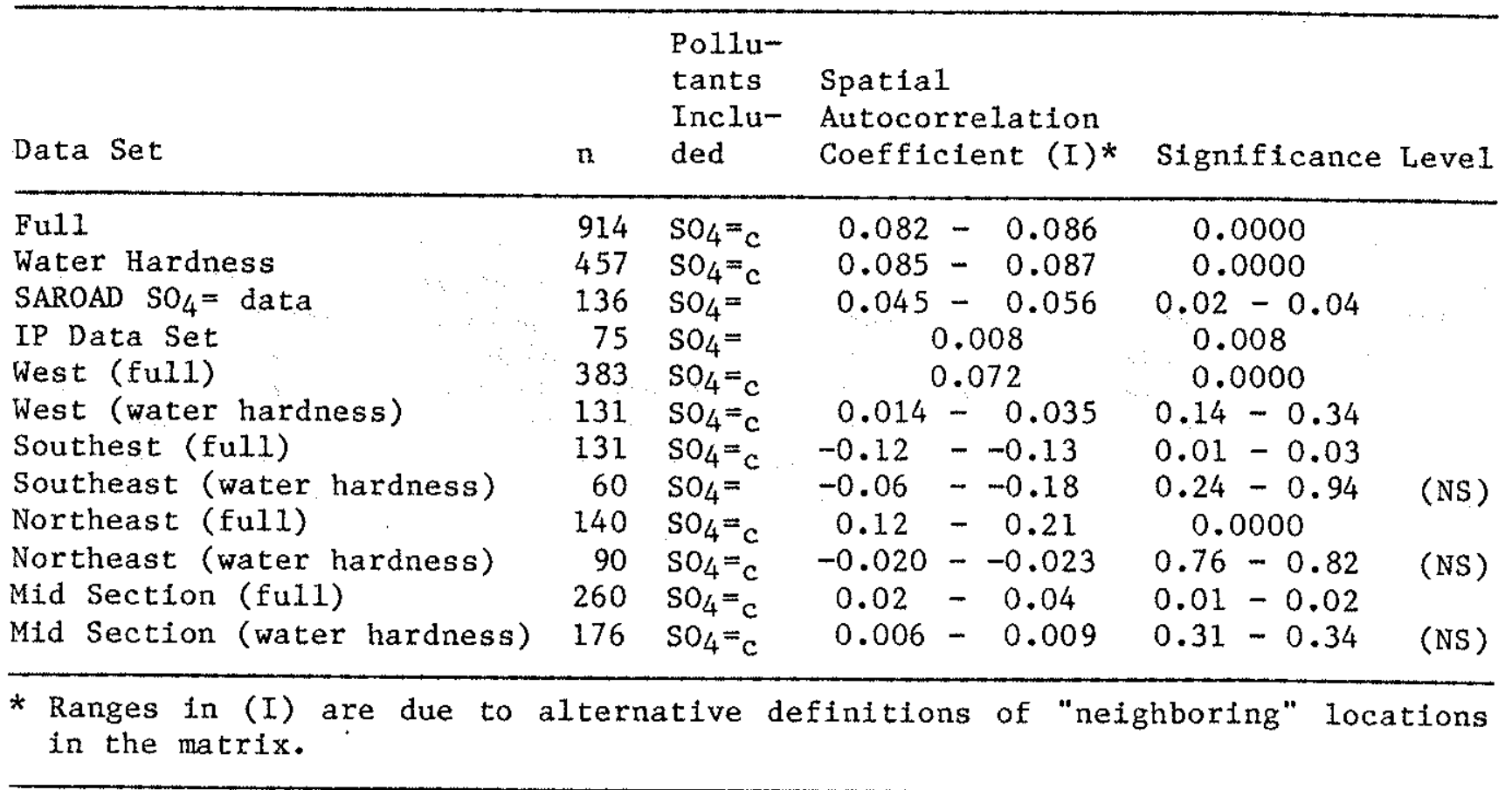

\subsubsection{Outlier Cities}

Residual plots were visually examined for outliers and their locations were identified. All the large negative residuals (observed 《 expected) were located in Florida, and were probably retirement communities. In contrast, North Miami Beach was a large positive outlier (observed $\gg$ expected). Many of the other positive outliers were heavy industrial cities, including Wheeling, WV; Steubenville, OH; Pittsburgh, PA; and Johnstown, PA. However, Hammond, IN was a negative outlier. Other positive outliers included Easton and Wilkes-Barre, PA (possible coal mining impact), Zanesville, OH; Watertown, NY; Atlantic City, NJ; Rockville, MD; Suffolk, VA; and Terre Haute, IN. No justification was apparent to delete any of these clties from the analysis.

\subsection{TWO-STAGE REGRESSION ANAL YSIS}

All of the environmental variables are associated to some degree with the demographic variables (Tables 4 and 6 ). To eliminate as much of this effect as possible in the regression coefficients, a two-stage regression procedure was employed. The previously determined demographic models were run for the full data set and the water hardness data set, each without any pollution variables in the model. The residuals from these regressions, which may be thought of as mortality rates "adjusted" for demographics, smoking, etc., then were used as the dependent variable with each pollutant, taken one at a time. This procedure was thought to result in assigning the minimum mortality effect (for a given data set) to each pollution variable. Further, it assumes that the same demographic models (and coefficients) are used for each pollutant. The fact that we have derived two such "true" models (or adjustment procedures) indicates the uncertainties about the non-pollution effects on mortality. 
The results are shown in Table 31 and Figure 18. Elasticlties are shown In Table 31, defined as $E_{1}=b_{i} \vec{x}_{1} / \bar{y}$ where $\bar{y}$ is the mean mortality rate for all cities, not just those having data on the particular pollutant $x_{i}$. Most of the elasticities are lower than their stepwise regression counterparts. A high degree of simflarity is seen among pollutants, especially for the water hardness set. This is also apparent from Figure 18, which indicates no significant differences among any of the pollutants, with the possible exception of SAROAD $\mathrm{SO}_{4}=$

Figure 19 presents a map of the residuals from the fixed demographic mode1 with no pollutants included. These values thus correspond to mortality rates "adjusted" for demographics, poverty, smoking, population change, etc. "5" corresponds to an observed mortality rate which is higher than expected, "3" to one that is about average, and " 1 " to a rate which is Iower than expected. We see 5 "s in all regions of the country, generally delineating major metropolitan areas, with some absences in the West such as Salt Lake City. However, in the Eastern US, 5"s also occur for smaller cities, notably in Appalachia, New England, and along the Southeast coastal plain.

The mortality residual plots based on adding either computed $\mathrm{SO}_{2}, \mathrm{SO}_{4}=$, or $\mathrm{NO}_{\mathrm{x}}$ to this fixed demographic model (Figures 15-17) appeared very similar to Figure 19, although some changes are also evident. The high mortality residuals in most metropolitan areas were not eliminated, even though the pollutant regression coefficients were highly statistically significant.

Table 31. Elasticities from Two-Stage Regressions

Stage 1: Mortality vs. $\%>65$, birthrate, $\%$ Spanish, $\%$ poor, smoking, population change

Stage 2: Residuals from Stage 1 vs. Pollutants.

\begin{tabular}{|c|c|c|c|c|}
\hline \multirow[b]{2}{*}{ Pollutant } & \multicolumn{2}{|c|}{ Full Data Set } & \multicolumn{2}{|c|}{ Water Hardness Data Set } \\
\hline & Elasticity & $t$ & Elasticity & $t$ \\
\hline $\mathrm{SO}_{2}$ & 0.051 & 6.7 & 0.038 & 5.1 \\
\hline $\mathrm{NO}_{\mathrm{x}}$ & 0.053 & 6.3 & 0.029 & 3.8 \\
\hline $\mathrm{SO}_{4}=$ (computed) & 0.050 & 6.3 & 0.038 & 4.6 \\
\hline $\mathrm{SO}_{4}=(\mathrm{IP})$ & 0.038 & 1.6 & 0.024 & 1.6 \\
\hline $\mathrm{SO}_{4}=\mathrm{SAROAD}$ & 0.110 & 4.7 & 0.047 & 2.6 \\
\hline $\mathrm{Fe}$ & 0.044 & 3.5 & 0.039 & 4.0 \\
\hline $\mathrm{Mn}$ & 0.040 & 4.4 & 0.033 & 4.5 \\
\hline Fine Particulates & 0.050 & 1.3 & 0.036 & 1.3 \\
\hline Total Particulates & 0.013 & 0.3 & 0.050 & 1.8 \\
\hline
\end{tabular}




\section{CORRELATION COEFFICIENTS}

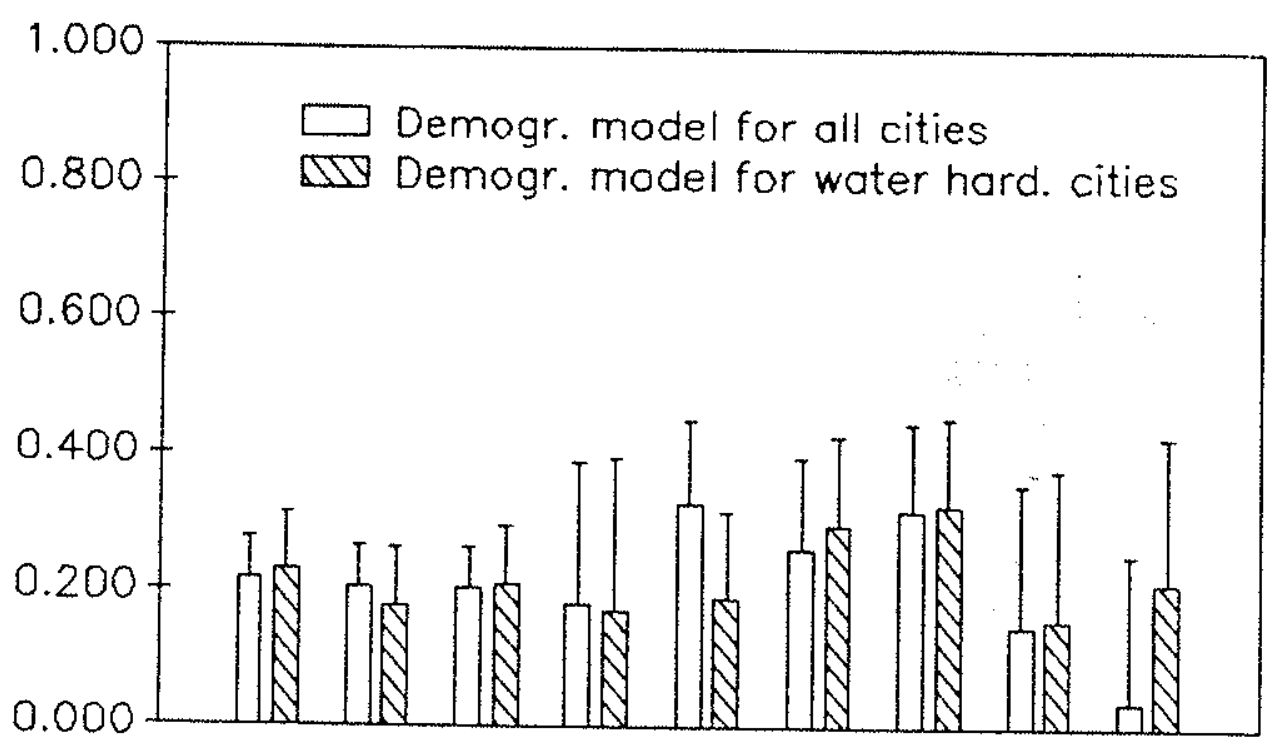

ELASTICHTIES, ABOUT THE MEAN

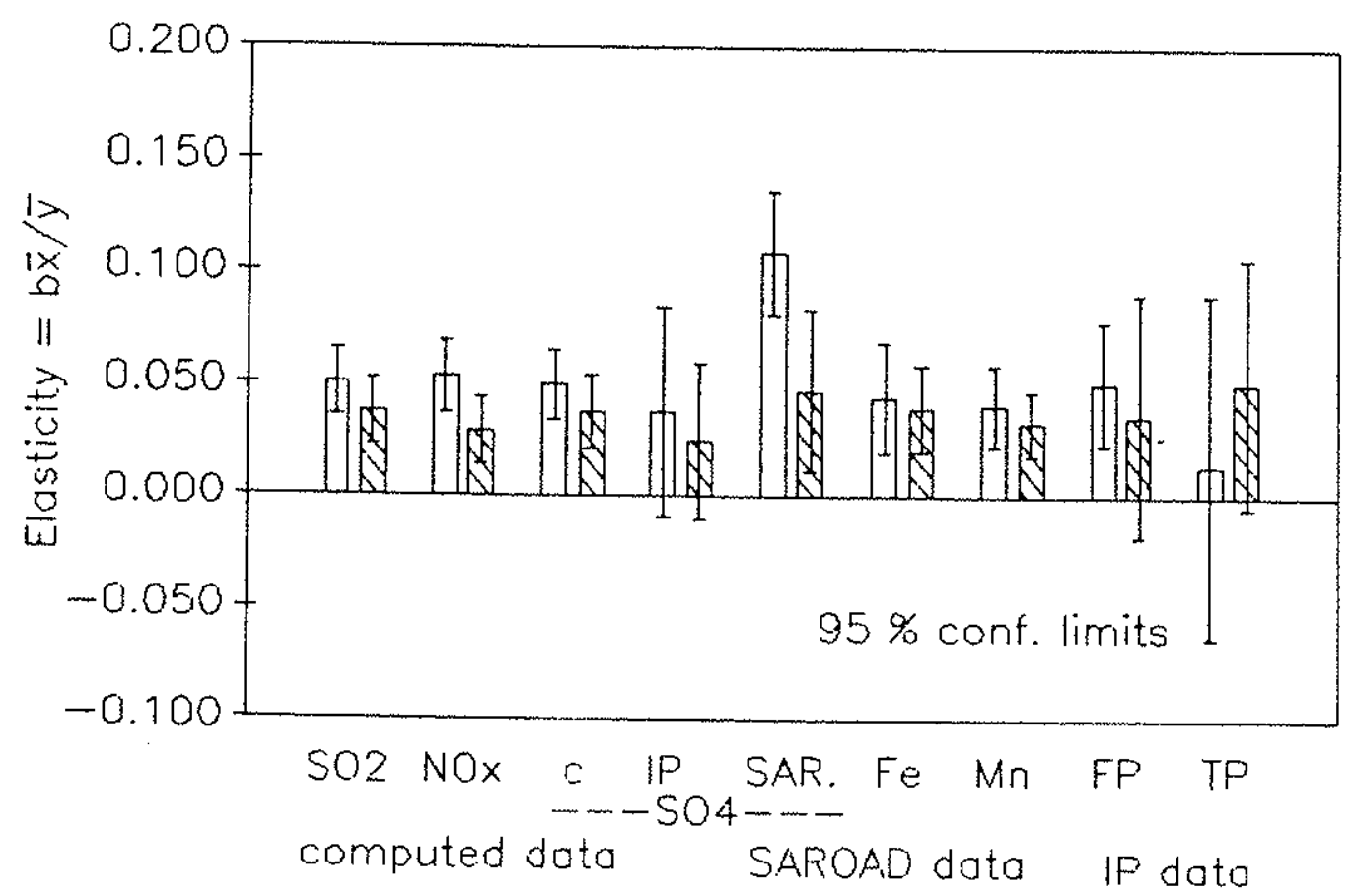

Figure 18. Correlation coefficients and elasticities for various pollutants vs. residuals from fixed demographic models (2-stage regressions). 


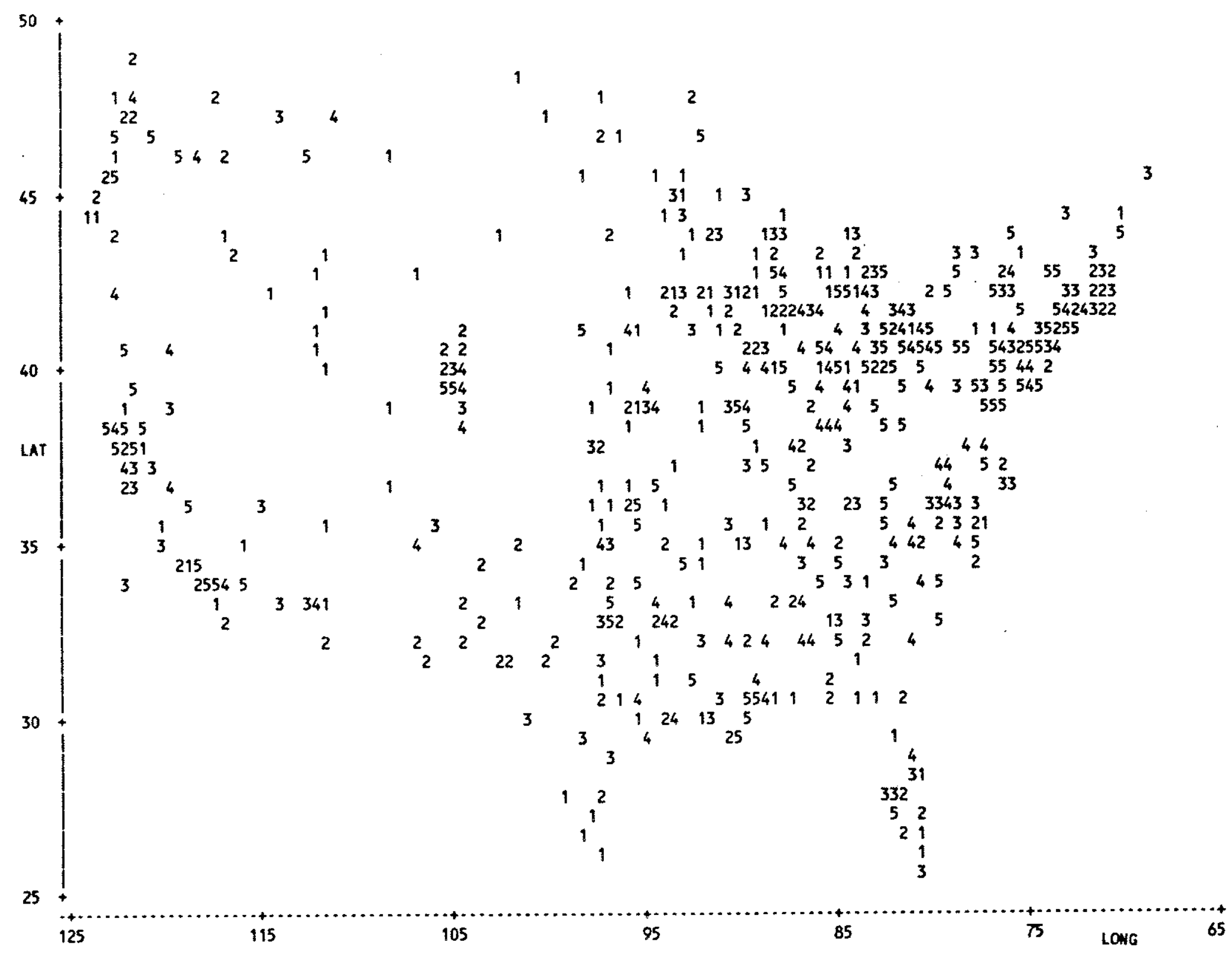

Figure 19. Map of residuals from mortality model with no air pollution variables. "5" denotes highest mortality (and residual); "1" denotes lowest mortality (negative residual). 
This suggests the presence of some other urban mortality factors not accounted for by this model.*

The regression coefficients in the fixed demographic model are of course free to adopt whatever values result in the minimum squared error for the pollutant. The ranges of these coefficient values as the nine pollutants are introduced, one at a time, are therefore of some interest:

$\begin{array}{lr}\%>65: & 0.543 \text { to } 0.702 \\ \text { smoking 78: } & 0.007 \text { to } 0.016 \\ \text { birth rate: } & 0.160 \text { to } 0.212 \\ \% \text { poor: } & 0.041 \text { to } 0.079 \\ \text { population change: } & -0.003 \text { to }-0.015 \\ \% \text { Spanish: } & -0.019 \text { to }-0.04\end{array}$

The variables are listed in order of their effect on mortality rate $\left(b_{i} * y\right)$; the ranges shown represent considerable uncertainty for the first three variables $(10-20 \%)$. However, at least part of the differences in coefficient values is associated with the restriction of the data sets for some pollutants to larger cities, which tend to result in larger coefficients for the age and smoking variables. The regression coefficients that resulted from use of city size as a weighting factor were nearly identical to the unweighted results.

\subsection{COMPARISON OF MODELS}

In Section 7.2 , pollutant effects on mortality were considered by allowing the demographic model to be freely adjusted, both in terms of the variables selected and their coefficients, in order to maximize adjusted $\mathrm{R}^{2}$ for the pollutant. The regression $R^{2}$ or the $t$ value for the pollutant then becomes the figures of merit to be used to compare pollutants. In Section 7.4 , we used those same figures of merit, but insisted that the demographic model be fixed for all pollutants, both in terms of the variables selected and their coefficients. In the following section, we present a third technique, in which the demographic model has a fixed structure but varying coefficients for all pollutants. Test of significance are developed to test whether differences in regressions (unexplained variance) are statistically significant.

\subsubsection{Methodology for Comparisons}

Use of related pollutants in the regression models for mortality rates gives rise to multi-factor models which differ very little from one another, as seen in Table 24, for example. There is always a temptation to declare the model with the highest adjusted $\mathrm{R}^{2}$ value or the highest $t$ statistic for the

* These maps encompassing the whole US tend to have about $50 \%$ hidden observations, since adjacent locations cannot be displayed separately at this scale. To test the hypothesis that the hidden observations are chosen randomly and do not result in a biased data presentation, we enlarged the section defined by $37^{\circ}$ latitude $\left\langle 42^{\circ}, 80^{\circ}<\right.$ longitude $<92^{\circ}$ (Ohio, Indiana, Illinois). The distribution of 1 's, 2 's etc. was no different than in Figure 19, using a $x^{2}$ test $(p=0.25)$. We thus concluded that it was safe to use residual maps with a large number of hidden observations, for visual evaluation. 
pollution variable as "best," (however close its competitors might be). This practice ignores the fact that a given data set represents only one realization from the universe of possible data, and that its regression statistics thus all carry confidence limits. If the models tested in Table 24 were independent, one could use the conventional confidence limits for $\mathrm{R}^{2}$ as a guide towards defining statistically significant differences between models. However, since these models generally only differ in the pollution variables chosen, they are not independent and special techniques are required to test the differences for statistical significance.

Snedecor and Cochran 28 give such a method, which requires the correlation between sets of residuals from alternative models, $R_{r}$, in order to compare two correlated variances (in this case the residuals from competing models for predicting the same set of $\left.y^{\prime} s\right)$. Their procedure appears to be similar to that
of Wolfe. 29

Snedecor and Cochran pose this problem in terms of a variance ratio

$$
\phi=\sigma_{1} 2 / \sigma_{2}{ }^{2}
$$

where is the (true) standard error of estimate from a regression. For the case for which the models have the same numbers of explanatory variables and thus degrees of freedom for exror:

$$
\phi=\frac{1-R_{1}^{2}}{1-R_{2}^{2}}
$$

For any single data set purporting to be a realization of the true relationship, we have a regression standard error of estimate $s$ which is an estimate of $\sigma$. Let $\mathrm{F}=\mathrm{s}_{1} 2 / \mathrm{s}_{2}{ }^{2}$; then confidence limits for $\phi$ are given by

$$
\phi=F\left(K \pm \sqrt{\mathrm{K}^{2}-1}\right)
$$

where $\quad K=1+\frac{2\left(1-R_{r}\right) t^{2}}{n-2}$,

$R_{r}$ is the correlation between sets of residuals for competing models 1 and 2 , and $t$ corresponds to the desired confidence interval for $n-2$ degrees of freedom.

In order to test the hypothesis that $\phi=1$, we are interested in confidence limits that include unity. The above expressions can be solved to yield the value of $F$ that would have to be observed in a given realization in order to find a statistically significant difference between models 1 and 2 . The parameters are the correlation between sets of residuals $R_{r}$ and the number of degrees of freedom ( $\sim$ the number of observations). The resulting expression for $k=1$ is:

$$
\phi=F(1 \pm 2 t) \sqrt{\frac{1-R_{r}^{2}}{n-2}}
$$


thus for $\mathrm{Rr}=0$ (uncorrelated residuals),

$$
\phi=F\left(1 \pm 2 t(n-2)^{-1 / 2},\right.
$$

which provides very nearly the same confidence limits for the regression correlation coefficients as does the standard approach using the $z$ transform (Snedecor and Cochran, 28 p. 185). However, for the case of $R_{r} \neq 0$, especially $\mathrm{R}_{\mathrm{r}}=1.0$, the expression for $\phi$ provides much tighter confidence limits. The correlation $R_{r}$ between alternative sets of residuals will be high when the residuals are controlled by either random factors or explanatory factors not included in the model, as opposed to the explanatory factors that distinguish model 1 from model 2 .

\subsubsection{Results}

Comparisons of the regression standard errors and thus degrees of fit were made according to the above protocol for all possible combinations of pollutants, taken one at a time. This required consideration of four different data sets, defined by the avallability of data on the various pairs of pollutants:

- computed $\mathrm{SO}_{4}=\mathrm{SO}_{2}$, and $\mathrm{NO}_{\mathrm{X}}$ : 914 cities,

- computed pollutants and SAROAD measured pollutants ( $\mathrm{Fe}, \mathrm{Mn}, \mathrm{SO}_{4}=$ ): 137 cities,

o computed pollutants and IP network pollutants (FP, TP, $\mathrm{SO}_{4}=$ ): 77 cities,

- all pollutants: 48 citles (maximum coincident data set).

Only 6 out of the 69 comparisons were statistically significant ( $<<0.05)$ : both computed $\mathrm{SO}_{2}$ and $\mathrm{SO}_{4}=$ provided better fits than $\mathrm{FP}, \mathrm{TP}$, or $\mathrm{SO}_{4}=$ (IP), for the 77 city data set. All other pollutant/data set combinations provided essentially equivalent regression fits, according to this statistical criterion. These findings are displayed graphically in Figure 20, in which a "+" entry indicates that the pollutant heading the column results in a lower regression standard exror than the pollutant at the left end of the row. When this difference is statistically significant, the symbol is entered in bold face. Of course, selection of a different required level of significance could have resulted in different pollutants belng judged as providing better regression fits. Note that 6 out of 69 at the 0.05 level is only marginally more than the 3 or 4 that would be expected due to chance.

Figure 20 indicates that some pollutants seem to have more than a random share of "wins." The scores are as follows:

- Computed $\mathrm{SO}_{2}$ : better fits in 19 out of 20 comparisons,

- Manganese: better fits in 12 out of 13 comparisons,

- Computed $\mathrm{SO}_{4}=$ : better fits in 12 out of 20 comparisons,

- Fine particles: better fits in 6 out of 13 comparisons, 
- Iron: better fits in 5 out of 13 comparisons,

- Computed $\mathrm{NO}_{\mathrm{X}}$ : better fits in 7 out of 20 comparisons,

- Measured (SAROAD) $\mathrm{SO}_{4}=$ : better fits in 4 out of 13 comparisons,

- Measured (IP) $\mathrm{SO}_{4}=$ : better fits in 2 out of 13 comparisons,

- Total particles: better fit in 1 out of 13 comparisons.

\begin{tabular}{|c|c|c|c|c|c|c|c|c|c|}
\hline & $\mathrm{NO}_{\mathrm{X}}$ & $\mathrm{SO}_{2}$ & $\mathrm{SO}_{4} \mathrm{C}$ & $\mathrm{SO}_{4} \mathrm{M}$ & $\mathrm{SO}_{4} \mathrm{IP}$ & $\mathrm{FP}$ & $\mathrm{TP}$ & $\mathrm{FE}$ & $\mathrm{MN}$ \\
\hline $\mathrm{NO}_{\mathrm{x}}$ & ." & + & + & - & - & + & - & - & + \\
\hline $\mathrm{SO}_{2}$ & - & . & - & - & - & - & - & - & - \\
\hline $\mathrm{SO}_{4}^{2} \mathrm{C}$ & - & + & . & - & - & - & - & - & + \\
\hline $\mathrm{SO}_{4} \mathrm{M}$ & + & + & + & . & - & + & - & - & + \\
\hline $\mathrm{SO}_{4}^{4} \mathrm{IP}$ & + & + & + & + & - & + & + & + & + \\
\hline$F P$ & - & + & + & - & - & . & - & - & + \\
\hline$T P$ & + & + & + & + & - & + & . & + & + \\
\hline $\mathrm{FE}$ & + & + & + & + & - & + & - & . & + \\
\hline $\mathrm{MN}$ & - & + & - & - & - & - & - & - & . \\
\hline
\end{tabular}

$\begin{array}{lllllll} & \mathrm{NO}_{\mathrm{X}} & \mathrm{SO}_{2} & \mathrm{SO}_{4} \mathrm{C} & \mathrm{SO}_{4} \mathrm{IP} & \mathrm{EP} & \mathrm{TP} \\ \mathrm{NO}_{\mathrm{X}} & + & + & + & - & - & - \\ \mathrm{SO}_{2} & - & + & - & - & - & - \\ \mathrm{SO}_{4} \mathrm{C} & - & + & + & - & - & - \\ \mathrm{SO}_{4} \mathrm{IP} & + & + & + & + & - & - \\ \mathrm{FP} & + & + & + & + & + & - \\ \mathrm{TP} & + & + & + & + & + & -\end{array}$

$\begin{array}{lllllll} & \mathrm{NO}_{\mathrm{x}} & \mathrm{SO}_{2} & \mathrm{SO}_{4} \mathrm{C} & \mathrm{SO}_{4} \mathrm{M} & \mathrm{FE} & \mathrm{MN} \\ \mathrm{NO}_{\mathrm{X}} & - & + & + & + & + & + \\ \mathrm{SO}_{2} & - & + & - & - & - & + \\ \mathrm{SO}_{4} \mathrm{C} & - & + & - & - & + & + \\ \mathrm{SO}_{4} \mathrm{M} & - & + & - & + & + & + \\ \mathrm{FE} & - & + & - & - & + & + \\ \mathrm{MN} & - & - & - & - & - & + \\ & {[\mathrm{n}=914]} & & & & \\ \mathrm{NO}_{\mathrm{X}} & + & + & + & & & + \text { statistically } \\ \mathrm{SO}_{2} & - & + & - & & & \\ \mathrm{SO}_{4} \mathrm{C} & - & + & - & & & \end{array}$

Figure 20. Regression fit comparison chart for single pollutants entered into a fixed demographic model. Bold = statistically significant. 
The chi-squared distribution (or a sign test) can be used to test if a given pollutant's successes are more frequent than would be expected due to chance. The null hypothesis here is that the occurrence of a better regression fit is a random event. For $p<0.05$ and 20 possibilities, more than 15 "wins" (or fewer than 5) would be statistically significant. For 13 possibilities, statistical significance would require more than 10 or fewer than 3 . Thus, according to this criterion, measured (IP) $\mathrm{SO}_{4}=$ and total particles result in poorer fits more often than would be expected due to chance, and computed $\mathrm{SO}_{2}$ and manganese provide better regression fits more often. When $\mathrm{SO}_{2}$ is compared to manganese, there were no statistically significant differences, and $\mathrm{SO}_{2}$ provided a slightly better fit for the 48 city data set while the reverse was true for the 137 city data set. Thus, based on this criterion we have no statistical basis for preferring one of these two pollutants over the other.

This analysis leads to a hierarchy of pollutants, with regard to their regression performance in the linear model described above:

- Better regression fits: computed $\mathrm{SO}_{2}$ and manganese,

- Indeterminate fits: computed $\mathrm{SO}_{4}=$, and measured (SAROAD) $\mathrm{SO}_{4}=$, computed $\mathrm{NO}_{x}$, fine particles, iron,

- Worse regression fits: measured (IP) $\mathrm{SO}_{4}=$ and fine particles.

Note that this hierarchy differs from the results of Table 24 and from those of Figure 18 .

\subsection{SUMMARY OF PHASE III FINDINGS}

The Phase III regression results confirmed that mortality is statistically significantly associated with air pollution in US cities, using ca. 1980 data. The association has practical significance, representing from about 5-10\% of all-cause mortality. These findings were robust across city size, by region, and generally were stronger for the higher levels of pollution. Thus, they do not appear to be artffacts of the analysis, within the constraints imposed by use of total (all cause, all ages) mortality.

However, the Phase III analysis also established that it is not possible to assign a specific air pollutant to this association with certainty. Some pollutants either showed no association or a negative one, including ozone, lead, and carbon monoxide, and thus could be eliminated from further consideration, based on the available data. However, of those pollutants which showed significant positive associations with mortality, it was considerably more difficult to determine which were "best" in order to suggest candidates for further investigations of possible causal relationships. Such determinations were hindered by collinearity among pollutants and by the large numbers of cities lacking measured values of pollutant concentrations.

In stepwise regressions which allow the demographic model to be adjusted (both different variables and different coefficients), the largest effects on mortality were seen for the three sulfate variables. However, the three computed pollution variables $\left(\mathrm{SO}_{2}, \mathrm{SO}_{4}=\right.$, and $\left.\mathrm{NO}_{x}\right)$ all tended to have the largest 
$t$ values (most statistically significant). Differences among these three were quite small, which led to the search for tests to determine whether small differences between regressions were statistically significant.

Taken one at a time in a fixed demographic model (varying coefficients) for the various possible data sets, the only statistically significant differences among the nine pollutants compared were that both computed $\mathrm{SO}_{4}=$ and $\mathrm{SO}_{2}$ provided better regression fits than any of the three pollutants from the inhalable particulate network (fine particles, total particles, and sulfate). However, considering that all of the 69 pairs of regressions compared in this way comprise a set of random results, both $\mathrm{SO}_{2}$ and manganese appeared superior to the others more often than chance would allow $(p<0.005)$, and measured (IP) sulfate and total particles appeared worse. All other pollutants were indistinguishable from one another on this basis.

Using a two-stage regression approach which forces each pollutant into a fixed demographic model with the same vaxiables and coefficients (but different numbers of cities according to the availability of pollutant data), manganese, iron, and $\mathrm{SAROAD} \mathrm{SO}_{4}=$ provided the best regression fits, but the elasticities of all nine pollutants were essentially the same (about $5 \%$ ). Note that this comparison uses mortality rates "adjusted" for demographics, smoking, and population change.

Thus among the three comparison techniques, no one pollutant is clearly "superior." In multiple pollutant models, significance was shown for either iron or manganese in combination with the computed pollutants (one at a time). It thus appears that statistical criteria alone will not suffice in defining air pollution relationships with total mortality. 


\subsection{DISCUSSION OF REGRESSION RESULTS}

\subsection{INTERPRETATION OF THE AIR POLLUTION RESULTS}

The preceding regressions showed a consistent positive association between total mortality and concentrations of sulfur oxides, nitrogen oxides, particulate trace metals, and fine particles. We need to consider the strength of these associations and possible alternative interpretations before speculating about causality, especially given the lack of spectficity of the results.

One way to quantify the strength of the association is by calculating the elastictty, which has been defined as

$$
E_{i}=b_{i} \frac{\bar{x}_{i}}{\bar{y}}
$$

which can be interpreted as a dimensionless regression coefficient. It represents the percentage that the dependent variable would change for a given percentage change in the independent variables. Thus, for the computed sulfate variable $(\bar{x}=5)$, a coefficient of 0.10 indicates a $5 \%$ effect on mortality $(\bar{y}=10)$. Thus, each percentage change in sulfate would result in a $0.05 \%$ change in mortality, or that complete elimination of sulfate would result in a $5 \%$ improvement in mortality. All of these statements are conditional on a causal relationship, which has not been established.

The sum of the air pollution elasticities derived in this study range from about 0.05 to over 0.20 (the higher figures based on inclusion of 1978 or 1982 TSP). These are very large figures, considering the modest concentration levels involved. By comparison, the elasticity for cigarette smoking ranges from about 0.18 to about 0.34 , depending on the regression; drinking water hardness, only about 0.04 . Elasticities for demographic variables also vary substantially: for $\% \geq 65,0.60-0.80$; for poverty, about $0.05 ; \%$ long term resident, 0.10 .

From the standpoint of the model fit, $1 . e$, explaining the variance or spatial variation in mortality rates, the variables may rank somewhat differently. The measure here is a standardized partial regression coefficient, defined as

$$
\beta_{i}=b_{i} \frac{\sigma_{x i}}{\sigma_{y}}
$$

By this measure, demographic factors are most important, explaining over $90 \%$ of the variance. Smoking only explains about $2 \%$, because of the relatively low spatial variation in smoking across the U.S. $\left(\sigma_{x}\right)$. Socioeconomic factors account for about $0.5 \%$ and alr pollution, about $3 \%$. Use of age-race-sex adjusted or specific mortality rates would thus create an entirely different regression situation, in that a much smaller degree of spatial variation would have to be explained by socioeconomic and pollution factors. Lower $\mathrm{R}^{2}$ 's would be expected, but the possibilities for confounding between demographic and po1lution factors would be greatly reduced. 
Table 32 lists previous estimates of regression coefficients for some of the variables used in this study. Agreement appears satisfactory, with the possible exception of $\% \geq 65$ and birthrate. The manganese coefficient in the present study appears to have a substantially higher coefficient than found in previous work, in spite of a much lower average concentration at present. This may be an indication of surrogate behavior, which would be characterized by constant elasticity.

\subsection{OTHER LIFESTYLE PARAMETERS}

Smoking is only one of a number of personal or lifestyle variables that can affect mortality rates. Others may include exercise, diet, obesity, ethnic orgin, and alcohol consumption. Few quantitative studies have been done on these effects, either separately or jointly. In any event, the lack of cityspecific measures of these factors makes their consideration for the present study design somewhat academic.

Alcohol consumption has been found to have mixed effects on mortality, small amounts being beneficial and large amounts harmful. 30 Thus it is difficult to use gross consumption data on an average per capita basis as an index variable. Since heavy alcohol consumption appears to often be accompanied by smoking (cirrhosis of the liver and respiratory cancer are correlated), the cigarette consumption variable may include some effects of alcohol use as well, through collinearity.

Body weight has similar effects; the lowest total mortality rates occur at average or slightly below average weights. 28 However, heart disease had more of a monotonic relationship with weight. For heart disease and total deaths, persons weighing more than $40 \%$ above average had approximately twice the average risk of dying.

Part of the unexplained variance in total mortality rates may be due to such lifestyle factors. If there are systematic regional variations in these results, some confounding may have occurred, for example with respect to the sulfur variables, which also have a reglonal distribution.

The behavioral risk factor survey also asked questions about body welght and exercise. Among the fragmentary results available, there did not seem to be regional patterns of excessive risk. Also, males were of ten less likely to be overweight or sedentary, which does not explain their excess mortality relative to females. Thus these factors may not be terribly important with respect to longevity.

\subsection{DRINKING WATER VARIABLES}

The region of very soft drinking water lies along the Eastern seaboard, including most Atlantic coast and some Gulf coast cities. Some West coast cities also have soft water. The high hardness region includes the Mid-west and parts of the Southwest. Some consumers in hard water areas use commercial softeners for laundry and bathing, but often not for cooking and drinking water.

The regression results for thts variable are equivocal. Water hardness was not selected as a significant predictor variable for the $n=159$ city set, 
Table 32. Independent Estimates of Regression Coefficients

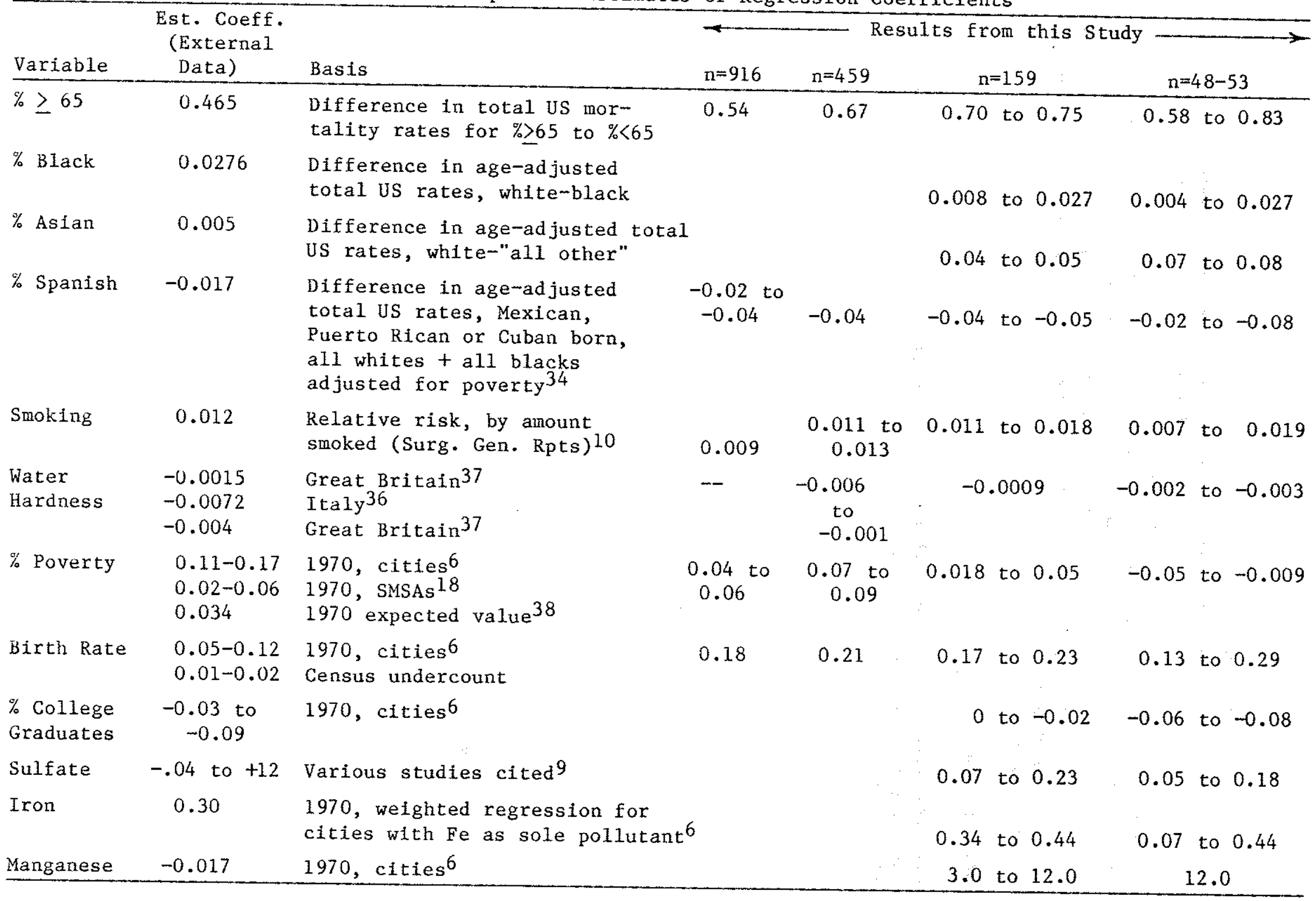


which were constructed specifically for this purpose. When included by means of "forced entry", the variable was not significant, regardless of which air pollutants were included in the regression. However, the variable was just significant $(p=0.05)$ for the $n=53$ data set, including the total particle mass variable, only when the total mass variable was included in the regression. (Conversely, the total particulate mass variable was only significant for this data set when the water hardness variable was included.) Water hardness was rarely significant in the Phase III analysis. The values of the water hardness coefficient were consistent with previous studies, 19,32 corresponding to about $1-3 \%$ of total mortality, based on the elasticity at the mean. Thus, water hardness appears to be less important than air pollution, at least for total mortality. Water hardness is expected to be more important for mortality from.heart disease.

\subsection{ETHNIC ORIGIN}

There are also sizable mortality differentials in the US population by country of origin, as noted by Kitagawa and Hauser 33 for the 1960 period. These reflect the same trends shown by the native countries, i.e.,

o U.K., Ireland and Finland; higher mortality,

- Mexico and Mediterranean countries; lower mortality,

- Austria and Eastern European countries; higher mortality.

These countries of orlgin are reflected in the U.S. Census Divisions as follows, based on the 1970 Census (1980 data not given in CCDB):

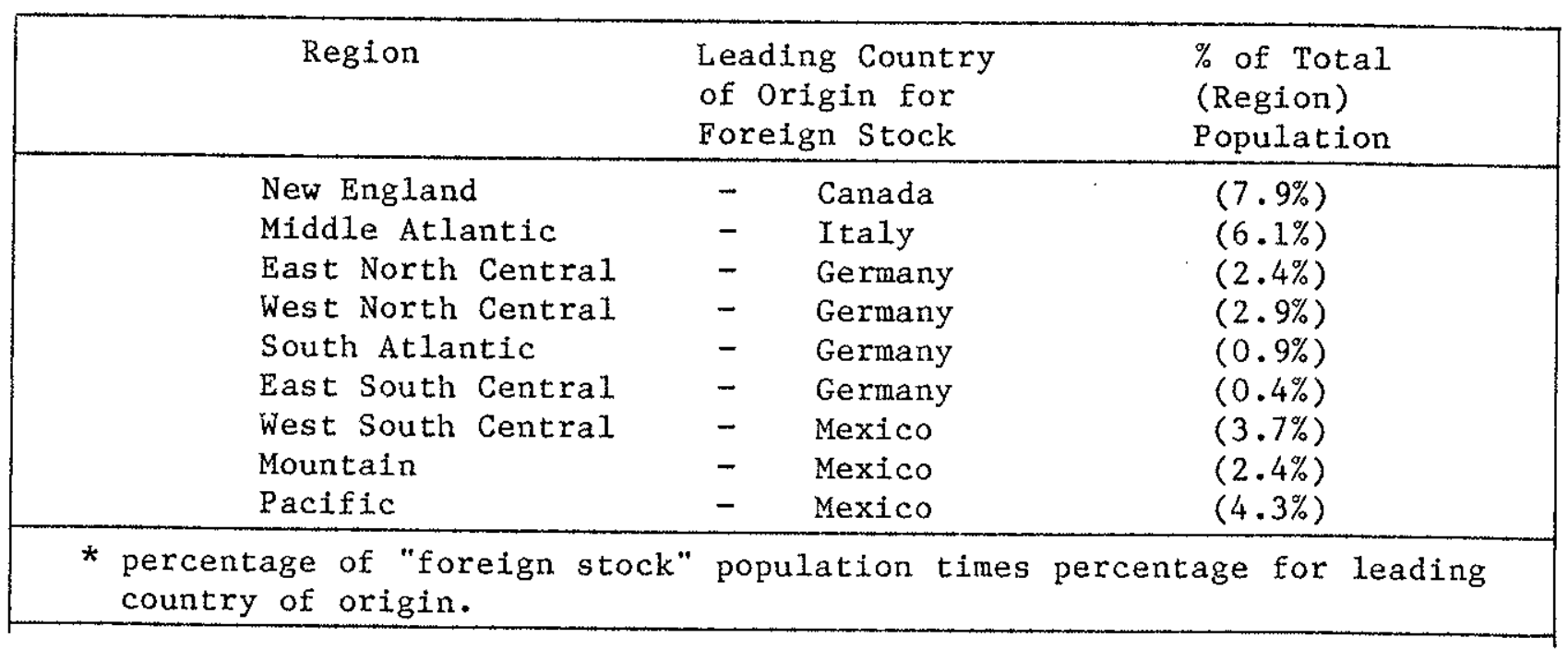

Thus one can see that entire regions are only slightly affected by the foreign born population (actually 1 st and 2 nd generations). However, some major cities may be slightly more affected; for example, in 1970 New York City had $8.6 \%$ Italian "foreign stock", while Chicago had 5.7\% polish. This difference might be enough to contribute a small mortality differential in favor of New York. 


\subsection{OTHER ETHNIC GROUPS}

\subsubsection{Asian}

The regression coefficient for the variable "\% Asian" was found to be positive, that is, after controlling for all other factors, cities with relatively high percentages of Aslans and Pacific islanders had higher mortality rates, which appears somewhat counterintuitive. First of a11, because of the ecologic nature of the regressions, this result does not necessarily imply that those particular groups had higher mortality rates themselves, only that those cities with higher percentages of Asians had higher overall mortality rates when all variables were accounted for. 1980 death rates for detailed ractal groups are not yet available; Kitagawa and Hauser 33 found that in 1960 Asian Indians had $32 \%$ higher mortality than whites; Japanese, $30 \%$ lower; and Chinese, $18 \%$ higher. If these groups are weighted according to their population numbers in 1980 , the result is a $2.7 \%$ increase in mortality relative to whites, in accordance with the present regression results. However, there are also sizable numbers of Filipinos, Koreans, and Vietnamese to be considered, for which no mortality data are available.

A further consideration is socioeconomic status and income. According to the 1980 Census, Asians and Pacific islanders had a higher median income than whites, but also a higher proportion earning under $\$ 5000$ annually. They also tended to be better educated. Thus, to the extent that education or income variables are used in the same regression with "\% Asian", there could be some interactions present.

\subsubsection{Spanish}

The Hispanic population tends to be poorly defined and includes both whites and blacks. Mortality statistics are not normally tabulated on this basis, but Rosenwaike 34 provided age-adjusted rates for three Hispanic subgroups on the basis of place of birth: 1979-81 deaths to those born in Cuba ( $20 \%$ of Rosenwaike's study group), Mexico (56\%), and Puerto Rico (24\%). The age-adjusted mortality rate for this group was about $12 \%$ lower than for the weighted average for all whites and blacks, with notable reductions in heart disease and cancer (increase in accidents, homicides, and liver disease). Rosenwaike noted that this large improvement in mortality among aged Hispanics was achieved in spite of a somewhat disadvantaged economic status (including substantially less use of the U.S. health care system). 35 Taking the poverty statistics into account, the mortality rate for this Hispanic subpopulation appeared to be about $19 \%$ lower than expected. This differential translates into an expected value for the "\% Spanish" regression coefficient of -0.017 , which is somewhat lower than that derived from these regressions, but stili within range. Rosenwaike points out that the Spanish population may be particularly prone to Census undercount, which would tend to inflate their mortality statistics and thus bring the exogenous coefficient more into line with these results.

We can only speculate about reasons for the reduced heart disease and cancer rates for Hispanics. Possibillties include selective migraton of the most fit (especially for Cubans, who had the lowest rates of the three subgroups, by far) and lifestyle parameters such as diet and smoking. 


\subsection{DISCUSSION - OTHER RELEVANT STUDIES}

Our analysis is intended to provide estimates of the effects of air pollution on total mortality, but also to give insights into other contributing factors that must be understood as part of the analytical process. In so doing, the work of previous authors must be considered.

\subsubsection{Sauer's Correlation Analysis of 1960's and 1970's Mortality}

Sauer ${ }^{14}$ presents data by states and for 510 State Economic Areas for a number of cause-of-death categories for 1968-72 mortality, taking into account age, race, and sex. Age was accounted for by presenting age-adjusted rates for persons aged 35-74 years. Although no regression models are used, he gives a number of interesting correlations that could shed some light on the possible sources of spatial variations in mortality. The diseases (causes of death) of primary interest to this study are:

major cardiovascular (MCV)

Ischemic and other heart disease (IHD)

lung cancer (LC)

influenza and pneumonia (FLU)

chronic respiratory disease (CRD)

suicide $(S)$

$$
\begin{aligned}
& \left(\text { ICD }{ }^{*}-390-458,582-4,780-796\right) \\
& (\text { ICD } 410-429) \\
& (\text { ICD } 160-163) \\
& (\text { ICD } 470-486) \\
& \text { (ICD } 490-3,517-19) \\
& \text { (ICD E950-E } 959)
\end{aligned}
$$

*ICD $=$ International Classification of Diseases. ses are:

The hypotheses that could be tested by means of Sauer's correlation analy-

- Are the relative rankings by state or SEA stable in time (1959-61. versus $1968-72$ )?

- Do blacks and whites have simflar patterns of mortality?

- Do males and females have similar patterns of mortality?

- Do these relationships vary by metropolitan versus non-metropolitan residence?

Formally, we postulate a relationship for each age-adjusted, sex, or race specific group and cause of death such as:

$$
\begin{array}{r}
\text { death } \text { rate }=a_{0}+a_{1} \text { (genetic factors) }+a_{2} \text { (personal habits) }+ \\
a_{3}(\text { local environment })+a_{4} \text { (regional factors). }
\end{array}
$$

Sauer's correlations, which represent partial derivatives of death rates for specific disease groups with respect to several of the above factors, can be used to hypothesize which of the above factors may be most important, and which may have environmental factors (relating to location). Suicide was included in the cause of death categories above as an example which is unlikely to have an environmental influence. One should also keep in mind that environmental conditions were changing in many cities from 1960 to 1970, usually for the better. 
Since Sauer's data comprise a large number of observations ( 510 for whites), the usual significance criteria for correlation are not very useful; a coefficient of 0.1 , which only explains $1 \%$ of the variance, is statisticaliy significant. For this reason, we will arbitrarily define a correlation coefficient greater than 0.7 as "high" (explains more than half of the variance), between 0.5 and 0.7 as "moderate," and less than 0.5 as "low" (less than $25 \%$ of the variance).

\subsubsection{1959-61 versus 1968-72.} time:

The following SEA correlations were presented by Sauer with respect to

\begin{tabular}{llclcc}
\hline & \multicolumn{2}{c}{ White males } & & \multicolumn{2}{c}{ White females } \\
\cline { 2 - 3 } & Metro. & Non-metro. & & Metro. & Non-metro. \\
\hline major cardiovascular (MCV) & 0.85 & 0.86 & & 0.84 & 0.82 \\
Ischemic heart disease (IHD) & 0.80 & 0.76 & & 0.84 & 0.79 \\
lung cancer (LC) & 0.54 & 0.78 & & 0.32 & 0.34 \\
influenza and pneumonia (FLU) & 0.50 & 0.36 & & 0.38 & 0.32 \\
chronic resp. dis. (CRD) & 0.70 & 0.66 & & 0.48 & 0.42 \\
suicide (S) & 0.55 & 0.55 & & 0.40 & 0.29 \\
\hline
\end{tabular}

"High" correlations over time indicate that the relative rankings of all the factors in Eq. (1) have remained stable in various locations over time, as is the case for all categories of heart disease and for lung cancer in non-metropolitan males. On the other hand, all other causes of death for females had low correlations, indicating changing causal factors. Temporal correlations do not give any hints as to the origins of the spatial patterns, nor whether the rates have changed in magnitude over time. Note that since changes in local environmental conditions have not been uniform from 1959 to 1972, those diseases with strong (loca1) environmental factors would be expected to show lower temporal correlations (Iung cancer and "FLU").

\subsubsection{Blacks versus Whites}

The following SEA correlations were shown by Sauer for blacks versus whites for 1968-72. Only SEA's with a black population greater than 10,000 were included ( $\mathrm{n}=91$ metropolitan, 64 non-metropolitan).

\begin{tabular}{lccccc}
\hline & \multicolumn{2}{c}{ Males } & & \multicolumn{2}{c}{ Females } \\
\cline { 2 - 3 } & Metro. & Non-metro. & & Metro. & Non-metro. \\
\hline major cardiovascular (MCV) & 0.73 & 0.62 & & 0.33 & 0.42 \\
ischemic heart disease (IHD) & 0.72 & 0.60 & & 0.47 & 0.58 \\
lung cancer (LC) & 0.10 & 0.24 & & 0.25 & 0.45 \\
influenza and pneumonia (FLU) & 0.39 & 0.38 & & 0.50 & 0.33 \\
chronic resp. dis. (CRD) & 0.04 & 0.19 & & 0.21 & 0.17 \\
suicide (S) & -0.03 & 0.26 & & 0.12 & -0.09 \\
\hline
\end{tabular}


Blacks and whites in a given SEA may be expected to have differing genetic and personal predisposing factors and differing local environments, but the same regional environment. Thus high black-white correlations indicate that regional factors may be more important than local or genetic factors. This was the case only for metropolitan male heart disease deaths. Smoking habits are known to differ between blacks and whites, and probably explain the low correlations for lung cancer, $C R D$, and perhaps female heart disease, together with the possible effects of local environmental conditions. The relatively low numbers of observations for black-white correlations weakens these conclusions somewhat.

\subsubsection{Males versus Females}

The following male/female correlations were presented for SEAs for 1959-61 and $1968-72$.

\begin{tabular}{llclcc}
\hline & \multicolumn{2}{c}{$1959-61$} & & \multicolumn{2}{c}{$1968-72$} \\
\cline { 2 - 3 } \cline { 5 - 5 } & Metro. & Non-metro. & & Metro. & Non-metro. \\
\hline major cardiovascular (MEV) & 0.63 & 0.69 & 0.78 & 0.74 \\
ischemic heart disease (IHD) & 0.72 & 0.68 & 0.81 & 0.77 \\
lung cancer (LC) & 0.21 & 0.32 & 0.49 & 0.46 \\
influenza and pneumonia (FLU) & 0.57 & 0.40 & 0.58 & 0.52 \\
chronic resp. dis. (CRD) & 0.67 & 0.35 & 0.58 & 0.44 \\
suicide (S) & 0.42 & 0.32 & 0.50 & 0.25 \\
\hline
\end{tabular}

Except for one-person households, males and females in a given SEA would be expected to have the same local and reglonal environments, somewhat similar personal factors, but differing genetic factors. The 1968-72 heart disease correlations imply such a finding, and the 1959-61 values are nearly large enough to be classified as "high." None of the other cause of death categories do, although it is interesting that all the male-female correlations are higher than the black-white correlations. The relatively larger correlations for "FLU" may reflect the contagious nature of the disease, for example, and for $\mathrm{CRD}$, the higher correlations in metropolitan areas may reflect the influence of local environmental factors.

In sumary, the above three tabulations of correlations imply that spatial patterns of heart disease deaths have been stable in time, may be influenced by local environmental factors, and perhaps by regional ones. Genetic and personal lifestyle factors would seem to be less important. These conclusions are admittedly speculative, but the marked differences between the heart disease correlations and those for other causes of death with respiratory connotations strongly suggest that the current air pollution mortality analysis be repeated for specific causes of death.

\subsubsection{Correlation Between Disease Categories}

One way to hypothesize about the potential nature of causal factors is to examine the correlations between these causes of death, as given below in Table 33 for white males and females in 1968-72 SEAs. 
Table 33. Correlations Between Major Causes of Death for Whites 1968-72

\begin{tabular}{|c|c|c|c|c|c|c|c|}
\hline & & $M C V$ & IHD & $\mathrm{LC}$ & FLU & CRD & $S$ \\
\hline $\mathrm{MCV}$ & $\begin{array}{l}\text { males } \\
\text { females }\end{array}$ & $\begin{array}{l}1.0 \\
1.0\end{array}$ & * & $\begin{array}{l}0.61 \\
0.22\end{array}$ & $\begin{array}{l}0.46 \\
0.40\end{array}$ & $\begin{array}{l}0.21 \\
\mathrm{NS}\end{array}$ & $\begin{array}{l}\text { NS } \\
\text { NS }\end{array}$ \\
\hline IHD & $\begin{array}{l}\text { males } \\
\text { females }\end{array}$ & & $\begin{array}{l}1.0 \\
1.0\end{array}$ & $\begin{array}{l}0.58 \\
0.25\end{array}$ & $\begin{array}{l}0.41 \\
0.25\end{array}$ & $\begin{array}{l}0.17 \\
\text { NS }\end{array}$ & $\begin{array}{l}\text { NS } \\
\text { NS }\end{array}$ \\
\hline LuC & $\begin{array}{l}\text { males } \\
\text { females }\end{array}$ & & & $\begin{array}{l}1.0 \\
1.0\end{array}$ & $\begin{array}{l}0.37 \\
0.18\end{array}$ & $\begin{array}{l}0.25 \\
0.28\end{array}$ & $\begin{array}{l}\text { NS } \\
0.28\end{array}$ \\
\hline FLU & males & & & & $\begin{array}{l}1.0 \\
1.0\end{array}$ & $\begin{array}{l}0.30 \\
0.20\end{array}$ & $\begin{array}{l}\text { NS } \\
\text { NS }\end{array}$ \\
\hline CRD & $\begin{array}{l}\text { males } \\
\text { females }\end{array}$ & & & & & $\begin{array}{l}1.0 \\
1.0\end{array}$ & $\begin{array}{l}0.38 \\
0.33\end{array}$ \\
\hline$S$ & $\begin{array}{l}\text { males } \\
\text { females }\end{array}$ & & & & & & $\begin{array}{l}1.0 \\
1.0\end{array}$ \\
\hline
\end{tabular}

The strongest correlation is for male heart disease versus lung cancer, which suggests smoking as a common (personal) factor (also see Ref. 36). The lack of correlation between CRD and either heart disease or lung cancer suggests the influence of other factors (local) for CRD, but since CRD rates are low ( $1.5 \%$ of total) there may also be a problem with sampling variability. The low correlations for females would seem to argue against an important common environmental factor for these diseases.

\subsubsection{Comparison of Average Rates}

To get some inslght into plausible hypotheses for local versus regional causal factors, it is necessary to consider the average rates, again as given by Sauer ${ }^{14}$ (Table 34 ). In general, the differences between race and sex groups tend to far outweigh those due to metropolitan status, except for ischemic heart disease. Acute deaths (heart attacks) are higher in non-metropolitan areas, whereas chronic deaths are just the opposite (these two subsets had been combined in the previous analysis). However, the large differences between death rates for chronic ischemic heart disease among the four groups imply that regional factors may operate as multipliers rather than as additives. The higher rates for non-metropolitan acute deaths argue against local air pollution as a common factor. Clearly a regression analysis for individual causes of death vs. various explanatory factors is warranted; Sauer's use of combined chronic and acute ischemic heart disease deaths may have masked some important relationships. Wallace and Gil140 have confirmed Sauer's findings with a county-level correlation analysis. 
Table 34. U.S. Age Adjusted Death Rates (Age 35-74) for 1968-72

\begin{tabular}{|c|c|c|c|c|c|c|c|c|}
\hline & \multicolumn{8}{|c|}{ (Deaths per 100,000 population) } \\
\hline & \multicolumn{4}{|c|}{ White } & \multicolumn{4}{|c|}{ Black } \\
\hline & \multicolumn{2}{|c|}{ Male } & \multicolumn{2}{|c|}{ Female } & \multicolumn{2}{|r|}{ Male } & \multicolumn{2}{|r|}{ Female } \\
\hline & Metro & Non-Metro & Metro & Non-Metro & Metro & Non-Metro & Metro & Non-Metro \\
\hline $\mathrm{MCV}$ & 818 & 813 & 350 & 336 & 1120 & 1244 & 759 & 846 \\
\hline IHD & 622 & 593 & 224 & 206 & 672 & 617 & 413 & 394 \\
\hline Acute & 401 & 463 & 130 & 140 & 306 & 386 & 170 & 213 \\
\hline Chronic & 221 & 130 & 94 & 66 & 369 & 201 & 243 & 180 \\
\hline LC & 120 & 108 & 26 & 19 & 161 & 113 & 28 & 19 \\
\hline FLU & 37 & 32 & 18 & 16 & 92 & 70 & 41 & 35 \\
\hline CRD & 53 & 59 & 14 & 13 & 53 & 39 & 16 & 11 \\
\hline S & 28 & 32 & 14 & 10 & 13 & II & 4 & 2 \\
\hline
\end{tabular}

\subsubsection{Sauer's Explanatory Hypotheses}

Sauer identifies the Southeast coastal plain as an area of high cardiovascular mortality for males, but advances no causal hypotheses. He finds high rates for all causes (males and females) dating as far back as 1949-51 in areas with mining activities or with a history of mining. Elevation above sea level is negatively associated with heart disease (as in 1949-51), as is lung cancer. However, CRD is positively associated. He also notes that the relationship with height above sea level is not borne out by international comparisons. Sauer identifies a weakering trend over time of the influence of population density, although suburban counties generally have lower death rates than do center-city counties, as was the case for 1949-51. The effect of medical care resources was mixed, depending on the type of medical practioner. Sauer concludes that if the whole country could achieve the lowest rates shown, 170,000 fewer deaths (14\%) would occur each year (to those under 75 years of age).

\subsubsection{Conclusions From Reanalyzing Sauer's Data}

In addition to Sauer's own findings, the following results are relevant to this inquiry.

o Patterns of heart disease and to a lesser extent, respiratory disease, have been stable in time.

- There are regional factors for heart disease (primarily ischemic) affecting males and females (and black males).

- Local factors may influence deaths from chronic respiratory disease.

- Smoking may be a common factor linking heart disease and lung cancer (males). 


\subsubsection{Cross-Sectional Studies in Other Countries}

The persistence of geographic patterns of mortality in the U.S. makes it impossible to achieve a truly independent verification of the regression findings simply by analyzing a different time period. However, there is no reason a priorl to expect the various factors affecting mortality to have similar interdependence in other countries, and thus confirming evidence should be sought from international studies.

\subsubsection{Chinn et a1. (UK) $)^{41}$}

Chinn et al. analyzed mortality in 116 counties and boroughs in England and Wales during the period 1969-1973.

- Dependent variables were mortality for infants (aged 0-1) and for males and females aged 45-54, 55-64, 65-74 - for all causes, stomach cancer, lung cancer, flu, pneumonia, bronchitis, hypertension, and ischaemic heart disease.

- Independent variables were (then-current) $\mathrm{SO}_{2}$ and particulate (British smoke) levels, various socioeconomic variables, latitude, temperature, rainfall, water hardness, and smoking (1imited data).

They concluded that there was "no consistent relation of smoke or sulphur dioxide with mortality from all causes or with mortality from specified causes postulated a priori to be related to pollution. In particular there was no significant association between smoke and mortality rates for respiratory illness. Comparison with results from similar analyses of data from two previous decades suggested that a decline in the strength of associations had occurred in parallel with declining levels of the pollution." They also found:

- No associations of infant mortality with smoke or $\mathrm{SO}_{2}$.

- Some sensitivity of results to the selection of data sets, especially for all-cause and heart disease mortality. Deleting the London boroughs, which were the highest in $\mathrm{SO}_{2}$, strengthened some of the $\mathrm{SO}_{2}$ correlations, especially for females and for deaths from heart disease. Several of these became significant $(p<0.05)$.

- Including either water hardness or smoking variables weakened the associations of male mortality with $\mathrm{SO}_{2}$.

- Even in 1948-50, female mortality from heart disease was not associated with air pollution (as an index variable).

- Associations were shown more often for the 45-64 age group than for the 65-74 age group.

The strengths of this study include:

- The geographic areas considered were quite small by U.S. standards (maximum of 70 square miles) and each contained four monitoring sites, 
on average. Thus exposure to the specific air pollutants considered appears to have been much better characterized than in most comparable U.S. studies.

- Both age-specific and cause-specific deaths were considered, and fiveyear averages (1969-73) were used to obtain numerical stability.

- The data for both $\mathrm{SO}_{2}$ and smoke contained an adequate range to be able to detect an effect, if one were to exist. Levels ranged from essentially background to almost twice the U.S. ambient standard. $\mathrm{SO}_{2}$ and smoke were only weakly correlated $(r=0.25)$.

- Both drinking water hardness and smoking were included, although the smoking analysis was quite crude.

The weaknesses included:

- Only winter pollution levels were used, since summer levels were "uniformly low." If the latter were strictly true, the degrees of association would not be affected but (nonstandardized) regression coefficients (not given) would be too low. Use of year-round data would have provided a more straightforward comparison with other studies.

- No data were included on frequency of fog, sulfate particles, oxidants, or acid aerosols.

- $\mathrm{SO}_{2}$ was correlated with male smoking, making it difficult to separate the effects of each.

- No attempt was made to construct long-term average levels of pollution from the available historical data.

- Although the paper presents regressions of current mortality on indices of past pollution levels (back to about 2950 ), it gives no indications as to what typical concentrations might have been at that time.

The findings of this study are in contradiction to many of the U.S. crosssectional studies, in that there is no association of small particles (British smoke) with mortality. It confirms the importance of considering smoking and drinking water hardness. The study provides no confirmation of the hypothesis that the very young and the very old are most susceptible to the effects of air pollution. The instability of the $\mathrm{SO}_{2}$ results and the correlation of $\mathrm{SO}_{2}$ with smoking (to the extent it could be shown with the linited smoking data available) suggest that the $\mathrm{SO}_{2}$ findings may be compromised through collinearity with smoking (when smoking was not included).

\subsubsection{Göttinger (West Germany) 42}

Census tracts in Munich were studied for deaths to males and females over 65 from all causes. Control variables included climate, education, and population density. Air pollution variables were $\mathrm{SO}_{2}$, particulates (TSP), and $\mathrm{CO}$. Only TSP was significant $(p<0.05)$ for both males and females. 


\subsubsection{Krzyzanowski and Wojtynlak (Poland) 43}

This was a 10 year follow up study of 4355 residents of Cracow, selected randomly. TSP and $\mathrm{SO}_{2}$ were measured in 20 locations, and the subsets were classified as to high (TSP $=180 \mathrm{ug} / \mathrm{m}^{3}$ and $\mathrm{SO}_{2}=114 \mathrm{ug} / \mathrm{m}^{3}$ ) and $10 \mathrm{w}$ ( TSP $=109$ $\mathrm{ug} / \mathrm{m}^{3}$ and $\mathrm{SO}_{2}=53 \mathrm{ug} / \mathrm{m}^{3}$ ) levels of pollution. Pollution was measured during the first 5 years of the 10-year study. Pollution was marginally significant for males $(p=0.051)$, more so for smokers $(p=0.029)$. For females, air po1lution was significant but negative $(p=0.024)$, but smoking was not significant. It was not possible to separate the effects of TSP from $\mathrm{SO}_{2}$. No explanations were offered for the negative finding for females.

\subsubsection{Comparisons of Individual Mortality Experience}

Hanis et al. 44 performed a retrospective study of refinery and chemical plant workers at three locations: Baton Rouge (LA), Baytown (TX), and Bayway/ Bayonne (NJ), controlling directly for smoking and occupational exposures. For all causes of death, the differences among the three locations were neglible $(0.25 \%)$ and all three were lower than the corresponding rate for the U.S. as a whole (probably a manifestation of the "healthy worker effect"). "Exposed" workers (to petroleum, petrochemicals, and related substances) had higher death rates than nonexposed workers for all causes (20\%) and for heart diseases $(40 \%)$. New Jersey workers had slightly higher cancer rates including lung cancer, but substantially lower deaths from respiratory disease. Baton Rouge workers had slightly lower $(4 \%)$ heart disease deaths. The results of this study suggest that regional mortality variations are small when like, controlled populations are compared.

\subsubsection{Trend Analysis}

Another largely unexplained phenomenon in US epidemiology is the nationwide decline in coronary heart disease mortality, which began in about 1968.45 The trend is stronger for acute deaths (37.4\% decline) than for chronic ( $14.1 \%$ decline), and for all age groups for acute but mainly older groups (65+) for chronic. Various life style factors have been considered as possible explanations (better diet, more exercise, etc.), but environmental factors have not yet been considered. The finding by Sauer of higher acute heart disease mortality in non metropolitan areas would appear to argue against improvements in local air quality as an explanation.

\subsection{EVIDENCE FOR CAUSALITY - PHYSTOLOGICAL BASIS}

The Phase III analysis concluded that $\mathrm{SO}_{2}, \mathrm{SO}_{4}=$, and $\mathrm{Mn}$ were all associated with mortality, and that criteria other than statistical were needed to consider causality. Appendix $B$ discusses the known phystological effects of some of these pollutants, notably $\mathrm{SO}_{2}$ and $\mathrm{NO}_{x}$. We note that time-averaged population exposure to $\mathrm{SO}_{2}$ will generally be poorly represented by outdoor concentration levels, since this reactive gas is strongly adsorbed by indoor surfaces. In addition, $\mathrm{SO}_{2}$ is usually absorbed by the moist upper airways and is not known to have long term health effects at the low concentrations involved here. 
Sulfate particles are generally small enough to penetrate deeply into the lung, where they may be dissolved in mucus. If these particles are sufficiently acidic, some changes to respiratory mechanics may result. However, normally there is sufficient ammonia present in situ to neutralize the small particles characteristic of secondary aerosols.

Manganese particles are usually small and are not known to be toxic at the concentration levels involved here. Not only is $\mathrm{Mn}$ an essential trace element, 46 but also, intake through food and water is likely to be larger than through inhalation. These findings of an association between mortality and Mn may indicate a surrogate for some aspect of heavy industry (which produces airborne $\mathrm{Mn}$ ). Analysis of mortality rates by cause and sex would be helpful in evaluating this hypothesis.

In summary, although each of the pollutants showing the strongest associations with mortality have been linked to adverse health effects in some way, none of them is known to have such an association on a physiological basis at the concentrations in question. 


\subsection{CONCLUSTONS}

This analysis shows that concentrations of certain air pollutants may be predictors of 1980* mortality in U.S. cities. The pollutants include sulfur oxides, oxides of nitrogen, particulate trace metals (Fe and $\mathrm{Mn}$ ), and fine particles; it is not possible to define the most important pollutants with certainty. The strength of the association between air pollution and mortality is about 5-10\%, which is somewhat higher than simflar estimates for 1970 mortality. No reasons are evident for this increase, since air concentrations of pollutants have decreased since 1970. No such associations were found for ozone, carbon monoxide, or lead particles; it is not known to what extent these negative findings are due to poor estimates of actual exposures to these pollutants. The analysis also showed that some of the pollutant/mortality associations are sensitive to the selection of data sets for analysis and to the structure of the models used to account for demographic and socioeconomic factors.

This inquiry was conducted in three phases. In the first phase, the po1lutants considered included a number of measured pollutants and one species, sulfate aerosol, for which concentrations were obtained from a numerical model. This procedure allowed a large number of cities (over 900) to be considered, since the limitations of measurement networks were avoided. In the second phase, the unimportant pollutant variables were dropped and a number of detailed statistical checks were made on the validity of the regressions.

Since the first two phases of this analysis concluded that the computed sulfate variable was usually statistically significant and thus very important, the analysis was extended in a third phase to include additional computed air pollutants, $\mathrm{SO}_{2}$ and $\mathrm{NO}_{x}$, in order to test the hypothesis that the success of the sulfate variable may have been due to the use of computed rather than measured values, per se. Although the correlation between computed values of $\mathrm{SO}_{4}=$ and $\mathrm{NO}_{\mathrm{X}}$ was only about 0.45 , there were no statistically significant differences in regressions employing any of the three computed pollutant variables (one at a time), either for all available cities or for various subset combinations. When these statistical comparisons of fixed demographic model regressions were extended to compare results for nine separate pollutants (one at a time), it became apparent that $\mathrm{SO}_{2}$ and manganese provided the lowest regression errors more often than would be predicted by chance, in contrast to sulfate and $\mathrm{NO}_{x}$.

The analysis also indicates that the usefulness of sulfate aerosol as a predictor of total mortality in cities may have increased since 1970 (and presumably earlier). The change may either be due to reduced variance (which could have resulted either from use of a computed measure of sulfate aerosol in the present study rather than actual measurements, or from changes in the covariance structure of the data set), or from an actual change in mortality.

These findings were shown to be generally robust to the presence of influential observations, although not necessarily to major changes in the data sets

\footnotetext{
*Actual 1979 calendar year deaths divided by the population estimated as of April 1, 1980.
} 
sets under consideration. Tests for behavior of the regression residuals (homogeneous variance) were satisfactory. Thus, on statistical grounds, the mortality models which were developed appear to be acceptable.

This analysis did not deal directly with the issue of causality, nor can any study of this type provide such information directly. Neither is it possible to separate acute effects from chronic effects: at best, the study provides hypotheses for further evaluation. However, it should be mentioned that the other variables in this model predict directions and magnitudes of effects due to demographic variability (age and race), cigarette smoking, and drinking water hardness which are in agreement with previous independent estimates. Thus there is no a priori reason to suspect that the air pollution effects shown are artifacts of the analysis. Further investigation appears warranted. On the other hand, cross-sectional analyses necessarily deal with the places of death and not the causes. No causal, i.e., physiological, mechanisms have been proposed which would explain the health effects mechanisms for long term exposure of these pollutants at the relatively low concentrations experienced ca. 1970-1980. Indeed, those pollutants with known adverse health effects at current ambient concentrations, such as lead, $\mathrm{CO}$, and ozone were not shown to be predictors of increased mortality, and some may have $\overline{\text { even indicated }}$ "beneficial" effects, a counterintuitive finding. In addition, there is no strong statistical evidence that past exposures (i.e., 1970) are better predictors of 1980 mortality than 1980 exposure estimates. Further, there is no confirmatory evidence available from international studies. Since the geographic pattern of "unexplained" mortality is not greatly changed by the introduction of air pollution variables into the model, it is possible that some important causal variable(s) may have been omitted from the analysis. 


\subsection{RECOMMNDATIONS}

The finding of possibly significant associations of human mortality with air pollution at current ambient concentrations requires further investigation and confirmation. First, those findings relating to the U.S. should be reviewed for consistency with respect to specific causes of death. Then, the analysis should be repeated for subsets of the population stratified by age, sex,* and race, to preclude the need for demographic adjustment variables. Such an analysis will require partitioning of statewide smoking rates into age, race and sex specific rates, using newly available survey data on behavioral risk factors. Use of age as a stratifying variable rather than as a control variable will reduce the variance of the dependent variable and allow consideration of lifetime exposures to pollution. Elimination of raclal control variables will increase the number of degrees of freedom, and should help compensate for the "noiser" mortality rates incurred when population subsets are used.

Finally, the findings should be confirmed in the light of international mortality experience, the only truly independent data available. This in turn may require inclusion of country of origin as a control variable in the U.S. studies.

* For example, white male mortality rates tend to be high in the Southeast U.S., whereas white female rates are high in the Northeast.

\section{ACKNOWLEDGENT}

The authors would like to thank their colleagues Dr. Neal L. Oden and Dr. J. Shannon at their respective institutions for helpful discussions and advice, and Dr. Richard A. Bradley, the U.S. Department of Energy Project Officer. Some useful comments on an earlier draft were also provided by Dr. Alan Marcus. The manuscript was typed by Donna Cange, with assistance from Rosa Palmore, Pamela Campbell, Liz Seubert, and Claire Lamberti, and was edited by Avril Woodhead. 


\subsection{REFERENCES}

1. Dunglison, Robert. Human Health. Len and Blanchard, Philadelphia, 1844.

2. Lave, L.B. and Seskin, E.P. "Air Pollution and Human Health," Science $169,723-733$ (1970).

3. Lave, L.B. and Seskin, E.P. Air Pollution and Human Health. Johns Hopkins University Press, 1978.

4. Mendelsohn, R. and Orcutt, G. "An Empirical Analysis of Air Pollution Dose-Response Curves," J. Environ. Econ. and Mgmt. 6, 85-106 (1979).

5. Chappie, M. and Lave, L. "The Health Effects of Air Pollution: A Reanalysis," J. Urban Econ. 12, 346-376 (1982).

6. Lipfert, F.W. The Association of Human Mortallty with Air Pollution: Statistical Analyses by Region, by Age, and by Cause of Death. Ph.D. Dissertation, Union Graduate School, Cincinnati, OH (1978). Eureka Publications, Mantua, NJ.

7. Crocker, T.G., Schulze, W., Ben-David, S, and Kneese, A.V. Methods Development for Assessing Air Pollution Control Benefits -- Vol. I: Experiments in the Economics of Air Pollution Epidemiology. Prepared for EPA, EPA-600/5-79-00Ia (1979).

8. Evans, J.S., Tosteson, T. and Kinney, P.L. "Cross-Sectional Mortality Studies and Air Pollution Risk Assessment," Environ. Int. 10, 55-83 (1984).

9. Lipfert, F.W. "Mortality and Air Pollution: Is There a Meaningful Connection?" Env. Sci. Tech. 19, 769-770 (1985).

10. CowelI, M.J. and Hirst, B.L. "Mortality Differences between Smokers and Non Smokers," Transactions, Soc. of Actuaries, Vol. XXXII, pp. 185-261 $(1980)$.

11. Kleinman, J.C., De Gruttola, V.G., Cohen, B.B. and Madans, J.H. "Regional and Urban-Suburban Differentials in Coronary Heart Disease Prevalence and Risk Factor Prevalence," J. Chron. Dis. 34, 11-19 (1981).

12. Mende11, N.R. and Yang, C-C. An Empirical Evaluation of State Tobacco Sales Tax Data as a Predictor of Cigarette Consumption. Prepared by the State University of New York, Feb. 1986. BNL 38877.

13. Selvin, S., Merrill, D., Wong, L. and Sacks, S.T. "Ecologic Regression Analysis and the Study of the Influence of Air Qualtty on Mortality," Environ. Health Persp. 54, 333-340 (1984).

14. Sauer, H.I. Geographic Patterns in the Risk of Dying and Associated Factors, Ages 35-74 Years. United States, 1968-72. DHHS Pub. No. (PHS) 80-1402, Sept. 1980 . 
15. Lave, L.B. Quantitative Risk Assessment in Regulation. Brookings Institution, Washington, DC (1982).

16. U.S. Department of Commerce. City and County Data Book, 1982. U.S. Government Printing office, Washington, DC, 1983.

17. Feinleib, M., Fabsitz, R. and Sharrett, A.R. Mortality from Cardiovascular and Non-cardiovascular Diseases for U.S. Cities. U.S. Department of Health, Education and Welfare, PHS, Nat. Inst. of Health, DHEW Publication No. (NIH) 79-1453, 1979.

18. Lipfert, F.W. "Air Pollution and Mortalfty: Specification Searches Using SMSA-based Data," J. Environ. Econ. \& Mgmt. 11, 208-243 (1984).

19. Lacey, R.F. Changes in Water Hardness and Cardiovascular Death-Rates. Technical Report TR 171, Water Research Center, Medmenham, England, Nov. 1981 .

20. Watson, J.G., Chow, J.C. and Shah, J.J. Analysis of Inhalable and Fine Particulate Matter Measurements, prepared for U.S. Environmental Protection Agency, Report No. EPA-450/4-81-035, Dec. 1981 .

21. U.S. Environmental Protection Agency, National Air Quality and Emission Trends Report, 1982. EPA 450/4-84-002, March 1984.

22. Shannon, J.D. "A Model of Regional Long-term Coverage Sulfur Atmospheric Pollution, Surface Removal, and Wet Horizontal Flux," Atm. Env. 15:5, 689-701 (1981).

23. Haenszel, W., Shemin, M.B. and Miller, H.P. Tobacco Smoking Patterns in the United States, Public Health Monograph No. 45, pp. 1-111, 1956.

24. Tukey, J.W., Exploratory Data Analysis. Addison-We1sey Publishing Co.,
1977.

25. Dixon, W.J., Brown, M.B., Engelman, L., Frane, J.W. and Jennrich, R.I. BMDP-77, Biomedical Computer Programs, P-Series. Univ. of California Press, Berkeley, CA, 1977.

26. SPSS Inc. SPSS-X User's Guide. McGraw-Hill Book Company, New York, NY,
1983.

27. Cliff, A.D. and Ord, J.K. Spatial Processes: Models and Applications. Pion, London, 1981.

28. Snedecor, G.W. and Cochran, W.G. Statisttcal Methods. 6th. ed., 1967, pp. 195-197, The Iowa State University Press, Ames, Iowa.

29. Wolfe, D.A. "On Testing Equality of Related Correlation Coefficients," Bionetrika 63, 214-215 (1976).

30. Gordon, $\mathrm{T}$. and Kannel, W.B. "Drinking and Mortality - The Framingham Study," Am. J. Epid. 120, 97-107 (1984). 
31. Lew, E.A. and Garfunkel, L. "Variations in Mortality by Weight Among 75,000 Men and Women," J. Chron. Dis. 32, 563-576 (1979).

32. Masironi, R. Geochemistry and Cardiovascular Diseases. In Environmental Geochemistry and Health, Phil. Trans. R. Soc. Lond. B 288, 1-216 (1979), pp. 193-201.

33. Kitagawa, E.M. and Hauser, P.M. Differential Mortality in the United States: A Study in Socio-economic Epidemiology, Harvard University Press, 1973 .

34. Rosenwaike, I. "Mortality Differentlals among Persons Born in Cuba, Mexico, and Puerto Rico Residing in the United States, 1979-1981, " Am. J. Publ. Health 77, 603-606 (1987).

35. Gardocki, G.J. Visits to Office-Based Physicians by Hispanic Persons: United States, 1980-81. NCHS Advance Data, No. 129, Feb. 17, 1987.

36. Leoni, V., Fabiani, L. and Ticchiarelli, L. "Water Hardness and Cardiovascular Mortality Rate in Abruzzo, Italy," Arch. of Env. Health 40, $274-278$ (1985).

37. Pocock, S.J., Shaper, A.G., Cook, D.G., Packham, R.F., Lacey, R.F., Powe11, P. and Russel1, P.F. "British Regional Heart Study: Geographic Variations in Cardiovascular Mortality, and the Role of Water Quality," British Med. J. (May 1980), 1243-1249.

38. Ventura, S. "Selected Vital and Health Statistics in Poverty and Non-poverty Areas of 19 Large Cities, United States, 1969-71, "Vital and Health Statistics: Series 21, No. 16, National Center for Health Statistics, Rockville, MD (1975).

39. Winkelstein, W., Jr. "Some Ecological Studies of Lung Cancer and Ischaemic Heart Disease Mortality in the United States," Int. J. Epidemiol. 14, 39-47 (1985).

40. Wallace, L. and Gill, V.J. Correlations Between Age-Adjusted Mortality Rates for White Males and Females in the United States. National Technical Information Service, PB 82-224 114 .

41. Chinn, S., duV. Florey, C., Baldwin, I.G. and Goigal, M. "The Relation of Mortality in England and Wales, 1969-73, to Measurements of Air Pollution," J. Epidem. Commun. Health 35, 174-179 (1981).

42. Göttinger, H.W. "A1r Pollution Health Effects in the Munich Metropolitan Area: Preliminary Results Based on a Statistical Model," Environ. Internat. 9, 207-220 (1983).

43. Krzyzanowski, M. and Wojtyniak, B. "Ten-year Mortality in a Sample of an Adult Population in Relation to Air Pollution," J. of Epid. and Comm. Health 36, 262-268 (1982). 
44. Hanis, N.M., Shallenberger, L.G., Donalestice, D.L. and Sales, E.A. "A Retrospective Mortality Study of Workers in Three Major U.S. Refineries and Chemical Plants," J. Occ. Med. 27, 361-369 (1.985).

45. Stamler, J. "The Marked Decline in Coronary Heart Disease Mortality Rates in the United States, 1968-1981; Summary of Findings and Possible Explanations," Cardiology 72, 11-22 (1985).

46. Committee on Biologic Effects of Atmosphexic Pollutants, National Research Council. Manganese. National Academy of Sciences, Washington, DC, 1973. 

APPENDIX A

AIR QUALITI AND

DRINKING WATER HARDNESS

DATA BASE

(173 cit1es) 
C1ties in the 53-c1ey Data Set

(dichotomous samplers)

\begin{tabular}{|c|c|}
\hline $\begin{array}{l}\text { Vu } \\
\text { vy } \\
\text { V }\end{array}$ & 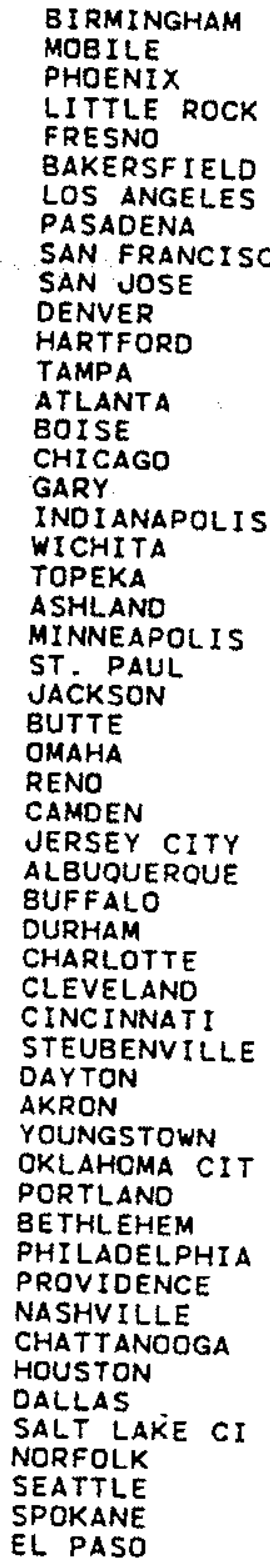 \\
\hline
\end{tabular}


AIR QUALITY DATA - MEDIAN CONCENTRATIONS, IN $\mu G / \mathrm{M}^{3}$ EXCZPT AS NOTED

WATER

\begin{tabular}{|c|c|c|c|c|c|c|c|c|c|c|c|c|c|c|c|}
\hline \multirow[b]{2}{*}{ STATE } & \multirow[b]{2}{*}{ CITY } & \multirow{2}{*}{$\begin{array}{l}\text { HARD. } \\
\text { (ppm) }\end{array}$} & \multirow{2}{*}{$\begin{array}{l}\text { ASTRAP } \\
\mathrm{SO}_{4}\end{array}$} & \multicolumn{3}{|c|}{$\infty 0$ (ppe) } & \multicolumn{3}{|c|}{ IRON } & \multicolumn{3}{|c|}{ LEAD } & \multicolumn{3}{|c|}{ SARRAD $\mathrm{SO}_{4}$} \\
\hline & & & & $\mathbf{F} \mathbf{3}$ & FoBS ${ }^{a}$ & mons & HED. & FoBs ${ }^{\mathrm{a}}$ & FION & MED. & foBs ${ }^{\mathrm{a}}$ & $\operatorname{mad}{ }^{6}$ & FED. & & \\
\hline AK & ANCHORAGE & 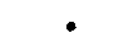 & & 2.30 & 14560 & 4 & 1.28 & 53 & 1 & 0.47 & 354 & 3 & 2.70 & 53 & \\
\hline AL & BTRMINGHAM & 59 & 5.09 & 2.10 & 11592 & 7 & 1.34 & 82 & 2 & 0.81 & 149 & 3 & 10.40 & 20 & \\
\hline $\mathrm{AL}$ & GADSDEN & 72 & 6.32 & - & - & - & 1.43 & 75 & 2 & 0.25 & 75 & 2 & 13.00 & 15 & \\
\hline AL & MOBILE & 20 & 4.78 & - & - & - & 0.66 & 56 & 1 & 0.33 & 56 & 1 & . & - & \\
\hline AR & LITTLE ROCK & 18 & 2.76 & & & - & 0.59 & 67 & 1 & 0.53 & 98 & 2 & - & - & \\
\hline $\mathrm{AZ}$ & PHOENIX & 244 & 1.35 & 2.20 & 23351 & 6 & 2.89 & 927 & 4 & 0.74 & 940 & 4 & 5.10 & 372 & \\
\hline $\mathrm{AZ}$ & TUCSON & 138 & 1.49 & 2.00 & 12576 & 3 & 0.93 & 130 & 1 & 0.31 & 647 & 6 & 4.70 & 186 & \\
\hline $\mathrm{CA}$ & BAKERSFIELD & 108 & 1.89 & 1.20 & 4273 & 1 & 2.23 & 51 & 1 & 0.55 & 375 & 2 & & & \\
\hline $\mathrm{CA}$ & BERKELEY & 26 & 1.95 & - & & - & 0.44 & 57 & 1 & 0.42 & 57 & 1 & 5.00 & 24 & \\
\hline $\mathrm{CA}$ & BURBANK & 207 & 2.08 & & & - & 1.55 & 8 & 1 & & - & . & 4.70 & 8 & \\
\hline $\mathrm{CA}$ & FRESNO & 119 & 0.73 & 1.80 & 14942 & 3 & 1.66 & 56 & 1 & 0.73 & 235 & 2 & 5.10 & 24 & \\
\hline $\mathrm{CA}$ & LONG BEACH & 62 & 2.08 & 2.50 & 6836 & 1 & 0.85 & 8 & 1 & 0.64 & 153 & 2 & 8.10 & 8 & \\
\hline $\mathrm{CA}$ & LOS ANGELES & 125 & 2.08 & 3.30 & 6143 & 4 & 1.58 & 96 & 2 & 0.90 & 417 & 3 & 10.80 & 185 & $\mathrm{~J}$ \\
\hline $\mathrm{CA}$ & OAKLAND & 26 & 1.95 & 1.40 & 3617 & 2 & 1.21 & 8 & 1 & 0.95 & 8 & 1 & 4.80 & 8 & \\
\hline $\mathrm{CA}$ & PASADENA & 126 & 2.08 & 3.20 & 5189 & 2 & 0.81 & 7 & 1 & 0.80 & 164 & 3 & 7.00 & 6 & \\
\hline $\mathrm{CA}$ & SACRAMENTO & 21 & 0.74 & 0.70 & 6251 & 3 & 1.02 & 111 & 1 & 0.38 & 282 & 3 & 3.00 & 24 & \\
\hline $\mathrm{CA}$ & SAN BERNARDINO & 133 & 1.11 & 2.50 & 5544 & 2 & 1.90 & 51 & 1 & 0.67 & 261 & 2 & 11.10 & 24 & \\
\hline $\mathrm{CA}$ & SAN DIEGO & 207 & 2.27 & 1.10 & 12652 & 3 & 1.29 & 116 & 1 & 0.48 & 303 & 2 & 9.80 & 24 & \\
\hline $\mathrm{CA}$ & SAN FRANCISCO & 58 & 0.39 & 2.20 & 5539 & 2 & 0.81 & 61 & 2 & 0.30 & 235 & 2 & 5.40 & 8 & \\
\hline $\mathrm{CA}$ & SAN JOSE & 194 & 0.39 & 3.00 & 3453 & 1 & 1.14 & 126 & 1 & 0.46 & 429 & 2 & 3.10 & 24 & \\
\hline $\mathrm{CA}$ & SANTA ANA & 141 & 4.13 & & & . & 1.06 & 51 & 1 & 0.59 & 137 & 1 & 8.65 & 16 & \\
\hline$\infty$ & DENVER & 116 & 1.95 & 3.70 & 20951 & 4 & 1.61 & 27 & 1 & 0.18 & 67 & 2 & 6.00 & 734 & \\
\hline CT & BRIDGEPORT & 29 & 9.88 & 2.70 & 5459 & 1 & 0.71 & 71 & 1 & 0.43 & 266 & 3 & 8.40 & 29 & \\
\hline CT & HARTFORD & 12 & 7.91 & 3.10 & 7890 & 2 & 0.93 & 21 & 1 & 0. & 216 & 4 & 9.70 & 21 & \\
\hline $\mathrm{CT}$ & NEW HAVEN & 43 & 9.48 & 2.20 & 3139 & 1 & 1.26 & 53 & 1 & 0.61 & 181 & 2 & 8.50 & 13 & \\
\hline CT & WATERBURY & 24 & 9.48 & 3.10 & 897 & 1 & 1.31 & 70 & 1 & 0. & 385 & 5 & 8.80 & 30 & \\
\hline$D C$ & WASHINGTON & 102 & 11.79 & 1.80 & 13243 & 7 & 0.88 & 37 & 1 & 1.00 & 554 & 9 & 11.70 & 144 & \\
\hline $\mathrm{DE}$ & WILMINGTON & 48 & 12.08 & 1.60 & 8482 & 1 & 0.44 & 30 & 1 & 0.40 & 210 & 3 & & - & \\
\hline FL & JACKSONVILLE & 274 & 4.89 & 1.50 & 24201 & 7 & 0.45 & 107 & 1 & 0.36 & 277 & 3 & 11.40 & 19 & \\
\hline FL & ORLANDO & 123 & 4.27 & 1.90 & 688 & 1 & 0.54 & 50 & 1 & 0.31 & 50 & 1 & - & - & \\
\hline FL & PENSACOLA & 20 & 4.37 & 0.60 & 3963 & 2 & 0.33 & 59 & 1 & 0.22 & 59 & 1 & & . & \\
\hline FL & TAMPA & 81 & 8.43 & 1.20 & 21823 & 5 & 0.84 & 129 & 1 & 0.53 & 662 & 6 & 9.00 & 138 & \\
\hline GA & ATLANTA & 20 & 6.75 & 2.10 & 8632 & 5 & 0.87 & 99 & 1 & 0.52 & 99 & 1 & 13.30 & 20 & \\
\hline GA & COLUMBUS & 25 & 4.98 & . & 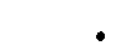 & . & 0.52 & 82 & 1 & 0.21 & 82 & 1 & & & \\
\hline
\end{tabular}

a Total number of observations included

b Number of monitoring sites supplying data. 


\begin{tabular}{|c|c|c|c|c|c|c|c|c|c|c|c|c|c|c|c|}
\hline \multirow[b]{2}{*}{ STATE } & \multirow[b]{2}{*}{ CITY } & \multirow{2}{*}{$\begin{array}{l}\text { WATKR } \\
\text { HARD. } \\
\text { (ppo) }\end{array}$} & \multirow{2}{*}{$\begin{array}{l}\text { ASTRAP } \\
\mathrm{SO}_{4}\end{array}$} & \multicolumn{3}{|c|}{$C O$ (ppm) } & \multicolumn{3}{|c|}{ IRON } & \multicolumn{3}{|c|}{ LRAD } & \multicolumn{3}{|c|}{$\mathrm{SAROAD} \mathrm{SO}_{k}$} \\
\hline & & & & HD. & FoBS ${ }^{a}$ & $\operatorname{AMN}{ }^{6}$ & 1EDD. & foBs $^{\mathrm{a}}$ & $\operatorname{MON}^{\mathrm{B}}$ & W. & fOBS $^{\mathrm{a}}$ & 7max' & BD. & fOBS $^{\mathrm{a}}$ & mow \\
\hline IA & CEDAR RAPIDS & 99 & 2.99 & 1.20 & 4546 & 1 & 0.70 & 102 & 1 & 0.25 & 102 & 1 & 6.90 & 31 & 1 \\
\hline IA & DAVENPORT & 128 & 5.01 & 1.40 & 4817 & 1 & 0.80 & 151 & 2 & 0.35 & 195 & 3 & 7.40 & 28 & 1 \\
\hline IA & DES MOINES & 78 & 2.67 & 3.10 & 11515 & 3 & 0.92 & 123 & 1 & 0.39 & 462 & 3 & 5.60 & 22 & 1 \\
\hline IA & DUBUQUE & 282 & 3.84 & 1.80 & 4598 & 1 & 0.37 & 73 & 1 & 0.13 & 110 & 1 & 9.30 & 20 & 1 \\
\hline IA & WATERLOO & 241 & 2.99 & & • & - & 0.81 & 45 & 1 & 0.13 & 45 & 1 & - & . & - \\
\hline ID & BOISE CITY & 85 & 0.49 & 3.00 & 8108 & 2 & 1.06 & 26 & 1 & 0.66 & 160 & 3 & 2.00 & 26 & 1 \\
\hline IL & CHICAGO & 133 & 7.65 & 2.40 & 19332 & 9 & 1.86 & 58 & 2 & 0.35 & 2530 & 18 & . & - & - \\
\hline IL & GRANITE CITY & 182 & 8.97 & 2.00 & 6130 & 1 & 3.52 & 18 & 1 & 0.44 & 18 & 1 & - & - & - \\
\hline IL & JOLIET & 361 & 7.65 & 1.30 & 4129 & 3 & 0.62 & 17 & 1 & 0.25 & 17 & 1 & - & . & - \\
\hline IL & PEORIA & 425 & 4.99 & 1.90 & 3416 & 2 & 0.99 & 25 & 1 & 0.28 & 25 & 1 & . & . & . \\
\hline IL & ROCKFORD & 352 & 3.99 & 2.40 & 3288 & 1 & 0.49 & 39 & $i$ & 0.19 & 39 & 1 & - & . & . \\
\hline IN & BLOOMINGTON & 111 & 10.25 & . & . & . & 0.57 & 23 & 1 & 0.63 & 23 & 1 & - & - & - \\
\hline IN & EAST CHICAGO & 133 & 7.19 & 1.90 & 1215 & 2 & 3.29 & 31 & 3 & 0.67 & 728 & 5 & 10.40 & 62 & 4 \\
\hline IN & ELKHART & 203 & 7.52 & & . & . & 0.95 & 11 & 1 & 0.37 & 11 & 1 & . & . & - \\
\hline IN & EVANSVILLE & 100 & 7.70 & 1.70 & 2417 & 2 & 0.68 & 105 & 1 & 0.28 & 105 & 1 & 13.60 & 20 & 1 \\
\hline $\mathrm{IN}$ & FORT WAYNE & 76 & 7.18 & . & . & - & 0.92 & 80 & 1 & 0.45 & 248 & 2 & 12.90 & 25 & 1 \\
\hline IN & GARY & 136 & 7.19 & 0.70 & 1094 & 2 & 3.07 & 64 & 2 & 0.33 & 189 & 3 & 9.20 & 91 & 6 \\
\hline IN & HAMMDND & 136 & 7.19 & 0.90 & 67 & 1 & 1.74 & 119 & 3 & 0.58 & 816 & 8 & 9.40 & 103 & 8 \\
\hline IN & INDIANAPOLIS & 241 & 8.76 & 3.00 & 11452 & 4 & 0.64 & 110 & 3 & 0.47 & 990 & 16 & 10.40 & 6 & 1 \\
\hline IN & KOKOMD & 402 & 8.76 & . & . & . & 1.46 & 19 & 1 & 0.45 & 109 & 1 & . & - & . \\
\hline $\mathrm{IN}$ & LAFAYETTE & 402 & 8.56 & . & . & - & 0.99 & 23 & 1 & 0.57 & 23 & $i$ & - & . & - \\
\hline IN & MARION & 138 & 8.76 & - & . & $\therefore$ & 0.65 & 24 & 1 & 0.42 & 24 & 1 & . & - & - \\
\hline IN & NEW ALBANY & 96 & 10.86 & • & . & . & 0.93 & 31 & 2 & 0.46 & 131 & 2 & 14.00 & 18 & 1 \\
\hline IN & RICHMND & 274 & 8.27 & - & - & - & 1.11 & 44 & 2 & 0.64 & 44 & 2 & - & - & - \\
\hline IN & SOUTH BEND & 403 & 6.97 & 1.10 & 898 & 1 & 0.82 & 149 & 2 & 0.30 & 186 & 5 & 8.60 & 19 & 1 \\
\hline IN & TERRE HAUTTE & 208 & 10.25 & . & . & . & 0.82 & 99 & 2 & 0.20 & 99 & 2 & 13.50 & 24 & 1 \\
\hline $\mathrm{KS}$ & KANSAS CITY & 276 & 3.30 & 1.50 & 6581 & 2 & 1.70 & 186 & 2 & 0.29 & 247 & 3 & 8.00 & 36 & 2 \\
\hline KS & TOPEKA & 100 & 1.93 & - & - & . & 0.93 & 84 & 2 & 0.25 & 84 & 2 & 6.60 & 21 & 1 \\
\hline kS & WICHITA & 86 & 1.78 & 1.60 & 7841 & 3 & 0.65 & 37 & 2 & 0.29 & 37 & 2 & 5.10 & 21 & 1 \\
\hline $\mathrm{KY}$ & ASHLAND & 93 & 9.70 & 1.50 & $786 \epsilon$ & 4 & 4.33 & 16 & 1 & 1.03 & 16 & 1 & 17.50 & 16 & 1 \\
\hline $\mathrm{KY}$ & COVINGTON & 112 & 11.42 & 2.00 & 1974 & 1 & 1.26 & 116 & 1 & 0.38 & 116 & 1 & 14.50 & 18 & 1 \\
\hline $\mathrm{KY}$ & LOUISVILLE & 90 & 10.86 & 2.50 & 10784 & 3 & 0.76 & 62 & 1 & 0.36 & 62 & 1 & . & . & - \\
\hline LA & BATON ROUGE & 38 & 3.67 & 0.60 & 882 & 1 & 0.46 & 104 & 1 & 0.51 & 104 & 1 & 10.50 & 5 & 1 \\
\hline IA & NEW ORLEANS & 74 & 4.34 & 0.80 & 3446 & 2 & 0.69 & 113 & 1 & 0.32 & 113 & 1 & 13.00 & 5 & 1 \\
\hline
\end{tabular}

a Total number of observations included

b Number of monttoring sites supplying data. 
AIR QUALITY DATA - MEDTIAN CONCENTRATIONS, IN $\mu G / \mathrm{A}^{3}$ EXCCKTT AS NOTKO

STATE CTTY

IA DAVENPORT

IA DES MDINES

IA DUBUQUE

ID BOISE CITY

IL CHICAGO

IL GRANITE CITY

IL JOLIET

II PEORIA

IL ROCKFORD

IN BLOOMINGTON

IN

IN

IN

IN

IN

IN

IN

IN

IN

IN

IN

IN

IN

KS

KS TRCA

KY ASHLAND

KY COVINGTON

$\mathrm{KY}$ LOUISVILLE

LA BATON ROUGE

LA NEW ORLEANS

LA SHREVEPORT
IA WATERLOO

MA BOSTON

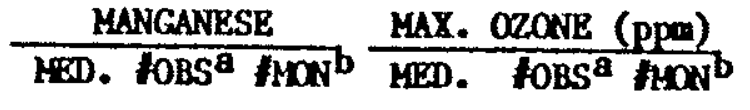

\section{$\begin{array}{lll}0.036 & 151 & 2\end{array}$}

$\begin{array}{lll}0.032 & 123 & 1\end{array}$

$\begin{array}{lll}0.020 & 73 & 1\end{array}$

$\begin{array}{lll}0.029 & 45 & 1\end{array}$

$\begin{array}{lll}0.023 & 26 & 1\end{array}$

$\begin{array}{lll}0.077 & 58 & 2\end{array}$

$\begin{array}{lll}0.188 & 18 & 1\end{array}$

$\begin{array}{lll}0.020 & 17 & 1\end{array}$

$\begin{array}{lll}0.037 & 25 & 1\end{array}$

$\begin{array}{lll}0.027 & 39 & 1\end{array}$

$\begin{array}{lll}0.028 & 23 & 1\end{array}$

$\begin{array}{lll}0.185 & 31 & 3\end{array}$

$\begin{array}{lll}0.034 & 11 & 1\end{array}$

$\begin{array}{lll}0.023 & 105 & 1\end{array}$

$0.033 \quad 80 \quad 1$

$\begin{array}{lll}0.154 & 64 & 2\end{array}$

$0.103119 \cdot 3$

$\begin{array}{lll}0.021 & 110 & 3\end{array}$

$\begin{array}{lll}0.091 & 19 & 1\end{array}$

$\begin{array}{lll}0.036 & 23 & 1\end{array}$

$\begin{array}{lll}0.045 & 24 & 1\end{array}$

$0.030 \quad 31 \quad 2$

$0.064 \quad 44 \quad 2$

$0.044 \quad 149 \quad 2$

$0.020 \quad 99 \quad 2$

$\begin{array}{lll}0.040 & 186 & 2\end{array}$

$\begin{array}{lll}0.028 & 84 & 2\end{array}$

$\begin{array}{lll}0.020 & 37 & 2\end{array}$

$\begin{array}{lll}0.111 & 16 & 1\end{array}$

$0.062 \quad 116 \quad 1$

$\begin{array}{lll}0.024 & 62 & 1\end{array}$

$0.020 \quad 104 \quad 1$

$\begin{array}{lll}0.020 & 113 & 1\end{array}$

$0.028 \quad 105 \quad 1$

$0.020 \quad 95 \quad 1$

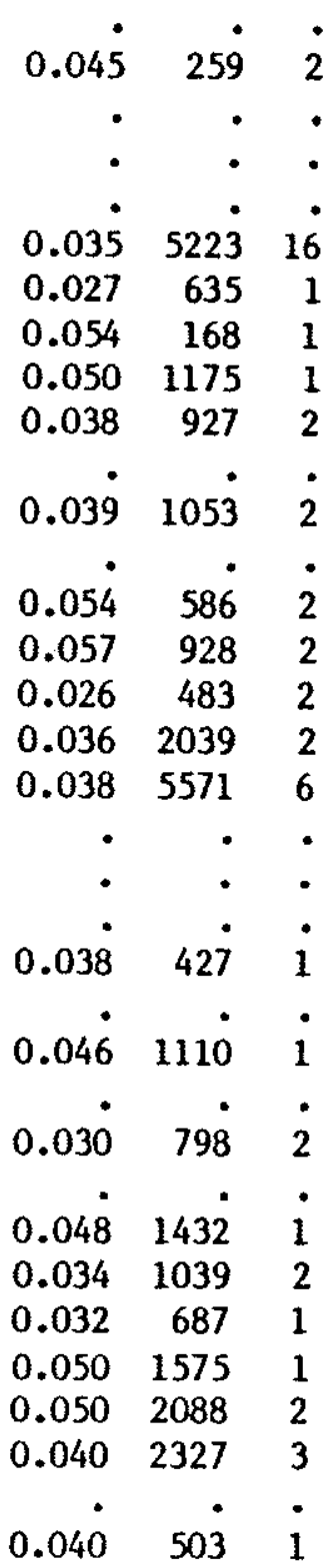

carritur HED. FOBS $^{\mathrm{a}}$ MaN $^{\mathrm{b}}$

$\begin{array}{lll}0.005 & 151 & 2\end{array}$

$\begin{array}{lll}0.001 & 123 & 1\end{array}$

$0.001 \quad 73 \quad 1$

$0.001 \quad 45 \quad 1$

$0.001 \quad 26 \quad 1$

$0.003 \quad 58 \quad 2$

$\begin{array}{lll}0.009 & 18 & 1\end{array}$

$0.00217 \quad 1$

$\begin{array}{lll}0.002 & 25 & 1\end{array}$

$\begin{array}{lll}0.006 & 39 & 1\end{array}$

$\begin{array}{lll}0.002 & 23 & 1\end{array}$

$0.003 \quad 618 \quad 5$

$0.001 \quad 11 \quad 1$

$0.001 \quad 105 \quad 1$

$0.001 \quad 165 \quad 2$

$0.002 \quad 183 \quad 3$

$\begin{array}{lll}0.003 & 456 \quad 7\end{array}$

$0.004 \quad 280 \quad 6$

$0.004 \quad 70 \quad 1$

$\begin{array}{lll}0.000 & 23 & 1\end{array}$

$0.001 \quad 24 \quad 1$

$0.001 \quad 31 \quad 2$

$0.001 \quad 44 \quad 2$

$0.001 \quad 149 \quad 2$

$\begin{array}{lll}0.001 & 99 & 2\end{array}$

$0.002 \quad 186 \quad 2$

$0.001 \quad 84 \quad 2$

$\begin{array}{lll}0.001 & 37 \quad 2\end{array}$

$\begin{array}{lll}0.003 & 16 & 1\end{array}$

$0.002 \quad 116 \quad 1$

$\begin{array}{lll}0.002 & 62 & 1\end{array}$

$\begin{array}{lll}0.001 & 104 & 1\end{array}$

$\begin{array}{lll}0.001 & 113 & 1\end{array}$

$0.001 \quad 105 \quad 1$

$\begin{array}{lll}0.001 & 95 & 1\end{array}$
VANADILA HED. fORS $^{\mathrm{a}}$ AMN $^{\mathrm{b}}$

DIOAOT. PARTICILATR

FTNE TOTAL FIRE-S TOT-S

$\begin{array}{lll}0.005 & 151 \quad 2\end{array}$ $\begin{array}{lll}0.005 & 123 \quad 1\end{array}$

$\begin{array}{lll}0.005 & 73 & 1\end{array}$

$\begin{array}{lll}0.005 & 45 & 1\end{array}$

$0.005 \quad 26 \quad 1$

$0.005 \quad 58 \quad 2$

$0.178 \quad 17 \quad i$

$0.091 \quad 25 \quad 1$

$\begin{array}{lll}0.055 & 39 & 1\end{array}$

$0.01131 \quad 3$

$0.005 \quad 86 \quad i$

$0.005 \quad 56 \quad 1$

$0.009 \quad 64 \quad 2$

$0.006 \quad 84 \quad 1$

$0.005 \quad 843$

$\begin{array}{lllll}12.120 & 33.010 & 1.040 & 1.430\end{array}$

$\begin{array}{llll}21.040 & 45.190 & 5.040 & 5.160\end{array}$

0.005 is $\quad$ i

$0.006 \quad 123 \quad i$

$0.005 \quad 84 \quad 1$

$0.005 \quad 186 \quad 2$

$0.005 \quad 84 \quad 2$

$0.006 \quad 37 \quad 2$

$0.01016 \quad 1$

$0.005116 \quad 1$

$0.005 \quad 62 \quad 1$

$\begin{array}{lll}0.005 & 104 & 1\end{array}$

$0.012 \quad 113 \quad 1$

0.005105

$0.047 \quad 95 \quad 1$

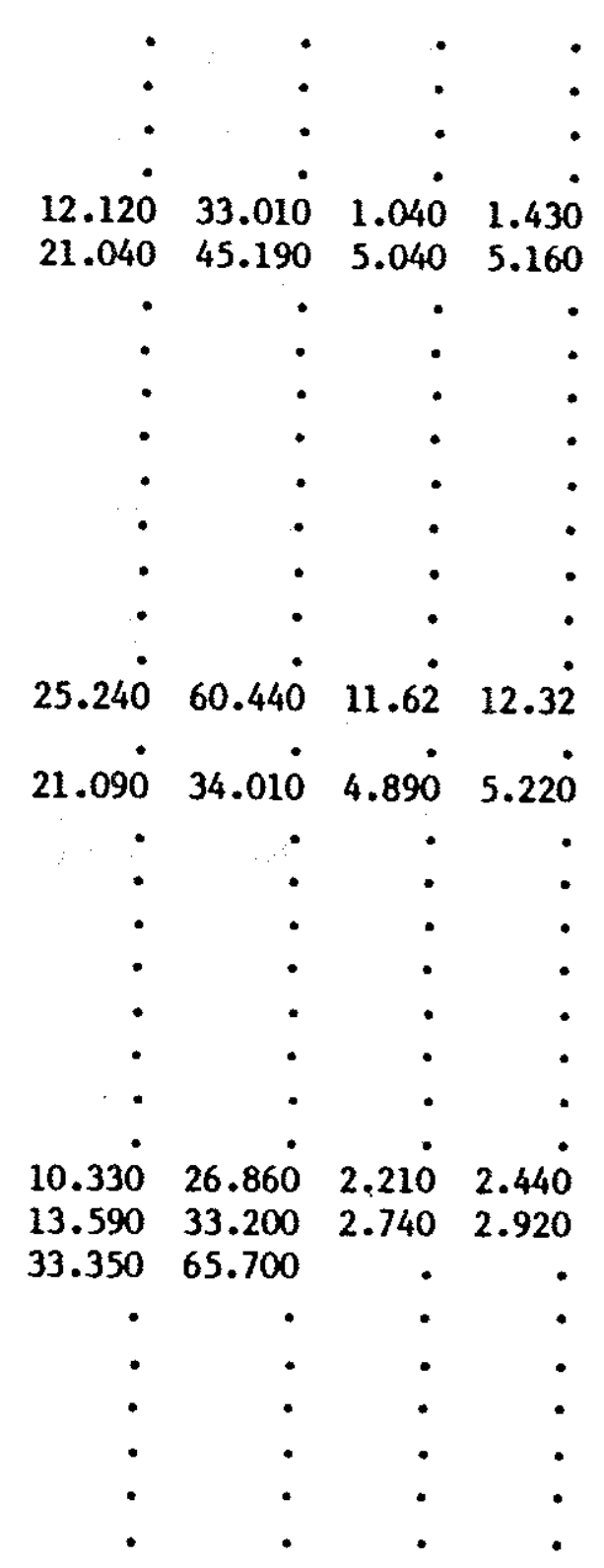

a Total number of observations included

b Number of monitoring sites supplying data. 
AIR QUALITY DATA - MEDIAN CONCWTTRATIONS, IN $\mu G / \mathrm{A}^{3}$ EXCGPT AS NOTED

\begin{tabular}{|c|c|c|c|c|c|c|c|c|c|c|c|c|c|c|c|c|c|}
\hline \multirow{2}{*}{ STATB } & \multirow[b]{2}{*}{ GTT } & \multicolumn{3}{|c|}{ MANGANESE } & \multicolumn{3}{|c|}{ MAX. OZONR (ppen) } & \multicolumn{3}{|c|}{ camme } & \multicolumn{3}{|c|}{ VAKADTIY } & \multicolumn{4}{|c|}{ DIGIOr. PARTICULATR } \\
\hline & & NED. & foBsa & $\operatorname{man}{ }^{b}$ & MED. & foBs ${ }^{\mathrm{a}}$ & frawb & KED. & foBs $^{\mathbf{a}}$ & $\operatorname{fmaN}^{b}$ & $\overline{\text { HED. }}$ & foBS ${ }^{a}$ & hodb & FINE & mơtal & FINE-S & TOT-S \\
\hline MA & BROCKTON & 0.027 & 30 & 1 & - & • & - & 0.002 & 30 & 1 & 0.041 & 30 & 1 & - & - & - & - \\
\hline MA & CAMBRIDGE & 0.020 & 52 & 1 & - & - & - & 0.001 & 52 & 1 & 0.036 & 52 & 1 & - & - & - & - \\
\hline MA & FAIL RIVER & 0.020 & 63 & 1 & 0.052 & 89 & 1 & 0.001 & 63 & 1 & 0.059 & 63 & 1 & - & - & . & - \\
\hline MA & LAWRENCE & 0.020 & 40 & 1 & 0.043 & 250 & 1 & 0.001 & 40 & 1 & 0.051 & 40 & 1 & - & - & - & • \\
\hline MA & LOWELL & 0.020 & 26 & 1 & - & - & - & 0.002 & 26 & 1 & 0.051 & 26 & 1 & - & - & - & - \\
\hline MA & NEW BEDFORD & 0.020 & 81 & 1 & - & - & - & 0.001 & 81 & 1 & 0.047 & 81 & 1 & - & - & - & - \\
\hline MA & SPRINGFIELD & 0.020 & 95 & 2 & 0.053 & 504 & 1 & 0.002 & 95 & 2 & 0.062 & 95 & 2 & - & . & - & - \\
\hline MA & WORCESTER & 0.020 & 113 & 2 & 0.051 & 731 & 3 & 0.001 & 113 & 2 & 0.053 & 113 & 2 & - & - & - & • \\
\hline $\mathbf{M D}$ & BALTIMORE & 0.056 & 53 & 1 & 0.033 & 2052 & 4 & 0.002 & 53 & 1 & 0.031 & 53 & 1 & . & - & - & . \\
\hline ME & PORTLAND & 0.020 & 107 & 2 & - & . & - & 0.001 & 107 & 2 & 0.062 & 107 & 2 & . & . & - & . \\
\hline MI & ANN ARBOR & 0.020 & 30 & 1 & $\cdot$ & - & - & 0.001 & 30 & 1 & 0.005 & 30 & 1 & . & . & - & - \\
\hline MI & DETROIT & 0.106 & 95 & 2 & 0.031 & 2841 & 3 & 0.006 & 95 & 2 & 0.007 & 95 & 2 & - & - & - & . \\
\hline MII & FLINT & 0.035 & 87 & 2 & 0.049 & 1220 & 1 & 0.001 & 87 & 2 & 0.005 & 87 & 2 & - & - & . & . \\
\hline MI & GRAND RAPIDS & 0.041 & 22 & 2 & 0.032 & 1128 & 2 & 0.003 & 22 & 2 & 0.005 & 22 & 2 & - & - & . & . \\
\hline MI & LANSING & 0.020 & 73 & 1 & 0.047 & 655 & 2 & 0.001 & 73 & 1 & 0.005 & 73 & $\overline{1}$ & . & . & . & . \\
\hline$M N$ & DULUTH & 0.032 & 114 & 2 & . & - & - & 0.001 & 114 & 2 & 0.005 & 114 & 2 & - & - & . & : \\
\hline $\mathbb{M N}$ & MTNEAPOLIS & 0.025 & 170 & 4 & 0.018 & 177 & 1 & 0.001 & 170 & 4 & 0.005 & 170 & 4 & 13.680 & 29.230 & 2.080 & 2.560 \\
\hline $\mathbf{M N}$ & ST PAIL & 0.034 & 60 & 2 & - & - & - & 0.003 & 60 & 2 & 0.005 & 60 & 2 & 12.920 & 25.470 & 2.150 & 2.300 \\
\hline$M D$ & RAYTOWN & 0.035 & 29 & 1 & - & - & - & 0.001 & 29 & 1 & 0.005 & 29 & 1 & • & • & - & . \\
\hline MS & JACKSON & 0.030 & 69 & 2 & 0.057 & 1253 & 1 & 0.002 & 69 & 2 & 0.005 & 69 & 2 & 15.710 & 31.920 & 4.780 & 5.140 \\
\hline $\mathrm{Mr}$ & BILLINGS & 0.040 & 224 & 2 & 0.033 & 494 & 2 & 0.002 & 203 & 2 & 0.010 & 172 & 2 & . & . & . & . \\
\hline Mr & BUTTE-SILVER BO & 0.059 & 553 & 6 & 0.030 & 527 & 1 & 0.008 & 570 & 6 & 0.010 & 289 & 4 & 7.210 & 21.910 & 1.030 & 1.030 \\
\hline MT & GREAT FALLS & 0.023 & 117 & 1 & - & - & - & 0.002 & 115 & 1 & 0.010 & 105 & 1 & - & - & - & - \\
\hline NC & CHARLOTTE & 0.020 & 115 & 1 & 0.054 & 2286 & 6 & 0.001 & 115 & 1 & 0.014 & 115 & 1 & 22.600 & 35.760 & 4.470 & 4.910 \\
\hline NC & DURHAM & 0.020 & 137 & 1 & - & - & - & 0.002 & 137 & 1 & 0.018 & 137 & 1 & 16.790 & 25.060 & 5.230 & 5.420 \\
\hline NC & GREENSBORO & 0.020 & 44 & 1 & . & - & - & 0.001 & 44 & 1 & 0.032 & 44 & 1 & - & - & - & - \\
\hline $\mathrm{NC}$ & RALEIGH & 0.020 & 42 & 1 & - & - & - & 0.003 & 42 & 1 & 0.006 & 42 & 1 & - & - & . & - \\
\hline NC & WINSTON-SALEM & 0.020 & 111 & 2 & - & - & - & 0.001 & 111 & 2 & 0.011 & 111 & 2 & - & - & - & - \\
\hline $\mathrm{NE}$ & LINCOLN & 0.025 & 72 & 2 & 0.034 & 1212 & 1 & 0.001 & 72 & 2 & 0.005 & 72 & 2 & - & - & - & - \\
\hline $\mathrm{NE}$ & OMAHA & 0.026 & 130 & 1 & 0.031 & 3079 & 3 & 0.001 & 130 & 1 & 0.005 & 130 & 1 & 13.070 & 39.900 & 2.020 & 2.240 \\
\hline $\mathrm{NH}$ & CONCORD & 0.020 & 37 & 1 & . & - & - & 0.001 & 37 & 1 & 0.031 & 37 & 1 & - & • & - & - \\
\hline $\mathrm{NJ}$ & BAYONNE & 0.020 & 72 & 1 & 0.054 & 1291 & 1 & 0.004 & 72 & 1 & 0.036 & 72 & 1 & - & - & - & - \\
\hline NJ & CAMDEN & 0.035 & 99 & 2 & 0.057 & 1333 & 1 & 0.003 & 99 & 2 & 0.030 & 99 & 2 & 19.330 & 33.680 & 5.240 & 5.870 \\
\hline $\mathrm{NJ}$ & ELIZABETH & 0.020 & 81 & 1 & - & - & - & 0.004 & 81 & 1 & 0.025 & 81 & 1 & • & - & - & - \\
\hline $\mathrm{NJ}$ & JERSEY CITY & 0.020 & 95 & 2 & - & - & - & 0.004 & 95 & 2 & 0.046 & 95 & 2 & 17.340 & 32.050 & 4.360 & 4.760 \\
\hline
\end{tabular}

a Total number of observations included

b Number of monitoring sites supplying data. 
AIR QUALITY DATA - MEDIAN CONCBNTRATIONS, IN $\mu$ G/AP EXCZPT AS NOTED

WATER

\begin{tabular}{|c|c|c|c|c|c|c|c|c|c|c|c|c|c|c|c|}
\hline \multirow[b]{2}{*}{ STATB } & \multirow[b]{2}{*}{ CITX } & \multirow{2}{*}{$\begin{array}{l}\text { HARD. } \\
\text { (ppm) }\end{array}$} & \multirow{2}{*}{$\begin{array}{l}\text { ASTRAP } \\
\mathrm{SO}_{4}\end{array}$} & \multicolumn{3}{|c|}{$\infty$ (ppon) } & \multicolumn{3}{|c|}{ IBON } & \multicolumn{3}{|c|}{ LEAD } & \multicolumn{3}{|c|}{ sAman $\mathrm{SO}_{4}$} \\
\hline & & & & MED. & $7 \mathrm{OBS}^{\mathrm{a}}$ & $7 \operatorname{MaN}^{6}$ & 100 & foBs ${ }^{\mathrm{a}}$ & $\operatorname{FHON}^{5}$ & HED. & FBS $^{8}$ & Find & 160. & FOBS & fHo \\
\hline LA & SHREVEPORT & 68 & 2.66 & - & - & - & 1.53 & 105 & 1 & 0.37 & 105 & 1 & - & • & 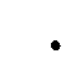 \\
\hline$M A$ & BOSTON & 12 & 6.01 & 3.10 & 16726 & 4 & 1.08 & 95 & 1 & 0.56 & 120 & 2 & 10.70 & 101 & 5 \\
\hline MA & BROCKTON & 11 & 6.15 & - & - & - & 0.57 & 30 & 1 & 0.33 & 30 & 1 & 8.40 & 13 & 1 \\
\hline MA & CAMBRIDGE & 56 & 6.01 & 2.70 & 197 & 1 & 0.61 & 52 & 1 & 0.39 & 52 & 1 & 10.20 & 36 & 1 \\
\hline $\mathrm{MA}$ & FALL, RIVER & 15 & 6.15 & - & - & - & 0.82 & 63 & 1 & 0.61 & 63 & 1 & 11.20 & 61 & 1 \\
\hline MA & LAWRENCE & 44 & 6.72 & - & - & - & 0.43 & 40 & 1 & 0.30 & 40 & 1 & 8.75 & 14 & 1 \\
\hline MA & LOWELL & 42 & 6.01 & 4.00 & 3717 & 1 & 0.99 & 26 & 1 & 0.52 & 54 & 1 & 7.35 & 14 & 1 \\
\hline MA & NEW BEDFORD & 15 & 6.15 & - & - & • & 0.39 & 81 & 1 & 0.29 & 81 & 1 & 11.00 & 81 & 1 \\
\hline MA & SPRINGPIELD & 12 & 7.29 & 1.80 & 7917 & 3 & 0.78 & 95 & 2 & 0.67 & 138 & 3 & 8.00 & 175 & 5 \\
\hline MA & WORCESTER & 9 & 7.29 & 1.50 & 6749 & 2 & 1.04 & 113 & 2 & 0.42 & 143 & 2 & 9.50 & 98 & 2 \\
\hline MD & BALTIMORE & 50 & 11.79 & 1.80 & 14741 & 6 & 1.31 & 53 & 1 & 0.56 & 688 & 5 & 12.00 & 152 & 4 \\
\hline$M \mathbb{E}$ & PORTLAND & 14 & 5.07 & - & • & - & 0.52 & 107 & 2 & 0.40 & 456 & 6 & 8.80 & 26 & 1 \\
\hline MI & ANN ARBOR & 80 & 7.43 & - & - & - & 0.58 & 30 & 1 & 0.20 & 30 & 1 & - & - & - \\
\hline MI & DETROIT & 98 & 7.43 & 1.70 & 20903 & 4 & 2.26 & 95 & 2 & 0.32 & 95 & 2 & - & - & - \\
\hline MI & FLINT & 86 & 5.69 & - & - & - & 1.03 & 87 & 2 & 0.15 & 87 & 2 & 13.20 & 22 & 1 \\
\hline MI & GRAND RAPIDS & 130 & 5.39 & 0.70 & 3925 & 2 & 1.08 & 22 & 2 & 1.00 & 22 & 2 & 14.10 & 22 & 2 \\
\hline MII & LANSING & 86 & 6.20 & - & - & - & 0.55 & 73 & 1 & 0.16 & 73 & 1 & 13.80 & 23 & 1 \\
\hline $\mathrm{M}$ & DULUTH & 44 & 1.34 & 2.90 & 3488 & 1 & 1.08 & 114 & 2 & 0.18 & 522 & 5 & 5.50 & 109 & 2 \\
\hline $\mathbf{M N}$ & MINNEAPOLIS & 68 & 1.72 & 1.80 & 10524 & 6 & 0.66 & 170 & 4 & 0.51 & 1311 & 9 & 6.60 & 110 & 2 \\
\hline $\mathbf{M}$ & ST PAUL & 58 & 2.16 & 2.10 & 12051 & 5 & 0.82 & 60 & 2 & 0.38 & 1603 & 9 & 7.10 & 357 & 6 \\
\hline$M$ & RAYTOWN & 86 & 3.30 & - & : & - & 1.52 & 28 & 1 & 0.24 & 88 & 1 & 8.50 & 29 & 1 \\
\hline MS & JACKSON & 47 & 3.64 & 0.90 & 3542 & 1 & 0.91 & 69 & 2 & 0.37 & 236 & 4 & 9.00 & 45 & 2 \\
\hline MT & BILLINGS & 148 & 1.07 & 1.30 & 3306 & 1 & 0.55 & 67 & 1 & 0.27 & 242 & 2 & 6.60 & 116 & 1 \\
\hline $\mathrm{MT}$ & BUTTE-SILVER BO & 56 & 0.74 & 1.50 & 1286 & 1 & 1.13 & 313 & 8 & 0.28 & 610 & 8 & 5.20 & 743 & 6 \\
\hline MT & GREAT FALLS & 151 & 0.93 & 1.10 & 4004 & 1 & 0.23 & 23 & 1 & 0.16 & 112 & 1 & 3.60 & 19 & 2 \\
\hline NC & CHARLOTTE & 22 & 9.19 & 2.40 & 28937 & 8 & 0.71 & 115 & 1 & 0.44 & 115 & 1 & 11.10 & 30 & 1 \\
\hline NC & DURHAM & 41 & 8.83 & 3.10 & 4632 & 1 & 0.59 & 137 & 1 & 0.39 & 189 & 2 & 10.00 & 20 & 1 \\
\hline NC & GREENSBORO & 40 & 8.83 & - & - & - & 0.52 & 44 & 1 & 0.25 & 162 & 1 & 9.90 & 21 & 1 \\
\hline NC & RALEIGH & 30 & 7.37 & 3.30 & 2681 & 2 & 0.37 & 42 & 1 & 0.29 & 133 & 1 & - & - & - \\
\hline NC & WINSTON-SALEM & 34 & 8.25 & 1.50 & 6165 & 2 & 0.61 & 111 & 2 & 0.34 & 214 & 2 & 11.10 & 29 & 1 \\
\hline NE & LINCOLN & 206 & 1.76 & 1.10 & 13167 & 2 & 0.72 & 72 & 2 & 0.29 & 72 & 2 & 4.90 & 25 & 1 \\
\hline NE & OMAHA & 236 & 2.16 & 1.90 & 9442 & 4 & 0.81 & 130 & 1 & 0.36 & 178 & 4 & 7.30 & 15 & 1 \\
\hline NH & CONCORD & 12 & 6.65 & - & - & - & 0.24 & 37 & 1 & 0.14 & 37 & $\mathfrak{l}$ & 6.40 & 24 & 1 \\
\hline $\mathrm{NJ}$ & BAYONNE & 25 & 9.88 & 0.90 & 7376 & 1 & 0.92 & 72 & 1 & 0.35 & 72 & 1 & 8.60 & 23 & 1 \\
\hline
\end{tabular}

a Total number of observations included

b Number of monttoring sites supplying data. 
AIR QUALITY DATA - MEDIAN CONCBNTRATIONS, DN $\mu G / \mathrm{H}^{3}$ EXCBPT AS BOTKD

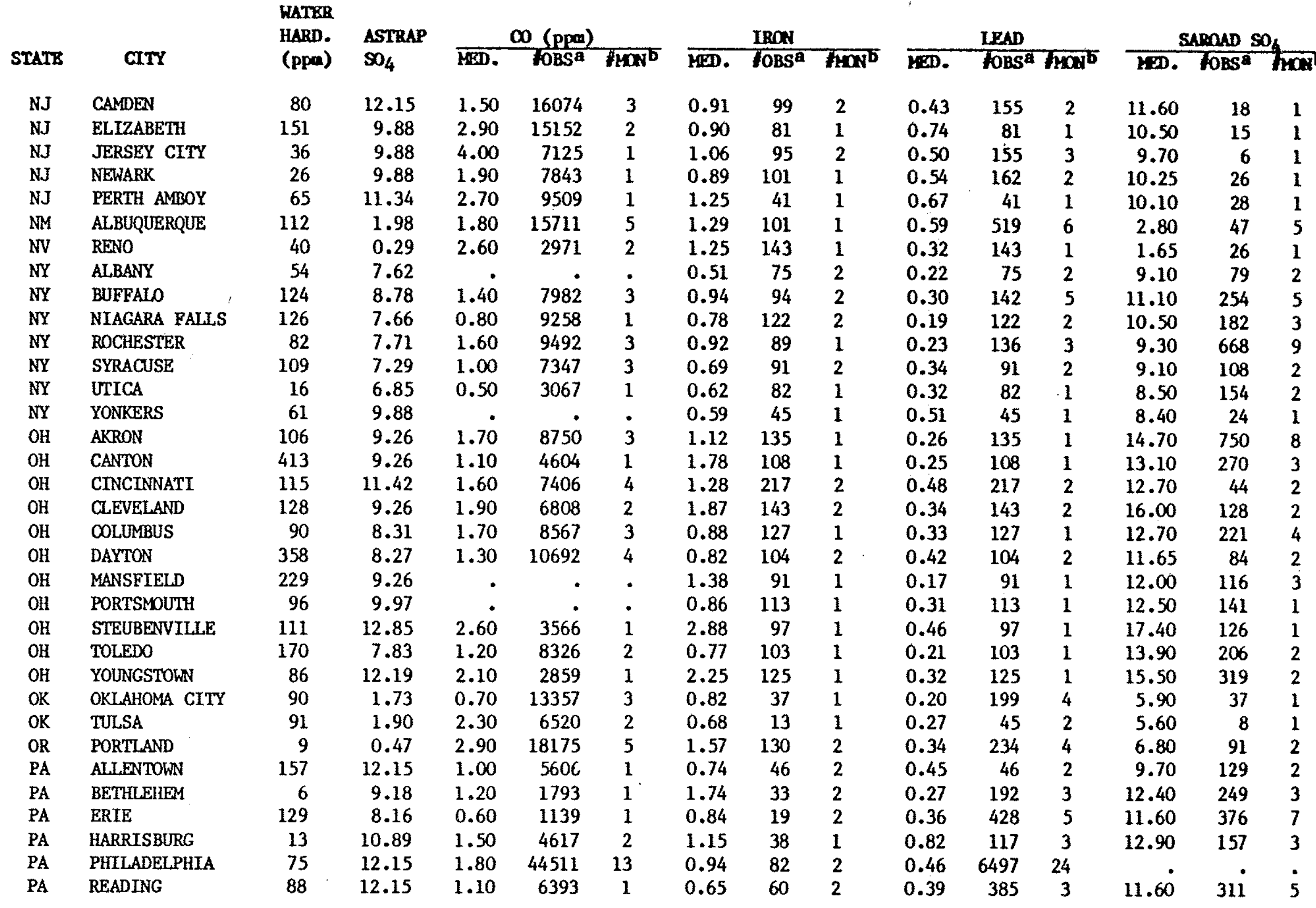

a Total number of observations included

b Number of monttoring sites supplying data. 
AIR QUALITY DATA - MEDTAN CONCEMTRATIONS, IN $\mu G / \mathrm{A}^{3}$ EXCEPT AS NOTED

\begin{tabular}{|c|c|c|c|c|c|c|c|c|c|c|c|c|c|}
\hline \multirow[b]{2}{*}{ STATE } & \multirow[b]{2}{*}{ CITX } & \multicolumn{3}{|c|}{ MANGANBSE } & \multicolumn{3}{|c|}{ MAX. OZONE (ppm) } & \multicolumn{3}{|c|}{ CAnMmi } & \multicolumn{3}{|c|}{ VARADIEA } \\
\hline & & 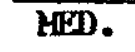 & FoBS & how & HED. & FoBS & $t_{100} b$ & KHD. & FOBSa & hanb & KED. & fORSa & \\
\hline NJ & NEWARK & 0.020 & 101 & 1 & 0.045 & 594 & 1 & 0.003 & 101 & 1 & 0.033 & 101 & \\
\hline $\mathrm{NJ}$ & PERTH AMBOY & 0.029 & 41 & 1 & . & . & - & 0.002 & 41 & 1 & 0.029 & 41 & \\
\hline NM & ALBUQUERQUE & 0.028 & 101 & 1 & 0.050 & 3239 & 4 & 0.001 & 101 & 1 & 0.005 & 101 & \\
\hline NV & RENO & 0.027 & 143 & 1 & 0.047 & 1016 & 2 & 0.001 & 143 & 1 & 0.007 & 143 & \\
\hline $\mathrm{NY}$ & ALBANY & 0.020 & 75 & 2 & - & - & - & 0.001 & 75 & 2 & 0.112 & 75 & \\
\hline $\mathrm{NY}$ & BUFFALO & 0.031 & 94 & 2 & 0.036 & 323 & 1 & 0.001 & 94 & 2 & 0.006 & 94 & \\
\hline $\mathrm{NY}$ & NIAGARA FALLS & 0.054 & 122 & 2 & 0.034 & 1334 & 1 & 0.001 & 122 & 2 & 0.008 & 122 & \\
\hline NY & ROCHESTER & 0.020 & 89 & 1 & 0.036 & 1691 & 2 & 0.001 & 89 & 1 & 0.017 & 89 & \\
\hline NY & SYRACUSE & 0.020 & 91 & 2 & 0.037 & 2349 & 4 & 0.001 & 91 & 2 & 0.008 & 91 & \\
\hline $\mathrm{NY}$ & UTICA & 0.024 & 82 & 1 & 0.039 & 1646 & 1 & 0.001 & 82 & 1 & 0.031 & 82 & \\
\hline $\mathrm{NY}$ & YONKERS & 0.020 & 45 & 1 & & . & - & 0.002 & 45 & 1 & 0.048 & 45 & \\
\hline $\mathrm{OH}$ & AKRON & 0.033 & 135 & 1 & 0.034 & 1294 & 3 & 0.002 & 135 & 1 & 0.005 & 135 & \\
\hline $\mathrm{OH}$ & CANTON & 0.083 & 108 & 1 & 0.030 & 1070 & 3 & 0.003 & 108 & 1 & 0.005 & 108 & \\
\hline $\mathrm{OH}$ & CINCINNATI & 0.039 & 217 & 2 & 0.037 & 4379 & 3 & 0.002 & 217 & 2 & 0.005 & 217 & \\
\hline $\mathrm{OH}$ & CLEVELAND & 0.078 & 143 & 2 & 0.043 & 1313 & 1 & 0.004 & 143 & 2 & 0.005 & 143 & \\
\hline $\mathrm{OH}$ & COLLMBUS & 0.024 & 127 & 1 & 0.029 & 4065 & 3 & 0.004 & 127 & 1 & 0.005 & 127 & \\
\hline $\mathrm{OH}$ & DAYTON & 0.029 & 104 & 2 & 0.034 & 2790 & 2 & 0.002 & 104 & 2 & 0.005 & 104 & \\
\hline $\mathrm{OH}$ & MANSFIELD & 0.045 & 91 & 1 & - & - & - & 0.002 & 91 & 1 & 0.005 & 91 & \\
\hline $\mathrm{OH}$ & PORTSMOUTH & 0.055 & 113 & 1 & . & - & - & 0.001 & 113 & 1 & 0.005 & 113 & \\
\hline $\mathrm{OH}$ & STEUBENVILLE & 0.118 & 97 & 1 & 0.045 & 1687 & 1 & 0.004 & 97 & 1 & 0.014 & 97 & \\
\hline $\mathrm{OH}$ & TOLEDO & 0.024 & 103 & 1 & 0.037 & 3264 & 2 & 0.001 & 103 & 1 & 0.006 & 103 & \\
\hline $\mathrm{OH}$ & YOUNGSTOWN & 0.094 & 125 & 1 & 0.030 & 1517 & 2 & 0.003 & 125 & 1 & 0.005 & 125 & \\
\hline $\mathrm{OK}$ & OKIAHOMA CITY & 0.024 & 37 & 1 & 0.049 & 1256 & 1 & 0.002 & 37 & 1 & 0.005 & 37 & \\
\hline OK & TULSA & 0.029 & 13 & 1 & 0.053 & 1483 & 1 & 0.001 & 13 & 1 & 0.005 & 13 & \\
\hline OR & PORTLAND & 0.049 & 130 & 2 & 0.023 & 226 & 1 & 0.003 & 130 & 2 & 0.023 & 130 & \\
\hline PA & ALLENTOWN & 0.032 & 46 & 2 & 0.033 & 1455 & 1 & 0.005 & 46 & 2 & 0.069 & 46 & \\
\hline PA & BETHLEHEM & 0.094 & 33 & 2 & 0.049 & 1499 & 1 & 0.010 & 33 & 2 & 0.043 & 33 & \\
\hline PA & ERIE & 0.020 & 19 & 2 & 0.040 & 1392 & 1 & 0.002 & 19 & 2 & 0.006 & 19 & \\
\hline $\mathrm{PA}$ & HARRISBURG & 0.037 & 38 & 1 & 0.044 & 1540 & 2 & 0.003 & 38 & 1 & 0.046 & 38 & \\
\hline $\mathrm{PA}$ & PHILADELPHTA & 0.039 & 82 & 2 & 0.033 & 7363 & 10 & 0.002 & 82 & 2 & 0.023 & 82 & \\
\hline PA & READING & 0.033 & 60 & 2 & 0.029 & 1552 & 1 & 0.002 & 60 & 2 & 0.055 & 60 & \\
\hline PA & SCRANTON & 0.020 & 8 & 1 & 0.054 & 1377 & 2 & 0.001 & 8 & 1 & 0.020 & 8 & \\
\hline RI & PROVIDENCE & 0.020 & 23 & 1 & 0.049 & 1425 & 2 & 0.003 & 23 & 1 & 0.036 & 23 & \\
\hline SC & COLUMBIA & 0.020 & 44 & 1 & • & - & - & 0.001 & 44 & 1 & 0.006 & 44 & \\
\hline$S D$ & SIOUX FALLS & 0.100 & 22 & 1 & 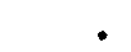 & - & . & 0.001 & 22 & 1 & 0.005 & 22 & \\
\hline
\end{tabular}

$\begin{array}{lllll}8.950 & 31.430^{\circ} & 1.670^{\circ} & 1.950^{\circ}\end{array}$

$\begin{array}{lllll}11.820 & 32.650 & 1.100 & 1.240\end{array}$

$23.530^{\circ} \quad 43.260^{\circ} 5.940^{\circ} 7.080^{\circ}$

$24.60 \dot{0} \quad 44.33 \dot{0} \quad 8.27 \dot{0} 8.770^{\circ}$

$23.12 \dot{0} \quad 39.570^{\circ} 6.470^{\circ} 6.91 \dot{0}^{\circ}$

$\begin{array}{lllll}24.580 & 47.870 & 7.090 & 8.060\end{array}$

$18.800^{\circ} \quad 33.340^{\circ} \quad 4.490^{\circ} \quad 4.580^{\circ}$

$23.09 \dot{0} \quad 44.960 \quad 4.030 \quad 4.11 \dot{0}$

$20.23 \dot{0} \quad 43.050^{\circ} \quad 6.050^{\circ} \quad 6.850^{\circ}$

$\begin{array}{llll}15.860 & 40.020 \quad 4.310 \quad 4.310\end{array}$

$14.660^{\circ} \quad 38.01 \dot{0} 2.030^{\circ} 2.600^{\circ}$

$\begin{array}{lllll}17.880 & 30.830^{\circ} & 5.48 \dot{0} & 5.64 \dot{0}\end{array}$

$\begin{array}{rrrr}21.040 & 38.110 & 5.780 & 6.360\end{array}$

$12.89 \dot{0}^{2} 2.490 \quad 3.890^{\circ} \quad 4.050^{\circ}$

a Total number of observations included

b Number of monttoring sites supplying data. 


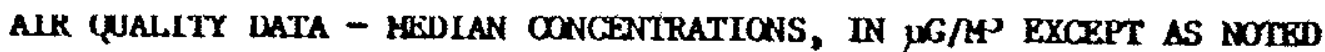

\begin{tabular}{|c|c|c|c|c|c|c|c|c|c|c|c|c|c|c|c|c|c|}
\hline \multirow[b]{2}{*}{ STATB } & \multirow[b]{2}{*}{ CITY } & \multicolumn{3}{|c|}{ MANGANESE } & \multicolumn{3}{|c|}{ MAX. OZONE (ppa) } & \multicolumn{3}{|c|}{ canmuar } & \multicolumn{3}{|c|}{ VANADTIOI } & \multicolumn{4}{|c|}{ DICTOT. PARTICULATR } \\
\hline & & NED. & fOBS ${ }^{a}$ & had & MED. & IOBS ${ }^{a}$ & $\operatorname{man}^{b}$ & HED. & foBs $^{a}$ & hoosb & HED. & $\operatorname{OBS}^{\mathrm{a}}$ & han ${ }^{b}$ & FTNE & Toral & FNE-S & TOT-S \\
\hline Tw & CHATTANODGA & 0.049 & 205 & 2 & 0.042 & 755 & 1 & 0.002 & 205 & 2 & 0.005 & 205 & 2 & 16.640 & 22.320 & 9.850 & 9.930 \\
\hline TN & KNOXVILLE & 0.038 & 80 & 2 & 0.035 & 1477 & 2 & 0.001 & 80 & 2 & 0.005 & 80 & 2 & - & - & • & . \\
\hline TN & MEMPHIS & 0.026 & 99 & 3 & 0.039 & 1424 & 2 & 0.001 & 99 & 3 & 0.005 & 99 & 3 & - & - & • & . \\
\hline TN & NASHVILLE-DAVID & 0.027 & 75 & 1 & 0.036 & 1486 & 2 & 0.001 & 75 & 1 & 0.005 & 75 & 1 & 20.450 & 32.990 & 3.610 & 3.870 \\
\hline $\mathrm{TX}$ & ABILENE & 0.020 & 353 & 2 & $\cdot$ & - & - & 0.030 & 353 & 2 & 0.002 & 353 & 2 & • & - & - & - \\
\hline $\mathrm{TX}$ & BEAUMDNT & 0.030 & 294 & 4 & 0.048 & 608 & 2 & 0.030 & 294 & 4 & 0.004 & 294 & 4 & - & - & - & - \\
\hline TX & DALLAS & 0.020 & 278 & 2 & 0.046 & 3085 & 4 & 0.030 & 278 & 2 & 0.002 & 278 & 2 & 16.480 & 34.740 & 2.730 & 3.300 \\
\hline $\mathrm{TX}$ & EL PASO & 0.050 & 478 & 7 & 0.047 & 2100 & 4 & 0.040 & 807 & 17 & 0.005 & 478 & 7 & 15.740 & 57.950 & 2.280 & 2.860 \\
\hline $\mathrm{TX}$ & FORT WORTH & 0.030 & 564 & 3 & 0.053 & 2360 & 2 & 0.030 & 564 & 3 & 0.002 & 564 & 3 & - & - & . & - \\
\hline $\mathrm{TX}$ & GALVESTON & 0.020 & 50 & 1 & • & - & - & 0.030 & 50 & 1 & 0.003 & 50 & 1 & - & - & - & . \\
\hline $\mathrm{TX}$ & HOUSTON & 0.024 & 1530 & 25 & 0.055 & 5011 & 8 & 0.030 & 263 & 3 & 0.006 & 263 & 3 & 13.370 & 32.440 & 3.380 & 3.460 \\
\hline TX & LAAREDO & 0.020 & 98 & 1 & - & - & - & 0.030 & 98 & 1 & 0.003 & 98 & 1 & - & - & - & - \\
\hline TX & LUBBOCK & 0.020 & 305 & 2 & - & - & - & 0.030 & 305 & 2 & 0.003 & 305 & 2 & . & . & - & - \\
\hline$T X$ & PORT ARTHUR & 0.020 & 167 & 4 & 0.051 & 231 & 1 & 0.030 & 167 & 4 & 0.006 & 167 & 4 & . & - & . & - \\
\hline$T X$ & SAN ANTONIO & 0.020 & 453 & 3 & 0.043 & 2578 & 3 & 0.030 & 453 & 3 & 0.002 & 453 & 3 & - & - & . & - \\
\hline TX & SEABROOK & 0.030 & 85 & 1 & 0.061 & 380 & 1 & 0.030 & 85 & 1 & 0.004 & 85 & 1 & 15.390 & 34.850 & 1.860 & 2.040 \\
\hline $\mathrm{TX}$ & TYLER & 0.020 & 223 & 1 & - & - & - & 0.030 & 224 & 1 & 0.002 & 223 & 1 & - & - & - & - \\
\hline $\mathrm{TX}$ & WACO & 0.020 & 235 & 1 & 0.041 & 235. & 1 & 0.030 & 235 & 1 & 0.002 & 234 & 1 & - & . & - & - \\
\hline TX & WICHITA FALLS & 0.030 & 180 & 1 & - & - & - & 0.030 & 180 & 1 & 0.003 & 180 & 1 & . & - & . & - \\
\hline UT & OGDEN & 0.028 & 29 & 1 & 0.052 & 1468 & 1 & 0.001 & 29 & 1 & 0.005 & 29 & 1 & - & - & . & - \\
\hline UT & SALT LAKE CITY & 0.046 & 23 & 1 & 0.049 & 1484 & 1 & 0.001 & 23 & 1 & 0.005 & 23 & 1 & 15.390 & 34.850 & 1.860 & 2.040 \\
\hline VA & NORFOLK & 0.022 & 146 & 2 & 0.037 & 443 & 1 & 0.001 & 146 & 2 & 0.074 & 146 & 2 & 16.910 & 30.250 & 5.880 & 6.730 \\
\hline VT & BURLINGTON & 0.027 & 14 & 1 & 0.049 & 527 & 2 & 0.001 & 14 & 1 & 0.026 & 14 & 1 & - & - & • & - \\
\hline WA & SEATTLE & 0.024 & 242 & 3 & 0.037 & 176 & 1 & 0.001 & 242 & 3 & 0.009 & 242 & 3 & 11.870 & 25.950 & 1.670 & 2.140 \\
\hline WA & SPOKANE & 0.036 & 108 & 1 & 0.041 & 587 & $\ell$ & 0.002 & 108 & 1 & 0.005 & 108 & 1 & 9.380 & 35.480 & 1.050 & 1.420 \\
\hline WA & TACOMA & 0.032 & 141 & 2 & 0.037 & 156 & 1 & 0.002 & 141 & 2 & 0.010 & 141 & 2 & - & - & - & - \\
\hline WI & EAU CLAIRE & 0.020 & 74 & 1 & $\bullet$ & - & - & 0.001 & 74 & 1 & 0.005 & 74 & 1 & - & . & - & - \\
\hline WI & KENOSHA & 0.020 & 85 & 1 & 0.057 & 584 & 3 & 0.002 & 85 & 1 & 0.005 & 85 & 1 & - & - & - & - \\
\hline WI & MADISON & 0.020 & 139 & 2 & 0.044 & 782 & 3 & 0.001 & 139 & 2 & 0.005 & 139 & 2 & - & - & - & - \\
\hline WI & RACINE & 0.032 & 87 & 1 & 0.050 & 1380 & 1 & 0.001 & 87 & 1 & 0.005 & 87 & 1 & - & . & - & - \\
\hline WI & SUPERIOR & 0.092 & 76 & 2 & 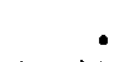 & - & - & 0.001 & 76 & 2 & 0.005 & 76 & 2 & - & - & . & - \\
\hline$W V$ & CHARLESTON & 0.042 & 63 & 2 & 0.048 & 1615 & 1 & 0.001 & 63 & 2 & 0.005 & 63 & 2 & 20.100 & 37.400 & 4.710 & 4.710 \\
\hline
\end{tabular}


AIR QUALITY DATA - MEDIAN ONCBNTRATIONS, IN $\mu G / M^{3}$ EXCRPT AS HOTEII

\begin{tabular}{|c|c|c|c|c|c|c|c|c|c|c|c|c|c|c|c|}
\hline \multirow[b]{2}{*}{ STATE } & \multirow[b]{2}{*}{ CITY } & \multirow{2}{*}{$\begin{array}{l}\text { WATBR } \\
\text { HARD. } \\
\text { (ppm) }\end{array}$} & \multirow{2}{*}{$\begin{array}{l}\text { ASTRAP } \\
\mathrm{SO}_{4}\end{array}$} & \multicolumn{3}{|c|}{$\infty$ (ppa) } & \multicolumn{3}{|c|}{ IRON } & \multicolumn{3}{|c|}{ LRAD } & \multicolumn{3}{|c|}{$\mathrm{SAPOAD} \mathrm{SO}_{4}$} \\
\hline & & & & KBD. & FBS ${ }^{\mathbf{a}}$ & ToNb & KED. & FoBS ${ }^{3}$ & $7 \operatorname{lax}^{6}$ & EED. & ToBsa & 7 Fan' & FED. & FoBs & hon \\
\hline PA & SCRANTON & 26 & 9.18 & 2.00 & 5824 & 1 & 0.64 & 8 & 1 & 0.23 & 76 & 2 & 11.10 & 221 & 2 \\
\hline RI & PROVIDENCE & 24 & 7.25 & 1.60 & 5570 & 2 & 0.63 & 23 & 1 & 0.79 & 500 & 4 & 9.60 & 112 & 1 \\
\hline SC & COLURBIA & 29 & 7.09 & 1.40 & 2446 & 1 & 0.45 & 44 & 1 & 0.34 & 251 & 2 & - & . & . \\
\hline $\mathrm{SD}$ & SIOUX FALLS & 484 & 1.52 & - & - & - & 1.10 & 22 & 1 & 0.37 & 22 & 1 & 4.60 & 22 & 1 \\
\hline TN & CHATTANOOGA & 59 & 7.25 & 3.20 & 2466 & 1 & 1.44 & 205 & 2 & 0.34 & 205 & 2 & 13.90 & 29 & 1 \\
\hline TN & KNOXVILLE & 116 & 8.22 & 3.00 & 5250 & 2. & 1.16 & 80 & 2 & 0.66 & 80 & 2 & 12.50 & 29 & 1 \\
\hline TN & MEMPHIS & 38 & 3.91 & 1.60 & 10579 & 5 & 0.66 & 99 & 3 & 0.47 & 134 & 5 & - & - & - \\
\hline $\mathrm{TN}$ & NASHVIILE-DAVID & 90 & 7.73 & 3.00 & 12410 & 5 & 0.67 & 75 & 1 & 0.38 & 2572 & 14 & 7.50 & 2001 & 14 \\
\hline $\mathrm{TX}$ & ABILENE & 194 & 1.36 & • & • & - & 0.90 & 353 & 2 & 0.16 & 353 & 2 & • & - & • \\
\hline$T X$ & BEAUMONT & 66 & 2.52 & 0.50 & 5069 & 2 & 0.76 & 294 & 4 & 0.27 & 294 & 4 & 6.20 & 5 & 1 \\
\hline $\mathrm{TX}$ & BROWNSVILLE & 266 & 0.39 & - & - & - & 1.08 & 314 & 3 & 0.25 & 314 & 3 & - & - & - \\
\hline$T X$ & DALIAS & 66 & 2.28 & 0.70 & 12348 & 4 & 0.72 & 887 & 16 & 0.59 & 969 & 16 & 11.60 & 11 & 1 \\
\hline $\mathrm{TX}$ & EL PASO & 146 & 2.45 & 1.70 & 15222 & 4 & 2.20 & 477 & 7 & 0.99 & 934 & 17 & 8.50 & 5 & 1 \\
\hline $\mathrm{TX}$ & FORT WORTH & 144 & 1.65 & 0.80 & 17425 & 2 & 1.21 & 564 & 3 & 0.44 & 652 & 4 & 5.20 & 5 & 1 \\
\hline $\mathrm{TX}$ & GALVESTON & 115 & 1.45 & • & • & - & 0.71 & 50 & 1 & 0.18 & 50 & 1 & 5.60 & 41 & 1 \\
\hline$T X$ & HOUSTON & 73 & 1.79 & 0.90 & 27445 & 4 & 1.88 & 263 & 3 & 0.61 & 1558 & 25 & 8.20 & 5024 & 30 \\
\hline $\mathrm{TX}$ & LAREDO & 328 & 0.47 & - & • & - & 1.43 & 98 & 1 & 0.11 & 98 & 1 & • & • & - \\
\hline$T X$ & LUBBOCK & 422 & 1.73 & - & - & - & 1.43 & 305 & 2 & 0.12 & 305 & 2 & - & • & - \\
\hline $\mathrm{TX}$ & PORT ARTHUR & 45 & 2.52 & - & - & - & 0.58 & 167 & 4 & 0.18 & 167 & 4 & - & - & - \\
\hline$T X$ & SAN ANTONIO & 223 & 0.97 & 0.90 & 11183 & 3 & 0.64 & 453 & 3 & 0.45 & 515 & 3 & 5.40 & 166 & 7 \\
\hline $\mathrm{TX}$ & SEABROOK & 94 & 1.45 & 0.30 & 1509 & 1 & 0.63 & 85 & 1 & 0.09 & 85 & 1 & - & - & - \\
\hline $\mathrm{TX}$ & TYLER & 71 & 2.37 & - & • & - & 1.29 & 224 & 1 & 0.35 & 224 & 1 & - & - & - \\
\hline $\mathrm{TX}$ & WACO & 156 & 1.79 & - & - & - & 0.55 & 235 & 1 & 0.17 & 235 & 1 & - & - & - \\
\hline $\mathrm{TX}$ & WICHITA FALLSS & 67 & 1.48 & - & - & - & 0.98 & 180 & 1 & 0.26 & 180 & 1 & 3.40 & 5 & 1 \\
\hline UT & DGDEN & 158 & 2.91 & 2.40 & 7867 & 2 & 1.25 & 29 & 1 & 1.21 & 29 & 1 & 3.80 & 29 & 1 \\
\hline UT & SALT LAKE CITY & 186 & 2.91 & 2.70 & 4962 & 2 & 1.87 & 23 & 1 & 1.44 & 23 & 1 & 5.50 & 23 & 1 \\
\hline VA & NORFOLK & 74 & 9.02 & 1.70 & 6610 & 1 & 1.13 & 146 & 2 & 0.25 & 205 & 3 & 13.00 & 107 & 2 \\
\hline VT & BURLINGTON & 56 & 5.35 & 0.90 & 7679 & 1 & 0.83 & 14 & 1 & 0.60 & 14 & 1 & 6.80 & 14 & 1 \\
\hline WA & SEATTLE & 18 & 2.41 & 2.90 & 29978 & 8 & 1.06 & 242 & 3 & 0.43 & 242 & 3 & 6.10 & 30 & 1 \\
\hline WA & SPOKANE & 156 & 0.71 & 3.00 & 16913 & 7 & 1.64 & 108 & 1 & 0.34 & 108 & 1 & 4.00 & 27 & 1 \\
\hline WA & TACOMA & 21 & 2.41 & 2.80 & 4443 & 1 & 1.33 & 141 & 2 & 0.46 & 141 & 2 & 5.70 & 30 & 1 \\
\hline WI & EAU CLAIRE & 54 & 2.38 & • & • & - & 0.28 & 74 & 1 & 0.16 & 74 & 1 & 7.40 & 25 & 1 \\
\hline WI & KENOSHA & 132 & 5.60 & - & - & . & 0.50 & 85 & 1 & 0.28 & 85 & 1 & 13.00 & 22 & 1 \\
\hline WI & MADISON & 345 & 3.99 & - & : & - & 0.46 & 139 & 2 & 0.16 & 139 & 2 & 9.20 & 29 & 1 \\
\hline WI & RACINE & 130 & 5.60 & 0.80 & 9178 & 1 & 0.77 & 87 & 1 & 0.23 & 87 & 1 & 9.10 & 29 & 1 \\
\hline WI & SUPERIOR & 50 & 1.62 & - & $\cdot$ & - & 1.57 & 76 & 2 & 0.24 & 76 & 2 & 7.50 & 26 & 1 \\
\hline WV & CHARLESTON & 32 & 11.17 & 1.10 & 3923 & 1 & 1.05 & 63 & 2 & 0.29 & 285 & 3 & 15.50 & 35 & 2 \\
\hline
\end{tabular}

Total number of observations included

b Number of monttoring sites sunplutne data. 
AIR QUALITY DATA - REDIAN CONCENTRATIONS, IN $\mu$ G/AP EXCEYT AS NOTZD

\begin{tabular}{|c|c|c|c|c|c|c|c|c|c|c|}
\hline \multirow{2}{*}{ STATE } & \multirow[b]{2}{*}{ CITY } & \multicolumn{3}{|c|}{ MANGANESE } & \multicolumn{3}{|c|}{ MAX. 0ZONE (ppo) } & \multicolumn{3}{|c|}{ cararris } \\
\hline & & $\mathbf{N O D}$ & 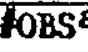 & $\operatorname{Man}{ }^{b}$ & MED. & & HON & MED. & FOBS ${ }^{\mathrm{a}}$ & \\
\hline $\mathbf{K}$ & ANCHORAGE. & 0.032 & 53 & 1 & 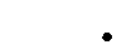 & $*$ & • & 0.001 & 53 & \\
\hline $\mathrm{L}$ & BIRMINGHAM & .055 & 82 & 2 & 0.057 & 269 & 1 & 0.002 & 82 & \\
\hline 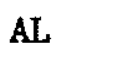 & GADSDEN & 0.060 & 75 & 2 & - & - & • & 0.001 & 75 & \\
\hline AL & MDBIIE & .025 & 56 & 1 & - & - & - & 0.001 & 56 & \\
\hline AR & LITTLE ROCK & 0.020 & 67 & 1 & 0.046 & 991 & $i$ & 0.001 & 67 & \\
\hline$z$ & PHOENIX & 0.065 & 940 & 4 & 0.049 & 4649 & 7 & 0.001 & 894 & \\
\hline$z$ & TUCSON & .020 & 130 & 1 & 0.051 & 2864 & 2 & 0.001 & 249 & \\
\hline A & BAKERSFIEILD & 0.038 & 51 & 1 & 0.067 & 1732 & 1 & 0.001 & 51 & \\
\hline $\mathrm{CA}$ & BERKELEY & 0.020 & 57 & 1 & & & . & 0.001 & 57 & \\
\hline$C A$ & BURBANK & 0.030 & 8 & 1 & 0.079 & 1521 & 1 & 203 & 8 & \\
\hline A & FRESNO & 0.035 & 56 & 1 & 0.061 & 5321 & 4 & 01 & 56 & \\
\hline A & LONG BEACH & 0.023 & 8 & 1 & 0.040 & 1331 & 1 & .001 & 8 & \\
\hline A & LOS ANGELES & .027 & 96 & 2 & 0.070 & 3126 & 5 & 02 & 96 & \\
\hline A & OAKIAND & .032 & 8 & 1 & 0.022 & 1472 & 2 & 01 & 8 & \\
\hline CA & PASADENA & 0.023 & 7 & 1 & 0.097 & 1496 & 2 & 0.001 & 7 & \\
\hline$A$ & SACRAMENTO & 0.020 & 111 & 1 & 0.048 & 2842 & 3 & 0.001 & 111 & \\
\hline A & SAN BERNARDINO & 0.044 & 51 & 1 & 0.109 & 2038 & 2 & 0.001 & 51 & \\
\hline A & SAN DIEGO & 0.023 & 116 & 1 & 0.057 & 3403 & 2 & 0.001 & 116 & \\
\hline $\mathrm{CA}$ & SAN FRANCISCO & 0.020 & 61 & 2 & 0.024 & 1332 & 2 & .002 & 61 & \\
\hline$A$ & SAN JOSE & 0.023 & 126 & 1 & 0.049 & 2770 & 2 & 0.001 & 126 & \\
\hline A & SANTA ANA & 0.020 & 51 & 1 & 0.066 & 866 & 1 & 01 & 51 & \\
\hline$\infty$ & DENVER & 0.042 & 27 & 1 & 0.041 & 3584 & 4 & 0.004 & 27 & \\
\hline CT & BRIDGEPORT & .020 & 71 & 1 & 0.062 & 795 & 1 & 0.003 & 71 & \\
\hline 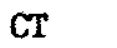 & HARTFORD & 020 & 21 & 1 & 0.055 & 941 & 1 & 0.002 & 21 & \\
\hline CT & NEW HAVEN & 0.026 & 53 & 1 & 0.057 & 920 & 1 & 0.002 & 53 & \\
\hline $\mathrm{CT}$ & WATERBURY & 0.023 & 70 & 1 & - & 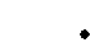 & - & 203 & 70 & \\
\hline$D C$ & WASHINGION & 0.020 & 37 & 1 & 0.035 & 4315 & 6 & 0.001 & 37 & \\
\hline$D E$ & WILMINGTON & 0.025 & 30 & 1 & & 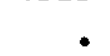 & . & 0.001 & 30 & \\
\hline FL & JACKSONVחLE & 0.020 & 107 & 1 & 0.049 & 1859 & 3 & 0.001 & 107 & \\
\hline $\mathrm{FL}$ & ORLANDO & 0.020 & 50 & 1 & - & - & - & 0.001 & 50 & \\
\hline $\mathrm{FL}$ & PENSACOLA & 0.020 & 59 & 1 & 0.053 & 1978 & 2 & 0.001 & 59 & \\
\hline EL & TAMPA & 0.020 & 129 & 1 & 0.046 & 2672 & 4 & 0.001 & 129 & \\
\hline & ATLANT & 0.020 & 99 & 1 & & 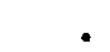 & . & 0.002 & 99 & \\
\hline & COLUMBUS & 0.020 & 82 & 1 & 0.049 & 416 & 1 & 0.001 & 82 & \\
\hline & CEDAR RAPIDS & 0.039 & 102 & 1 & 0.043 & 1676 & 1 & 0.001 & 102 & \\
\hline
\end{tabular}

\begin{tabular}{lrr}
\multicolumn{3}{c}{ VANADHA } \\
\hline YED. & FOBS & fH \\
& & \\
0.005 & 53 & 1 \\
0.005 & 82 & 2 \\
0.008 & 75 & 2 \\
0.005 & 56 & 1 \\
0.006 & 67 & 1 \\
0.005 & 102 & 1 \\
0.005 & 130 & 1 \\
0.038 & 51 & 1 \\
0.005 & 57 & 1 \\
0.006 & 8 & 1 \\
0.006 & 56 & 1 \\
0.010 & 8 & 1 \\
0.009 & 96 & 2 \\
0.010 & 8 & 1 \\
0.007 & 7 & 1 \\
0.005 & 111 & 1 \\
0.007 & 51 & 1 \\
0.009 & 116 & 1 \\
0.009 & 61 & 2 \\
0.005 & 126 & 1 \\
0.008 & 51 & 1 \\
0.005 & 27 & 1 \\
0.026 & 71 & 1 \\
0.050 & 21 & 1 \\
0.033 & 53 & 1 \\
0.019 & 70 & 1 \\
0.047 & 37 & 1 \\
0.021 & 30 & 1 \\
0.030 & 107 & 1 \\
0.010 & 50 & 1 \\
0.005 & 59 & 1 \\
0.014 & 129 & 1 \\
0.005 & 99 & 1 \\
0.005 & 82 & 1 \\
0.005 & 102 & 1 \\
& &
\end{tabular}

DIGAOT. PARTICULATE

FINE TOTAL FINE-S TOT-S

a Total number of observations included

b Number of monttoring sites supplying data. 


\section{APPENDIX B}

PATHOPHYSIOLOGICAL EFFECTS OR AIR POLLUTION 


\section{PATROPHTSIOLOGICAL ETRCTS OF AIR POLLUTIOA}

\section{ARATOMT ARD FURCTION OF THE RESPIRATORT SYSTEM}

The respliatory system's major function is to supply the human body with oxygen and to eliminate carbon dioxide. The uppermost part of the system is the pharynx, which lncludes the mouth and nose and extends to the trachea. In this part of the system inhaled afr is warmed to body temperature and saturated with water vapor, preventing dessication of and damage to the lower respiratory tissues. The aasal mucosa, with a surface area of about 160 square centimeters, is covered with glands which secrete the fluld necessary to molsten the air. Sneezing is forceful way of eliminating trapped particles and 1ritating substances.

The airway consists of the trachea, bronchl, and bronchioles. The trachea divides lato the two major bronchl, which divide into amaller bronchi, on down to the bronchioles. At each division the diameter decreases. The larger alrways have rigid cartilage rings whtch keep them from collaps1ng. The smaller branches lack cartilage, but have a stong muscular lining. The muscle can contract and relax and thus regulate the atr flow to lower regions.

The Interior of the trachea and bronchl are covered with mucous glands and clliary cells. The latter carry a number of small fibers that sweep mucous fluid and particles outward where they are expectorated or swallowed. Mucous which has collected in the bronchl as a reaction to infection or to substances in the inhaled air is expelled by coughing and by the cillary action. This clears the passages and prevents noxious particles from reachIng the more delicate lower t1ssues.

The bronchioles divide further and finally end in ten to twenty alveol1. These are thin membrances in which a dense network of capillary vessels is embedded. The gas exchange takes place here while the red blood cells are squeezed through the narrow vessels. The hydrodynamic force necessary to pump the blood through the caplllaries comes from the contraction of the right ventricle of the heart.

The Interior of the alveoll are covered with a thin layer of fluid, which acts as a surfactant and keeps the surface tension low. The elastic flbers in the space between the alveolar sacs create a tendency of the alveoll to collapse during the expiration phase. Inhalation creates a tension of about $-3 \mathrm{~mm}$ mercury in the alveoli. The low surface tenston allows alr to be drawn in without collapse of the alveoli.

\section{REACTIOH TO POLLUTANTS}

Particulates and gaseous substances in the air exert their effect mostly on the respiratory system and heart. An effect on the skin and mucous 
nembranes, such as the conjunctivae, can occur, but 1s of lesser importance as posible contributory factor to 111 health and premare death.

The ways in which alr pollution could potentially affect life expectancy are numerous, and are outlined below.

I. Effects on Pulmonary Function

A. Interference with clearance mechanisms resulting in secondary pneumonia

B. Inclting immunologically mediated reactions

C. Inclting non-1mmunologically mediated inflammation

D. Asphyxiation

E. Carcinogenes 1s or co-carcinogenesis

II. Effects on Cardlovascular Function

A. Pulmonary blood ressels

1. Primaty destruction or thickening of vessel walls

2. Destruction of pulmonary vascular bed secondary to fibrosis or emphysema

B. Coronary and Systemlc Vasculature

1. Induction of vascular spasm

2. Acceleration of atherosclerosis

C. Myocardium

1. Metabollc polsoning

2. Induction of arrhythmias

a. directly

b. through mechanisms of hypoxia

III. Effects on other systems

A. Inhibition of metabolism

B. Distant carcinogenesis

C. Induction of metabolic enzymes

Examples of a number of these possible mechanisms can be found by exanlning the reaction to various types of particulate and gaseous pollutants found in the alr. Some of the examples are from occupational exposures and may not affect the mortality patterns of the general population. However, they do serve as examples of the potential mechanisms by which afr pollutants might affect mortality.

We will review mechanisms and examples under each of the types of pollutants that are known to exist. It should be recognized, however, that there is reason to belleve that certain combinations of pollutants may in fact have synergistic effects. For example, certain small particles of wetallic orlgin such as 1ron or manganese may catalyze the oxidation of sulfur dioxide to sulfur trioxide, the precursor of sulfuric acid. Thus, while sulfur dioxide by 1 tself may have mildly irritating effects, its presence when combined with that of certain small partlculates might increase or otherwise alter its effect on the respiratory system. 
Reduced pulmonary function has been recognized as a risk factor for coronary therosclerosis, 1 weparate from the effects of clgarette smoking. Although detalled mechanlsms for these increased risks have not been well established, it is possible that alr pollution exposure is a contributing factor.

\section{DOSTS}

If the clliary lining of the upper part of the bronchlal tree functions well, particles greater than 5 mfcrons in diameter are removed from the upper part of the respiratory system. Smaller particles may reach lower branches of the bronchial tree and particulates less than one micron in diameter can be deposited in alveoli. Very small particles behave like gases and remain suspended in the atr by Brownian motion. Some of these very small particles will be depostted eventually on the walls of the terminal alveoll.

In the alveol1, particles may be phagocytosed by white blood cells or macrophages; moved outwards and be removed by the ciliary lining of the larger bronchiol1; accumulate in the connective tissues filling up the space between the alveolar sacs; or enter the lymphatic system to be carrled away and captured in the reglasi lumph glands. The particles may reduce the surface tension maintained by the surfactant. They may activate enzymes auch as elastase, present in macrophages, which could then destroy alveolar tissue. Some insoluble particles such as carbon, quartz, silica and asbestos, may become trapped in the interstitial lung tissue. Soluble particles would not be trapped; their effects would depead on chemical reactions within the sys tem.

Inflamatory reactions occurring as a result of activation of enzymes or as result of trapping in the interstitial lung tissue can result in destruction of alveolar tissue. Hith destruction of lung tissue in the alveoli, changes occur which lead to disease and disability. Reduction of the alveolar capillary bed increases the resistance to the blood flow from the right side of the heart. The flow is maintained by increase in pressure in the pulmonary vascular system. The increased pressure leads to hypertrophy of the heart muscle. With continued increases in resistance, eventually the heart is no longer able to generate the necessary pressure and the heart muscle begins to fall.

Reduction of the exchange surface area of the alveoli results in poor oxygenation of the-blood. The hypoxia can aggravate the induced pulmonary hypertension as well as falling to provide adequate oxygenat1on for normal cell function throughout the body. Destruction of elastic fibers between the alveolar sacs leads to afr trapping in the alveol1, thus contributing to poor gas exchange.

The assoclation of various pneumoconioses and occupational exposure to dusts has long been recognfzed. In most of these pneumoconloses the dust gives rise to a flbrosis in the spaces surrounding the alveoli and bronchioles. The fibrosis is the end result of repair of tissue damage. 
Thle damege could occur directly (as in all1cosis), at a resit of forelgn body reaction (as in abestoss), or as result of an lmmunologic reaction (as In bagassosis). The progressive flbrosis leads to a reduction of the volume of the pulmonary capillary bed, as well as to a decrease in gas exchange across the alveolar membranes. The diminished gas exchange and diminished volume lead to progressive hypoxia, which an further agravate pulmonary hypertension, predispose to cardiac arrhythmis, and dimlnish functlonal resplratory reserve. Death follows as a result of pulmonary fallure, which may be precipitated by infection, or as a result of right heart fallure.

\section{GASES}

The locus of action of gaseous substances depends on their solubility in the mucous flulds Ilning the resplratory tract and the concentration in the inspired alr. Highly water soluble gases $\left(\mathrm{SO}_{2}\right)$ are absorbed in the upper alrways. Less soluble gases $\left(\mathrm{CO}, \mathrm{O}_{3}\right)$ reach the more vascularized lower reglons of the resplratory system and can damage the alveolar tissue, or enter the blood stream and exert thelr toxlc effect on remote organs, such as liver, kIdney, bones, nerrous system, or heart.

\section{Hydrocarbons}

Hydrocarbons, in particular the polynuclear aromatic hydrocarbons such as benzo(a)pyrene, are frequently implicated as carcinogens based on animal tests. Oxygenated derivatives such as formaldehydes may act as allergens or irritants which affect the pulmonary system or as carcinogens. Aromatic hydrocarbons such as benzene may also have slgnificant toxicity to the bone marrow.

\section{Sulfux 0xides}

Acute episodes of high pollution with an associated dramatic increase in the number of deaths among high risk individuals have occurred in Belgium, 2 London, 3 Pennsylvan1a, Japan, and New York City. Follaw up of the population of Donora, Pennsylvanta, which was exposed in 1948 to an acute sulfur dfoxide fog, demonstrated a continued higher mortality in the decade followIng the exposure. 4 However, anfmal experiments showed that sulfur dioxide was only a mild irritant and concentrations up to $1 \mathrm{ppm}$ do not cause pulmonary damage. As mentioned before, sulfur dioxide may be converted to sulfur trioxide which forms sulfuric acld in the presence of water. Sulfuric acid is a very potent 1rritant and can cause severe bronchial constriction and coughing. In higher concentrations (at the milligram/m leve1), it can lead to necrosis with a resulting fibrotic reaction. Some sulfates may act chemically on cell membranes, causing release of histamines, thus initiating bronchiolar constriction. 


\section{Altrogen Oxides}

Nitrogen oxides, particularly nitrogen dioxide, have been demonstrated to cause pulmonary disease in enfmals after chronic exposure. Changes observed lacluded loss of clliary action in the bronchlal tree with resulting impafred abllity to combat infections, as well as distended alveoll leading to emphysematous changes. In animals, systemic effects such as welght loss and increased wethemoglobln levels have been observed.5 In humans atudy performed by the USPHS in Chattanooga, Tennessee suggested that observed eplsodes of bronchitis might be associated with higher levels of nitrogen dioxide. 6

\section{Carbon Monoxide}

Carbon monoxide compromises cardlovascular system function by forming a tightly bound complex with hemoglobin, called carboxyhemoglobin. Hemoglobin has an affint ty for carbon monoxide 200 to 400 times greater than its affinIty for oxygen. Carboxyhemoglobin decomposes slowly, thus lmpatring the oxygen carrylng capacity of the blood. Chronic low levels of carbon monoxide exposure may accelerate atherosclerosis and/or precipitate coronary vessel spasm. ${ }^{7}$ Shinshu disease, in a Japanese population habitually exposed to high carbon monoxide concentrations, included angla pectoris, heart valve lestons, and premature atherosclerosis. 8

\section{Ozone}

Ozone is a strong oxidant and an irritant to the upper part of the respiratory system. Acute exposures to very high levels of ozone can precipItate pulmonary edema. Whether chronic exposures to low levels can be harmful is more questionable. In animals ozone has been implicated in pulmonary fibrosis, tumor induction, bronchitis, acceleration of aging, and in reduction of the ability to combat infection.9 These effects have not been demonstrated in man and a diminished sensitivity to ozone has been observed in persons chronlcally exposed to low levels of ozone.10-13

\section{SUMMART}

Most available information about the effects of air pollution on health refers to the effects on the respiratory system. These effects range from bronchiolar constriction and coughing induced by irritants to pulmonary fibrosis. Direct effects upon the heart as well as more distant target organs may be suspected, but evidence is lacking. The heart might also be affected by its attempts to compensate for pulmonary disease, or by hypoxia occurring as a result of lung disease. 
1. Irledman, G.D., Klataky, A.L., and Slegelaub, A.B. Lung Function and Risk of Myocardial Infarction and Sudden Cardiac Death, New Ingland J. of Medlclae 214 No. 20, May 13, 1976, pp. 1071-1075. Also aee Ancel Key", Seven Countries. A Multivarlate Analys1s of Death and Coronary Heart Dlaease, Harvard Un1verstty Press, 1980, PP. 235-247.

2. Roholn, $K$. The fog disaster in the Meuse valley: A fluorine intoxicat10D. J. Indus. Hyg. Tox1c., 19:126, 1937.

3. Lambert, P.M. and Reid, D.D. Smoking, alr pollution, and bronchitis in Britain. Lancet $1: 853 ; 1970$.

4. Clocco, A. and Thompson, D.J. A follow-up of Donora ten years after: Methodology and findings. Am. J. Public Health, 51:155, 1961.

5. Freeman, G. et 1. Healing in rat lung after subacute exposure to nitrogen dioxide. Am. Rev. Resp15. D18. 100:662, 1969.

6. Shy, C.M. et al. The Chattanooga achool chlldren study: Effects of community exposure to nftrogen oxide. J. Alr Pollut. Control Assoc. $20: 539,1970$.

7. Sorokina, S.T. A study of carbon monoxide concentrations in the alr of living dwellings and 1 ts effect on the organism. USSR 11t. 8:207, 1963.

8. Komatsu, F. Shinshu shinkinska. D1g. Sc1. Labour 10:315, 1955.

9. Stokinger, H.E. et al. Ozone toxiclty studies III: Chronic injuries to lungs of animals, following exposure at a low level. AMA, Arch. Indus. Health 16:514, 1957.

10. Turino, G.M. Effect of carbon monoxide on the cardiorespiratory system. Circulation $63: 2531,1981$.

11. Horvath, S.M. Nitrogen dloxide, pulmonary function, and resplratory d1sease. Bull. N.Y. Acad. Med. 56:835, 1980 .

12. Goldstein, B.D. Experimental and clinical problems of effects of photochemical pollutants. Bull. N.Y. Acad. Med. 56:899, 1980.

13. Melton, C.E. Effects of long term exposure to low levels of ozone: $A$ review. Aviat. Space and Eaviron. Med. 53:105, 1982. 
"A Statistical Study of the Macroepidemiology of Air Pollution and Total Mortality"

Please note that, since publication of this report, errors have been discovered in the long-range transport model used to estimate expected concentrations of $\mathrm{SO}_{2}, \mathrm{SO}_{4}{ }^{2-}$, and $\mathrm{NO}_{\mathrm{X}}$, such that spatial bias may be present in these estimates. Accordingly, mortality regressions based on these estimates $(n=916)$ should not be used. Estimates based on actual air quality measurements are not affected.

Frederick W. Lipfert 